Wissenschaftszentrum Weihenstephan

für Ernährung, Landnutzung und Umwelt

Lehrstuhl für Ökologische Chemie und Umweltanalytik

der Technischen Universität München

\title{
Emissions Minimization of Chlorinated Micropollutants in Coal Solid Waste Co- Combustion by Primary Measures
}

\author{
Marchela Edvart Pandelova
}

Vollständiger Abdruck der von der Fakultät Wissenschaftszentrum Weihenstephan für Ernährung, Landnutzung und Umwelt der Technischen Universität München zur Erlangung des akademischen Grades eines

Doktors der Naturwissenschaften

genehmigten Dissertation.

Vorsitzender:

Univ.-Prof. Dr.-Ing. R. Meyer-Pittroff.

Prüfer der Dissertation:

1. Univ.-Prof. Dr. rer. nat., Dr. h. c. (RO) A. Kettrup

2. Univ.-Prof. Dr. rer. nat., Dr. agr. habil. H. Parlar

3. Priv.-Doz. Dr. rer. nat., Dr. agr. habil. K.-W. Schramm

Die Dissertation wurde am 06.07.2004 bei der Technischen Universität München eingereicht und durch die Fakultät Wissenschaftszentrum Weihenstephan für Ernährung, Landnutzung und Umwelt am 08.11.2004 angenommen. 
The practical part of the proposed work is carried out from August 2001 till August 2004 in Institute for Ecological Chemistry of GSF-Research Centre for Environmental and Health $\mathrm{GmbH}$ (Neuherberg).

To all who have contributed to the successful completion of this work I would like to warmly thank.......

... Prof. Dr. A. Kettrup for the opportunity to be member of his excellent scientific team; for the perfect work possibility and his pleasure lead style.

... PD Dr. K.-W. Schramm for the great support and understanding during my PhD work; for his high motivation and efficiency; for his essential tutorial influence on my result representation skill; for the long and inspiring research discussion

... Prof. Dr. D. Lenoir for the brilliant ideas; for the great chance to be in touch with his versatile knowledge and respectable experience

... Prof. Dr. H. Parlar for the acceptance to be reviewer of this work

.... Mr. B. Henkelmann for the carried out PCDD/F-, PCB and PCBz -measurements; for the many answers about analytical problems that he ever clear it and never complained

... Mrs. J. Kotalik for her friendly welcome in dioxin laboratory; for her help and kindly tutorial during the long clean-up procedure and the pleasure atmosphere around her; for her support in the beginning of my stay in Munich

... Mr. N. Fischer for his help during the sample preparation; for his responsiveness; for his friendly work atmosphere

... Mrs. V. Péronnet for the fruitful collaboration in the field of "sampling" accreditation; for her enthusiasm and motivation.

... Mrs. B. Danzer for her support and assistance during my PhD work

...my colleagues F. Jäkle, H. Hofbauer, M. Ciumasu, C. Rießbeck, N. Milanov, N. Chahbane, M. Blumenstock, K. Fried, L. Hollosi, A. Fekete and many other colleagues of IÖC for their friendly and helpful work atmosphere

... my parents Ani and Edi for their love, care and understanding during all my study

... my husband Stanislav for his great motivation to begin that PhD work; for his optimism and understanding during the work; for his nice character. 


\section{Publications connected to this work}

1. M. Lebikyan; D. Lenoir; K.-W. Schramm and A. Kettrup (2002). Pattern of regioisomers of chlorinated biphenyls in emission samples, $22^{\text {th }}$ International Symposium on Halogenated Environmental Organic Pollutants and POPs (Dioxin 2002). Barcelona, Spain

2. D. Lenoir; K.-W. Schramm and M. Lebikyan (2002). Formation, mechanism, and minimization of chlolrinated micropollutants (dioxins) formed in technical incineration processes, International Workshop of Hazardous Halo-Aromatic Pollutants. Venice, Italy .

3. V. Peronnet; M. Pandelova; A. Kettrup and K.-W. Schramm (2003). Implementation of a quality system in a research facility, Presentation, International Conference QA/QC in the field of emission and air quality measurements. Praha, Czech Republic

4. M. Pandelova; K.-W. Schramm and D. Lenoir (2003). Emission minimization in coal-solid waste co-combustion by primary measures, Presentation, $8^{\text {th }}$ international Congress of Combustion By-Product. Umea, Sweden.

5. M. Pandelova; D. Lenoir, A. Kettrup and K.-W. Schramm (2003). Primary measures for reduction of PCDD/F in co-combustion of lignite coal and waste:effect of various inhibitors, Presentation, $23^{\text {th }}$ International Symposium on Halogenated Environmental Organic Pollutants and POPs (Dioxin 2003). Boston, USA

6. M. Pandelova; D. Lenoir, A. Kettrup and K.-W. Schramm (2004). Primary measures for reduction of PCDD/F in co-combustion of lignite coal and waste:effect of various inhibitors. Environmental Science and Technology: submitted.

7. M. Pandelova; D. Lenoir, A. Kettrup and K.-W. Schramm (2004). Correlation between PCDD/F, PCB and PCIBz in coal/waste combustion. Influence of various inhibitors, $24^{\text {th }}$ International Symposium on Halogenated Environmental Organic Pollutants and POPs (Dioxin 2004). Berlin, Germany 


\section{List of Abbreviations}

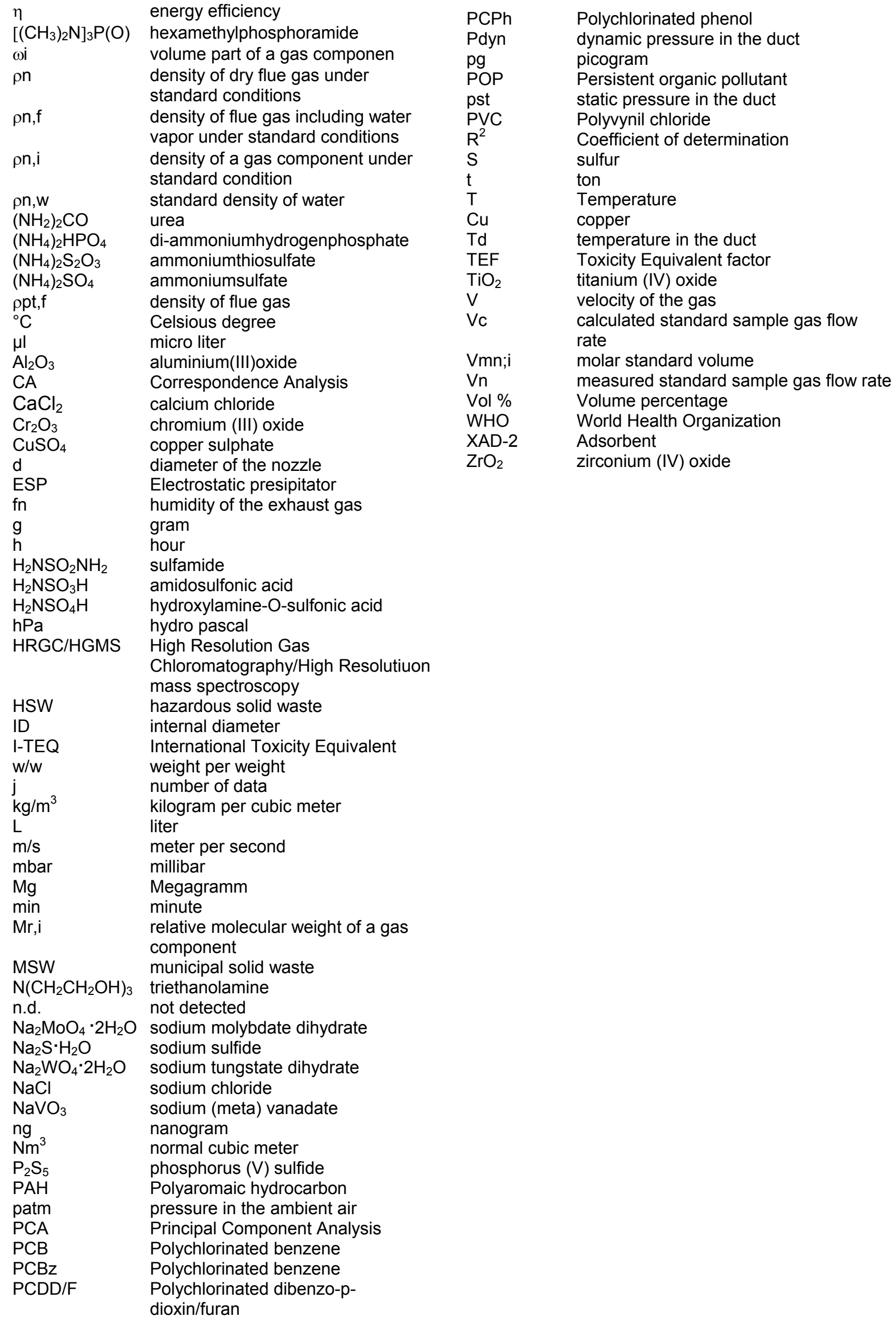




\section{Content}

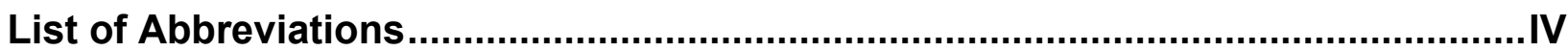

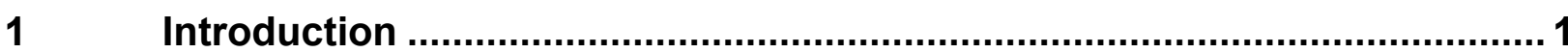

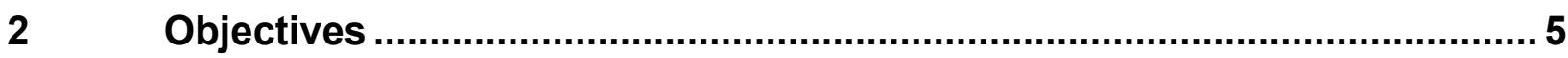

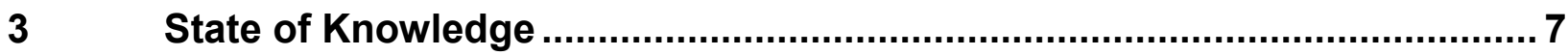

3.1 PCDD/F, PCB and PCBz

3.1.1. Dioxin nomenclature and properties ...............................................................

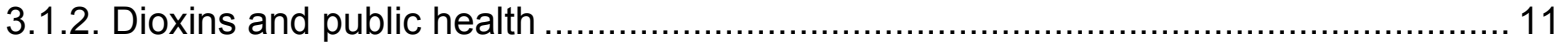

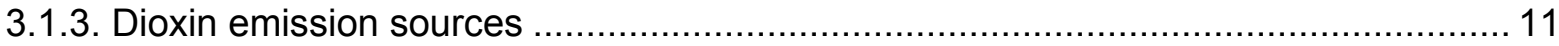

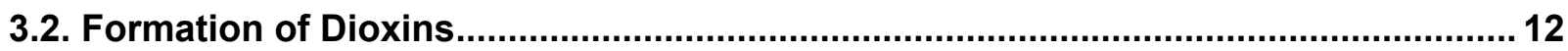

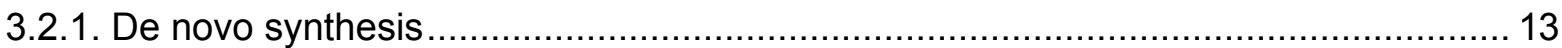

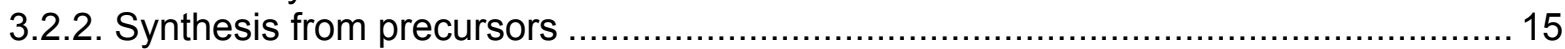

3.2.3. Influence of the operation parameters and the fuel type on PCDD/F emissions ....... 17

3.3. Correlation between PCDD/F , PCB and PCBz …….............................................. 19

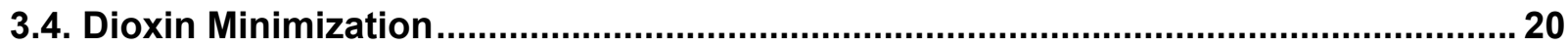

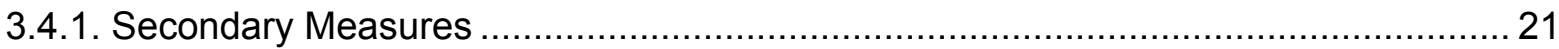

3.4.2. Primary Measures …………………………………………………….... 22

3.4.2.1. Minimization of dioxins formation by adjustment of the operation

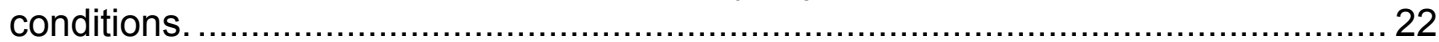

3.4.2.2. Use of additives inhibiting the PCDD/F formation .................................... 23

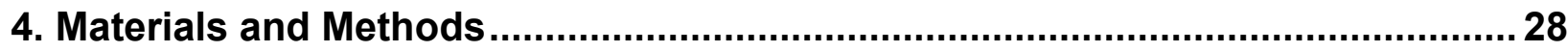

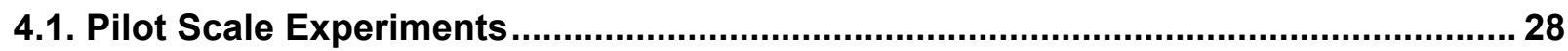

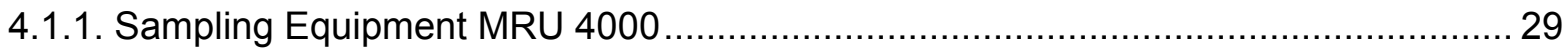

4.1.2. Controlled parameters before sampling ………............................................... 32

4.1.3. Validation of the sampling measurements ......................................................... 34

4.1.4. Laboratory preparation prior the sampling ………............................................... 34

4.1.5. Laboratory work after the sampling ................................................................... 35

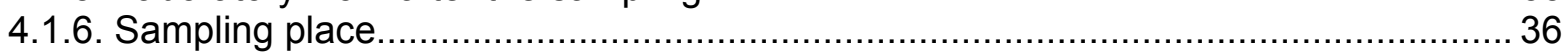

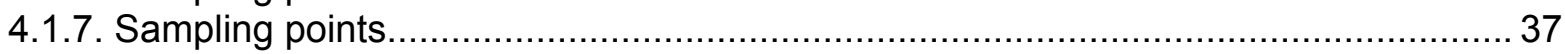

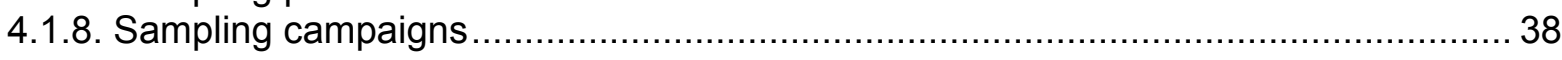

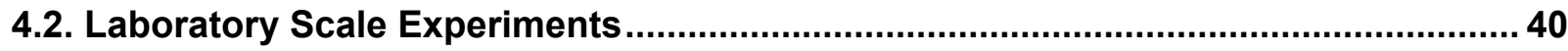

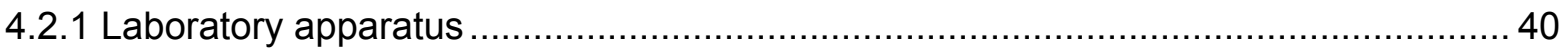

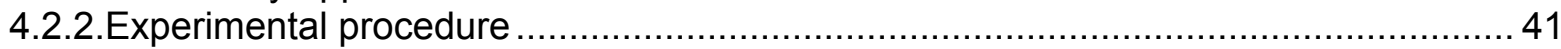

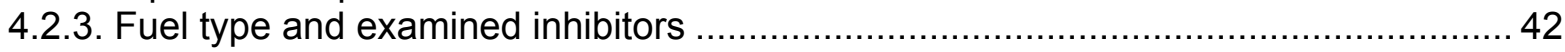

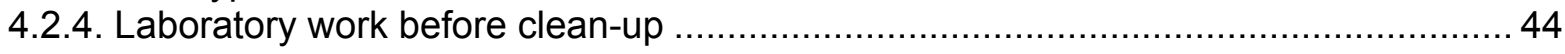

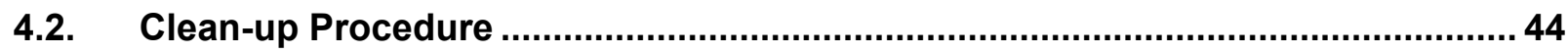

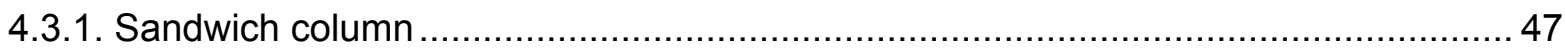

Preparation of the sandwich column: ............................................................. 47

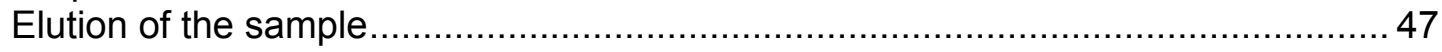




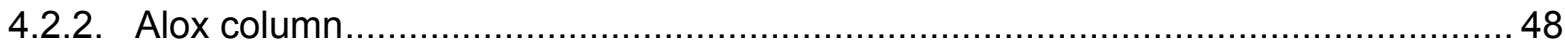

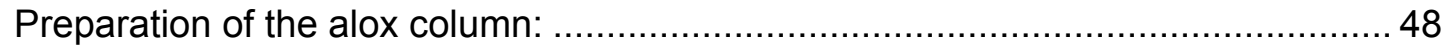

Elution of PCB and PCBz Fraction.............................................................. 48

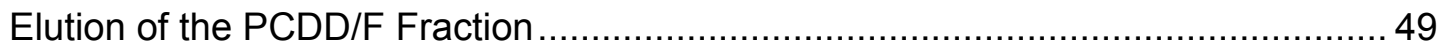

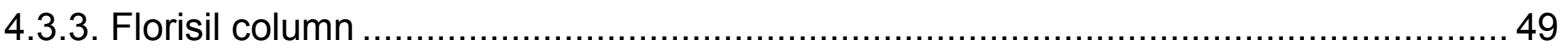

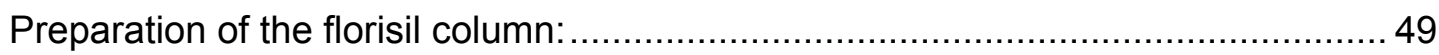

Preparation of the Thielen and a Olsen column ................................................ 50

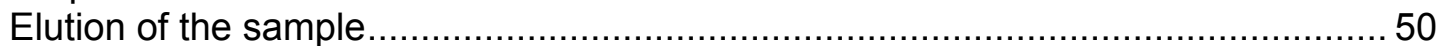

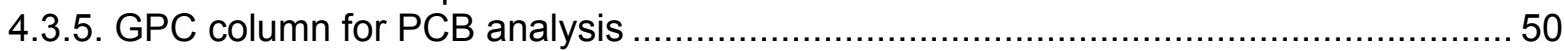

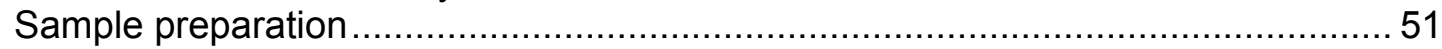

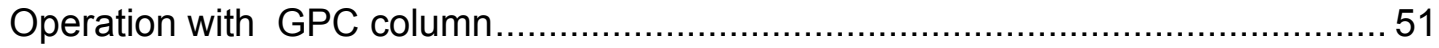

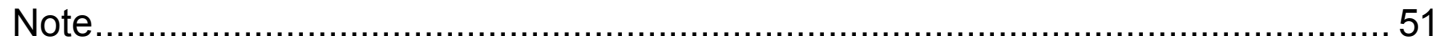

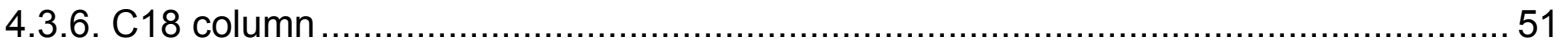

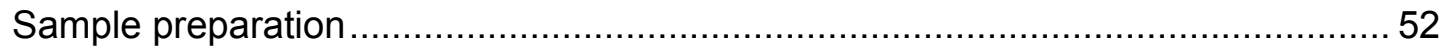

Preparation of the C18 column: ................................................................. 52

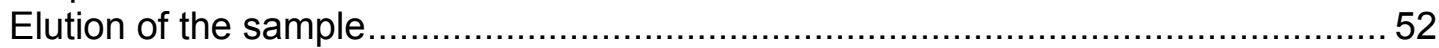

After C18 clean up column .................................................................... 52

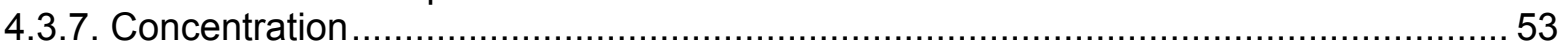

4.3. Detection \& Quantification with HRGC/HRMS ....................................................53

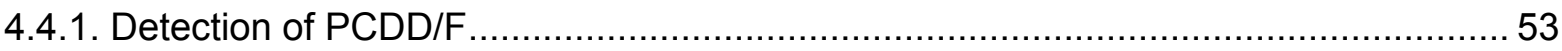

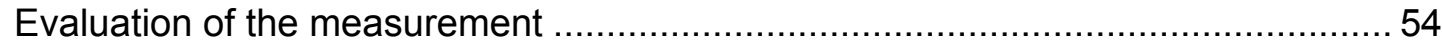

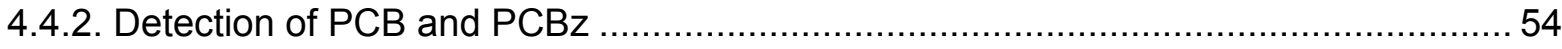

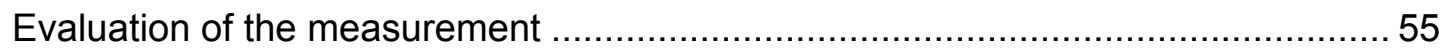

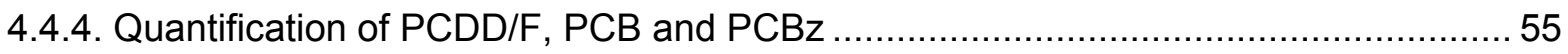

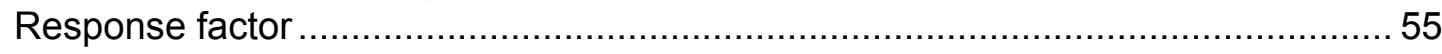

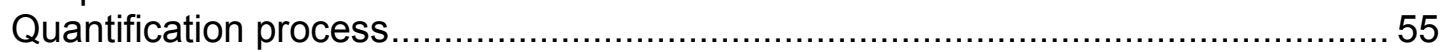

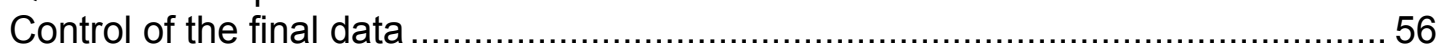

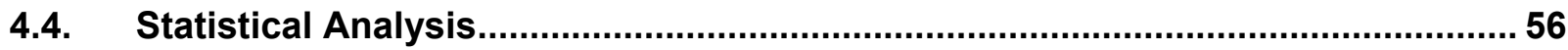

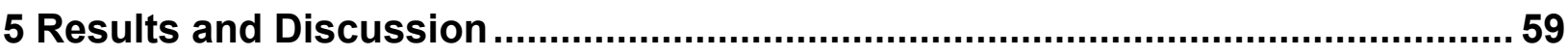

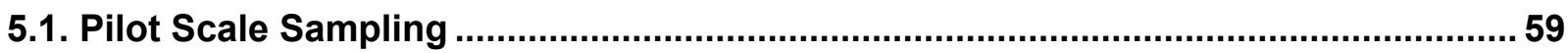

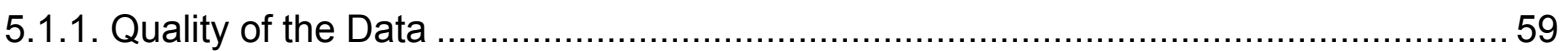

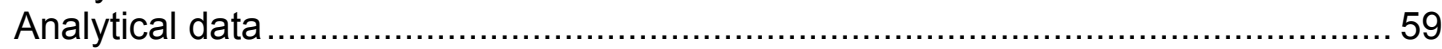

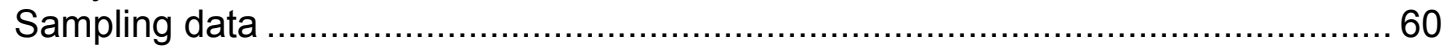

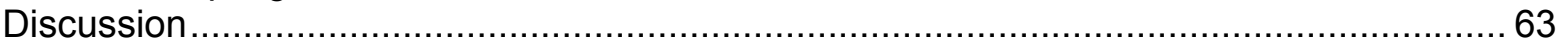

5.1.2. Influence of Combustion Parameters on the Formation of PCDD/F and PCB in a

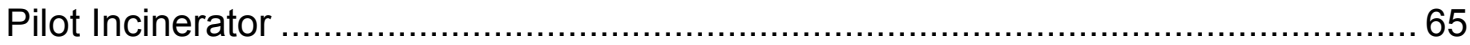

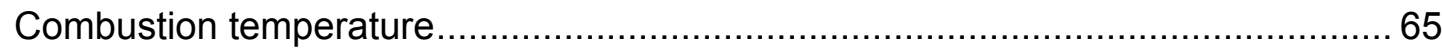

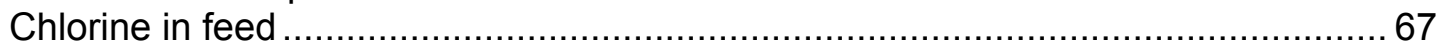

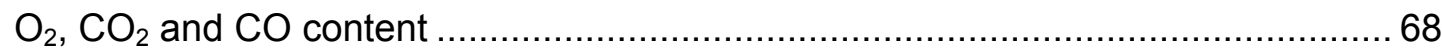

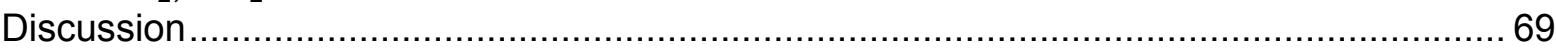

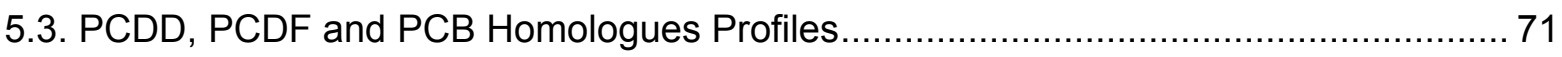

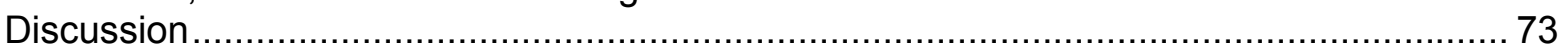

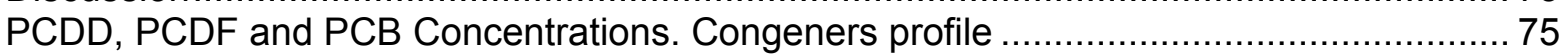

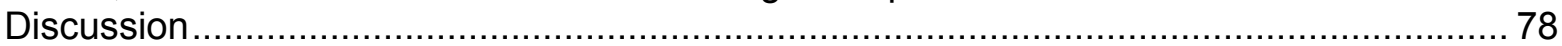

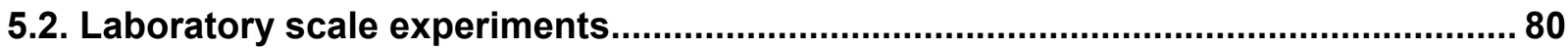

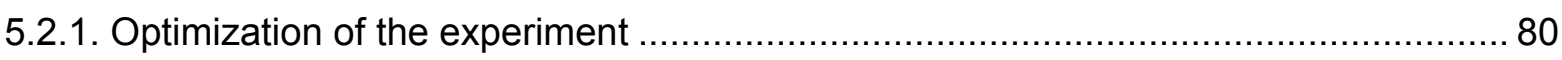

Homogenization of the combustion fuel ..................................................... 80

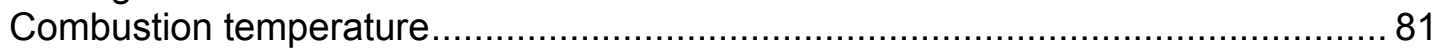

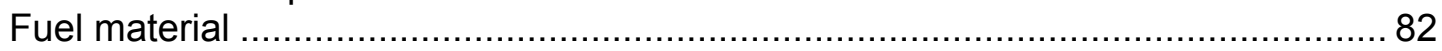

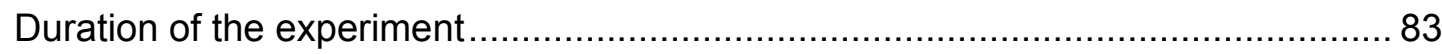




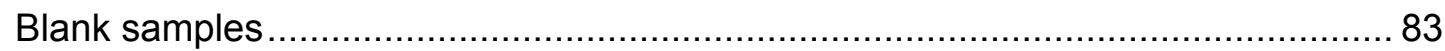

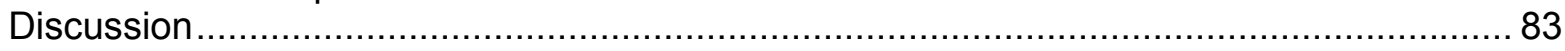

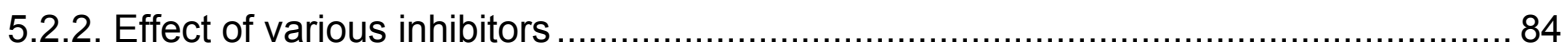

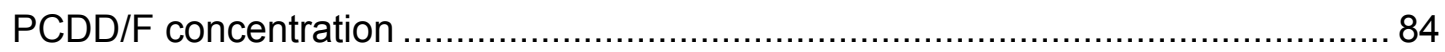

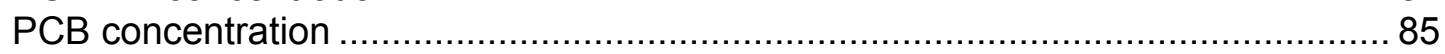

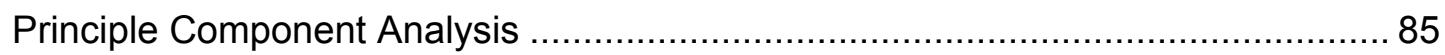

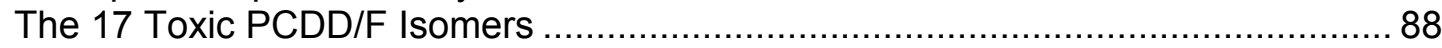

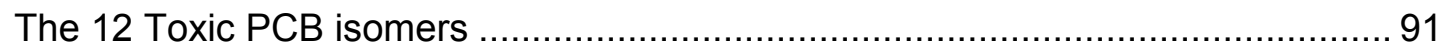

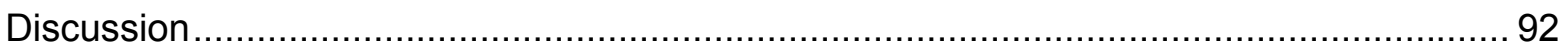

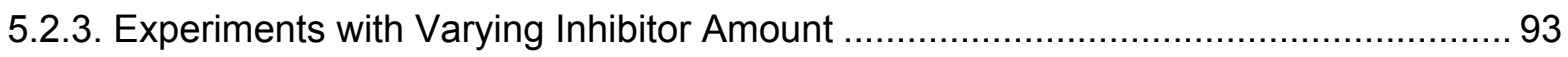

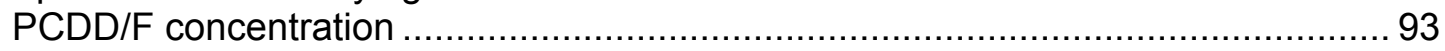

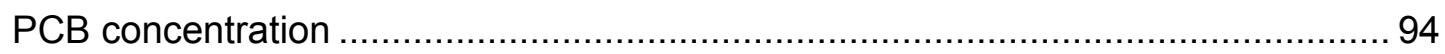

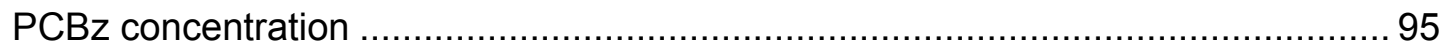

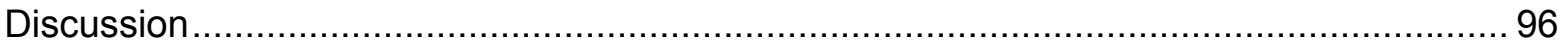

5.2.4. PCDD/F and PCB Homologue Distribution for the 20 Different Inhibitors Present

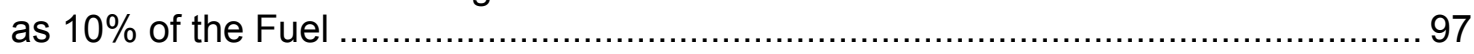

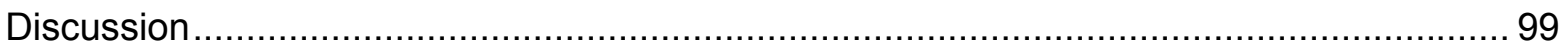

5.2.5. PCDD/F, PCB and PCBz Homologue Distribution for the $\left(\mathrm{NH}_{4}\right)_{2} \mathrm{SO}_{4}$ and

$\left(\mathrm{NH}_{4}\right)_{2} \mathrm{~S}_{2} \mathrm{O}_{3}$ Present as $10 \%, 5 \%, 3 \%$ and $1 \%$ of the Fuel................................... 100

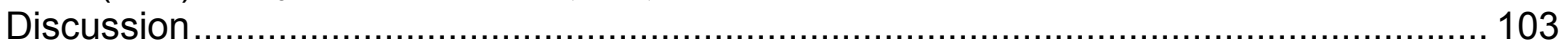

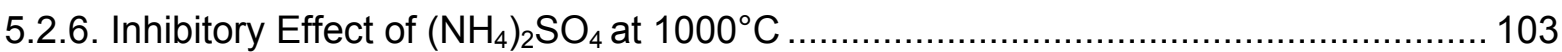

5.2.6.1. Combustion where the sample is introduced at preheated $1000^{\circ} \mathrm{C}$ furnace .......... 104

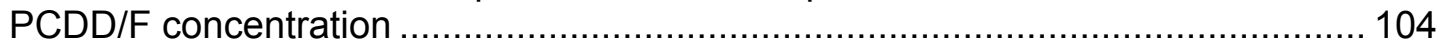

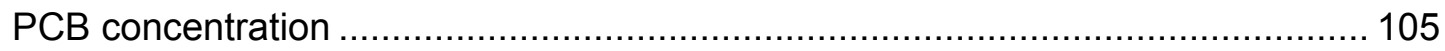

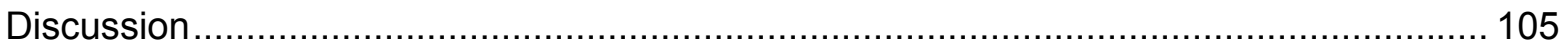

5.2.6.2. Combustion where the sample is introduced at preheated $200^{\circ} \mathrm{C}$ programmed

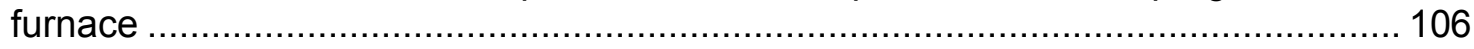

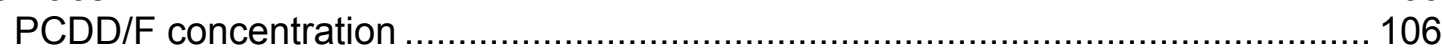

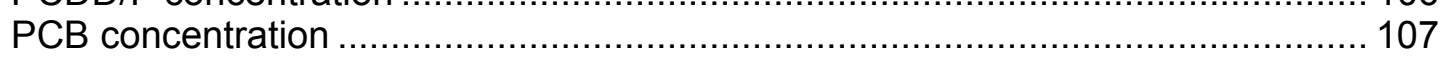

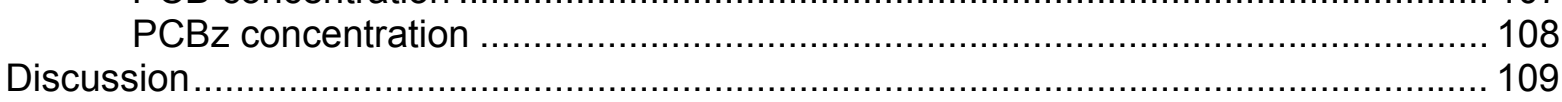

\subsection{Correlation between PCDD, PCDF, PCB and PCBz in coal / solid waste and PVC} combustion at the influence of various inhibitors.

5.3.1. Correlation between PCDD, PCDF, PCB and PCBz. Influence of Varying Inhibitors

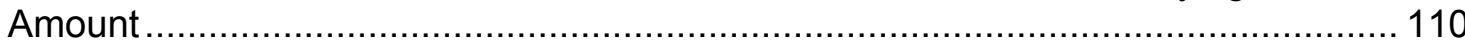

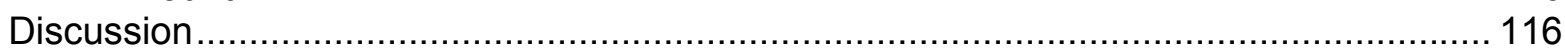

5.3.2. Correlation between PCDD, PCDF and PCB. Influence of Various Inhibitors. ........ 118

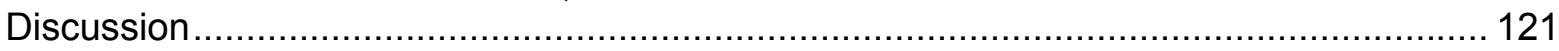

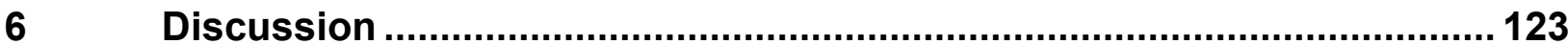

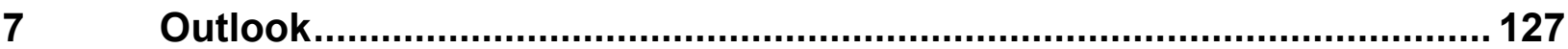

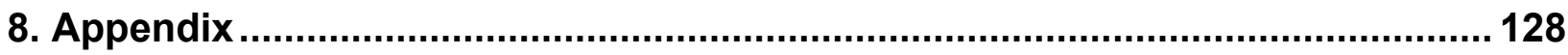

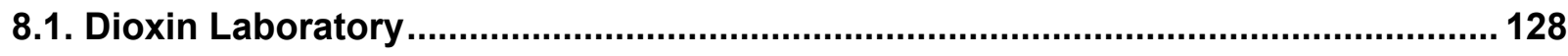

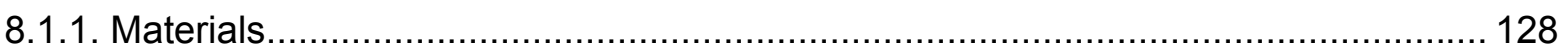

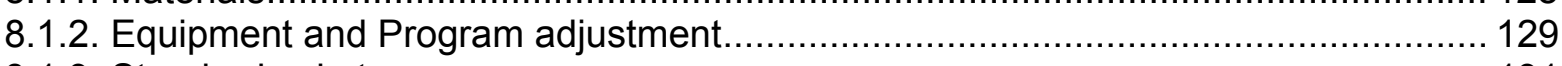

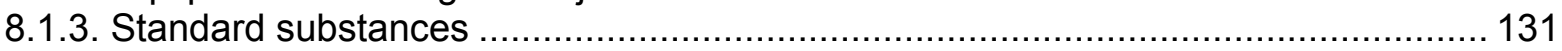

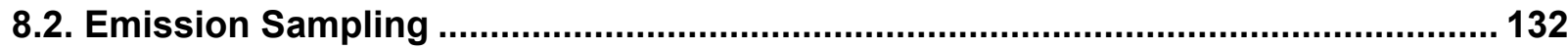

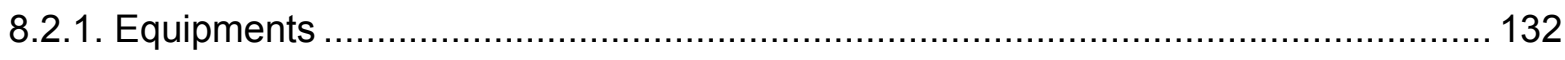




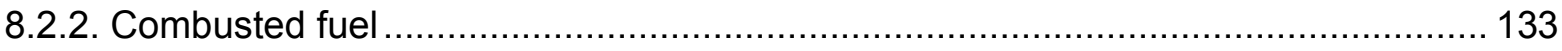

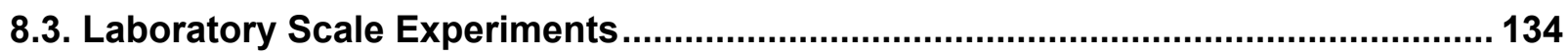

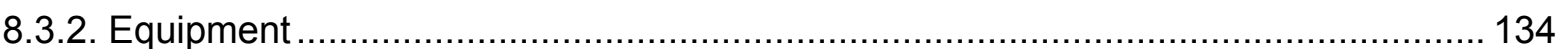

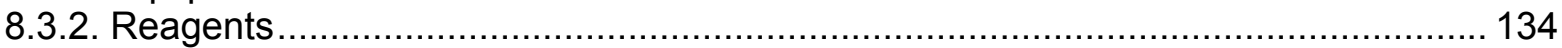

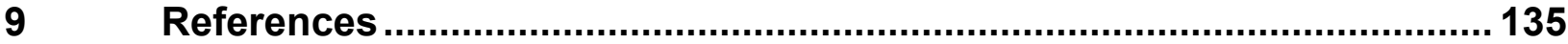




\section{Figures}

Fig. 3.1: Polychlorinated di-p-benzo-dioxin (a); Polychlorinated di-p-benzo-furan (b); Polychlorinated benzene (c); Polychlorinated biphenyl (d) .

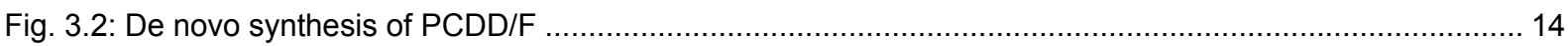

Fig.3.4: Copper catalysed formation of PCDD/F from ortho- chlorophenol and chlorbenzene ........................... 16

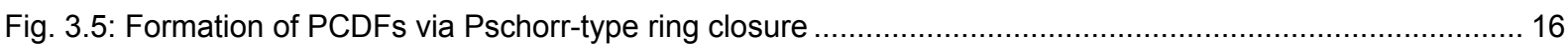

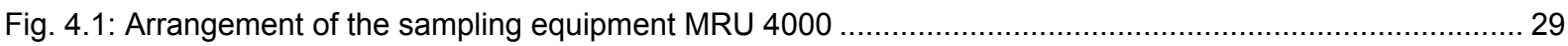

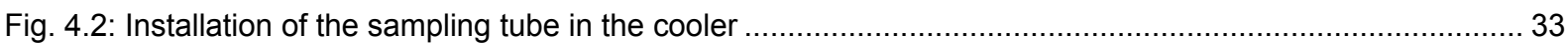

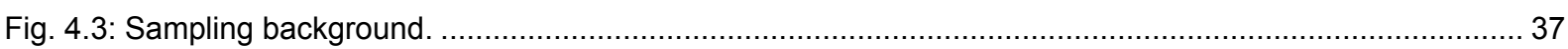

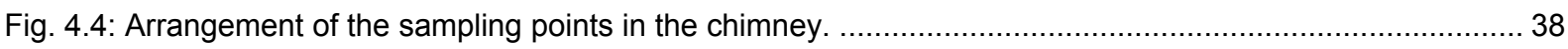

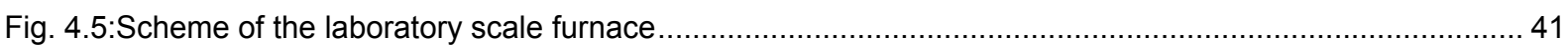

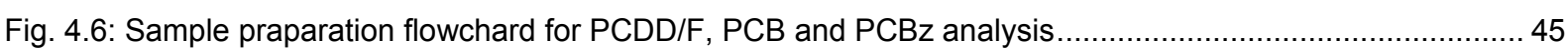

Fig. 4.7: Continued preparation flowchard for PCB and PCBz analysis ................................................. 46

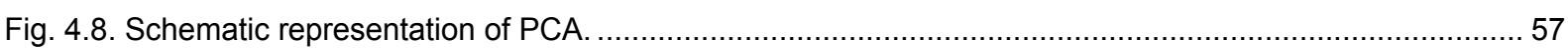

Fig. 5.1: Measured and calculated standard sample gas flow rate after a wood incinerator .............................63

Fig. 5.2: PCDD/F I-TEQ value $\left(\mathrm{pg} / \mathrm{m}^{3}\right)$ in poplar wood combustion at different temperatures.............................66

Fig. 5.3: PCDD/F I-TEQ value $\left(\mathrm{pg} / \mathrm{m}^{3}\right)$ in poplar wood and 10\% PVC combustion at different temperatures ........66 66

Fig. 5.4: PCB I-TEQ value $\left(\mathrm{pg} / \mathrm{m}^{3}\right)$ in poplar wood and 10\% PVC combustion at different temperatures .............67

Fig. 5.5: PCDD/F I-TEQ value $\left(\mathrm{pg} / \mathrm{m}^{3}\right)$ in wood and wood $/ 10 \%$ PVC combustion campaigns at similar temperatures.

Fig. 5.6: Correlation between PCDD/F I-TEQ value and $\mathrm{O}_{2}, \mathrm{CO}_{2}$ and $\mathrm{CO}$ gas concentration in wood/10\% PVC

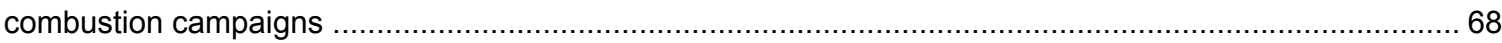

Fig. 5.7: Percentage of PCDD homologues mass distribution of the sampling campaign No.2-8 ..................... 71

Fig. 5.8: Percentage of PCDF homologues mass distribution of the sampling campaign No.2-8...................... 72

Fig. 5.9: Percentage of PCB homologues mass distribution of the sampling campaign No.4,7 and $8 \ldots \ldots \ldots \ldots \ldots . . . . .72$

Fig. 5.10: Sum of tetra-octa PCDD (A) and sum of tetra-octa PCDF (B) for sampling campaign No. 2-8 …....... 75

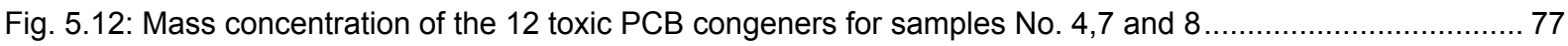

Fig. 5.13: Mass concentration of the 17 toxic PCDD/F congeners for sample No. 2-8. ................................... 78

Fig. 5.14: I-TEQ values (pg/sample) of the 17 toxic PCDD and PCDF congeners emitted during fuel combustion at $500^{\circ} \mathrm{C}$ in a laboratory scale furnace.

Fig. 5.16: PCB I-TEQ (pg/g) values of the flue gas after combustion of lignite coal, solid waste and PVC for the samples without inhibitor and 20 different compounds used at $10 \%$ inhibitor of the fuel......

Fig. 5.17: Score plot of PCB (A), PCDD (B) and PCDF (C) of 5 replicates treated without any inhibitor (A) and 20 samples with $10 \%$ inhibitor.

Fig. 5.18: PCDD/F I-TEQ pg/g fuel values in the flue gas for the samples without inhibitor and with $\left(\mathrm{NH}_{4}\right)_{2} \mathrm{SO}_{4}$ and $\left(\mathrm{NH}_{4}\right)_{2} \mathrm{~S}_{2} \mathrm{O}_{3}$ at $10 \%, 5 \%, 3 \%$ and $1 \%$ and $\left(\mathrm{NH}_{2}\right)_{2} \mathrm{CO}+\mathrm{S}$ at $10 \%, 3 \%$ and $1 \%$ as inhibitor of the fuel. 94

Fig. 5.19: PCB I-TEQ pg/g fuel values in the flue gas for the samples without inhibitor and with $\left(\mathrm{NH}_{4}\right)_{2} \mathrm{SO}_{4}$ and $\left(\mathrm{NH}_{4}\right)_{2} \mathrm{~S}_{2} \mathrm{O}_{3}$ at $10 \%, 5 \%, 3 \%$ and $1 \%$ and $\left(\mathrm{NH}_{2}\right)_{2} \mathrm{CO}+\mathrm{S}$ at $10 \%, 3 \%$ and $1 \%$ as inhibitor of the fuel.

Fig. 5.20: Sum $\mathrm{PCBz} \mathrm{pg} / \mathrm{g}$ fuel values in the flue gas for the samples without inhibitor and with $\left(\mathrm{NH}_{4}\right)_{2} \mathrm{SO}_{4}$ and $\left(\mathrm{NH}_{4}\right)_{2} \mathrm{~S}_{2} \mathrm{O}_{3}$ at $5 \%, 3 \%$ and $1 \%$ and $\left(\mathrm{NH}_{2}\right)_{2} \mathrm{CO}+\mathrm{S}$ at $3 \%$ and $1 \%$ of the fuel.

Fig. 5.21: Percentage of PCDD (A), PCDF (B) and PCB (C) homologues mass distribution of the samples with and without inhibitor during combustion of lignite coal, solid waste and PVC in lab scale experiments....... 98

Fig. 5.22: Percentage of PCDD (A) and PCDF (B) homologues mass distribution of the samples without inhibitor and with $10 \%, 5 \%, 3 \%$ and $1 \%\left(\mathrm{NH}_{4}\right)_{2} \mathrm{SO}_{4}$ and $\left(\mathrm{NH}_{4}\right)_{2} \mathrm{~S}_{2} \mathrm{O}_{3}$ during combustion of lignite coal, solid waste and $\mathrm{PVC}$ in lab scale experiments 100 
Fig. 5.23: Percentage of $\mathrm{PCB}(\mathrm{A})$ and $\mathrm{PCBz}(\mathrm{B})$ homologues mass distribution of the samples without inhibitor and with $5 \%, 3 \%$ and $1 \%\left(\mathrm{NH}_{4}\right)_{2} \mathrm{SO}_{4}$ and $\left(\mathrm{NH}_{4}\right)_{2} \mathrm{~S}_{2} \mathrm{O}_{3}$ during combustion of lignite coal, solid waste and PVC in lab scale experiments

Fig. 5.24: PCDD/F I-TEQ pg/g fuel values in the flue gas at $1000^{\circ} \mathrm{C}$ for the samples without inhibitor and with

$\left(\mathrm{NH}_{4}\right)_{2} \mathrm{SO}_{4}$ at $10 \%$ and $5 \%$ introduced at preheated $1000^{\circ} \mathrm{C}$ furnace...... 104

Fig. 5.25: PCB I-TEQ pg/g fuel values in the flue gas at $1000^{\circ} \mathrm{C}$ for the samples without inhibitor and with $\left(\mathrm{NH}_{4}\right)_{2} \mathrm{SO}_{4}$ at $10 \%$ and $5 \%$ introduced at preheated $1000^{\circ} \mathrm{C}$ furnace. 105

Fig. 5.26: PCDD/F I-TEQ pg/g fuel values in the flue gas at $1000^{\circ} \mathrm{C}$ for the samples without inhibitor and with

$\left(\mathrm{NH}_{4}\right)_{2} \mathrm{SO}_{4}$ at $5 \%$ introduced at preheated $200^{\circ} \mathrm{C}$ programmed furnace. 107

Fig.5.27: PCA score plot of 21 cases (samples) and 36 variables (PCDD/F, PCB and PCBz homologues) ....... 111

Fig. 5.28: CA score variables plots for the samples with lower TEQ $(A)$ and higher TEQ $(B) \ldots \ldots \ldots \ldots \ldots \ldots \ldots 113$

Fig. 5.29: Couple points of score variables plot $(B)$ of CA in Fig. 22 .................................................. 115

Fig.5.30: Couple points of score variables plot $(A)$ of CA in Fig. 22 ...................................................... 116

Fig.5.31: PCA score plot of 49 cases (samples) and 26 variables (PCDD/F and PCB homologues)................ 119

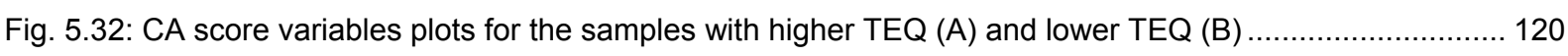

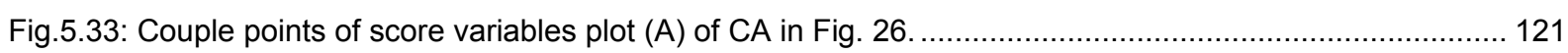

\section{Tables}

Tab.1.1: Energy efficiency of power plant and waste incinerator [4] .................................................... 2

Tab.1.2: Costs for reduction of dust emissions, $\mathrm{CO} / \mathrm{NOx}$, and $\mathrm{SO}_{2}$ in co-combustion [4]................................... 3

Tab.1.3: Costs for reduction of dust emissions, $\mathrm{CO} / \mathrm{NOx}$, and $\mathrm{SO}_{2}$ in coal / waste combustion [4] ...................... 3

Tab. 3.1: Homologues and congeners of PCDD, PCD , PCB and PCBz ................................................. 8

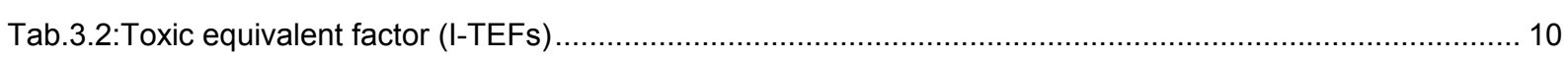

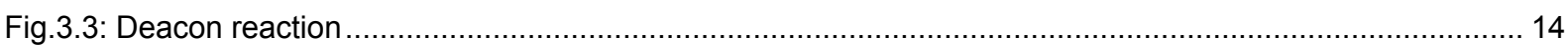

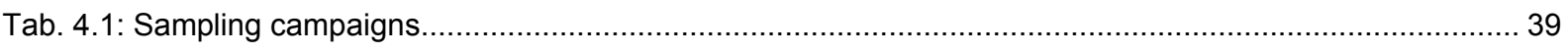

Tab. 4.2: Clean-up procedure for PCDD/F, PCB and PCBz analysis ...................................................... 47

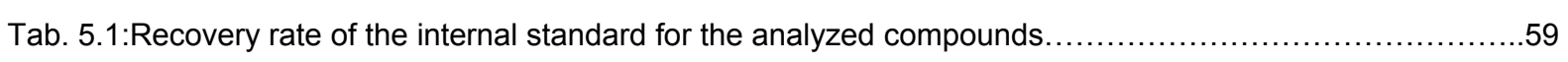

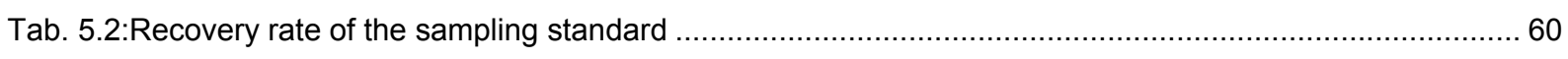

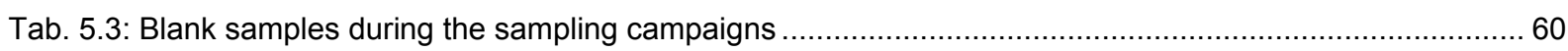

Tab. 5.4: Comparison of the PCDD/F I-TEQ value of the back-up cartridge and the total emission sample ......... 61

Tab. 5.5:Comparison of the PCDD/F I-TEQ value of the resin XAD-2 cartridge and the total emission sample .... 62

Tab. 5.6:Comparison of the PCB I-TEQ value of the resin XAD-2 cartridge and the total emission sample ..........62

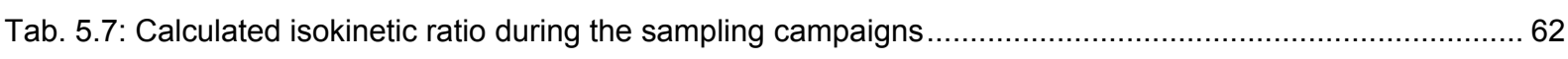

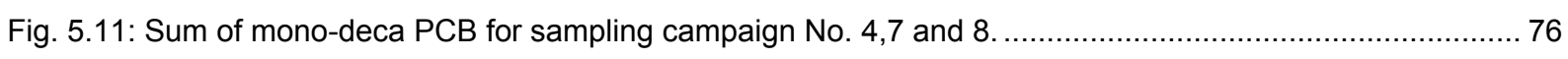

Tab. 5.8: PCDD/F I-TEQ value (pg/g) of homogenized and not homogenized combusted fuel samples ...............80

Tab. 5.9: PCDD/F and PCB I-TEQ values (pg/g) for samples combusted at $300^{\circ} \mathrm{C}, 400^{\circ} \mathrm{C}$ and $500^{\circ} \mathrm{C} \ldots \ldots \ldots \ldots . . . . .82$

Tab. 5.10: PCDD/F and PCB I-TEQ values (pg/sample) of the blank samples performed in a laboratory scale furnace

Fig. 5.15: PCDD/F I-TEQ (pg/g) values of the flue gas after combustion of lignite coal, solid waste and PVC for the samples without inhibitor and 20 different compounds used at $10 \%$ inhibitor of the fuel...................... 84

Tab. 5.11: Values of the 17 toxic PCDD/F isomers $\mathrm{pg} / \mathrm{g}$ fuel for the most effective inhibitors and the average value of the sample without inhibitor.

Tab. 5.12: Values of the 12 toxic PCB isomers pg/g fuel for the most effective inhibitors and the average value of the sample without inhibitor.

Tab. 5.13: 2,3,7,8-TCDD I-TEQ (pg/g) fuel values in the flue gas at $1000^{\circ} \mathrm{C}$ for the samples without inhibitor and with $\left(\mathrm{NH}_{4}\right)_{2} \mathrm{SO}_{4}$ at $10 \%$ and $5 \%$ introduced at preheated $1000^{\circ} \mathrm{C}$ furnace. 
Fig. 5.27: PCB I-TEQ pg/g fuel values in the flue gas at $1000^{\circ} \mathrm{C}$ for the sample without inhibitor and with $\left(\mathrm{NH}_{4}\right)_{2} \mathrm{SO}_{4}$ at $5 \%$ introduced at preheated $200^{\circ} \mathrm{C}$ programmed furnace. 108

Fig. 5.28: $\mathrm{PCBz} \mathrm{pg} / \mathrm{g}$ fuel values in the flue gas at $1000^{\circ} \mathrm{C}$ for the sample without inhibitor and with $\left(\mathrm{NH}_{4}\right)_{2} \mathrm{SO}_{4}$ at

$5 \%$ introduced at preheated $200^{\circ} \mathrm{C}$ programmed furnace. 108

Tab. 5.14: Number of the cases used for PCA and CA statistical analyses. 110

Tab.5.15: Number of the variables used for PCA and CA statistical analyses. * - I-TEQ value..... 111

Tab. 5.16: Number of the cases used for PCA and CA statistical analyses. 118

Tab. 5.17: Number of the variables used for PCA and CA statistical analyses. * - I-TEQ value 118

Tab. 8.1:Equipment and program adjustment for PCDD/F analysis 129

Tab. 8.2:Equipment and program adjustment for PCB analysis 130 


\section{SUMMARY}

This study addresses co-combustion of coal-solid waste mixtures in pilot and laboratory-scale combustors, with emphasis on monitoring of toxic chlorinated hydrocarbon emissions like: polychlorinated dibenzo-p-dioxins (PCDD), polychlorinated dibenzofurans (PCDF), polychlorinated biphenyls (PCB) and polychlorinated benzenes (PCBz). The objectives of the work are stress on the socalled primary measures technique which cause reduction of the toxic emission prior formation the chlorinated micropollutants. This approach includes adjustment of operation condition such as temperature, turbulence, and residence time. Primary measures may include the addition of some selected compound in the post combustion zone aiming in reducing the formation of PCDD/F and their precursor; it is known as inhibition and differs the flue gas cleaning methods as it deals with the prevention of PCDD/F.

Emissions of polychlorinated dibenzo-p-dioxins (PCDD) and polychlorinated dibenzofurans (PCDF) are sampled isokinetically. According to VDI guidelines 3499 PCDD/F the used method of sampling is "cooled sucking tube probe method" where the automatic sampling system MRU 4000 is employed. The emission samples are prepared according standard clean-up procedure for PCDD/F and PCB and further analysed at HRGC/HRMS. Every cartridge is registered and extracted twice with Soxhlet apparatus clean-up, each of them 24h for glass wool and resin cartridges. Preparation and elution employs sandwich, alox, florisil, and Thilson-Olson columns. Poplar wood and different percent mixture of wood and PVC were studied. In order to find relevant conditions of formation for PCDD/F different temperatures in the stack $\left(150{ }^{\circ} \mathrm{C}-500{ }^{\circ} \mathrm{C}\right)$ were investigated during combustion. The result of PCDD/F relevant to the combustion at different temperature shows that the highest concentrations are detected for the sample at $500^{\circ} \mathrm{C}$. PCDF concentration is about three times higher than PCDD in every emission sample. The reason is attributed to the mechanisms of formation of the chlorinated hydrocarbons. These results led to the conclusion to study on PCDD/F formation at temperatures higher than $350{ }^{\circ} \mathrm{C}$ and less than $600^{\circ} \mathrm{C}$ as reaction optimum.

A series of experiments in laboratory scale condition for the prevention of PCDD/F formation by inhibitors were performed. Thermally resistant inorganic compounds were added directly to the fuel. Investigations about PCDD, PCDF, PCB and PCBzpattern are developed, as well as about the corresponding treatment PCDD/F-results 
by means of multivariate statistical methods. Principle Component Analysis and Correspondence Analysis are used to find the correlations between the PCDD/F and indicator parameters. The influence of varying inhibitors amount on these relationships was also investigated.

The fuel-types used in this study are lignite coal from Puertollano (CIEMAT, Spain), pre-treated municipal solid waste (Rethmann Plano $\mathrm{GmbH}$ ) and PVC (waste from ground floor). The weight percentage content for the lignite coal is $80 \%$ and for the chlorinated compounds is $20 \%$ as 13.33:6.66 respectively for the solid waste and PVC. In case of inhibitor experiments, the inhibitor is present as $10 \%$ of the fuel. Four different groups with 20 different compounds are used as inhibitors: metal oxides group; $\mathrm{N}$-contents group; $\mathrm{S}$-contents group; $\mathrm{N}$ - and $\mathrm{S}$-contents group. $\mathrm{A}$ laboratory scale horizontal split-tube furnace (Carbolite, England) is used for the experiments. The flue gases occurring during the experiment are trapped into 3 impingers in series, each of them filled with toluene. The combustion experiments are performed according to the same procedure each time in order to achieve comparable results. The furnace temperature is $400{ }^{\circ} \mathrm{C}$, the air flow is $2 \mathrm{~L} / \mathrm{min}$, the weight of the sample is $10 \mathrm{~g}$ and the duration of the experiment is $30 \mathrm{~min}$.

The total amounts of PCDD/F, PCB and PCBz generated during experiments with lignite coal, solid waste and PVC are high enough to investigate substantial inhibition. The experimental results with inhibitors manifested very different values for PCDD/F and PCB. Metal oxides show no inhibitory effect while compounds containing $\mathrm{N}$ - and $S$ show strong reduction of PCDD/F and PCB-values. Two inorganic compounds such as $\left(\mathrm{NH}_{4}\right)_{2} \mathrm{SO}_{4}$ and $\left(\mathrm{NH}_{4}\right)_{2} \mathrm{~S}_{2} \mathrm{O}_{3}$ were considered as the most effective inhibitors among the additives. Both substances were used at 10, 5, 3 and $1 \%$ of the fuel. The results show that $\left(\mathrm{NH}_{4}\right)_{2} \mathrm{SO}_{4}$ and $\left(\mathrm{NH}_{4}\right)_{2} \mathrm{~S}_{2} \mathrm{O}_{3}$ are still effective inhibitors at $10 \%$ and $5 \%$ of the fuel for PCDD/F, PCB and PCBz. If the percentage of these substances is decreased further, the suppressing effect of dioxin formation also decreased. $\left(\mathrm{NH}_{4}\right)_{2} \mathrm{SO}_{4}$ might also reduce the PCDD/F flue gas emission up to $90 \%$ even at $3 \%$ of the fuel. In order to proof the stability and efficiency of the inhibitor, the proposed compound was also used at different combustion conditions. The final conclusions state that at temperature of $1000{ }^{\circ} \mathrm{C}$, even of $5 \%$ of $\left(\mathrm{NH}_{4}\right)_{2} \mathrm{SO}_{4}$ the fuel is still effective inhibitor for PCDD/F, PCB and PCBz formation. The reduction by its use is estimated up to $90 \%$. $\left(\mathrm{NH}_{4}\right)_{2} \mathrm{SO}_{4}$ is a low cost and non- toxic material. That makes it applicable for use in a full scale combustion unit. 


\section{Introduction}

Incineration of solid waste has become an important method for processing of this material and for energy production [1]. Municipal waste incineration is widely used to dwindle the waste volume. Further it reduces the potential infection threat and the bulk of the medical waste, and for this reason incineration is a promising approach to handling hazardous chemical and biological waste. The increasing costs of the municipal waste management and disposal options in the recent years, and the desire of the most developed countries to utilise the organic waste material from landfill depots, increase the interest of some power plants to use coal together with the waste for energy production. The technology of co-firing of fossil fuel, biomass and waste has been a promising technique for many years. It could help the greenhouse gas emissions and waste quality to be reduced on one hand and on the other hand it will enable the utilization of the waste energy, thus preserving fossil fuel resources [2]. Coal-waste co-combustion can be also specially attractive for countries which do not waste incinerators.

The question arises as to what advantages, technical or economical, are offered by the co-utilization of waste material and coal [3]. The benefits and disadvantages of this technique must be considered.

The partial replacement of coal by waste material can be a way of introducing renewable energy. In a number of countries, this is regarded as being of significant environmental benefit, and the respective governments subsidize and provide inducements to encourage these activities.

The coal is considered beneficial because supply of some of the waste and biomass materials is unreliable, and the quality of the delivered fuel is subject to only limited control. There are risk of the most waste / biomass energy conversion projects, and the co-utilization of coal can be regarded as a means of reducing these risks, in as much as coal supply of a prescribed quality specification is assured in most industrial countries.

In Germany possible types of fuel for coal fired power plants are [4]:

- domestic coal

- imported coal

- equivalent fuels: Petcoke compatible materials (e.g. sludge)

- substitute fuel 
There are even theories to justify the actual use of substitute fuels. One of the most important theories is based on the energetic efficiency of the waste utilization in power plants. So, if the efficiency of about 35 to $40 \%$ for coal-fired power plants is compared with the situation of common waste incineration plants (10-25 \%) (Tab.1.1.), it is even worth while to use smaller quantities of waste derived fuel in power plants.

Tab.1.1: Energy efficiency of power plant and waste incinerator [4]

\begin{tabular}{|c|c|c|}
\hline fuel & \multirow{2}{*}{ coal } & waste \\
\cline { 1 - 2 } Energy recovery & $\eta=35-45 \%$ & $\eta=10-25 \%$ \\
\hline Electric power & $\eta=$ ca. $85 \%$ & $\eta=$ ca. $80 \%$ \\
\hline Coupling of heat and power & $\eta=87 \%$ & $\eta=80 \%$ \\
\hline District heating & &
\end{tabular}

There is enough substitute fuel in every country and city. The European Union waste accumulations are 500 million tones per year (tpy) of which $30 \%$ is the deal of municipal solid waste. Only $7 \%$ of this is incinerated for power production. The potential of substitute fuel in Germany is 400 Mill. $t$ waste per year (in total), as one part of this: 40 Mill. $t$ domestic and similar waste (combustible). 12 Mill. $t$ of this burnt in MSW plant; as another part of this: 90 Mill. $t$ special waste; 10 Mill. $t$ of this is hazardous waste; 3.5 Mio. $t$ (dry matter) of this is sludge also part of this: 0.7 Mill. $t$ meat and bone meal (MBM). Approximately 50000 t per day domestic, paper and bio wastes are disposed in Munich city [5].

The major gas emissions from incineration of coal and waste are carbon dioxide and water vapor. Wood and municipal waste emit more carbon dioxide than coal during an electricity generation processes, whatever technologies are used. Sulfur removal from coal gas is a relatively a straightforward process. The presence of wood tar and hydrochloric acid from after the incineration further complicates the gas purifying process. Incinerators require high capital costs and trained operators thus making the waste incineration technology much more costly. The calculated investment and operational costs for reduction of dust emissions, $\mathrm{CO} / \mathrm{NOx}$, and $\mathrm{SO}_{2}$ in power plants using coal / waste incineration (Tab.1.2.) are around threefold more expensive than coal power plants (Tab.1.3). 
Tab.1.2: Costs for reduction of dust emissions, $\mathrm{CO} / \mathrm{NOx}$, and $\mathrm{SO}_{2}$ in co-combustion [4]

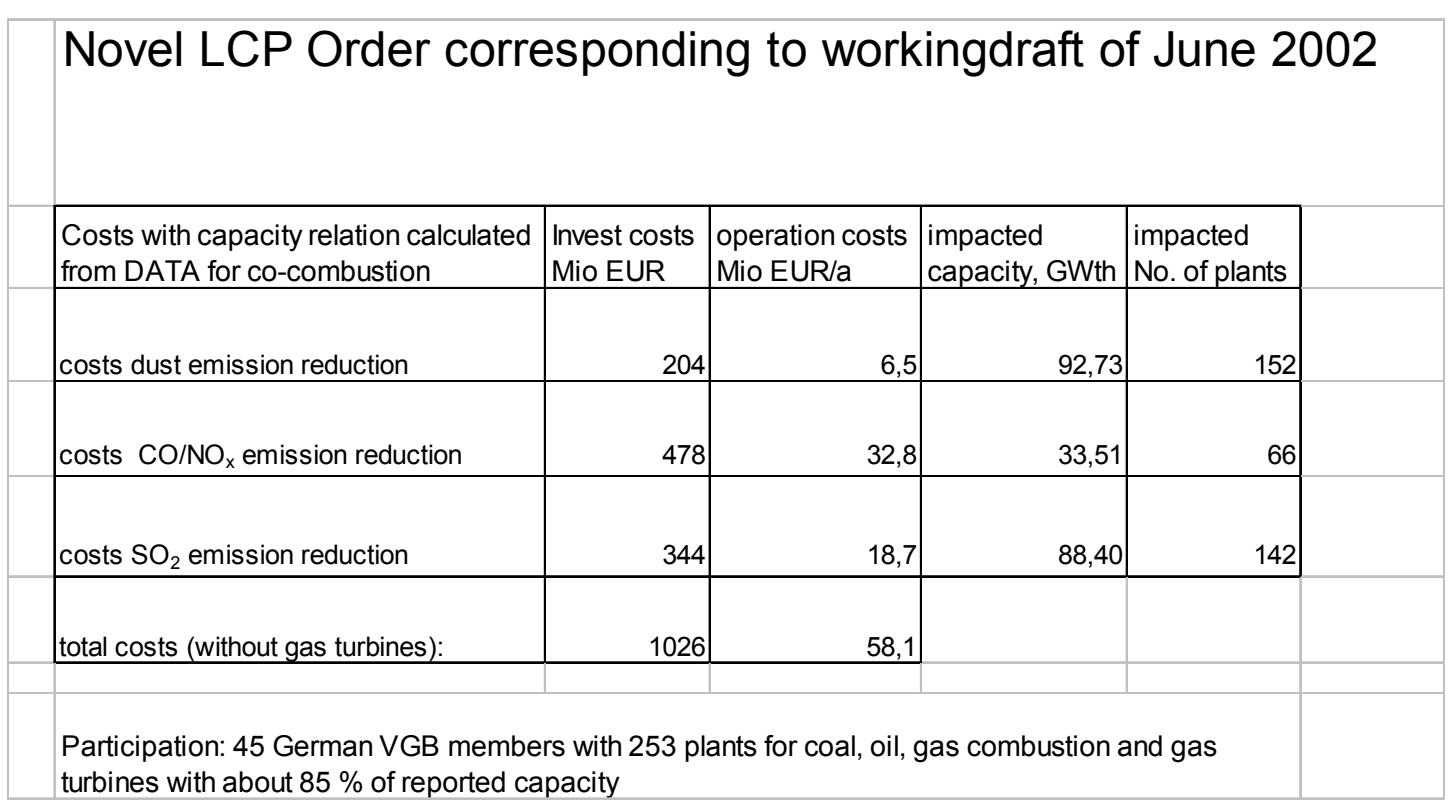

Tab.1.3: Costs for reduction of dust emissions, CO/NOx, and $\mathrm{SO}_{2}$ in coal / waste combustion [4]

\section{Waste incineration and co-combustion order}

\begin{tabular}{|r|r|r|r|r|}
\hline $\begin{array}{c}\text { Costs with capacity relation } \\
\text { calculated from DATA for co- } \\
\text { combustion }\end{array}$ & $\begin{array}{l}\text { Invest costs } \\
\text { Mio EUR }\end{array}$ & $\begin{array}{l}\text { operation costs } \\
\text { Mio EUR/a }\end{array}$ & $\begin{array}{l}\text { impacted } \\
\text { capacity, GWth }\end{array}$ & $\begin{array}{l}\text { impacted } \\
\text { No. of plants }\end{array}$ \\
\hline costs dust emission reduction & 126 & 4,05 & 56,518 & 73 \\
\hline costs CO/NQemission reduction & 63 & 4,32 & 4,196 & 19 \\
\hline & & & & \\
costs $\mathrm{SO}_{2}$ emission reduction & 82 & 4,46 & 20,118 & \\
\hline & 271 & 12,83 & & \\
total costs: & & & &
\end{tabular}

However, the above mentioned application of co-combustion of coal with solid waste entails some environmental risk due to the chemical nature of the used fuel. The experience from the operation of such facilities has shown that these installation often do not comply with the emission control regulations. The exhaust gas may contain many potentially harmful substances, including particulate matter; oxides of nitrogen; oxides of sulfur; carbon monoxide; volatile organic compounds, polycyclic aromatic compounds. Some emissions are formed in part by incomplete combustion that may lead to the formation of PCBs and dioxin and furans. These compounds are known as persistent organic pollutants (POPs). 
Over the last few years, the control on the release of dioxins in the atmosphere have become more widespread, with an increasing consensus in Europe for an emission limit for the flue gas of $0.1 \mathrm{ng} / \mathrm{Nm}^{3}$ based on the TEQ value (5). The experience shows that for instance the co-combustion of a mixture containing $75 \% \mathrm{w} / \mathrm{w}$ coal and $25 \% \mathrm{w} / \mathrm{w}$ even straw in a $0.5 \mathrm{MWt}$ pilot scale results in dioxin-furan emissions more than $0.25 \mathrm{ng} \mathrm{TEQ} / \mathrm{Nm}^{3}[6]$, while the co-combustion of $80 \%$ coal- $20 \%$ sewage sludge in semi-industrial furnace results in dioxin emission level about $0.3 \mathrm{ng} \mathrm{TEQ} / \mathrm{Nm}^{3}$ [7]. Both values are above current regulation of $0.1 \mathrm{ng} T E Q / \mathrm{Nm}^{3}$.

This thesis is focused on the use of primary measures to minimize the toxic emissions such dioxins, furans, PCBs and PCBz in order to comply with the limit value of $0.1 \mathrm{ng} \mathrm{TEQ} / \mathrm{Nm}^{3}$. 


\section{Objectives}

Combustion of organic matter in the presence of chlorine and metals is widely recognized as a major source of PCDD/F in the environment [8]. Waste incineration is one of the main sources of PCDD/F. Hence, the formation of PCDD/F in a waste incinerator is an inevitable process unless chlorine and hydrogen chloride can be completely eliminated, which is impossible in practice [9]. Basic questions regarding PCDD/F formation can be formulated as follows: (i) what is the influence of process parameters such as reagents, surface, chlorine sources, temperature, catalysts, reaction time on their formation, (ii) what reaction mechanisms are involved, (iii) are the corresponding reaction mechanisms thermodynamically or kinetically controlled able and (iv) can laboratory-scale experiments explain the formation mechanisms in full-scale incinerators?

As can be seen, PCDD/F formation is a difficult multivariate problem. The presence of PCDD/F in the flue gas of waste incineration were first observed in 1977 [10]. Since that time many researchers have provided a survey on the reaction mechanisms related to dioxin formation but still the relevant reaction pathways are unclear. The PCDD/F minimization during incineration arised other open questions. A comprehensive knowledge of the PCDD/F inhibition strategies is only possible if the the formation mechanisms are known. On the other hand the understanding the PCDD/F minimization provides significant information on the PCDD/F reaction mechanisms.

The motivation behind this work is based on the environmental and economical challenges posed by the combination of coal / waste combustion in power plants. This application entails high PCDD/F emissions due to the chemical nature of the solid waste. Over the last few years, the control over the release of dioxins into the atmosphere has become more widespread which has led to an increasing consensus in Europe for an emission limit in flue gas of $0.1 \mathrm{ng} / \mathrm{Nm}^{3}$ based on the TEQ value [11]. PCDD/F emissions from flue gas can be controlled by the so called primary and /or secondary measures in order to comply with the limit value of $0.1 \mathrm{ng} / \mathrm{Nm}^{3} \mathrm{TEQ}$. Secondary measures stress the use of flue gas purifying systems. During their use, toxicologically relevant residues are produced and collected and their disposal can cause further environmental risks. The installation and operating costs of secondary measures are much more expensive than primary measures, and cannot be considered for coal power plants. Primary measures include adjustment of operation 
conditions and focus on the additives of selective compounds or inhibitors that can substantially inhibit the formation of PCDD/F. The aim of this work is to identify the most effective inhibitors for PCDD/F with low cost and low toxicity.

During this work the main questions are:

- How is it possible to produce dioxins during combustion in a pilot plant?

- Which operating parameters influence the dioxins formation?

- What type of laboratory scale furnace and incineration procedure is suitable for further inhibitory investigations?

- Which compounds can be used for PCDD/F minimization?

- Are they still effective at lower percentage of the fuel mixture?

- Do the used successful inhibitor survive and retain its dioxins suppression effect also at a higher temperature $\left(1000^{\circ} \mathrm{C}\right)$ ? 


\section{State of Knowledge}

\subsection{PCDD/F, PCB and PCBz}

\subsubsection{Dioxin nomenclature and properties}

The compounds of main interest in this work are PCDD, PCDF, PCB and PCBz:

- $\quad$ Polychlorinated dibenzo-p- dioxins (PCDD)

- $\quad$ Polychlorinated dibenzo-p- furans (PCDF)

- $\quad$ Polychlorinated biphenyls (PCB)

- $\quad$ Polychlorinated benzenes (PCBz)

Polychlorinated dibenzo-p- dioxin (PCDD) and furans (PCDF) are compounds with similar chemical properties. Each compound consists of two benzene rings interconnected by oxygen atoms (Fig.3.1). Polychlorinated biphenyl (PCB) molecules are similar to PCDD and PCDF but the two benzene rings are connected by a direct carbon bond without oxygen atom. Polychlorinated benzene (PCBz) consists of only one benzene ring.

All PCDD and PCDF are organic solids with high melting point and low vapour pressure. They are characterized by extremely low water solubility, and have the ability for being strongly absorbed on the surface of the particulate matter. The water solubility of dioxin and furan decreases and the solubility in organic solvents and fats increases with increasing the chlorine content. Non- and mono-ortho-substituted PCB congeners have a high toxicity, similar to the polychlorinated dibenzo-p-dioxins and polychlorinated dibenzo-p-furans (PCDD/F). Therefore, these dioxins like PCBs are referred to as dioxin-related compounds (Fig. 3.1). These congeners are strongly hydrophobic and thus highly lipophylic. 


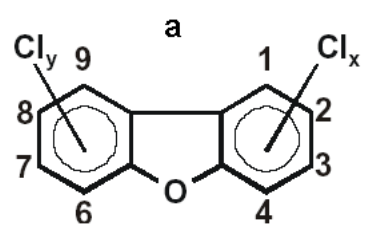

c

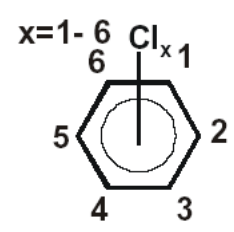

$x+y=1-8$

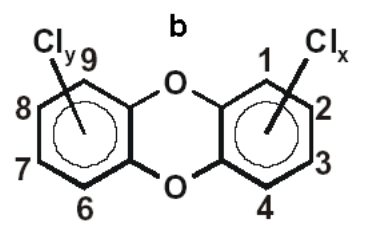

d

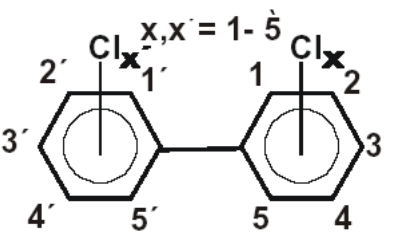

Fig. 3.1: Polychlorinated di-p-benzo-dioxin (a); Polychlorinated di-p-benzo-furan (b); Polychlorinated benzene (c); Polychlorinated biphenyl (d) .

Tab. 3.1: Homologues and congeners of PCDD, PCD , PCB and PCBz

\begin{tabular}{ccccc}
\hline Homologue & \multicolumn{4}{c}{ Number of congeners } \\
\cline { 2 - 5 } & PCDD & PCDF & PCB & PCBz \\
\hline Monochloro $(\mathrm{M})$ & 2 & 4 & 3 & 1 \\
Dichloro $(\mathrm{D})$ & 10 & 16 & 12 & 3 \\
Trichlolro $(\mathrm{Tr})$ & 14 & 28 & 24 & 3 \\
Tetrachloro $(\mathrm{T})$ & 22 & 38 & 42 & 3 \\
Pentachloro $(\mathrm{Pe})$ & 14 & 28 & 46 & 1 \\
Hexachloro $(\mathrm{Hx})$ & 10 & 16 & 42 & 1 \\
Heptachloro $(\mathrm{Hp})$ & 2 & 4 & 24 & - \\
Octachloro $(\mathrm{O})$ & 1 & 1 & 12 & - \\
Nonachloro & - & - & 3 & - \\
Decachloro & - & - & 1 & 12 \\
\hline
\end{tabular}

There are 75 PCDD, 135 PCDF, 209 PCB and 19 PCBz each differing in the number of the position of the chlorine atoms. Each individual PCDD or PCDF is referred to as a congener (giving 210 in total), while group of congeners with the same number of chlorine atoms are called homologues. The number of the congeners in each homologues group is shown in Tab. 3.1.

Often the term "dioxin" means PCDD and PCDF.

PCDD and PCDF congeners with chlorine atoms in position 2, 3, 7, and 8 are of particular concern, especially the tetrachloro-CDD congener 2,3,7,8-TCDD which is 
the most toxic dioxin. The toxicity effect of the dioxins present in the emission gases by the so-called "toxic equivalent" or Toxicity Equivalent Factor (TEF) is estimated. It is generally assumed that only 17 of the 210 dioxin and furan congeners and 12 of the 209 PCB congeners are toxic. Since 2,3,7,8-TCDD is the most toxic, its TEF is 1.0. The most toxic PCB congener among the 209 isomers is $3,3^{\prime}, 4,4^{\prime}, 5-\mathrm{PeCB}$. If the assigned value of the isomers is converted by the TEF, the final sum is so-called Toxic Equivalent (TEQ). TEQ is individual for each congener. The international values of the TEFs are termed into international toxic equivalent factor, or I-TEFs. The I-TEFs of the seventeen 2,3,7,8-positioned congeners of PCDD and PCDF are present in Tab.3.3. The sum of the individual TEQs for a mixture of PCDD and PCDF is termed the international toxic equivalent or I-TEQ.

$$
\sum_{i=1}^{n} \mathrm{C}_{\mathrm{i}}{ }^{*} \mathrm{I}-\mathrm{TEF} \mathrm{F}_{\mathrm{i}}=\mathrm{I}-\mathrm{TEQ} .
$$

The recent revision of the TEF scheme was undertaken by the World Health Organization (WHO). The proposed scheme includes coplanar congeners of PCBs by defining TEFs for 12 coplanar PCBs. They are also listed in Tab.3.3. 
Tab.3.2:Toxic equivalent factor (I-TEFs)

\begin{tabular}{|c|c|c|}
\hline Congener & I-TEFs & WHO TEF \\
\hline 2,3,7,8-TCDD & 1 & 1 \\
\hline 1,2,3,7,8-PeCDD & 0.5 & 1 \\
\hline 1,2,3,4,7,8-HxCDD & 0.1 & 0.1 \\
\hline 1,2,3,7,8,9-HxCDD & 0.1 & 0.1 \\
\hline 1,2,3,6,7,8-HxCDD & 0.1 & 0.1 \\
\hline 1,2,3,4,6,7,8-HpCDD & 0.01 & 0.01 \\
\hline OCDD & 0.001 & 0.0001 \\
\hline $2,3,7,8-\mathrm{TCDF}$ & 0.1 & 0.1 \\
\hline $2,3,4,7,8-\mathrm{PeCDF}$ & 0.5 & 0.5 \\
\hline $1,2,3,7,8-\mathrm{PeCDF}$ & 0.05 & 0.05 \\
\hline $1,2,3,4,7,8-\mathrm{H} \times \mathrm{CDF}$ & 0.1 & 0.1 \\
\hline $1,2,3,7,8,9-\mathrm{H} \times \mathrm{CDF}$ & 0.1 & 0.1 \\
\hline $1,2,3,6,7,8-\mathrm{H} \times \mathrm{CDF}$ & 0.1 & 0.1 \\
\hline $2,3,4,6,7,8-\mathrm{H} \times \mathrm{CDF}$ & 0.1 & 0.1 \\
\hline $1,2,3,6,7,8-\mathrm{H} \times \mathrm{CDF}$ & 0.1 & 0.1 \\
\hline $2,3,4,6,7,8-\mathrm{H} \times \mathrm{CDF}$ & 0.1 & 0.1 \\
\hline $1,2,3,4,6,7,8-\mathrm{HpCDF}$ & 0.01 & 0.01 \\
\hline $1,2,3,4,7,8,9-\mathrm{HpCDF}$ & 0.01 & 0.01 \\
\hline OCDF & 0.001 & 0.0001 \\
\hline 3,4,4',5-ТCВ (\#81) & - & 0.0001 \\
\hline 3,3',4,4'-TCB (\#77) & - & 0.0001 \\
\hline $3,3^{\prime}, 4,4^{\prime}, 5$-РeCB (\#126) & - & 0.1 \\
\hline $3,3^{\prime}, 4,4^{\prime}, 5,5^{\prime}-\mathrm{H} \times \mathrm{CB}(\# 169)$ & - & 0.01 \\
\hline 2,3,3',4,4'-PeCB (\#105) & - & 0.0001 \\
\hline 2,3,4,4',5 -РeCB (\#114) & - & 0.0005 \\
\hline 2,3',4,4',5-РeCB (\#118) & - & 0.0001 \\
\hline 2',3,4,4',5-РeCВ (\#123) & - & 0.0001 \\
\hline $2,3,3^{\prime}, 4,4^{\prime}, 5-\mathrm{H} \times \mathrm{CB}$ (\#156) & - & 0.0005 \\
\hline $2,3,3^{\prime}, 4,4^{\prime}, 5^{\prime}-\mathrm{HxCB}(\# 157)$ & - & 0.0005 \\
\hline $2,3^{\prime}, 4,4^{\prime}, 5,5^{\prime}-\mathrm{H} \times \mathrm{CB}(\# 167)$ & - & 0.00001 \\
\hline 2,3,3',4,4',5,5'-НрСВ (\#189) & - & 0.0001 \\
\hline
\end{tabular}




\subsubsection{Dioxins and public health}

In 1968 it became clear that polychlorinated biphenyls posed serious health risks, when several thousand people in Japan were affected by a strange illness. Many of them exhibited a broad spectrum of symptoms, such as changes of the skin and mucous membranes, dizziness, coughing and damage of the central nervous system. It is known now that the presence of PCB products was the most probable main cause of illness caused by the rice oil disaster in Japan in 1968 (POP, Swedish Environmental Protection Agency).

High concentrations of polychlorinated dibenzo-p-dioxin and furans (PCDD/F) are produced during the waste incineration [1]. The emitted toxic gases disperse into the air and some people close to the facilities may be after either exposed directly through inhalation or indirectly through consumption of food and water contaminated by deposition of the pollutants from air in soil, vegetables and water. According to the report released for public comment in 1994 by United State Environmental Protection Agency (EPA) dioxin is a cancer hazard for the people and the exposure to dioxin can cause reproductive problems; dioxin can cause immune system damage and interfere with regulatory hormones as well [12] [13]. In humans, dioxins have a halflife of about 7 years.

\subsubsection{Dioxin emission sources}

Many natural sources can release dioxins. For instance, before the large-scale manufacturing and the use of chlorinated chemicals began, biological formation of PCDD and PCDF in sediments and solid, especially forest soils, had been observed. Öberg and co-workers [14] and [15] have been noted the potential of natural formation of $\mathrm{PCDD} / \mathrm{F}$ in sewage sludge under normal environmental conditions. Anyway the man-made sources of PCDD/F are dominant and can be divided into a number of main categories: waste incineration, combustion of fuel in stationary sources, chemical waste, crematories, paper production, forest fires and agricultural burning.

Waste incinerators were the main sources of dioxin in emissions. These include waste incinerators such as MSW, sewage sludge, medical waste and hazardous waste burning of various fuels, such as coal, wood, and crude oil products. By the end of 1978, Dow Chemical scientists announced that chlorinated dibenzodioxins were found in all particulates collected inside and close to combustion facilities [16]. 
Dioxins were detected in fly ash from municipal and industrial incinerators [17] [18] [19] [20], city dust, in commercial sludge fertilizer, as well as in the cigarette smoke and soot from home fire places [21]. There are roughly 3000 incinerators in Japan of which $960 \mathrm{~g}-\mathrm{TEQ} /$ year dioxins came from the industrial waste incinerators [22]. The substance flow of Co-PCBs show that the TEQ amount of Co-PCBs released from MSW incineration facilities is higher than the input amount. Some congeners such as No. 126 and No. 169 drastically increase the ratio of output to input amounts [23]. Due that fact the Japanese government established a Guideline for Controlling PCDD/PCDFs on MSW Management [24]. Approximately eight thousand tons of PCBs were produced in China during 1960's and 1970' due to municipal waste incinerators [25].

Over the last decade, the amount of waste generated by hospitals has increased. Around 465000 tons of biohazardous waste such as "hospital wastes", "medical wastes", and "infection wastes" is generated in the United States each year by 377 000 healthcare facilities [26]. In the recent years, many hospitals stopped operating their incinerators because the units were old and had no emission control systems.

PCDD/F can be performed during various types of steel production and scrap metal recovery. The calculated WHO-PCBs amount in eight industrial plants and crematories have been measured by Luthardt et.al. [17]. In the secondary aluminium melting processes, aluminum scrap, to which organic materials are attached, is melted together with salt at temperature of approximately $700-800^{\circ} \mathrm{C}$. These conditions are favorable for PCDD/F formation [27].

\subsection{Formation of Dioxins}

Incomplete combustion of organic matter in combustion chambers leads to the formation of organic fragments, commonly organic precursors to dioxin/dibenzofuran molecule. They are easily adsorbed onto the surface of the fly ash in the post combustion zone, and following a complex series of reactions which are catalysed by metals (mainly copper) in the fly ash, leading to the formation of PCDD/PCDF along the other chlorinated trace organics.

Chlorinated pollutants like chlorinated benzenes (PCBz), phenols (PCPh), biphenyls (PCB) and dibenzo-dioxins and -furans (PCDD/F) are formed in many incineration processes like municipal waste incinerators. As the flue gases leave the primary combustion chamber, these compounds are cooled down from $1000^{\circ} \mathrm{C}$ to $650-250^{\circ} \mathrm{C}$ and subsequently condense. As a result during different molecular rearrangements 
the PCDD/F are formed. Many hypothesis and much data have been gathered about their formation in combustion processes. Theoretical calculations have shown that these compounds are formed through heterogeneous mechanisms by surface catalysed processes rather than via homogeneous gas phase reactions [28].

Two pathways have been proposed so far to explain the formation of PCDD/F during incinerations: (i) de novo synthesis where carbon, chlorine and hydrogen in fly ash somehow react in the presence of the gas-phase oxygen to form chlorinated aromatic compounds such as PCDD/F and (ii) through various precursors, such as chlorophenols which can be formed in the gas phase during incomplete combustion and further combined in a heterogeneous way and catalytic reactions with the fly ash surface [9].

\subsubsection{De novo synthesis}

The name of de novo theory of thermal dioxin formation is known as incineration process where the flue gases are quickly cooled down to $250-450^{\circ} \mathrm{C}$ and the carbon source form new organic chemical compounds including dioxins. The elemental carbon can have different modifications including different functional groups. The laboratory experiments show that coal, soot, graphite, active carbon and different PAHs under equal conditions (temperature, catalyst, atmosphere) enable PCDD/F formation [29].

The mechanism of the de novo reaction is widely discussed, especially by Stieglitz and coworkers [30] [31] [1] [32] [33] who proposed copper as a catalyst and also worked with a "model fly ash". They postulated partly oxidation and chlorination of the carbon skeleton which results in dioxins formation by direct and indirect pathways.

The de novo synthesis of dioxins occurs essentially in a process of partial oxidation and partial chlorination of the carbon matrix. According to the second indirect pathway of de novo synthesis the major products are $\mathrm{CO}$ and $\mathrm{CO}_{2}$ and some aliphatic compounds which via condensation processes form a variety of organic compounds including PCDD, PCDF, PCBz, PCPh and PCB.

Copper chlorides have been shown to play a predominant role in surface-catalysed chlorination reactions [34] [35] [36]. The main thermal pathway of chlorinated dibenzodioxins and furans have been discovered in laboratory studies. The experiments indicate that the common form of copper in a combustion system is cupric oxide which can catalyse acetylene in the presence of $\mathrm{HCl}$. This reaction occur 
In the further steps $\mathrm{Cl}_{2}$ produced chlorinates aromatic ring structures through electrophilic substitution reactions. The carbon source is derived from unburnt particular matter reacting with $\mathrm{O}_{2}$ and $\mathrm{Cl}_{2}$ to form PCDD and PCDF. Many copper catalysts $\left(\mathrm{Cu}, \mathrm{CuCl}, \mathrm{CuCl}_{2}, \mathrm{CuO}, \mathrm{Cu}_{2} \mathrm{O}\right.$ and $\left.\mathrm{CuSO}_{4}\right)$ can promote this reaction, whereas Fe-based catalysts are found to be not active in the Deacon process [9].

Milligan and Altwicker observed the de novo synthesis at time scale of 5, 20 and 30 min [39]. They noticed that the amount of PCDD/F formed during the de novo synthesis is linear with respect to the reaction time. Blaha and Hagenmaier [40] tested a model fly ash and discovered that de novo synthesis can take place at a time scale as short as $1 \mathrm{~min}$. Based on these investigations and the experience of the other researchers, Huang proposed a kinetic model of de novo synthesis [41]. When this model is applied to industrial incineration conditions, PCDD/F formation level in the gas phase and solid phase is in a good agreement with incinerator measurements.

The condition of de novo synthesis of dioxins to occur is the presence of carbon together with oxygen and minute quantities of chlorine and metal ions at $250-400^{\circ} \mathrm{C}$.

\subsubsection{Synthesis from precursors}

The precursor theory is supported by the existence of a relationship between the concentration of chlorobenzenes and chlorophenols with the concentration of PCDD/F in the flue gas. Chlorophenol is converted to PCDD by the Ulmann type II reaction, via a double cyclization process [42]. This reaction occurs as a heterogeneous process on the surface of copper species which are present in nearly all kinds of fly ash. Various chlorophenols have been shown to be precursors of PCDD/F in laboratory experiments. Karasek and Dickson used 3,4,5-trichlorophenol and pentachlorophenol in their classical experiment using a fixed bed reactor [43]. Various chlorophenols show a similar reactivity but with some small differences e.g. tetrachlorophenol is more reactive than pentachlorophenol by a factor of 4 the same condition [36]. Altwicker in his study has shown that 2,3,4,6-tetrachlorophenol forms PCDD more rapidly than either penta- or tri-chlorophenol [44]. Hell has shown also that formation of PCDD is possible via condensation reactions of gaseous 2,4,6trichlorphenol and 2,3,4,6- tetrachlorphenol [45]. Chlorobenzenes are the major products among the chlorinated organic compounds derived from 2,4,5trichlorophenol with lesser quantities of PCDD and PCDF. 
at temperatures between $300-500^{\circ} \mathrm{C}$. Lenoir et. al. proposed a reaction mechanism for formation of the observed chloroaliphatic and chloraromatic compounds involving metallacyclization reactions [37].

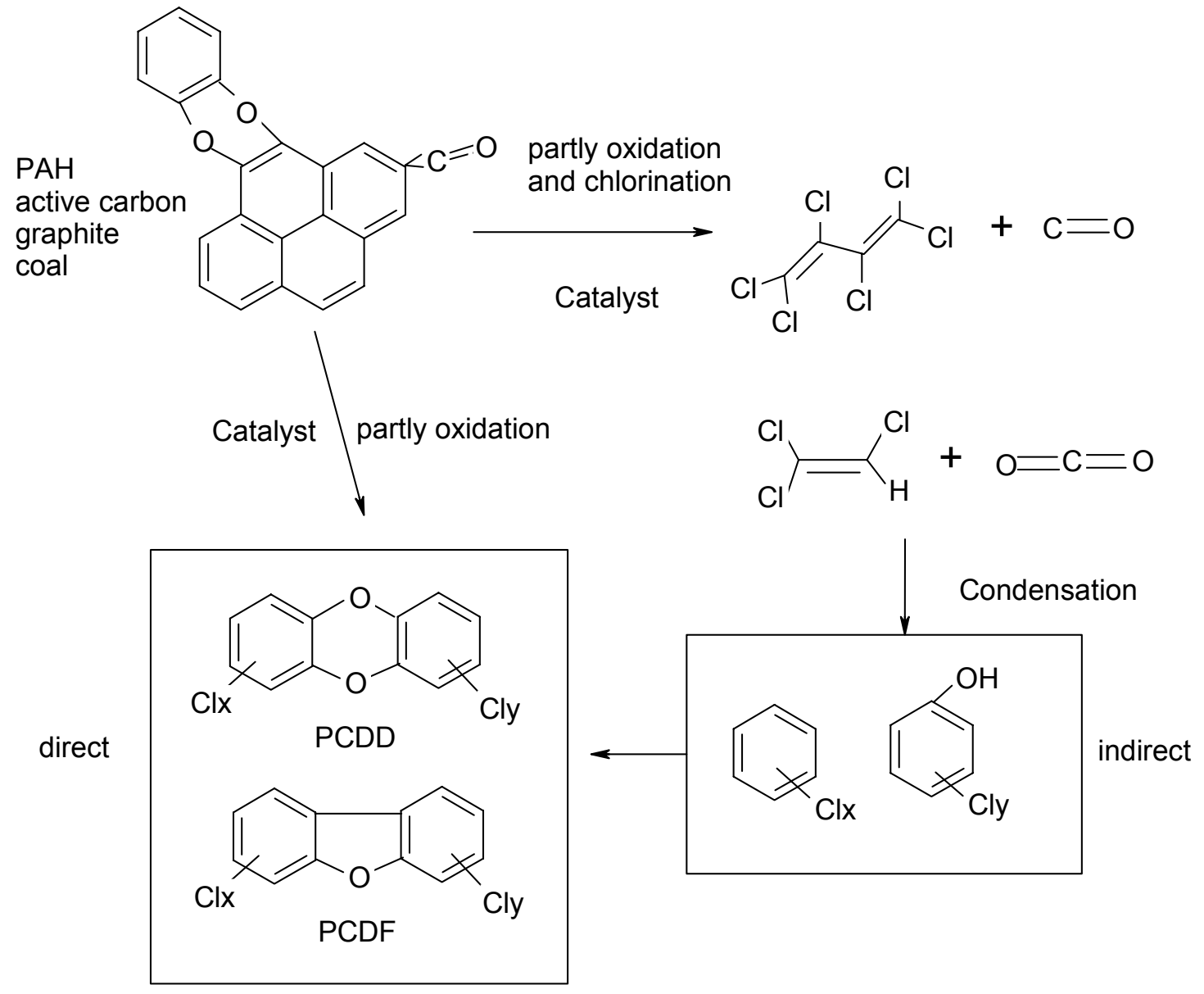

Fig. 3.2: De novo synthesis of PCDD/F

By this mechanism with the help of $\mathrm{CuCl}_{2}$ acetylene is converted into dichloroacetylene. The experimental results also demonstrate that dichloroacetylene is an important precursor in surface-catalyzed chlorination and molecular growth of acetylenic compounds. This mechanism provides a tool toward the PCDD/F formation.

Laboratory experiments have successfully produced PCDD and PCDF through simulating postfurnace conditions of municipal waste combustors [38]. Theory shows that this PCDD/F formation occur due to de novo synthesis from compounds within the flue gas and fly ash. This synthesis involves the Deacon process reaction:

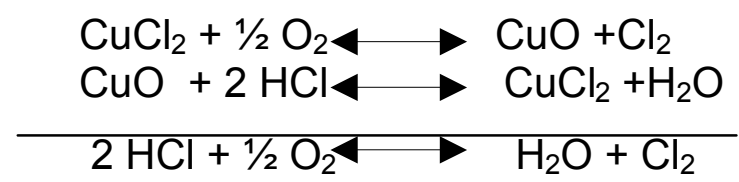

Fig.3.3: Deacon reaction 
Ortho-chlorophenol and chlorbenzene by ethersynthesis and Ullmann reaction are involved in PCDF synthesis (Fig. 3.4.). The classical Ulmann reaction, the copper catalyst and the aryl radicals form the aryl-copper complex. In the subsequent steps this complex is coverted into biaryl. The experiments with 1,2,4,5-tetrachlorobenzene $\left(10 \% \mathrm{O}_{2}, 300^{\circ} \mathrm{C}\right)$ and tetrachlorophenol yield PCDD/F with typical PCDD/PCDF ratio 20-40.<smiles>Oc1ccccc1Cl</smiles><smiles>Clc1cccc(O[Ga])c1Cl</smiles><smiles>ClOc1cc(Cl)ccc1Cl</smiles><smiles>O=C(O)c1cc2c(cc1Cl)Oc1ccc(Cl)cc1O2</smiles><smiles>Clc1ccc(Oc2cccc(Cl)c2[BH2-]Oc2cccc(Cl)c2Cl)c(Cl)c1</smiles><smiles>Clc1cccc2c1oc1ccccc12</smiles>

PCDF

Fig.3.4: Copper catalysed formation of PCDD/F from ortho- chlorophenol and chlorbenzene After considering the results obtained from the experiments it turns out that chlorobenzes are far less reactive precursors [44]. Alternatively, Pschorr-type ring closure (Fig. 3.5.) of the 2-phenoxybenzene diazonium cation with various catalysts provides an effective method for the formation of dibenzofurans. That Pschorr-type mechanism could be also applied to PCDDs.

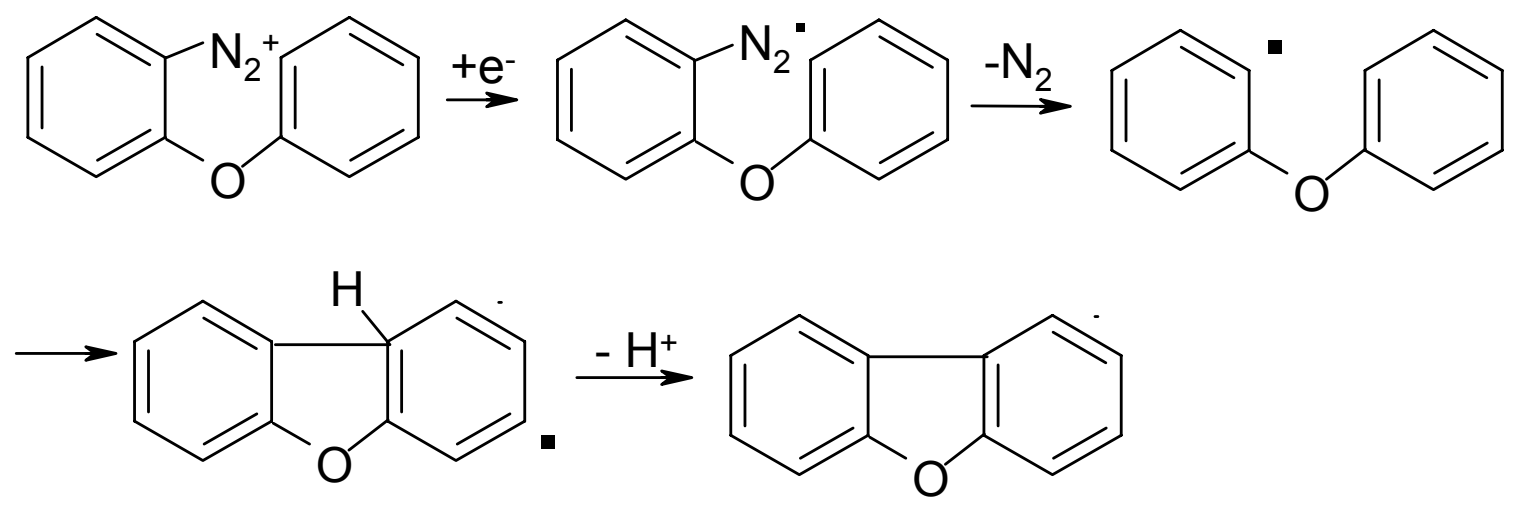

Fig. 3.5: Formation of PCDFs via Pschorr-type ring closure

Comparing de novo synthesis with precursor formation Huang has summarised [29] : 
- The rate of dioxin formation in the precursor theory is several orders of magnitudes higher than that in de novo synthesis.

- The typical homologue profile during de novo synthesis can produce furan/dioxin ratio $>1$. But in precursor formation less furans are formed and the furan/dioxin ratio is much smaller than 1.

- From de novo synthesis the actual incineration data show typical decrease order of PCBz > PCPh > PCDF > PCDD > PCB.

The above mentioned evidence suggests that de novo synthesis is the dominant mechanism of dioxin formation in the real combustion processes. Taking into account the basic chemistry the precursor formation pathway is much easier than de novo synthesis. However in actual combustion systems dioxin formation from precursors is limited. On the other hand the starting material for de novo synthesis, $\mathrm{O}_{2}$ and carbon in fly ash, is relatively abundant.

\subsubsection{Influence of the operation parameters and the fuel type on PCDD/F emissions}

The knowledge on the effect of the different experimental parameters is important for the understanding of the mechanisms of PCDD/F formation and for elaborating a method to control these parameters. Often statistical analysis is used in order to calculate the role and importance of some parameters for PCDD, PCDF, PCB and PCBz formation.

De novo formation of PCDD and PCDF has been investigated in an Entrained Flow Reactor (EFR) to simulate combustion conditions [46]. The comprehensive data is further evaluated with PCA. The amount of $\mathrm{Cl}_{2}$ in the gas phase is considered as an important parameter for the PCDF formation; on the other hand the levels of $\mathrm{O}_{2}$ are not found to be a significant PCDF rate controlling parameter. Overall the most significant parameter for the rate of both PCDD and PCDF formation has been revealed to be the reaction time. A maximum formation rate is observed between $300-400^{\circ} \mathrm{C}$ for PCDD and $400-500^{\circ} \mathrm{C}$ for the PCDF. The correlation between the CO and $\mathrm{O}_{2}$ concentration and the PCDD/F emissions have been studied in a fluidised bed incinerator [47]. Under conditions of incomplete combustion, $\mathrm{CO}$ concentration is positively and $\mathrm{O}_{2}$ is negatively correlated with the total PCDD/F emissions. Adding of only $3 \% \mathrm{PVC}$ to the fuel results in an increase in PCDD/F concentrations. It was observed that dioxins amount did not depend of the $\mathrm{HCl}$ concentration and the high water content. However Takashita has reported in his work that $\mathrm{HCl}$ concentration 
level in flue gas is very effective in the control of PCDD/F formation [48]. Gullett has prooved statistically that both higher $\mathrm{HCl}$ and sulfur dioxide concentrations favor a higher relative formation of the lower chlorinated PCDF homologues [49]. Increased $\mathrm{SO}_{2}$ resulted in significant larger fraction of MCDF due to a leftward shift in the homologue profile. The role of $\mathrm{SO}_{2}$ is proposed to prevent the molecular chlorination or encourage dechlorination processes. Shifts in homologue profiles due to changes in $\mathrm{HCl}$ concentration demonstrated conditions in which the proportion of DiCDF and TrCDF is significantly increased.

A laboratory-scale-fluidised -bed incinerator has been used to study the influence of several combustion parameters [50]. The most important parameter has been reported to be the residence time in the post combustion zone. Blumenstock proposed that non-optimal combustion conditions resulted in increased concentrations of mono-to trichlorinated PCDD, PCDF and PAH, while PCBz and PCB and higher chlorinated PCDD/F are only weakly affected or even decreased [51]. Reaction time is positively correlated to concentration of precursors.

The function of chlorine in the formation of PCDD/F, PCB and PCBz has been widely investigated by many authors. Wikström et.al. [52] found a good correlation between the total chlorine content in the fuel and the formation of the hepta- and octachlorinated PCDD/F homologues. The effect of inorganic and organic chlorine in the fuel mixture has been also studied by Halonen [53], [54]. The laboratory plant experiments have shown that organic chlorine promote the particle-bound PCDD/F formation whereas inorganic chlorine has been observed to be more effective on $\mathrm{PCDD} / \mathrm{F}$ formation in the gas-phase. Comparing the organic chlorine source such as tetrachloroethylene $\left(\mathrm{C}_{2} \mathrm{Cl}_{4}\right)$ and inorganic chlorine such as sodium chloride $(\mathrm{NaCl})$ it has found that more highly substituted PCDD/F congeners were detected when organic chlorine is the additive to the fuel.

Wang elaborated a organic chlorine content threshold value of $0.8-1.1 \%$ which can strongly relate to the mechanism of PCDD/F formation [55]. In the same study it was calculated that if chlorine level in the waste of the MSW incinerators exceeds this threshold, the rate of PCDDF formation is quickly increased. However if the chlorine level is below that threshold the PCDD are dominating.

The influence of metal oxides ( $\mathrm{CdO}, \mathrm{CuO}, \mathrm{Fe}_{2} \mathrm{O}_{3}, \mathrm{PbO}, \mathrm{MoO}_{3}, \mathrm{ZnO}$ ) on the formation and the distribution behaviour of PCDD/F during simulated fire was investigated in a laboratory scale incinerator [56]. It was found that adding a mixture of metal oxides 
resulted in an increase of PCDD by factor 14 and PCDF by factor 7 whereas the PCDF amount was increased 17 times.

\subsection{Correlation between PCDD/F, PCB and PCBz}

The routine measurements of PCDD/Fs are difficult and expensive. As a consequence, there is a growing tendency to find surrogates of PCDD/Fs. Based on this knowledge the exact reaction mechanisms can be developed in order to characterize PCDD/F emissions from combustion processes and their effective inhibition techniques as a primary goal. In particular chlorobenzenes have attracted much attention because of their good correlation with PCDD/F I-TEQ value [57], [58], [59], [60], [61], [62], [63].

$\mathrm{PCBz}$ is present in incinerator emissions at much higher concentrations than PCDD/F [50]. Among the PCBz, either pentachlorobenzene or hexachlorobenzene [61], [63] are the dominating congeners. I-TE and PCDD/F concentrations are most accurately predicted from the concentrations of pentachlorobenzene [62]. However, Öberg proposed hexachlorobenzene as an indicator of dioxin production [61]. Some lower chlorinated PCDD, PCDF, PCPh and PCBz were identified as a surrogate for the toxicity carried by the PCDD/F in the flue gas at hazardous waste incinerator (HWI) plants [60]. The most promising candidates for an easily accessible compound group of I-TEQ surrogates at the HWI plant are the chlorinated benzenes. 2,3,7,8tetrachlorodibenzodioxin was closely correlated with the concentrations of pentachlorophenol, pentachlorobenzene and hexachlorbenzene in the flue gas of three waste incinerators. The proposed correlation is valid for all sampling points of the waste incinerators including the dry EST and wet scrubber where the I-TE values are much lower. Furthermore Blumenstock found that all isomers of PCBz which are good surrogates for the emissions of the I-TEQ in the flue gas show similar correlation coefficient values also in the stack gas [57]. However, only few higher chlorinated phenols (trichlorophenols and higher) are found with a high I-TEQ correlation in the stack gas. Further, the flue gas purifying system of the plant influences the PCPh isomers pattern in the stack gas dramatically.

A recent study suggest that the measurement of $\mathrm{PCPh}$ in waste incineration flue gases, combined with multivariate statistics, could be used as a surrogate for assessment of PCDD/F emissions [64]. The partial least squares (PLS) results indicate that almost all of the PCPh isomers are correlated either fairly with PCDD or 
closely with PCDF in the gas phase, but only certain isomers, particularly 2,3,4,6-, and penta - CPh, are of importance in the particle phase.

Concentrations of selected mono-to tri-CDD/CDF congeners show promising correlations with CDD/CDF TEQ values [65]. According to these results the monitoring of these congeners may be used to observe flue gas concentrations for calculation of TEQ emissions.

The correlation between PCDD/F and PCB is not so widely investigated as other indicator parameters such as PCBz and PCPh. On the other hand the correlation between the PCB and PCDD/F is important in order to understand the mechanisms of PCDD/F formation. It is already known that PCB molecules are also precursors of PCDD/F formation [36], [9]. Using Principal Component Analysis Fängmark et.al. reported a positive correlation among PCDD/F and the three planar PCB analysed [50]. Blumenstock has suggested that the formation of PCB seems to be different from the other chlorinated aromatics, which may be hind of different formation mechanisms of PCDD/F and PCB. Investigations at a hazardous waste incinerators by Kaune et. al. [62], for example, pointed out that some PCBs are good indicators for I-TEQ values.

The first relationship of PCDD/F on chlorobenzenes in emissions has reported by Oehme et. al. [63] using linear regression techniques. To improve the accuracy of the prediction, multiple regression [66] and PLS [67] were used. Multiple regression may improve the accuracy of estimating PCDD/F and I-TEQ values from indicator parameters but has the draw back that many parameters rather than a single one must be measured. That is why, these methods do not make use of the advantages of the indicator parameter concept. Statistical analysis of the results is useful, if performed in order to determine whether there exist a relationship between the investigated compounds [51], [65], [67]. The present study is based also on statistical analysis like Correspondent Analysis (CA) and is focused on linear regression equations with one independent variable to study the dependence of I-TE on the indicator parameters.

\subsection{Dioxin Minimization}

Technical incineration processes are the major a source of potential emissions of hazardous substances into the environment. Two approaches have been developed for the control of PCDD/F emissions to the environment. PCDD/F emissions from flue gas can be controlled by the so called secondary and /or primary measures in order 
to comply with the limit value of $0.1 \mathrm{ng} / \mathrm{m}^{3} \mathrm{TEQ}$. Secondary measures belong to the "end pipe" treatments of emissions. The so-called secondary measures is focused on the removal of PCDD/F from flue gas after their formation by means of gas cleaning devices. Upon their use, toxicologically relevant residues are produced and collected and their disposal can cause further environmental risks. The installation and operating costs of secondary measures are expensive and cannot easily and economically be considered for coal power plants. The second approach, the socalled primary measures, includes an adjustment of the operation conditions (temperature, turbulence, air flow, residence time) and focus on the additives of selective compounds or inhibitors that can inhibit the formation of PCDD/F substantially in the combustion process [47] [50]. The influence of parameters such as water, carbon monoxide, and carbon dioxide; amount of gas-phase chlorine; reaction temperature; and reaction time in the flue gas has been investigated [46].

\subsubsection{Secondary Measures}

The cleaning devices which are commonly equipped in MSW incinerators are[68]: Electrostatic precipitator (ESP) - collect and control particulate matter that evolves during combustion, by introducing a strong electric field in the flue gas steam. This in turn charges the particles entrained in the combustion gases. Large collection plates receive an opposite charge to attract and collect the particles.

Selective catalytic reduction (SCR) - Catalysts employed for the SCR of NOx emissions also demonstrate the ability to decompose organohalogenic compounds, including PCDD/Fs.

Fabric Filter (FF) - control device made from woven fibreglass material which remove dioxins associated with particles and any vapours that adsorb to the particles

Dry Scrubber (DS) - involved both the removal of acid gas and particulate matter from post-combustion gases

Wet scrubber (WS) - device designed for acid gas removal; consist of a two- stage scrubber, first removes $\mathrm{HCl}$ and afterwards removes $\mathrm{SO}_{2}$. This technique is more common to MSWI in Europe than in the United States.

End-of-pipe treatment - An effective of end-of-pipe treatment is the combination of a scrubber, a bag filter coupled with an active carbon injection in the bag filter. The carbon can be burnt in the incinerator to destroy the PCDD/F and heavy volatilised metals will be removed in the scrubber. 
The presented data of the thermal waste treatment plants of modern MSWI in Bavaria show very high removal efficiency for PCDD/F by active carbon sorption at fabric filter and less effective removal for PCB and PAH [69]. Fabric filter cleaning system is also successfully used by the Belgium IVRO MSWI [70]. Chlorobenzenes removal from fly ash of MSWI in Japan is effectively removed to $49 \%$ during surfactant-assisted column flotation process [71]. The data of other Japanese MSWIs proposed that wet scrubbers influence on minimizing the memory effect of chlorinated aromatic compounds due to the changed PCDD/F homologue profiles at outlet gas of WS [72].

\subsubsection{Primary Measures}

\subsubsection{Minimization of dioxins formation by adjustment of the operation conditions.}

The following conditions can be considered as guidelines for the best operating procedure [68]:

- Combustion temperature - The major source for PCDD/F formation is due to residues present from incomplete combustion. It is generally considered that at a temperature above $850^{\circ} \mathrm{C}$ any dioxins in the feed will be destroyed.

- Residence time - Sufficient residence time is recommendable in order to ensure complete combustion of the fuel. At $850^{\circ} \mathrm{C}$, a gas residence time in the combustion zone should be greater than $2 \mathrm{~s}$.

- Excess oxygen -To ensure further the complete destruction in the hot flue gas is a recommended at $3-6 \%(\mathrm{v} / \mathrm{v})$ excess oxygen level.

- Turbulence in the combustion chamber - A Reynolds number greater than 10,000 is recommended.

- Flue gas monitoring - Continuous analysis of oxygen, $\mathrm{SO}, \mathrm{NOx}, \mathrm{HCl}, \mathrm{CO}$ and $\mathrm{CO}_{2}$ should be implemented. Deviations from the specific criteria levels will lead to an automatic shutdown of the MSW feedstock. In most countries, MSW incinerators are required to have on-line continuous analysis of the emission components.

- Optimum size of MSW incineration plant - Based on the data in literature MSW incinerator operate most effectively and with minimum PCDD/F formation in the range of through-puts from 350 to $400 \mathrm{Mg} / \mathrm{h}$.

These approaches have been successfully applied to prevent emissions of PCDD/F and co-planar PCB in crematories in Japan [73]. The factors are listed below: 
- The temperature at $800^{\circ} \mathrm{C}$ is kept in main/secondary chamber during the whole cremation;

- Connecting one secondary chamber to one main chamber;

- Installation of high efficiency dust collector.

\subsubsection{Use of additives inhibiting the PCDD/F formation}

- Alkaline and metal compounds

In recent years many additives for $\mathrm{PCDD/F}$ reduction have been investigated in emission gases during incinerations. Some of these compounds are $\mathrm{NH}_{3}, \mathrm{CaO}, \mathrm{KOH}$, $\mathrm{Al}_{2} \mathrm{O}_{3}$, and $\mathrm{Na}_{2} \mathrm{CO}_{3}$ [74] [75]. These compounds are alkaline and their mechanism can be explained by a change in the acidity of the fly ash [76], which can lead to destruction of aromatic bound chlorine by elimination reactions. $\mathrm{CaO}$ mixed with the fuel material reduce the emissions of chlorinated hydrocarbons by a factor of $>200$ compared to the experiments without any inhibitors. The results indicate that $\mathrm{CaO}$ acts preliminary as a $\mathrm{HCl}$ adsorber. Similar effects are also observed for $\mathrm{KOH}$ and $\mathrm{Na}_{2} \mathrm{CO}_{3}$. However, the mixture of $\mathrm{Al}_{2} \mathrm{O}_{3}$ and the fuel material increases the amount of chlorinated hydrocarbons formed. The use of $\mathrm{Ca}(\mathrm{OH})_{2}$ spray in incinerators is suggested to result in dechlorination and destruction of PCDD, PCDF and PCB compounds [77]. The suppressing effect of $\mathrm{CaCO}_{3}$ on the dioxin emissions from PVC laboratory incineration is additionally discussed [78]. The results obtained by the use of $\mathrm{CaCO}_{3}$ indicate that approximately half of $\mathrm{HCl}$ gases are removed and the dioxin formation in exhaust gas is significantly suppressed. The waste material from the $\mathrm{CaCl}_{2}$ manufacturing process, in which the oxides of $\mathrm{Ca}, \mathrm{Mg}, \mathrm{Si}$ and $\mathrm{Fe}$ are involved is tested for the fixation of $\mathrm{HCl}$ in it [79]. It has been found that the waste introduced in to the incinerator effectively decreases the amount of $\mathrm{HCl}$ by which the formation of dioxin is highly suppressed.

The metal oxide catalysts have commonly been loaded on various supports to increase the dispersion. Titanium is well-known for the strong metal-support interaction. Recently, vanadium-based commercial catalysts designed for the NOx removal by SCR have been proposed as an active catalyst for the destruction of PCBz and PCDD/F emissions [80]. Thus, supported transition metal oxides and vanadium-containing multi-metallic oxides were investigated for catalytic destruction of PCDD/F. Among the test catalysts, V-Mo-Ox $/ \mathrm{TiO}_{2}$ catalyst have shown a good activity for oxidation of PCDD/F in flue gas emitted from municipal solid waste 
incineration [80]. It has been shown that mixed oxide catalysts based on $\mathrm{TiO}_{2} / \mathrm{V}_{2} \mathrm{O}_{5} / \mathrm{WO}_{3}$ lead to the destruction of chlorinated aromatic compounds, such as monochloro-, 1,2-dichloro-, and 1,2,4-trichlorobenzene in a laboratory-scale fixed bed reactor and a waste incineration plant [81]. The catalytic oxidation of 1,2dichlorobenzene has been investigated over a series of transition metal oxides (i.e. $\mathrm{Cr}_{2} \mathrm{O}_{3}, \mathrm{~V}_{2} \mathrm{O}_{5}, \mathrm{MoO}_{3}, \mathrm{Fe}_{2} \mathrm{O}_{3}$ and $\mathrm{Co}_{3} \mathrm{O}_{4}$ ) supported on $\mathrm{TiO}_{2}$ and $\mathrm{Al}_{2} \mathrm{O}_{3}$ [82]. $\mathrm{Cr}_{2} \mathrm{O}_{3}$ - and $\mathrm{V}_{2} \mathrm{O}_{5}$-based catalysts are present as the most effective ones. Chromium oxide catalyst supported on $\mathrm{TiO}_{2}$ and $\mathrm{Al}_{2} \mathrm{O}_{3}$ are also examined in a fixed-bed flow reactor system. In a pilot plant study, the catalysts revealed $93-95 \%$ decomposition of the total PCDD/F emission [83]. In addition it is found that $\mathrm{Au}-\mathrm{V}_{2} \mathrm{O}_{5} / \mathrm{TiO}_{2}$ and $\mathrm{Au}-$ $\mathrm{V}_{2} \mathrm{O}_{5} / \mathrm{ZrO}_{2}$ catalysts are very active in the complete oxidation of benzene [84].

- Nitrogen compounds

Based on the idea to block the catalytic active sides of copper species many researcher have used nitrogen compounds like amines or alkanolamines as inhibitors in order to reduce the PCDD/F emissions [37], [85], [42], [86], [87]. A significant reduction of PCDD/F concentration is observed in the fly ash of the incinerator when $10 \%$ amine mixture is sprayed into the post-combustion zone at about $400^{\circ} \mathrm{C}$ [88]. It has been shown by spectroscopy that deactivation of copper species by amines is achieved by formation of nitrides on the surface of this metal. Further the active sides of the catalyst are blocked by the adsorbed ethanolamine, which is involved in dehydroamination reaction that are favored on the catalyst [42]. Organic amines like ethanolamine, triethanolamine and monoethanolamine are successfully used to prevent the formation of PCDD/F from pentachlorophenol on fly ash [85] [87]. Dickson commented that the inhibition of catalytic activity could be a result of several processes: formation of stable, inactive compounds with the surface active sides; formation of strong bonded organometallic complexes; physical adsorption on the active sides by the inhibitor. However, the laboratory experiments using triethanolamine indicated that the inhibitory effect on the fly ash samples varies from sample to sample. Ethylenediaminetetraacetic acid (EDTA) and nitrilotriacetic acid have been used as inhibitors in a laboratory scale furnace [76]. Both compounds show reduction of the degree of chlorination of PCDD and nitrilotriacetic acid has been proposed for use in the post-combustion zone of incinerators.

Urea and sodiumammoniumhydrogenphosphate dissolved in a water-methanol solvent have been also investigated as inhibitors for PCDD/F reduction. These 
substances are injected into the flue gas stream and cause reductions of PCDD/F in the particle-phase of up to $90 \%$ with sodiumammoniumhydrogenphosphate and $70 \%$ with urea [89]. Among the nitrogen-containing compounds, urea has been examined by several research teams for its PCDD/F inhibiting ability [85], [90]. Ruokojärvi mentioned that the addition of small particles urea promoted greater inhibitory effect on PCDD/F concentrations due to their large surface area [91]. A possible explanation for the inhibitory effect of the nitrogen compounds according Ruokojärvi is based on the presence of a lone pair of electrons of these compounds which can form stable complexes with the catalysing transition metals [92], [89]. Based on laboratory scale experiments and statistical evaluation the use of urea is discussed as an innovative, effective and low cost prevention technique of PCDD/F formation [93].

In most of the studies presented above, the experiments are performed under laboratory scale conditions. However, in full-scale studies the PCDD/F inhibition will be affected by several operation factors such as location and temperature of the inhibitor injection. In addition, the unadsorbed / unreacted inhibitors present in flue gas could also cause problems [94]. Furthermore, the introduction of organic compounds in the post-combustion zone could result in high $\mathrm{CO}$ concentration in the stack gas. Preliminary studies on this inhibition technique showed the difficulties and the problems of this method [88].

- Sulfur compounds

Other inhibitors have the ability to complex with or bind to metal ions, which catalyses the PCDD/F formation. The experimental results suggest that the reaction of $\mathrm{Cu}$ (II) with $\mathrm{SO}_{2}$ to form $\mathrm{CuSO}_{4}$ in the presence of oxygen renders the catalyst less active and leads to decreasing PCDD formation. Inactivity is also due to the reduced ability of $\mathrm{Cu}$ (II) and $\mathrm{Cu}$ (I) species to promote a second catalytic step of biaryl synthesis [38].

$$
\mathrm{CuO}+\mathrm{SO}_{2}+1 / 2 \mathrm{O}_{2} \longleftrightarrow \mathrm{CuSO}_{4}
$$

Since $\mathrm{Cl}_{2}$ has higher reactivity the reaction with aromatic compounds results in dioxin formation. Thus, the most effective procedure is to control this reaction in order to reduce the dioxin formation. Therefore, sulfur containing substance is converted into $\mathrm{SO}_{2}$ and reduces $\mathrm{Cl}_{2}$ to $\mathrm{HCl}$ according to the following reaction: 


$$
\mathrm{SO}_{2}+\mathrm{Cl}_{2}+\mathrm{H}_{2} \mathrm{O} \longleftrightarrow \mathrm{SO}_{3}+2 \mathrm{HCl}
$$

Another possibility is, that the presence of $\mathrm{SO}_{2}$ gas affect the PCDD and PCDF mechanisms by either sulfonating the phenolic precursors or replacing the oxygen link(s) with $S$ and forming polychlorodibenzo-thiophene (PCDT) and polychlorothianthrenes (PCTA) which are the sulfur analogs of PCDD and PCDF.

The influence of different amount of sulfur on fly ash, added before thermal treatment is discussed [95]. It has been found that increasing amount of sulfur reduces the formation of $\mathrm{PCBz}$, especially the $\mathrm{Cl}_{2}$ - and $\mathrm{Cl}_{3}$-isomers. In contrast, the formation of PCDD is preferred compared to that of PCDF due to their formation via different precursors. The addition of sulfur to the fly ash leads to increasing the amount of chlorinated thiophene, benzothiophenes and dibenzothiophenes. This indicates that intermediate aromatic and aliphatic structures with carbon-chlorine bonds may react with sulfur under dimerization and cyclization. With increasing content of sulfur in fly ash, a shift on the formation of higher chlorinated de-novo products is observed.

Dioxin reduction tests by sulfur component addition were carried out using small scale fluidised bed combustor system [96]. Dioxin reduction occurred for each test where gaseous $\mathrm{SO}_{2}$ was added. However, the effect of coal addition to the test fuel was observed greater than in case of gaseous $\mathrm{SO}_{2}$ addition. Coal and pure sulfur added to the fuel showed the much greater effect on dioxin reduction. Ogawa found also a negative correlations of $\mathrm{S} / \mathrm{Cl}$ ratio in coal to dioxin concentration. Gullett proposed that low PCDD and PCDF emission level in coal combustion is due to the relatively lower concentration of $\mathrm{Cu}$ found in coal compared to municipal waste [38].

- Nitrogen and Sulfur Compounds

Urea and some sulfur and nitrogen compounds such as hydroxylamine-O-sulfonic acid, amidosulfonic acid, sulfur and sulfamide have been successfully used as inhibitors in a laboratory-scale experiment with a refuse-derived fuel [97] [93]. In all cases where an inhibitor has been added to the fuel, relative increase of the octachlorinated homologues has been observed. Significant PCDD/F reduction about $96 \%$ has been reported during the combustion of mixtures containing $1 \%$ amidosulfonic acid used as additives. Inhibition of PCDD/F has been investigated under laboratory condition by addition of nitrogen and sulfur compounds such as ethylenediaminetetraacetic acid (EDTA), nitrilotriacetic acid (NTA) and $\mathrm{Na}_{2} \mathrm{~S}$ [76]. 
With these compounds, a reduction in PCDD/F formation of $80-90 \%$ has been achieved. EDTA and $\mathrm{Na}_{2} \mathrm{~S}$ reduce the degree of chlorination of PCDD; for PCDF, the same effect has been seen with $\mathrm{Na}_{2} \mathrm{~S}$. 


\section{Materials and Methods}

\subsection{Pilot Scale Experiments}

Emissions of polychlorinated dibenzo-p-dioxins (PCDD) and polychlorinated dibenzofurans (PCDF) are sampled isokinetically with automatic sampling system MRU 4000, according to VDI guidelines 4220 and ISO/IES 17025 [98], [99]. The sampling error can be reduced by using an automatic sampling system, especially for processes with fluctuations in the volumetric flow rate of exhaust gases and dust as well as soot gases.

Isokinetic condition means that the velocity of the sampled gas is equal to the velocity of the exhaust gas in the duct [100].

$$
v_{\text {duct }} \approx v_{\text {sample }}
$$

Symbols used:

$\begin{array}{llll}A & = & \text { area of effective nozzle diameter } & \left(\mathrm{m}^{2}\right) \\ \rho_{n} & = & \text { density of dry flue gas under standard conditions } & \left(\mathrm{kg} / \mathrm{m}^{3}\right) \\ \rho_{n, i} & = & \text { density of a gas component under standard conditions } & \left(\mathrm{kg} / \mathrm{m}^{3}\right) \\ \omega_{i} & = & \text { volume part of a gas component } & (\mathrm{Vol} \%) \\ M_{r, i} & = & \text { relative molecular weight of a gas component } & (\mathrm{kmol} / \mathrm{kg}) \\ V_{m n ; i} & = & \text { molar standard volume } & \left(\mathrm{m}^{3} / \mathrm{kmol}\right) \\ \rho_{n, f} & = & \text { density of flue gas including water vapor under } & \\ & & \text { standard conditions } & \left(\mathrm{kg} / \mathrm{m}^{3}\right) \\ f_{n} & = & \text { humidity of the exhaust gas } & \left(\mathrm{kg} / \mathrm{m}^{3}\right) \\ \rho_{n, w} & = & \text { standard density of water } & \left(\mathrm{kg} / \mathrm{m}^{3}\right) \\ \rho_{p t, f} & = & \text { density of flue gas } & \left(\mathrm{kg} / \mathrm{m}^{3}\right) \\ p_{a t m} & = & \text { pressure in the ambient air } & (\mathrm{hPa}) \\ p_{s t} & = & \text { static pressure in the duct } & (\mathrm{hPa}) \\ T_{d} & = & \text { temperature in the duct } & (\mathrm{K}) \\ V & = & \text { velocity of the gas } & (\mathrm{m} / \mathrm{s}) \\ p_{d y n}= & \text { dynamic pressure in the duct } & (\mathrm{hPa}) \\ V_{c} & = & \text { calculated standard sample gas flow rate } & \left.(\mathrm{m})^{3} / \mathrm{h}\right) \\ V_{n} & = & \text { measured standard sample gas flow rate } & \left.(\mathrm{m})^{3} / \mathrm{h}\right)\end{array}$


$d \quad=\quad$ diameter of the nozzle

$j \quad=\quad$ number of data

\subsubsection{Sampling Equipment MRU 4000}

$\mathrm{PCDD} / \mathrm{F}$ isokinetic sampling is "the cooled suction tube probe method" according to DIN EN 1948-1. The used automatic sampling system is MRU 4000 of GSM, Neuss, Germany (formally Ströhlein company). The sucking device is connected to this arrangement (Fig. 4.1).

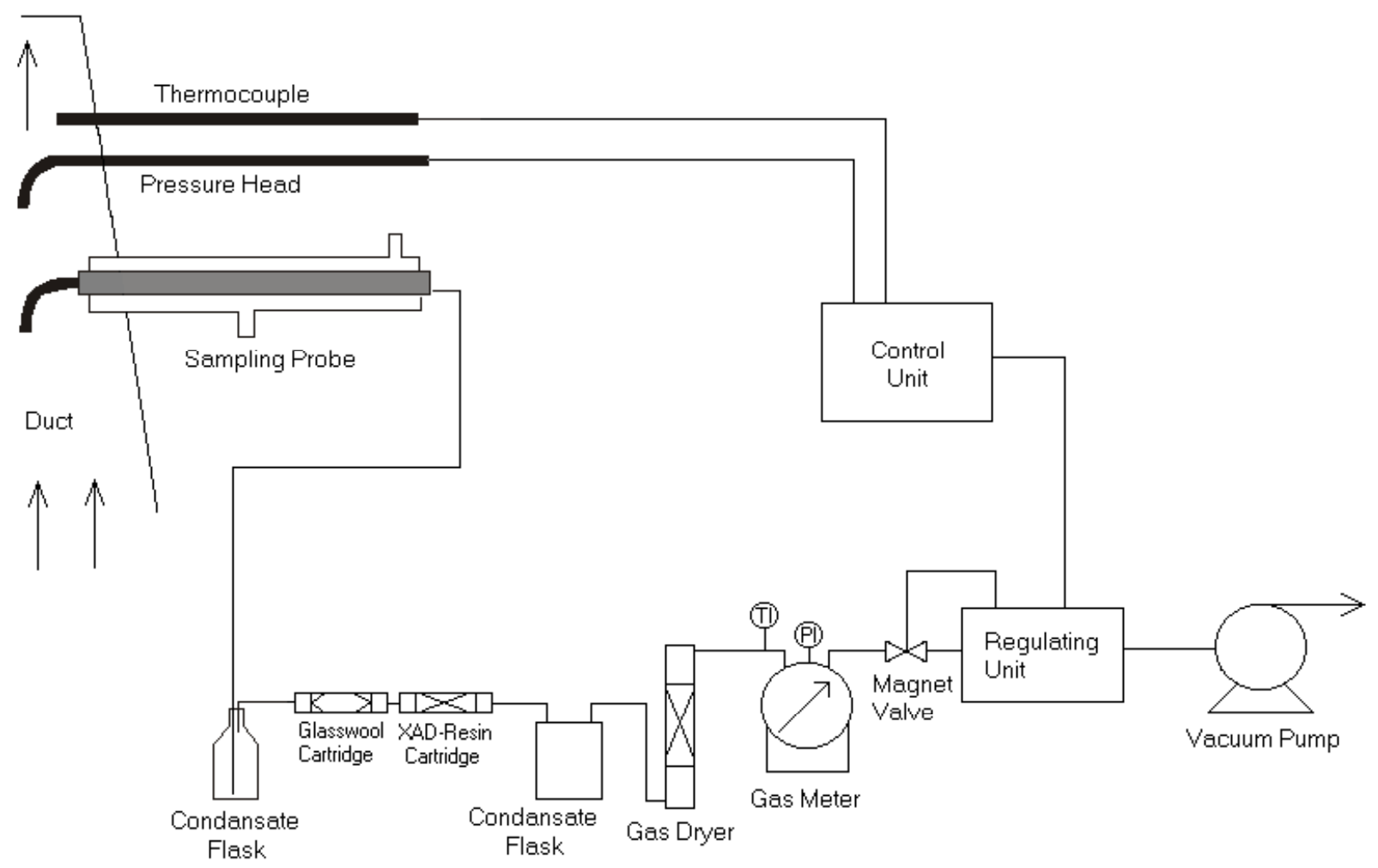

Fig. 4.1: Arrangement of the sampling equipment MRU 4000

Regulation unit is installed between the gas volume meter and vacuum pump. The sampled gas is sucked through one sampling train with a sample volume rate of about $1.5 \mathrm{~m}^{3} / \mathrm{h}$ (VDI 3499). It is the optimal gas flow rate for PCDD/F and PCB [59]. The automatic sampling is controlled from MRU control unit. The signals of the control unit are sent to a notebook where the MRU software is installed. It is also possible that data of the program are transferred to control unit MRU 4000 through the RS232 interface cable. The sucking process begins when pump is switched on by MRU software (in case of automatic sampling) or manual (in case of manual 
sampling). The flow parameters can be followed on-line on the screen. The MRU 4000 operates independently.

Downstream, a battery of cartridges are connected to collect the soot particles and gaseous PCDD/F. If high dusty samples are expected $\left(>5 \mathrm{mg} / \mathrm{m}^{3}\right)$ than the first cartridge is filled with pre-heated glass wool. It is used for trapping the PCDD/F which are adsorbed to the soot. On the bottom of the cartridge a glass fibre filter is fixed to retain fine particles. The second cartridge contains $50 \mathrm{~g}$ XAD-2 resin for absorption of the gaseous PCDD/F. A second back-up XAD-2 cartridge is attached to control the breakthrough of PCDD/F. The tubes are embedded to the condensate flask of the gas volume meter. The condensate flask is a $1 \mathrm{~L}$ brown flask. It plays the role of an impingner during the sampling process. The flask is in half full with a distillate water. The volume parts of the gas components are measured on-line with an gas analyzer TESTO 350, Lenzkirch, Germany. Second notebook is required for TESTO 350. The flue gas probe of the gas analyzer is positioned in the duct. The density of dry flue gas under standard conditions is determined from the volume parts of the gas components and the density of each gas component under standard conditions. The density of a gas component under standard conditions is the ratio of its relative molecular weight and its molar standard volume.

$$
\begin{aligned}
& \rho_{n}=\sum \frac{\omega_{i}}{100 \%} \cdot \rho_{n, i} \\
& \rho_{n, i}=\frac{M_{r, i}}{V_{m n, i}}
\end{aligned}
$$

where $\mathrm{i}$ is $\mathrm{CO}_{2}, \mathrm{O}_{2}, \mathrm{CO}, \mathrm{N}_{2}$. The density of carbon monoxide and nitrogen is 1.250 $\mathrm{kg} / \mathrm{m}^{3}$, of oxygen and carbon dioxide $1.429 \mathrm{~kg} / \mathrm{m}^{3}$. The measured values are ste by introduced from the operator in MRU software before sampling. Both equipments operate independently.

A thermocouple is fitted in the orifice and delivers the temperature of the exhaust gas. The static and dynamic pressure in the duct is measured by a pressure head. These parameters are needed to determine the density of the flue gas and is then used to calculate the velocity of the gas.

The density of dry flue gas under standard conditions is converted into the density of flue gas including water vapour under standard conditions. 


$$
\rho_{n, f}=\frac{\rho_{n}+f_{n}}{1+\frac{f_{n}}{\rho_{n, w}}}
$$

With the density of humid flue gas under standard conditions the gas density of flue gas is calculated.

$$
\rho_{p t, f}=\rho_{n, f} \cdot \frac{273.15}{1013} \cdot \frac{\left(p_{a t m}+p_{s t}\right)}{T_{d}}
$$

The velocity of the gas can be determined according to equation 7 .

$$
v=\sqrt{200 \cdot \frac{p_{d y n}}{\rho_{p t, f}}}
$$

Then a nozzle diameter is chosen which corresponds to the velocity of the exhaust gas at a sample gas flow rate of about $1.5 \mathrm{~m}^{3} / \mathrm{h}$. The calculations are done by the control unit.

$$
V_{n}=v \cdot \frac{\pi}{4} d^{2} \cdot 3600 \cdot \frac{\left(p_{a t m}+p_{s t}\right)}{T_{d}} \cdot \frac{273.15}{1013} \cdot \frac{\rho_{n, w}}{\rho_{n, w}+f_{n}}
$$

The automatic system continuously adapt to the velocity of the exhaust gas.

With the fixed nozzle diameter and the varying exhaust gas velocity, the flow rate is regulated by the evaluation and control unit by adding ambient air after the sampling train. The system is qualified for an isokinetic sampling according to the guideline VDI 4220. The final sampling values are saved in MRU software under report, actual and info files. Additional sampling reports are created for each sampling campaign. There, the hole information connected to the sampling such as fuel in use, duration of the sampling, sampling place and operator, MRU and TESTO data, isokinetic ratio, validation of the sampling are documented. That documents are attached to the PCDD/F and/or PCB test report, MRU and TESTO protocols.

The sampling can also be operated manually. That may happen if the dynamic pressure of the chimney is very low or very high. In such cases the regulation valve is positioned completely open or close during the automatic sampling. That normally terminates the automatic MRU 4000 work. The same problem can appear if the nozzle diameter chosen is not appropriate.

In case of manual sampling the steering of the system is controlled by the operator. The static and dynamic pressure in the duct is measured by a pressure head which is connected to the electronic-micro manometer Digima LPU, SI-Special instruments, 
Nördlingen, Germany. The temperature and the volume parts of the gas components are measured with an gas analyzer TESTO 350. An adjustable valve is installed between the gas volume meter and the vacuum pump. The gas flow is obtained by calculation of all parameters during the sampling period into the excel sheet of the sampling report. The values on the gas meter are noted in the beginning and at the end of the sampling. The sampled gas volume is calculated.

\subsubsection{Controlled parameters before sampling.}

The parts of the sampling equipment are regularly maintained and calibrated according standard calibration procedures. An external calibration of devices measuring temperature, gas flow, dynamic and static pressure and velocity is performed by competent certified institutions which deliver a certificate. These calibrated devices are used for internal calibration of the sampling devices used for emission sampling of PCDD/F and PCB. The results of each calibration is documented in a protocol sheet.

Before sampling the following parameters are controlled:

Tightness of the sampling system.

All connections are checked and possible closed with a teflon tape. The flow rate at standard condition $\left(\mathrm{m}^{3} / \mathrm{h}\right)$ is determined. The gas entrance is closed with a finger or stopper. The pump is started and runs for 30 seconds. The duration and the volume is noted. A leak is eventually found out. The flow rate for the tightness test (leak) has to be lower than $\mathbf{2} \%$ of the gas flow rate at standard sampling conditions.

Temperature in the condensate flask

The condensate flask is cooled with a cooling system (Cryostat Julabo FC600). The set temperature of Julabo is about $10^{\circ} \mathrm{C}$, so that the temperature in the condensate flask is less than $20^{\circ} \mathrm{C}$. At external sampling places, Julabo can be replaced by dried ice.

Humidity of the emission gases.

In MRU software, the barometric pressure $(\mathrm{hPa})$ and the measured humidity $\left(\mathrm{kg} / \mathrm{m}^{3}\right)$ have to be noted.

The humidity test is performed for each sampling place at the estimated temperature in the chimney just before the sampling.

$\mathrm{CaCl}_{2}$ (granulated, 1-2 mm) has to be dried 1 hour in the oven at $120^{\circ} \mathrm{C}$. An Ushaped glass tube is filled to its two thirds with dried $\mathrm{CaCl}_{2}$ and weighed (about $60 \mathrm{~g}$ ). 
Then a capillary glass tube is held into the flue gas channel and connected with the U-shaped glass tube. The other entrance is connected to a pump with a flow rate of 2 litres per minute (adjusted with the measuring scale of the pump). The test is carried out for 5 minutes. About $10 \mathrm{~L}$ (by higher quantities the capacity of the adsorbent would be exceeded) is passed through. Afterwards the glass tube is weighed again. The humidity will be calculated with:

$\Delta \mathrm{m}=\mathrm{m} \mathrm{CaCl} 2$ afterwards $-\mathrm{m} \mathrm{CaCl} 2$ before

$\Delta \mathrm{m}$ corresponds to the quantity of water, which $\mathrm{CaCl}_{2}$ absorbed $\left(\mathrm{Kg} / \mathrm{m}^{3}\right)$.

Measurement of the temperature in the chimney, the velocity and the nozzle diameter The thermocouple and the pressure head are moved from above to down or from the right to the left at $2 \mathrm{~cm}$ intervals in the cross section of the tube. After that the probe and the pressure head have the same velocity, but they have to be located with a minimum distance of $5 \mathrm{~cm}$ from the pipe wall in the flue gas channel.

The environmental parameters and the operation ability of the measuring devices.

- At the measuring site the good working conditions (electric power, water, light, ventilator and tools) before sampling have to be checked.

- The sampling tube in the metal cooler is installed (Fig.4.2). The cooling water of the glass probe for leaks is checked before each experiment in order to minimize damage of XAD-cartridge or contact with electricity. The water connections of Julabo equipment are also checked.

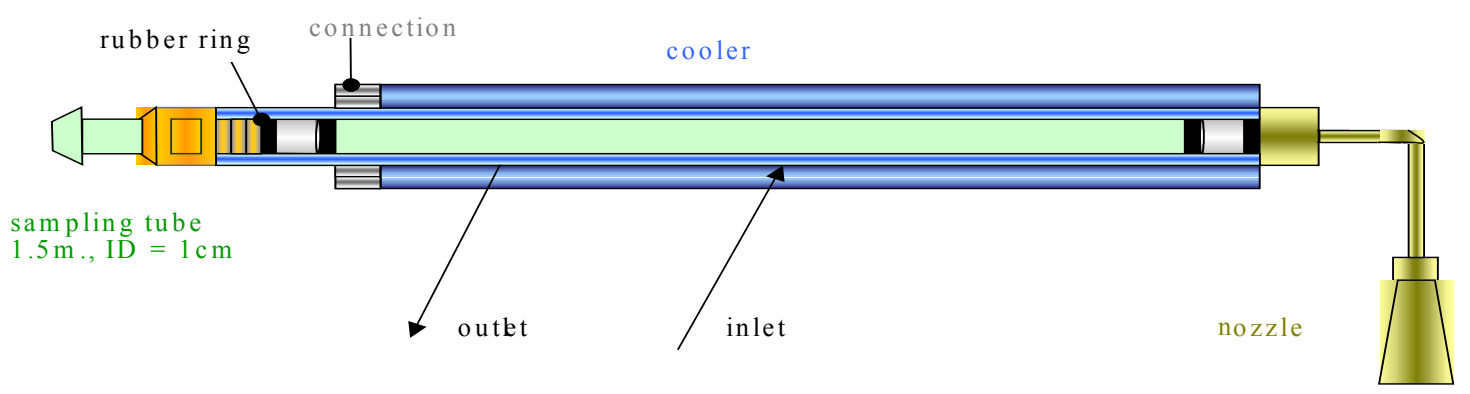

Fig. 4.2: Installation of the sampling tube in the cooler 
- The operating ability of the portable flue gas analyser TESTO, MRU 4000 system and referred software are checked before sampling. The sensor of the Testo instrument is automatically cleaned with fresh air. If the sensors of MRU system are really dusty, they are blew out with stream of nitrogen.

\subsubsection{Validation of the sampling measurements}

In the sampling report validation of the sampling measurements with the following controls is noted:

- the blank value has to be lower than $10 \%$ of the limit value for PCDD/F for the flue gas (0.1 ng I-TEQ/ $\left.\mathrm{Nm}^{3}[100]\right)$,

- the calculated value of a sample has to be higher than the blank value,

- the value of the back-up cartridge has to be lower than $10 \%$ of the other cartridges (resin + glass wool).

- the recovery rate of sampling standards must be more than $50 \%$ and less than $120 \%$

- the isokinetic ratio should be about 1.

According VDI 2066 the isokinetic ratio is:

$$
\text { Isokinetic ratio }=\frac{\text { Theoretical volume flow }}{\text { Measured volume flow }}=\frac{A_{\text {nozzle, effective }{ }^{*} v}}{V_{n}}
$$

- $\quad$ the regulation difference between calculated and measured sampled gas flow rate for MRU 4000 sampling system is estimated as less than $\mathbf{5 \%}$

$$
\Delta \bar{V}=\frac{\sum_{1}^{j} \frac{\left|V_{c}-V_{n}\right|}{V_{n}}}{j}
$$

\subsubsection{Laboratory preparation prior the sampling}

All glass tubes and pieces, empty XAD-cartridges and condensate flask (=2 $L$ brown glass bottle) are cleaned with toluene / n-hexane / acetone / methanol and washed in washing machine and dried in an oven at $450^{\circ} \mathrm{C}$. The nozzles and the bends of the nozzles are placed in a beaker with toluene and treated for $1 \mathrm{~h}$ in an ultrasonic bath. 
The cartridges are filled with ca. $50 \mathrm{~g}$ XAD-resin. The cartridge is tapped several times on the table to compress the XAD-2 package. Heated glass wool is placed in the cartridge and pressed on the XAD-2 resin. Afterwards $100 \mu$ sampling standard is added on glass wool. If high dust concentrations are expected in the flue gases at the sampling point, a second cartridge, filled up only with compressed annealed glass wool, is prepared.

\subsubsection{Laboratory work after the sampling}

The condensate from the condensate flask is transferred on top of the XAD-cartridge, just after the sampling. The eluat is disposed. All glass parts (inclusive the condensate flask, also sucking tube) are first rinsed with $1.5 \mathrm{~L}$ dest. water, the rinsing water is also transferred to the XAD-cartridge. The eluat is disposed. The wet XAD-I glass wool- cartridges, the $1 \mathrm{~L}$ condensate flask, the other pre-cleaned glassware and also nozzle, manifold and bends are transferred to the laboratory.

The XAD cartridges from the sampling are dried for $1 \mathrm{~h}$ by a light stream of nitrogen (1 bar), to remove the condensate water, which disturbs the Soxhlet extraction.

If the rinsing solvent contains a lot of soot, it is previously filtered over the dried XADcartridge. The eluat is collected into the same $1 \mathrm{~L}$ flask and used for the Soxhlet extraction. Afterwards the enriched soot on the XAD-cartridge is fixed with glass wool.

Prior extraction appropriate (depending on the class of analysed compound) internal labelled standard solution is added on the glass wool of the XAD cartridge: $100 \mu \mathrm{l}$ PCDD/F solution, $20 \mu \mathrm{l}$ PCB solution, $10 \mu \mathrm{C}_{4}-\mathrm{C}_{6} \mathrm{CBz}$ labelled standard solution. Two Soxhlet extractions are carried up for PCDD/F, PCB and PCBz analysis. First the PCB and PCBz are extracted with n-hexane. Second the PCDD/F are extracted with toluene.

\section{PCB extraction with $\mathrm{n}$-hexane}

The cartridge is placed in a $500 \mathrm{ml}$ Soxhlet extractor. Some boiling stones as well as $700 \mathrm{ml} \mathrm{n}$-hexane, consisting of rinsing $\mathrm{n}$-hexane and additional pure $\mathrm{n}$-hexane, are placed in a $1000 \mathrm{ml}$ round bottom flask.

At these conditions the sample is extracted for $24 \mathrm{~h}$. After cooling to room temperature the cooler and extractor is rinsed with $n$-hexane. All the rinsing solvents are combined with the extract. 


\section{$\underline{\text { PCDD/F extraction with toluene }}$}

Here, the $1000 \mathrm{ml}$ round flask is filled with $700 \mathrm{ml}$ toluene, consisting of rinsing toluene and additional pure toluene. The duration of the extraction is $24 \mathrm{~h}$. After cooling to room temperature the cooler and extractor is rinsed with toluene. All the rinsing solvents are combined with the extract.

After the extractions $50 \%$ of each extract is stored in an extra flask for further analysis (reference sample). The remaining $50 \%$ of the extract is reduced to $1 \mathrm{ml}$ by the vacuum evaporator. If the solvent contains water, it is dried over sodium sulphate through a funnel.

The reduced extracts of toluene and n-hexane are transferred one after the other to the first clean-up column.

\subsubsection{Sampling place}

The performed sampling campaigns are done at the Institute for Ecological Chemistry, GSF- National Research Centre for Environment and Health. The sampling place is a outhouse near the institute. It is equipped with a small domestic stove. The diameter of the its chimney is $12 \mathrm{~cm}$ and the length from the first curve after the stove to the second one is $123 \mathrm{~cm}$. The sampling place is supplied with water and electricity.

Emission samples of the combustion of selected fuel mixture in pilot scale unit are sampled by MRU sampling system. A ventilator is used to maintain the gas flow. It is located in a second outhouse very close to the sampling place (Fig. 4.3.). The chimney of the domestic stove is connected by pipes to the ventilator. During the sampling the exhaust gases are introduced through the ventilator into the neighboured outhouse. The detected velocity at such conditions is around 1.3 $-1.5 \mathrm{~m}$ I s (data correspondent to the more capacity ventilator). During combustion processes the velocity in the chimney can reach around $6 \mathrm{~m} / \mathrm{s}$. That lead to an increase of the dynamic pressure in the chimney. 


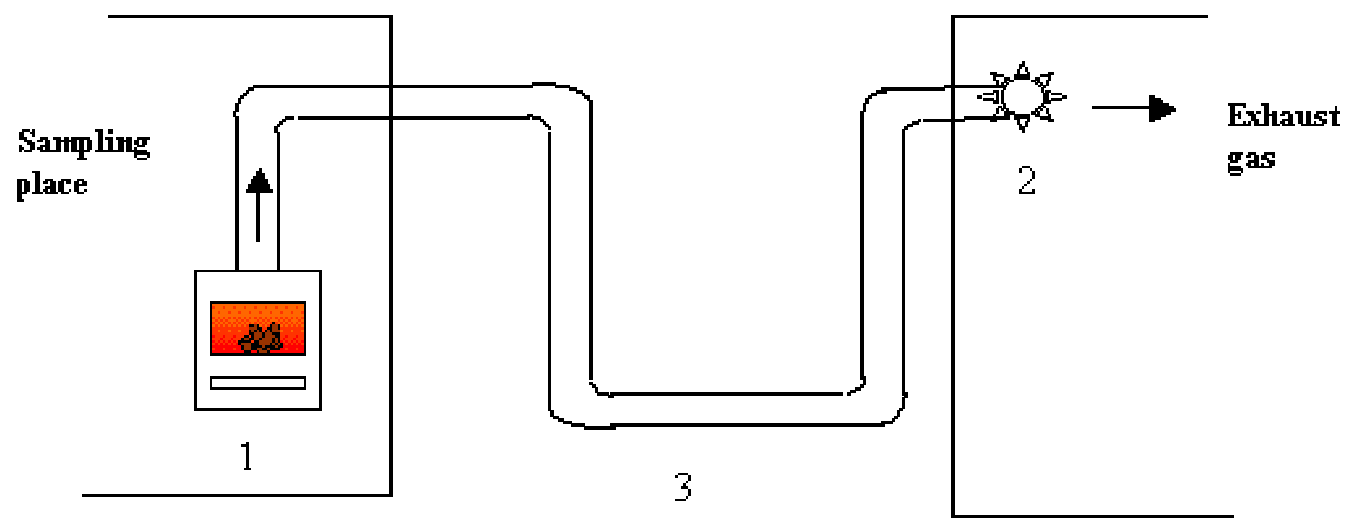

Fig. 4.3: Sampling background. (1-domestic stove, 2- ventilator, 3-pipes)

\subsubsection{Sampling points}

In order to select the location of the sampling equipment in the duck, the sampling points have to be defined. Measurement of the velocity in the sampling plane at different points in the duck with Prandl-tube is required. It is found that the velocity is constant between 2 and $8 \mathrm{~cm}$ of the internal diameter of the chimney.

The hole of the Prandl-tube has to be placed in distance more than $5 \mathrm{dh}$ (standard), where

$$
\mathrm{dh}=\frac{4 * \text { area of sampling plane }}{\text { perimeter of sampling plane }} \quad \text { or } \quad \mathrm{dh}=\frac{4 * \Pi \mathbf{r}^{2}}{2 \prod \mathrm{r}}
$$

After calculation the estimated sampling point of the Prandl-tube is $65 \mathrm{~cm}$ after the last curve of the chimney. The sucking tube (cooler) with nozzle and the thermocouple are placed in $5 \mathrm{~cm}$ distance from each other, downstream the Prandl tube. The ends of the three sensors are arranged in the same linier of the sampling plane (Fig. 4.4.). The Testo instrument is placed $15 \mathrm{~cm}$ upstream of the Prandl-tube. 

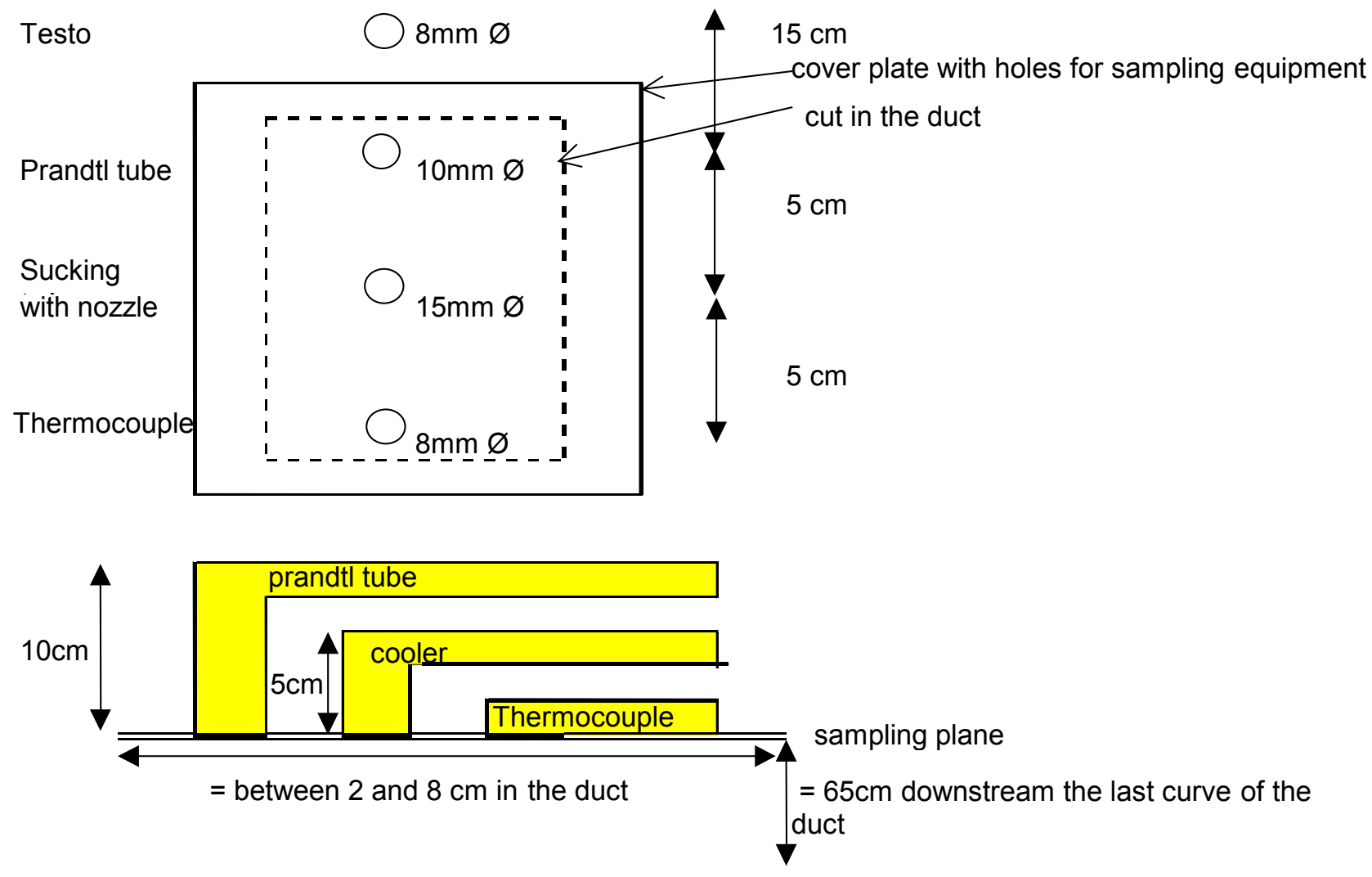

Fig. 4.4: Arrangement of the sampling points in the chimney.

\subsubsection{Sampling campaigns}

Several sampling campaigns are performed at different combustion conditions (Tab. 4.1.) by MRU sampling device. The fuel in use was:

- poplar wood

- Beech/ Oak wood

- $\mathrm{PVC}$

- Solid waste 
Tab. 4.1: Sampling campaigns

\begin{tabular}{|c|c|c|c|c|c|c|}
\hline No & $\begin{array}{l}\text { Sample } \\
\text { number }\end{array}$ & $\begin{array}{l}\text { Type of } \\
\text { cartridge }\end{array}$ & Combusted Fuel & $\begin{array}{c}\text { Quantity of } \\
\text { Fuel (Kg) }\end{array}$ & $\begin{array}{l}\mathrm{PCCD} / \mathrm{F} \\
\text { analysis }\end{array}$ & $\begin{array}{c}\text { PCB } \\
\text { analysis }\end{array}$ \\
\hline 1 & C0109008 & resin & - * & - & & \\
\hline 2 & $\begin{array}{l}\text { C0111007 } \\
\text { C0111009 } \\
\text { C0111010 }\end{array}$ & $\begin{array}{c}\text { back-up } \\
\text { resin } \\
\text { glass wool }\end{array}$ & poplar wood & 2.25 & $\begin{array}{l}\checkmark \\
\checkmark \\
\checkmark\end{array}$ & \\
\hline 3 & $\begin{array}{l}\text { C0112007 } \\
\text { C0112008 } \\
\text { C0112009 }\end{array}$ & $\begin{array}{c}\text { back-up } \\
\text { resin } \\
\text { glass wool }\end{array}$ & poplar wood & 4.8 & $\begin{array}{l}\checkmark \\
\checkmark \\
\checkmark\end{array}$ & \\
\hline 4 & $\begin{array}{l}\text { C0201021 } \\
\text { C0201022 }\end{array}$ & $\begin{array}{l}\text { back-up } \\
\text { resin and } \\
\text { glass wool }\end{array}$ & $\begin{array}{c}90 \% \text { poplar wood : } \\
10 \% \text { PVC }\end{array}$ & $\begin{array}{l}2.25 \\
0.26\end{array}$ & $\begin{array}{l}\checkmark \\
\checkmark\end{array}$ & $\checkmark$ \\
\hline 5 & $\begin{array}{l}\text { C0201024 } \\
\text { C0201025 }\end{array}$ & $\begin{array}{l}\text { back-up } \\
\text { resin and } \\
\text { glass wool }\end{array}$ & poplar wood & 2 & $\begin{array}{l}\checkmark \\
\checkmark\end{array}$ & \\
\hline 6 & $\begin{array}{l}\text { C0202018 } \\
\text { C0202019 }\end{array}$ & $\begin{array}{l}\text { back-up } \\
\text { resin and } \\
\text { glass wool }\end{array}$ & poplar wood & 4 & $\begin{array}{l}\checkmark \\
\checkmark\end{array}$ & \\
\hline 7 & $\begin{array}{l}\text { C0203005 } \\
\text { C0203006 }\end{array}$ & $\begin{array}{c}\text { resin } \\
\text { glass wool }\end{array}$ & $\begin{array}{c}90 \% \text { poplar wood : } \\
10 \% \text { PVC }\end{array}$ & $\begin{array}{c}3.4 \\
0.34\end{array}$ & $\begin{array}{l}\checkmark \\
\checkmark\end{array}$ & $\begin{array}{l}\checkmark \\
\checkmark\end{array}$ \\
\hline 8 & $\begin{array}{l}\text { C0204001 } \\
\text { C0204002 }\end{array}$ & $\begin{array}{c}\text { resin } \\
\text { glass wool }\end{array}$ & $\begin{array}{c}90 \% \text { poplar wood : } \\
10 \% \text { PVC }\end{array}$ & $\begin{array}{l}1.77 \\
0.18\end{array}$ & $\begin{array}{l}\checkmark \\
\checkmark\end{array}$ & $\begin{array}{l}\checkmark \\
\checkmark\end{array}$ \\
\hline 9 & $\begin{array}{l}\text { C0204016 } \\
\text { C0204017 }\end{array}$ & $\begin{array}{c}\text { resin } \\
\text { glass wool }\end{array}$ & $\begin{array}{c}90 \% \text { poplar wood : } \\
10 \% \text { PVC }\end{array}$ & $\begin{array}{c}2.2 \\
0.22\end{array}$ & $\begin{array}{l} \\
\checkmark\end{array}$ & $\begin{array}{l}\checkmark \\
\checkmark\end{array}$ \\
\hline 10 & C0309019 & $\begin{array}{l}\text { resin and } \\
\text { glass wool }\end{array}$ & $\begin{array}{c}85 \% \text { Beech/ Oak } \\
\text { wood: } \\
10 \% \text { solid waste : } \\
5 \% \text { Spanish PVC }\end{array}$ & $\begin{array}{c}10 \\
1.16 \\
0.57\end{array}$ & $\checkmark$ & $\begin{array}{r}\checkmark \\
\quad *\end{array}$ \\
\hline 11 & C0311039 & $\begin{array}{l}\text { resin and } \\
\text { glass wool }\end{array}$ & $\begin{array}{c}97 \%(85 \% \text { Beech/ } \\
\text { Oak wood : } \\
10 \% \text { solid waste : } \\
5 \% \text { Spanish PVC }): \\
3 \%\left(\mathrm{NH}_{4}\right)_{2} \mathrm{SO}_{4}\end{array}$ & $\begin{array}{l}4.76 \\
0.55 \\
0.22 \\
0.17\end{array}$ & $\checkmark$ & $\begin{array}{l}\checkmark \\
\quad *\end{array}$ \\
\hline
\end{tabular}

* hair drier is used to maintain gas flow

${ }^{* *}$ PCBz are also analyzed 
The concentration of PCDD/F, PCB and PCBz are calculated in $\mathrm{pg} / \mathrm{Nm}^{3}$. The sample gas flow at normal condition is on the base of: $\mathrm{T}=0{ }^{\circ} \mathrm{C}, \mathrm{p}=1013 \mathrm{mbar}, \mathrm{O}_{2}=$ $11 \mathrm{Vol} \%$, humidity $=0 \mathrm{Vol} \%$. The sampled gas volume as well as the type of steering, temperature in the chimney and calculated isokinetic ratio are shown in Tab. 4.2.

Tab. 4.2: Sampling data

\begin{tabular}{|c|c|c|c|}
\hline $\begin{array}{c}\text { No } \\
\text { sampling }\end{array}$ & Steering & $\begin{array}{c}\mathrm{T},{ }^{\circ} \mathrm{C} \text { in } \\
\text { the } \\
\text { chimney }\end{array}$ & $\begin{array}{c}\text { Sample gas } \\
\text { flow in normal } \\
\text { condition }\end{array}$ \\
\hline 1 & automatically & 25 & - \\
\hline 2 & manual & 150 & 1.47 \\
\hline 3 & manual & 500 & 1.59 \\
\hline 4 & automatically & 180 & 1.66 \\
\hline 5 & manual & 250 & 0.97 \\
\hline 6 & manual & 300 & 1.45 \\
\hline 7 & manual & 200 & 2.84 \\
\hline 8 & manual & 130 & 0.77 \\
\hline 9 & manual & 700 & 0.42 \\
\hline 10 & automatically & 383 & 1.73 \\
\hline 11 & automatically & 330 & 0.66 \\
\hline
\end{tabular}

\subsection{Laboratory Scale Experiments}

The proposed work to elaborate the efficiency of additional dioxin preventing compounds in the raw fuel, before combustion is studied at laboratory conditions. The examination of the effect of that inhibitors is tested at lower temperature area of the post combustion zone in the gas phase. These experiments require a furnace with safety feature, readily accessible control, controlled heating, clean and dust free work tube. A three zone horizontal tube furnace CARBOLITE $\mathrm{GmbH}$, UbstadtWeiher, Germany is used for that purpose.

\subsubsection{Laboratory apparatus}

A laboratory scale horizontal split-tube furnace (Split Tube furnace (3-zone) type HZS \& TVS, Carbolite, England) (Fig. 4.5.), is used for the lab-scale experiments. The laboratory reactor consisted of a quartz tube with $I D=14 \mathrm{~cm}$ and a length of $150 \mathrm{~cm}$, $3 / 4$ of the length of which is placed into the heatable zone of the furnace. From the 
cooled part of the quartz tube the sampling boat is pushed to the middle of the heated zone when the desired temperature is achieved.

The flue gases occurring during the experiment are trapped into 3 impingers in series, each filled with $70 \mathrm{~mL}$ toluene. The remaining gases are passed into a small glass wool cartridge filled with active carbon. That unit is continuously connected to the vacuum pump. The inlet of the air flow and the outlet of the vacuum pump are controlled with a rotameter (ROTA). About $1 \mathrm{~mm}$ size bubbles are observed during the process in the impinger. The first impinger is previously spiked with $100 \mu \mathrm{l} C E N$ sampling PCDD/F standard. The combustion experiments are performed according to the same procedure each time in order to achieve comparable results.

\section{5}

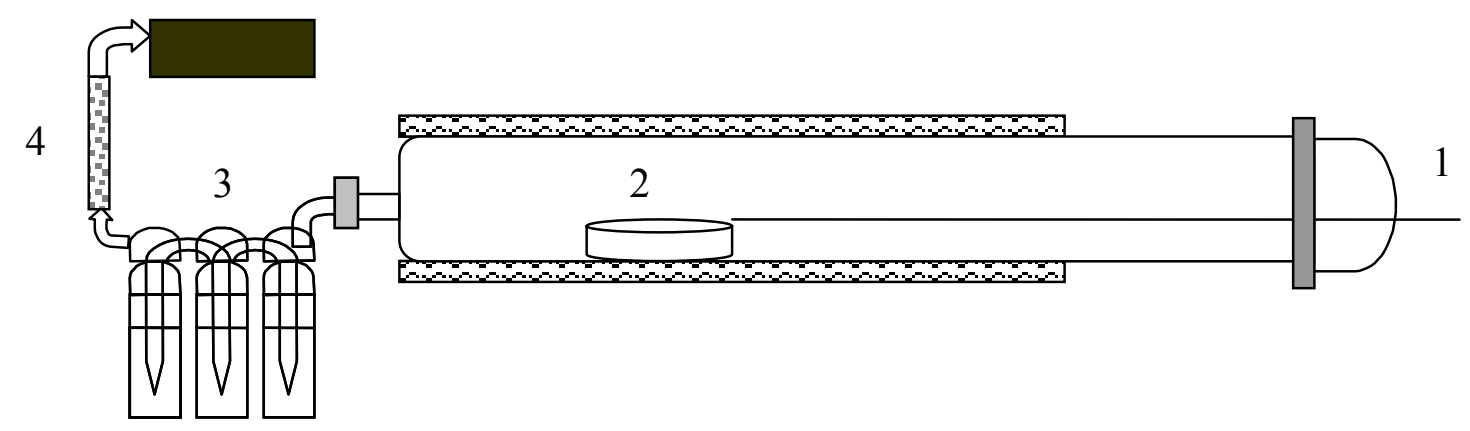

Fig. 4.5:Scheme of the laboratory scale furnace (1-inlet with air flow, 2-sampling boat, 3-toluene impingers, 4-glass wool filter, 5-vacuum pump).

To avoid memory effects, the furnace is cleaned mechanically and with the solvents toluene and acetone after each experiment. Afterwards it is heated at $850^{\circ} \mathrm{C}$ for $2 \mathrm{~h}$ at a gas flow of $2 \mathrm{~L} / \mathrm{min}$.

\subsection{Experimental procedure}

Several different experiments are performed in order to investigate the optimal PCDD/F formation and inhibitory effect of various compounds. During that study the general experimental parameters are the weight of the combusted fuel $10 \mathrm{~g}$ and the air flow $2 \mathrm{~L} / \mathrm{min}$. Most of the experiments are performed with compressed air and some other with synthetic air. Blank samples are generated when the air supply is changed. The temperature in use and the duration of the experiments varied from serial of samples to other one. The experiments are explained below.

1. At $300^{\circ} \mathrm{C}$ and $500^{\circ} \mathrm{C}$, the duration of the experiments is $15 \mathrm{~min}$

2. At $400^{\circ} \mathrm{C}$, the duration of the experiments is $30 \mathrm{~min}$ 
3. In order to optimise the experiment at $1000^{\circ} \mathrm{C}$ two different procedures are performed

a) the sampling boat is pushed to the middle of the heated zone when $1000^{\circ} \mathrm{C}$ is achieved. The duration of the experiments is $15 \mathrm{~min}$.

b) the sampling boat is pushed to $200^{\circ} \mathrm{C}$ heated zone and the temperature is increased continuously to $800^{\circ} \mathrm{C}$ and then $1000^{\circ} \mathrm{C}$. The duration of the experiment in that case is $60 \mathrm{~min}$

At $1000^{\circ} \mathrm{C}$ the impingners are placed in cups filled with dry-ice in order to cool the hot flue gases leaving from the furnace. The system is opened one hour after the experiment, to protect from accidental incidents of fast cooling. To avoid memory effects the furnace is cleaned mechanically and with the above mentioned solvents and heated at $1000^{\circ} \mathrm{C}$ for $2 \mathrm{~h}$ with a gas flow of $2 \mathrm{~L} / \mathrm{min}$.

\subsubsection{Fuel type and examined inhibitors}

In this study a series of experiments are performed for prevention of PCDD/F formation by use of various inhibitors added to the fuel before combustion. The fueltypes used in this study are lignite coal from Puertollano (Spain), pre-treated municipal solid waste (Rethmann Plano $\mathrm{GmbH}$ ) and used PVC (waste from ground carpet).

The weight percentage content for the lignite coal is $80 \%$ of the total fuel. The motivation behind that high percentage is based on the main interest of coalcombustion in that study. The chlorinated compounds are $20 \%$ with a $13.3: 6.7$ ratio of the solid waste to PVC.

Different optimisation processes are examined before the final experimental procedure is established. That optimisations concern:

- the formation of dioxins in the mixture fuel. Experiments with coal / solid waste fuel and without any PVC are also performed. The emitted PCDD/F amount is not high enough to study the inhibition processes. Addition of 6.7\% PVC to the fuel resulted in a substantial increase of PCDD/F, PCB and PCBz. The influence of $\mathrm{PVC}$ is already known as important parameter in incineration processes [47].

- sample homogeneity. Prior to the experiment, each fuel is stirred with a mechanical mortar to generate a particle size of less than $1 \mathrm{~mm}$. For the solid 
waste, the mixing procedure is performed after cooling the larger pieces in liquid nitrogen for $30 \mathrm{~min}$. This procedure preserves the composition of the solid waste. Before combustion the fuel mixture is thoroughly homogenized in the sampling boat. This measures are assumed to decrease the variables between the samples.

Twenty different additives are investigated at a level of $10 \%$ of the total fuel during the experiments. Generally they can be divided into four main groups according to their chemical structure: metal oxides; $\mathrm{N}$-containing compounds; S-containing compounds and $\mathrm{N}$ - and $\mathrm{S}$ - containing compounds. For the inhibitor experiments, the inhibitor is added as $10 \%$ of the fuel. The remaining $90 \%$ fuel is mixed in the same manner mentioned above for samples without additives. The three of the most effective inhibitors for PCDD/F reduction, $\left(\mathrm{NH}_{4}\right)_{2} \mathrm{~S}_{2} \mathrm{O}_{3},\left(\mathrm{NH}_{4}\right)_{2} \mathrm{SO}_{4}$, and $\left(\left(\mathrm{NH}_{2}\right)_{2} \mathrm{CO}+\mathrm{S}\right)$ (1:1) are also used at an amount of $5 \%, 3 \%, 1 \%$ of the fuel.

The compounds investigated as inhibitors are divided into four main groups according their chemical nature and structure and are as followed:

\section{Metal oxides:}

chromium (III) oxide $\left(\mathrm{Cr}_{2} \mathrm{O}_{3}\right)$ (Merck);

titanium (IV) oxide $\left(\mathrm{TiO}_{2}\right)$ (Merck);

sodium (meta) vanadate $\left(\mathrm{NaVO}_{3}\right)$ (Fluka);

zirconium (IV) oxide $\left(\mathrm{ZrO}_{2}\right)$ (Merck);

aluminium(III)oxide $\left(\mathrm{Al}_{2} \mathrm{O}_{3}\right)$ (ICN-EcoChrom);

sodium molybdate dihydrate $\left(\mathrm{Na}_{2} \mathrm{MoO}_{4} \cdot 2 \mathrm{H}_{2} \mathrm{O}\right)$ (Fluka);

sodium tungstate dihydrate $\left(\mathrm{Na}_{2} \mathrm{WO}_{4} \cdot 2 \mathrm{H}_{2} \mathrm{O}\right)$ (Fluka).

2. N-containing:

di-ammoniumhydrogenphosphate $\left(\left(\mathrm{NH}_{4}\right)_{2} \mathrm{HPO}_{4}\right)$ (Merck);

triethanolamine $\left(\mathrm{N}\left(\mathrm{CH}_{2} \mathrm{CH}_{2} \mathrm{OH}\right)_{3}\right)$ (Merck);

hexamethylphosphoramide $\left(\left[\left(\mathrm{CH}_{3}\right)_{2} \mathrm{~N}\right]_{3} \mathrm{P}(\mathrm{O})\right)$ (Sigma-Aldrich Chemie).

3. S- containing:

sulfur (S) (Sigma-Aldrich Chemie);

phosphorus $(\mathrm{V})$ sulfide $\left(\mathrm{P}_{2} \mathrm{~S}_{5}\right)$ (Merck);

sodium sulfide $\left(\mathrm{Na}_{2} \mathrm{~S} \cdot \mathrm{H}_{2} \mathrm{O}\right)$ (Merck).

4. $\mathrm{N}$ - and $\mathrm{S}$ - containing:

hydroxylamine-O-sulfonic acid $\left(\mathrm{H}_{2} \mathrm{NSO}_{4} \mathrm{H}\right)$ (Merck);

amidosulfonic acid $\left(\mathrm{H}_{2} \mathrm{NSO}_{3} \mathrm{H}\right)$ (Sigma-Aldrich Chemie); 
sulfamide $\left(\mathrm{H}_{2} \mathrm{NSO}_{2} \mathrm{NH}_{2}\right)$ (Sigma-Aldrich Chemie);

ammoniumthiosulfate $\left(\left(\mathrm{NH}_{4}\right)_{2} \mathrm{~S}_{2} \mathrm{O}_{3}\right)$ (Merck);

urea+sulfur ( $\left.\left(\mathrm{NH}_{2}\right)_{2} \mathrm{CO}+\mathrm{S}\right)$ (1:1) (urea, techn.);

ammoniumsulfate $\left(\left(\mathrm{NH}_{4}\right)_{2} \mathrm{SO}_{4}\right)$ (Merck).

A residue of olive oil named pomace (50\% carbon and $50 \%$ oxygen) is also tested as inhibitor for PCDD/F in such a fuel mixture.

\subsubsection{Laboratory work before clean-up}

After completing the experiment, the impingners are transferred in GSF-Research Centre for Environmental and Health, Institute for Ecological Chemistry, dioxin laboratory. There the sample is transferred into a $500 \mathrm{ml}$ round flask. The used glassware is rinsed three times with pure toluene which is added to the same flask. The sample is reduced to $1 \mathrm{ml}$ by the vacuum evaporator. The reduced extract is transferred to the first clean-up column.

\subsection{Clean-up Procedure}

The clean-up procedure for PCDD/F, PCB and PCBz take place in dioxin laboratory, GSF- Research Centre, Institute for Ecological Chemistry, (Neuherberg, Germany). Dioxin laboratory is an accredited laboratory against the standard DIN EN ISO/IEC 17025 [100]. That certificate provides for the dioxin laboratory a guarantee of the quality of its measurements. It demonstrates the competence of this testing laboratory to carry out specific tests.

The clean-up steps are explained below carried out according to the corresponding SOP (standard operated procedure) (Tab. 4.2.). These SOPs are verified against the above-mentioned standard. All rights of this SOPs are reserved from dioxin laboratory.

Once registered in dioxin laboratory sample is processed for further PCDD/F and/or PCB specific clean-up steps (Fig. 4.6. and 4.7.). The clean-up procedure for PCB and $\mathrm{PCBz}$ is general. 


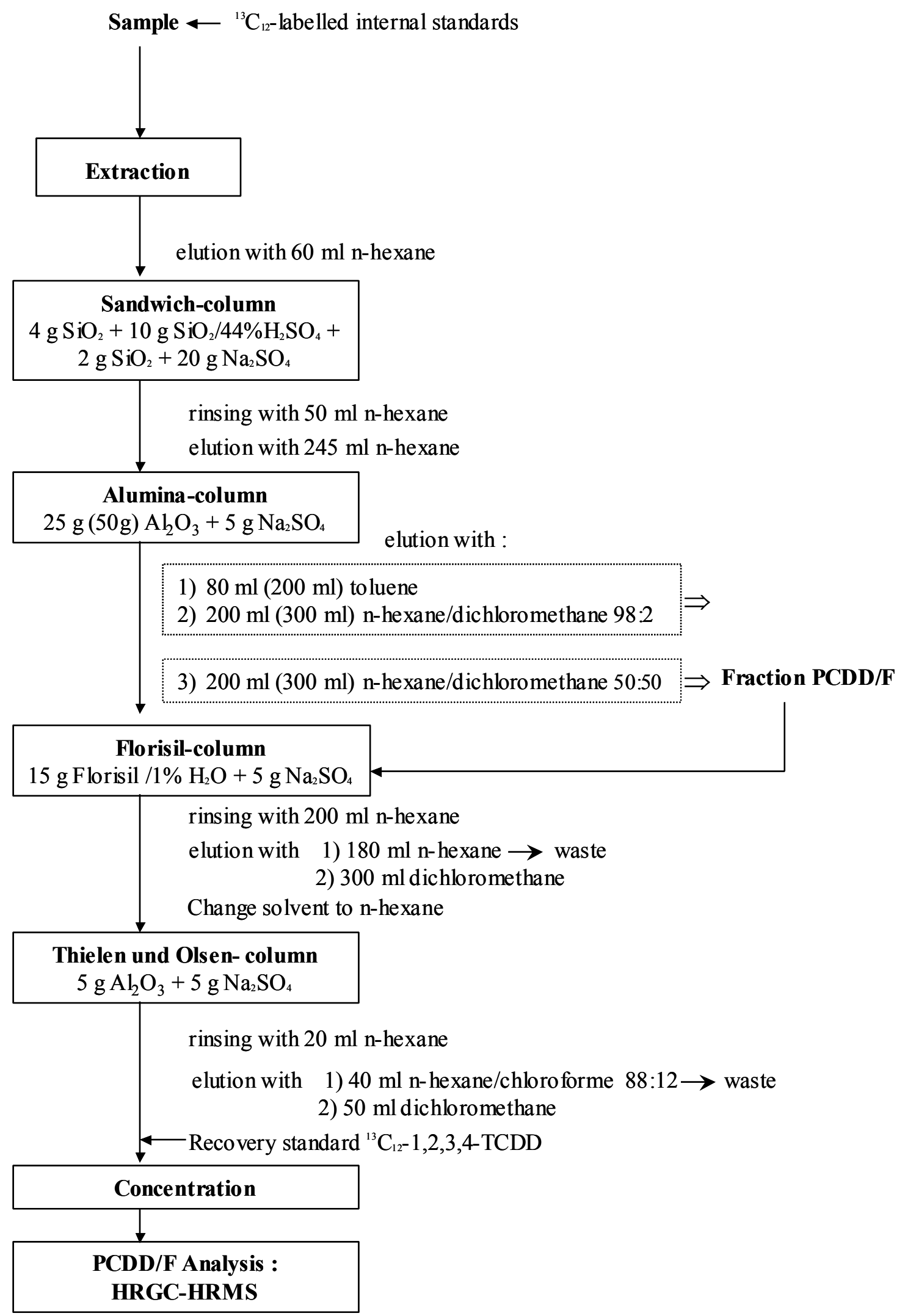

Fig. 4.6: Sample praparation flowchard for PCDD/F, PCB and PCBz analysis 
Alumina-column

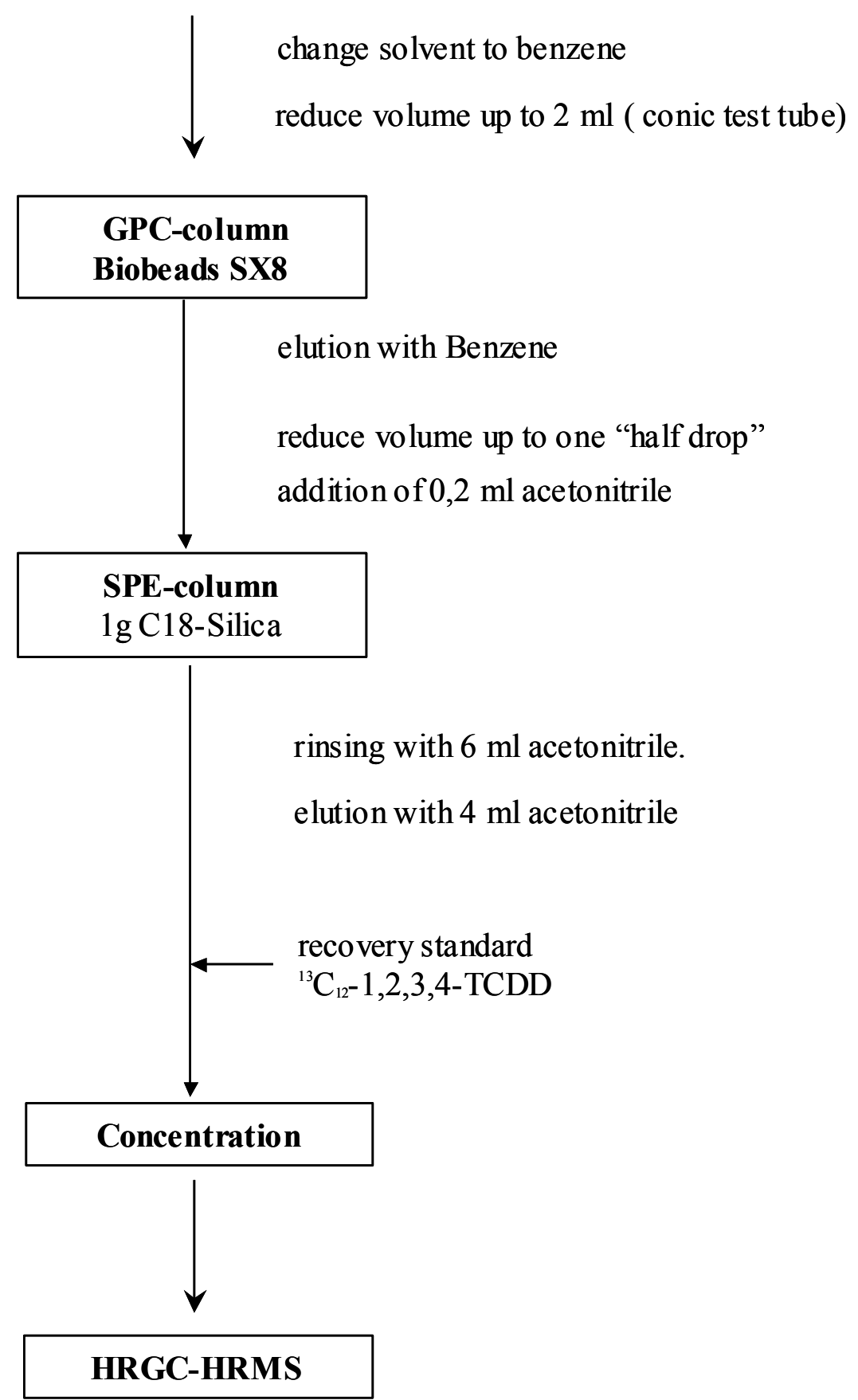

Fig. 4.7: Continued preparation flowchard for PCB and PCBz analysis 
Tab. 4.2: Clean-up procedure for PCDD/F, $P C B$ and $P C B z$ analysis

\begin{tabular}{|c|c|c|}
\hline PCDD/F analysis & PCB, PCBz analysis & Clean-up steps \\
\hline$\checkmark$ & $\checkmark$ & Sandwich-column \\
\hline$\checkmark$ & $\checkmark$ & Alox-column \\
\hline & $\checkmark$ & GPC-column \\
\hline$\checkmark$ & $\checkmark$ & C18-column \\
\hline$\checkmark$ & & Florisil-column \\
\hline$\checkmark$ & $\checkmark$ & $\begin{array}{c}\text { Thielen and Olsen-column } \\
\text { extracts into vials }\end{array}$ \\
\hline
\end{tabular}

\subsubsection{Sandwich column}

On the sandwich column many organic compounds are oxidized or sulphured by reaction with the sulphuric acid. The resulting polar bonds are absorbed at the silica gel. It is eluted with the non polar solvent $n$-hexane. This clean-up step oxides polyaromatic hydrocarbons (PAH).

Preparation of the sandwich column:

$4 \mathrm{~g}$ silica gel are weighed and transferred to a chromatography column. Similarly $10 \mathrm{~g}$ silica gel impregnated with concentrated sulphuric acid are weighed and transferred to the column. Subsequently, another $2 \mathrm{~g}$ silica gel are weighed and transferred to the column. The upper layer consists of $5 \mathrm{~g}$ water-free sodium sulphate.

\section{Elution of the sample}

In order to avoid blank values the packed sandwich column is rinsed with $60 \mathrm{ml} \mathrm{n}$ hexane. Before the upper layer becomes dry appropriate (depending on the class of analysed compound) internal labelled standard solution $100 \mu \mathrm{l}$ PCDD/F solution, 20 $\mu \mathrm{l}$ PCB solution, $10 \mu \mathrm{l} \mathrm{T}_{4}-\mathrm{T}_{6} \mathrm{CBz}$ labelled standard solution is added (If the sample is processed already with Soxhlet extraction, the internal standard is not spiked again). The reduced $2 \mathrm{ml}$ sample is transferred with a Pasteur pipette to the packed column. In case of samples treated prior with Soxhlet extraction, the upper layer of the sandwich column is loaded only with the $2 \mathrm{ml}$ extract. Such procedure is performed for the emission cartridges which are spiked before Soxhlet extraction with internal standards. 
Later, the sample flask is rinsed 3 times with a small quantity of $n$-hexane : the sample or rinsing solvent are given successively with the same Pasteur pipette on the sodium sulphate layer of the column. $245 \mathrm{ml} \mathrm{n}$-hexane is filled into the dropping funnel. Before the upper layer is becoming dry, the eluent is slowly dropped on the column, and thus the upper layer is not whirled up. The sample (dropping rate is approx. 2 drops/second) is collected in a round flask. If the sulphuric acid layer is dark coloured till the lower end, the clean-up sandwich column is repeated. For the emission samples double sandwich column is prepared frequently.

Finally the sample is reduced at the rotary evaporator in a bath with temperature $60^{\circ} \mathrm{C}$ and at a pressure from 500 to 550 mbar. The reduced approx. $2 \mathrm{ml}$ sample should be colourless or less coloured than the initial fraction.

\subsubsection{Alox column}

At that clean-up step, the first polar bond toluene fraction (PCDD/F) is collected and separated from the second fraction, which contains PCBs and other chlorinated aromatics.

Preparation of the alox column:

$25 \mathrm{~g}$ alumina oxid is filled into a chromatography column with a high-grade steel funnel. The upper layer consists of $20 \mathrm{~g}$ water-free sodium sulphate.

For the determination of the PCB and PCBz the packed column is rinsed with $80 \mathrm{ml}$ toluene in order to avoid blank values and for conditioning. The eluent is given to the solvent waste.

\section{Elution of PCB and PCBz Fraction}

Before the upper layer becomes dry, the reduced $2 \mathrm{ml}$ sample is transferred with a Pasteur pipette to the already packed column. The sample flask is rinsed 3 times with a small quantity of toluene: the sample or rinsing solvent are given successively with the same Pasteur pipette on the sodium sulphate layer of column.

$80 \mathrm{ml}$ toluene are filled into the dropping funnel. Before the upper layer becomes dry, the eluent is slowly dropped on the column. A further elution is dropped as a mixture of $200 \mathrm{ml} \mathrm{n}$-hexane / dichloromethane in the volume ratio of 98:2. The sample is collected in the same round flask. 
Elution of the PCDD/F Fraction

Before the upper layer is becoming dry, $200 \mathrm{ml} \mathrm{n}$-hexane / dichloromethane is filled into the dropping funnel in a volume ratio of 50:50 and carefully dropped on the column.

The sample is collected in a new round flask. Finally the collected sample is reduced to approx. $2 \mathrm{ml}$ at the rotary evaporator first with $60^{\circ} \mathrm{C}$ with normal pressure to remove dichloromethane and then with 500 to 550 mbar for hexane.

\subsubsection{Florisil column}

At this step chlorinated aromatic bonds are separated. They are present in most samples at a very high excess.

Preparation of the florisil column:

$15 \mathrm{~g}$ florisil deactivated with $1 \%$ water are homogenized into a beaker and transferred over a glass funnel to the chromatography column. The upper layer consists of $5 \mathrm{~g}$ water-free sodium sulphate.

Elution of the sample

In order to avoid blank values the packed sandwich column is rinsed with $150 \mathrm{ml} \mathrm{n}$ hexane. Before the upper layer is becoming dry, the reduced $2 \mathrm{ml}$ sample is transferred with a Pasteur pipette to the already packed column. The sample flask is rinsed 3 times with a small quantity of $n$-hexane: the sample or rinsing solvent are given successively with the same Pasteur pipette on the sodium sulphate layer. 150 $\mathrm{ml} \mathrm{n}$-hexane are filled into the dropping funnel. Before the upper layer is becoming dry, the eluent is slowly dropped on the column, and thus the upper layer is not whirled up. The sample is collected in a round flask. This flask is kept until the end of the analysis. Before the upper layer is becoming dry, the column is eluted with $300 \mathrm{ml}$ dichloromethane. The dichloromethane fraction is collected in a new flask. Finally the sample is reduced at the rotary evaporator up to approx. $2 \mathrm{ml}$ (temperature $60^{\circ} \mathrm{C}$, normal pressure).

- If a further clean-up step with a Thielen and a Olsen column will be carried out the sample is dissolved in $\mathrm{n}$-hexane. Approx. $50 \mathrm{ml}$-hexane are added to the florisil fraction and the sample is again reduced to approx. $2 \mathrm{ml}$ with 500 to $550 \mathrm{mbar}$ at the rotary evaporator. 


\subsubsection{Thielen and a Olsen column}

At that clean-up step, the still remaining interfering compoounds, such as non polar halogenated aromatics, sulphurs, PAH and some polar pollution are eliminated.

\section{Preparation of the Thielen and a Olsen column}

A small chromatography column is filled with $5 \mathrm{~g}$ alumina with a high-grade steel funnel. The upper layer consists of $5 \mathrm{~g}$ water-free sodium sulphate.

\section{Elution of the sample}

In order to avoid blank values the packed alumina oxid column is rinsed with $20 \mathrm{ml} \mathrm{n}$ hexane. The reduced fractions of the florisil column are transferred with a Pasteur pipette to the already packed column. Before the upper layer is getting dried, the sample flask is rinsed 3 times with a small quantity of $n$-hexane / chloroform (88:12): the sample or rinsing solvent is given successively with the same Pasteur pipette on the sodium sulphate layer of column. $35 \mathrm{ml}$-hexane/chloroform (88:12) is filled into the dropping funnel. Before the upper layer becoming dry, the eluent is slowly dropped on the column.

The sample is collected in a round flask. This flask is kept until the end of the analysis. Before the upper layer becoming dry, the column is eluted with $50 \mathrm{ml}$ dichloromethane. The dichloromethane fraction is collected in an appropriate pear shape flask. Finally the collected sample is reduced to approx. $0.2 \mathrm{ml}$ at the rotary evaporator (temperature $60^{\circ} \mathrm{C}$ and at a normal pressure, then $300 \mathrm{mbar}$ ).

\subsubsection{GPC column for PCB analysis}

GPC separates the molecules according their size. The separation is based on a negative filter effect of the porous stationary phase: small molecules are held, large molecules are eluted first. The stationary phase consists of Biobeads SX8, a copolymer of styrene and $8 \%$ divinylbenzene. Benzene is used as mobile phase. GPC separates: fats, oils, fatty acids, sulphur, 5-7-Ring PAH, a part of the phosphoric acid esters and a part of the Phthalic acid esters. 
Sample preparation

The sample has to be present in benzene, because other solvents cause another swelling behaviour of the Biobeads and thus a destruction of the GPC column. For the GPC auto sampler, conic shaped glass has to be used and the sample volume needs to be exactly $2 \mathrm{ml}$.

The first alox PCB fraction is present as hexane extract. That sample is reduced to approx. $2 \mathrm{ml}$ at the rotary evaporator at $60^{\circ} \mathrm{C}$ and 500 to $550 \mathrm{mbar}$ and transferred in GPC auto sampler glass. The sample flask is rinsed three times with benzene. The glass is placed in the heating plot (water bath) of the blow-off equipment and the volume of solvent is reduced to $2 \mathrm{ml}$ at $50^{\circ} \mathrm{C}$ under gentle stream of nitrogen.

Operation with GPC column

About $110 \mathrm{ml}$ benzene is used for every sample. Prior start of the GPC column the following program is loaded: Drain $30 \mathrm{~min}$, Collect $14 \mathrm{~min}$, Rinse $2 \mathrm{~min}$. Later the pump is switched off independently after processing of the sample. In the conic flasks, the eluted fraction amounts is about $40 \mathrm{ml}$ benzene solution. The volume of the fraction is reduced to nearly $0.5 \mathrm{ml}$ at the rotary evaporator at $50^{\circ} \mathrm{C}$ and 250 mbar.

Note

That clean up procedure with GPC column is performed only for the emission samples. The laboratory scale experiments samples are not processed with that column. The first alox PCB fraction is transferred into a conic flask with a Pasteur pipette. The sample flask is rinsed 3 times with a small quantity dichloromethane and the rinsing solvent is given successively with the same Pasteur pipette to the conic flask.

\subsubsection{C18 column}

The C18-Material is an octadecyl modified silica gel. On this hydrophobic stationary phase, long chained hydrocarbons can be adsorbed; these hydrocarbons cause interferences mainly in the analysis of mineral oil, sewage sludge and sediment samples. Acetonitrile is used as a polar eluent. 
Sample preparation

The sample from the GPC or the samples after alox is reduced approx. to $0.5 \mathrm{ml}$ with a rotary evaporator. This volume is carefully reduced to approx. 1/2 drop (almost to the dryness) by a light stream of nitrogen at the sample concentrator. After that, 0.2 $\mathrm{ml}$ acetonitrile is given into the conical flask.

Preparation of the C18 column:

A PTFE frit is inserted into an empty $8 \mathrm{ml}$ glass cartridge. The frit is pressed with a glass rod to the bottom of the cartridge. After filling with $1 \mathrm{~g}$ dry C18-material, the cartridge is plugged with another PTFE frit. The last frit is firmly pressed again with a glass rod into the cartridge.

\section{Elution of the sample}

The already prepared C18-cartridge is conditioned with $4 \mathrm{ml}$ of acetonitrile. For that, the cartridge is placed on to the vacuum manifold. An empty $8 \mathrm{ml}$ sample vial is placed in the vacuum manifold under the drain tube.

The solvent is sucked through the cartridge with a gentle vacuum (approx. 900 mbar) until the adsorbent is wet and the solvent is dropping free of bubbles out of the drain tube. After that, the vacuum is switched off, in order to keep a normal dropping rate of approx. 1 drop per second. The cartridge shouldn't run dry before sample addition.

For collecting the sample, a new empty $8 \mathrm{ml}$ sample vial is placed in the vacuum manifold under the outlet of the already conditioned cartridge. The sample $(0.2 \mathrm{ml})$, is added with a Pasteur pipette on the conditioned C18-cartridge. The conical flask is rinsed with two times with $0.4 \mathrm{ml}$ acetonitrile. As soon as the rinsing solvent passed completely through the upper PTFE frit, another $3 \mathrm{ml}$ acetonitrile is added for elution.

\section{After C18 clean up column}

The sample vial with the sample from the C18-cartridge is reduced (almost to the dryness) in the light stream of nitrogen at the sample concentrator. The evaporation is carried out very carefully, otherwise the recovery of the lower chlorinated PCBs is becoming worse. At the end of the evaporation the solvent is changed to toluene by three times adding 3 drops of toluene. Then the sample is transferred immediately into a vial. 


\subsubsection{Concentration}

The sample concentrator is used in this step. The temperature of the heating block of that device is adjusted to $45^{\circ} \mathrm{C}$ and the safety temperature to $50^{\circ} \mathrm{C}$. The nitrogen supply is opened. The valves, over the pipettes, are so far opened, that the surface of water moves gently, in order to check the nitrogen stream.

An appropriate quantity of PCB or PCDD/F recovery standards solutions (20 or $25 \mu \mathrm{l}$ ) is filled into a inner part of the vial with a micro litre syringe. The PCB recovery standard is general also for the PCBz. In case of further PCB and PCBz analysis, only one portion of $20 \mu \mathrm{l}$ recovery standard is spiked. The level of the standard in the micro-insert is marked with a felt-tip pen. Afterwards, the micro-insert is placed into a brown glass vial sample and placed in the sample concentrator.

After the last clean-up step, the reduced sample is transferred carefully and stepwise with a Pasteur pipette into the micro-insert without dropping beside. The flask is rinsed 3 times with a small quantity of dichloromethane. This solvent is transferred with the already used pipette into the vial and evaporated to the correspondent mark. Then the vial is closed with a septum cap. After arrangement, the sample is either measured with HRGC/HRMS or kept in the refrigerator.

\subsection{Detection \& Quantification with HRGC/HRMS}

The quantification of PCDD/F, PCB and PCBz is performed on a high-resolution gas chromatography instrument (60 m Rtx-2330 polar capillary column, Restek) coupled with a high-resolution mass spectrometer (MAT 95, Finnigan) (HRGC/HRMS). The tetra- to octachloro- isomers of PCDD/F, mono- to deca-isomers of PCB and tetra- to hexa- PCBz isomers are identified and quantified.

\subsubsection{Detection of $P C D D / F$}

The measuring of PCDD and PCDF is possible by GC/MS where the tetra - hexa chlorinated isomers are separated gas chromatographically through special isomer specific capillary column (Restek Rtx-2330) and detected by the help of mass spectroscopy Finnigan MAT 95.

The entry parameters of the isomer specific separation are: 
Start temperature: $120^{\circ} \mathrm{C}$, Start time: $0.00 \mathrm{~min}$, Heating rate $1: 12.0^{\circ} / \mathrm{s}$, End temperature 1: $280^{\circ} \mathrm{C}$, Hold time 1: $5.00 \mathrm{~min}$, Heating rate 2: $12.0^{\circ} \mathrm{s}$, End temperature 2: $300^{\circ} \mathrm{C}$, Hold time 2: $5.00 \mathrm{~min}$, Kryo-cooling: out, Equilibration time: 0.20 min, GC Run time: 50.00 min, Loading Modus: Splitless.

For confirmation of the result or in case of poor detection of 7- and 8- chlorinated isomers, second measurement with non polar capillary column (J\&W DB-5ms), coupled to Finnigan MAT 95 mass-spectrometer is performed. The entry parameters of that non-polar column separation are:

Start temperature: $50^{\circ} \mathrm{C}$, Start time: $0.00 \mathrm{~min}$, Heating rate 1: $12.0 \%$, Plateau temperature 1: $280^{\circ} \mathrm{C}$, Hold time 1: $600 \mathrm{~s}$, Heating rate 2: $12.0 \%$, Plateau temperature 2: $300^{\circ} \mathrm{C}$, Hold time 2: $600 \mathrm{~s}$, Kryo-cooling: out.

\section{Evaluation of the measurement}

Before quantification analysis of the measured results, qualitative consideration has to be done. That procedure include control of the total ionic current and detection of eventual electronic interferences which can disturb the measurement.

The chromatographic separation is considered as sufficient when

- All marked standards are available and well-defined for identification

- The retention time of all isomers is present in the defintime window

\subsubsection{Detection of $P C B$ and $P C B z$}

The measuring PCB is possible by GC/MS where the mono - deca chlorinated isomers are separate gas chromatographically through $5 \%$-Phenylphase employed column (J\&W DB-5ms or J\&W DB-XLB) and coupled with mass spectroscopy Finnigan MAT 95. The measuring of PCB is performed by the sensitive MID-Mode where specific single bonds are registered.

The entry parameters of the isomer specific measurements are:

Start temperature: $50^{\circ} \mathrm{C}$, Start time: $0.00 \mathrm{~min}$, Heating rate 1: $12.0 \%$, Plateau temperature 1: $280^{\circ} \mathrm{C}$, Hold time 1: $300 \mathrm{~s}$, Heating rate 2: $12.0 \%$, Plateau temperature 2: $300^{\circ} \mathrm{C}$, Hold time 2: $300 \mathrm{~s}$, Kryo-cooling: out. 
Evaluation of the measurement

The same procedure as the evaluation of the PCDD/F measurement.

\subsubsection{Quantification of $P C D D / F, P C B$ and $P C B z$}

The quantification procedure of PCDD/F, PCB and PCBz is equal. The criteria of the final controlled values are also the same.

Response factor

Prior quantification, the amount of the internal standards of the investigated analyte (PCDD/F, PCB and PCBz) has to be calculated. In order to estimate it, the actual response factors of the recovery standards has to be documented. For that purpose 3 different mixtures are prepared:

For PCDD/F: $5 \mu \mathrm{l}$ internal standard, $5 \mu \mathrm{l}$ recovery standard and $5 \mu \mathrm{l}$ sampling standard

For PCB: $5 \mu$ internal standard, $5 \mu$ recovery standard

For PCBz: $5 \mu$ internal standard, $5 \mu$ l recovery standard

$1 \mu \mathrm{l}$ of each mixture is analysed and quantified as separate sample. The data is saved.

\section{Quantification process}

The quantification of the height of the available sample signals are integrated with QUAN program of the MAT95S Workstation. Here, the retention times given by the software are compared with the retention times during the measurement. When the check is completed, the chromatographic peaks are integrated. The calculated data file is saved as "rtx" in the QUAN program. Subsequently the file is transferred by FTP program into ".asc" file. The last one can be executed with Microsoft Excel program. Here, the calculated response factor, the type of measurement and the output data are requested. The saved excel data are finally placed in five sheets providing the following information:

1. Raw data - the measured raw data of the "rtx" file

2. Calculation - the concentration of each congeners calculated according to (10). 
3. Test report - summary of the most important values such as the most toxic congeners, sum of the homologues, I-TEQ value and general information for the corresponding sample

4. Test report II - information on the limit of detection

5. Graphic - figure of the congeners and homologues profiles

\section{Control of the final data}

The final data is controlled again. The above mentioned criteria are manually checked, corrected and saved:

- The retention time of the labelled standards and the measured analytes are equal or differ less than \pm 3 sec.

- The recovery rate of the used standards is between $50-120 \%$

- The proportion of the two measured intensive isotope mass is less than $\pm 15 \%$ of the theoretical value

- The signal/noise ratio of each isomer is higher than 3:1

- The amount of each isomer of the measured sample is 3 times higher than the blank sample

\subsection{Statistical Analysis}

Statistical Package 3.11g, Kovach Computing Service [101] is used for the Principle Component Analysis (PCA) and Correspondence Analysis (CA).

PCA is one of the best known and earliest methods. That methodology is first described by K. Pearson (1901) as a means of fitting planes by orthogonal least squares and later proposed by Hotelling (1933) for a particular purpose of analysing correlation structures.

The main applications of PCA are: (1) to reduce the number of the variables and (2) to detect structure in the relationship between the variables or to classify the variables. PCA fall under the general heading of factor analysis which have generated the dependence or variation in the responses [102]. Initially defined principle components of a multivariate sample statistically and algebraically are then visualized by a so-called score plot for observation. Samples with similar emissions are located close to each other in the score plot, while those that have divergent emission patterns are located further apart. That analysis is used to reflect on the effect of the different 20 inhibitors on the congener patterns emitted. The current 
analysis is performed separately for PCDD PCDF and PCB. No transformation of the data is performed during the statistical analysis.

The first linear component of the observation is that linear compound of the responses whose sample variance is maximal for all coefficient vectors normalized. The second linear component is perpendicular to the first, and so on (Fig. 4.8).

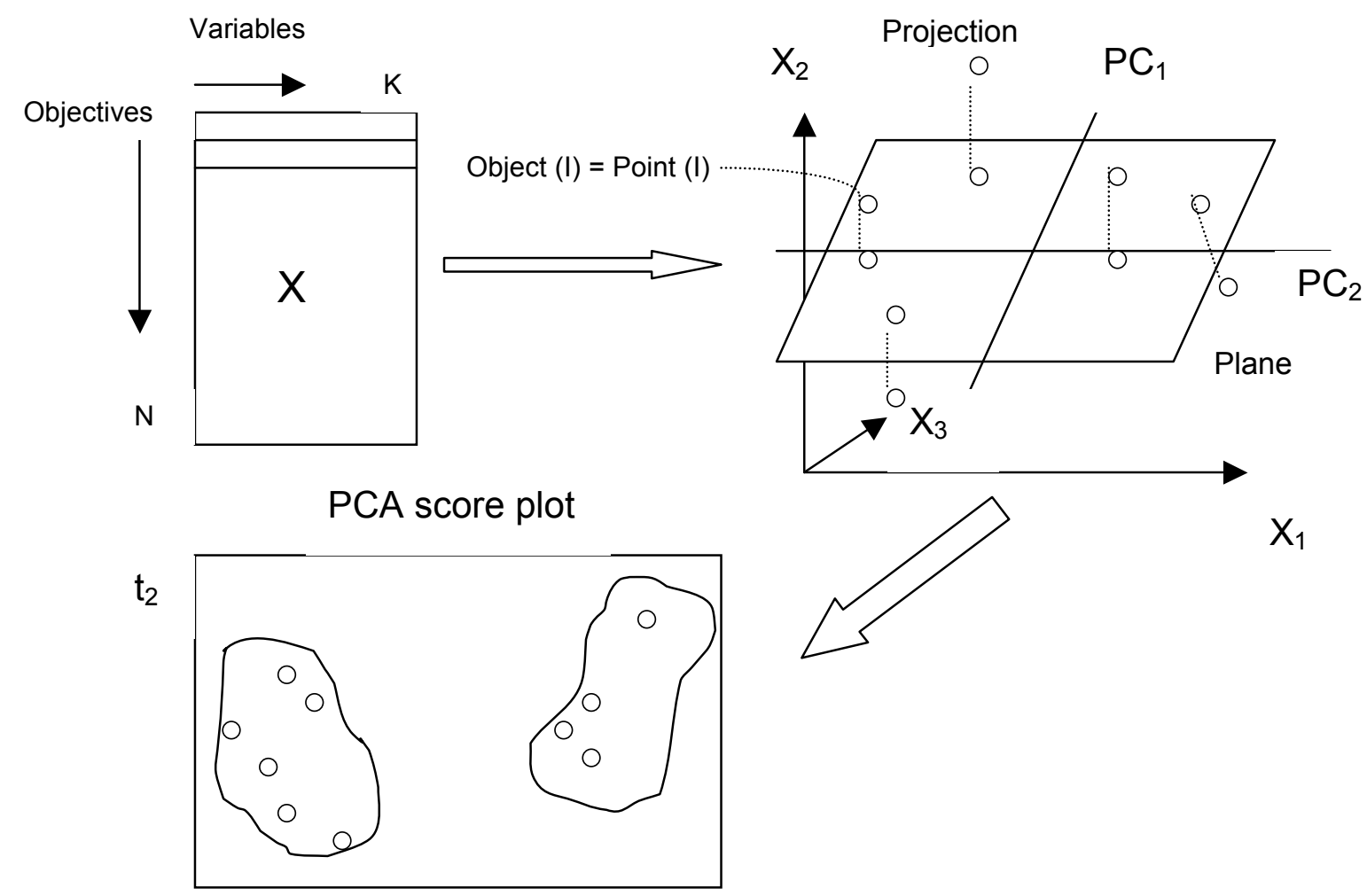

$t_{1}$

Fig. 4.8. Schematic representation of PCA.

Generally principal components are those linear combination of the responses which explain progressively smaller portion of the total sample variance. Geometrically the principal components are the new variates specified by the axes of a rigid rotation of the ordinal response coordinate system into an orientation corresponding to the direction of maximum variance in sample scatter configuration. The eigenvalue for the first axis is the largest, the second the second largest and so on [101]. Recommendable is when the first two or three axes account for a large proportion of variance of $50-60 \%$ or more. In some cases the first axis might account for over 90$95 \%$ of the variance.

Correspondence Analysis is a exploratory technique designed to analyse simple twoway and multi-way tables containing some measure of correspondence between the rows and columns. The purpose of CA is to reproduce the distances between the row 
and/or column points in a two-way table and multi-way tables in a lower-dimensional display. The result provide information which is similar in nature to those produced by factor analysis and it allow to explore the structure of categorical variables included in the table. Important are the distances of the points in the two-dimensional display. That row points which are closer to each other reflect of their similarity regarding to the pattern. Obviously the final goal of CA is to find theoretical interpretation for the extract dimension. The effect result of CA is usually to find the most correlated variables (congeners and homologues) between the PCDD, PCDF, PCB and PCBz data. No transformation of the data is performed during the statistical analysis. CA is performed separately for the groups of samples (higher and lower toxicity) visualized prior by the PCA score plot. Points resulted closer to each other in CA score plot are additionally observed for their coefficient of determination $\left(R^{2}\right)$ in a two-dimensional graphic. That method provide easier discussion about the best correlations among the set of different congeners and PCDD, PCDF, PCB and PCBz homologues. 


\section{Results and Discussion}

\subsection{Pilot Scale Sampling}

\subsubsection{Quality of the Data}

The repeatability of the emission sampling can not be estimated because the operation parameters of the equipment are not constant. In order to control the repeatability, isochronously another sampling of independent accredited institute has to be performed. The comparison of the measured data is sufficiently assessed when the sampling and analytical values are repeatable.

\section{Analytical data}

The quality of the analytical data followed the above mentioned criteria (4.4.4, Control of the final data).

\section{Recovery Rate}

The recovery rate indicates the losses of the sample during its preparation such as rinsing of the glassware, extraction, clean-up. That grade show a statement of the quality of the final result. The recovery rate regard the rate of the marked standards corresponding for the sample. According US-EPA the recovery rate of the internal standard for aromatic and chlorinated aromatic compounds has to be between 40 and $120 \%$ [103] . In Table 5.1. the average recovery rate of the internal standard for the measured classes compounds is shown.

Tab. 5.1:Recovery rate of the internal standard for the analyzed compounds (PCDD/F data $n=22, P C B$ data $n=8)$

\begin{tabular}{|c|c|c|}
\hline Analyst & Isotop labelend internal standard & Recovery rate (\%) \\
\hline PCDD/F & DiCDD-OCDD; TriCDF-OCDF & $61-113$ \\
\hline PCB & MCB-DCB & $48-60$ \\
\hline
\end{tabular}

According VDI 2066, DIN EN 1948 and DIN EN 13284-1 [104], [105] the recovery rate of the sampling standard should be around $100 \%$ and even more than $100 \%$. The maximal value is $120 \%$. It is generally known that the recovery rate for the lower chlorinated and high-volatile compounds is lower than for the low volatile compounds. The reason can be found in the physical-chemical properties of that compounds and their high absorption affinity to the laboratory materials used (glassware, chemical absorbents). In Table 5.2. the average recovery rate of the sampling standard is calculated. 
Tab. 5.2:Recovery rate of the sampling standard $(n=22)$

\begin{tabular}{|c|c|}
\hline Sampling standard & Recovery rate (\%) \\
\hline DiCDD-OCDD; TriCDF-OCDF & $72-104$ \\
\hline
\end{tabular}

\section{Blank value}

For every sampling campaign a blank sample is prepared. It supplied a value for the contaminations during the clean-up procedure of the glassware, absorbents, solvent and etc. The preparation procedure of the blank sample is the same as for all other samples.

\section{Sampling data}

The quality of the sampling data followed the above mentioned criteria (4.1.3. Validation of the sampling measurement).

Blank value

Two different blank samples are performed during the sampling campaigns explained in this study (Tab. 5.3.).

Tab. 5.3: Blank samples during the sampling campaigns

\begin{tabular}{|c|c|c|c|}
\hline Sample number & Type blank sample & PCDD/F I-TEQ & PCB I-TEQ \\
\hline 0111008 & Sampling without fire & $0.71 \mathrm{pg} / \mathrm{Nm}^{3}$ & - \\
\hline 0201023 & glassware & $11.6 \mathrm{pg} / \mathrm{sample}$ & $0.19 \mathrm{pg} / \mathrm{sample}$ \\
\hline
\end{tabular}

The PCDD/F amount of sample No. 0111008 is the amount of the dioxins in the sucked volume gas flow of the chimney examined at room temperature. During that sampling, the system is prepared for normal sampling campaign but no combustion is running. The sample is not analysed for PCB.

Sample No. 0201023 is a blank sample for the PCDD/F and PCB amount of the used glassware. Here, the sampling device and glassware are connected and ready for sampling but no sucking procedure was applied. Later all pieces are disconnected and processed for further rinsing, clean-up and analysis procedures as normal emission samples. The PCDD/F and PCB amount of that sample is used for validation of the other emission samples.

\section{Back-up Cartridge}

Low amounts of the PCDD/F in the back-up cartridge ensure good sampling practice. The achieved control proof that the analysed aromatic compounds are absorbed efficiently into the XAD-2 cartridge. The back-up cartridge is used during the training period, for the first No 2 - 6 sampling campaigns (Tab. 5.4.). The samples are 
analysed for PCDD/F. It is accepted that the percentage of PCB amount in the backup cartridge compared to the total sample, is not differ out from the received value for PCDD/F. During the performed sampling campaign No 2-6, only the back-up cartridge of sample 0201022 (campaign 4) is analysed for PCB.

Tab. 5.4: Comparison of the PCDD/F I-TEQ value of the back-up cartridge and the total emission sample

\begin{tabular}{|c|c|c|c|c|}
\hline $\begin{array}{c}\text { Sampling } \\
\text { campaign }\end{array}$ & $\begin{array}{c}\text { Back-up } \\
\text { sample } \\
\text { number }\end{array}$ & $\begin{array}{c}\text { PCDD/F I-TEQ } \\
\left(\mathbf{p g} / \mathbf{m}^{\mathbf{3}}\right) \\
\text { Back-up }\end{array}$ & $\begin{array}{c}\text { PCDD/F I-TEQ } \\
\left(\mathbf{p g} / \mathbf{m}^{\mathbf{3}}\right) \\
\text { Total sample }\end{array}$ & $\begin{array}{c}\text { \% of the total } \\
\text { sample }\end{array}$ \\
\hline 2 & 0111007 & 2.1 & 547 & 0.38 \\
\hline 3 & 0112007 & 324 & 105520 & 0.31 \\
\hline 4 & 0201021 & 254 & 17909 & 1.42 \\
\hline 5 & 0201024 & 75.8 & 30809 & 0.25 \\
\hline 6 & 0202018 & 371 & 14662 & 2.53 \\
\hline
\end{tabular}

* total sample - glass wool and resin cartridge PCDD/F amount

$\underline{\text { Resin and glass wool cartridge }}$

During the sampling campaigns No. 2-3 and 7-9, resin and glass wool cartridges are used (see Tab.4.1.). All the samples are analysed separately for PCDD/F and the samples corresponding to sampling campaigns No.7-9 are analysed also for PCB. The final results pointed out dominating PCDD/F and PCB amount in the glass wool cartridge compared to the resin XAD-2 cartridge (Tab.5.5.). The percentage of the PCDD/F and PCB I-TEQ value of the resin cartridge to the total sample is strongly dependent of the combustion conditions during the sampling. Very low PCDD/F content $(0.9 \%)$ in the resin cartridge of campaign No.3 is estimated. It means that that sampling is characterized by a highly sooty gases which are mostly trapped into the first glass wool cartridge. According to the PCB data in Tab. 5.6., it seems that the XAD-2 cartridge absorbed more aromatic PCB compounds in comparison to the PCDD/F. During campaign No. 8, the PCDD/F amount in the resin cartridge is about three times lower than the PCB amount in the same sample. 
Tab. 5.5:Comparison of the PCDD/F I-TEQ value of the resin XAD-2 cartridge and the total emission sample

\begin{tabular}{|c|c|c|c|c|}
\hline $\begin{array}{c}\text { Sampling } \\
\text { campaign }\end{array}$ & $\begin{array}{c}\text { PCDD/F I-TEQ } \\
\left(\mathrm{pg} / \mathrm{Nm}^{3}\right) \\
\text { resin cartridge }\end{array}$ & $\begin{array}{c}\mathrm{PCDD} / \mathrm{F} \text { I-TEQ } \\
\left(\mathrm{pg} / \mathrm{Nm}^{3}\right)\end{array}$ & $\begin{array}{c}\mathrm{PCDD} / \mathrm{F} \mathrm{I-TEQ} \\
\left(\mathrm{pg} / \mathrm{Nm}^{3}\right) \\
\text { glass wool cartridge }\end{array}$ & $\begin{array}{c}\% \text { of the total } \\
\text { sample }\end{array}$ \\
\hline 2 & 141 & 406 & 547 & 25.78 \\
\hline 3 & 950 & 104570 & 105520 & 0.90 \\
\hline 7 & 359 & 1076 & 1435 & 25.02 \\
\hline 8 & 48.3 & 988 & 1036.3 & 4.66 \\
\hline 9 & 5820 & 27489 & 33309 & 17.47 \\
\hline
\end{tabular}

Tab. 5.6:Comparison of the PCB I-TEQ value of the resin XAD-2 cartridge and the total emission sample

\begin{tabular}{|c|c|c|c|c|}
\hline $\begin{array}{c}\text { Sampling } \\
\text { campaign }\end{array}$ & $\begin{array}{c}\text { PCB I-TEQ } \\
\left(\mathrm{pg} / \mathrm{Nm}^{3}\right) \\
\text { resin cartridge }\end{array}$ & $\begin{array}{c}\text { PCB I-TEQ } \\
\left(\mathrm{pg} / \mathrm{Nm}^{3}\right)\end{array}$ & $\begin{array}{c}\mathrm{PCB} \text { I-TEQ } \\
\left(\mathrm{pg} / \mathrm{Nm}^{3}\right) \\
\text { glass wool cartridge }\end{array}$ & $\begin{array}{c}\% \text { of the total } \\
\text { sample }\end{array}$ \\
\hline 7 & 9.7 & 53.4 & 63.1 & 18.16 \\
\hline 8 & 5.4 & 25.1 & 31.5 & 17.70 \\
\hline
\end{tabular}

Isokinetic ratio

The isokinetic ratio provide a standardization and a better comparability of the results. Furthermore the sampling error is minimized by using an automatic sampling system especially in processes with fluctuations and dust in the exhaust gas. The automatic system makes a continuous adaption to the velocity of the exhaust gas possible. With the fixed nozzle diameter and the varying gas velocity, the flow rate is regulated by the evaluation and the control unit by adding ambient air. The system is qualified for an isokinetic sampling according guideline VDI 2066 and EN 1948 [100], [106], [107], [104]. The calculated isokinetic ratios of the performed sampling campaigns are presented in Tab. 5.5. The values are based on the manual and automatic steering data during the sampling.

Tab. 5.7: Calculated isokinetic ratio during the sampling campaigns

\begin{tabular}{|c|c|c|c|}
\hline $\begin{array}{c}\text { No. of sampling } \\
\text { campaign }\end{array}$ & Isokinetic Ratio & $\begin{array}{c}\text { No. sampling } \\
\text { campaign }\end{array}$ & Isokinetic Ratio \\
\hline 1 & 1.12 & 6 & 1.32 \\
\hline 2 & 1.12 & 7 & 1.45 \\
\hline 3 & 1.76 & 8 & 1.81 \\
\hline 4 & 1.34 & 9 & 1.83 \\
\hline 5 & 1.40 & 10 & 1.70 \\
\hline
\end{tabular}


Regulation difference between calculated and measured sampled gas flow rate for MRU $\underline{4000 \text { sampling system }}$

The error of the MRU system between the actual and calculated gas flow rate called regulation difference is found as less then $5 \%$ [108]. The sample gas flow rate is calculated with the formulas above (10). The measured gas flow rate is acquired from the gas volume meter. It delivers electrical impulses to the control unit, proportional to the gas volume which is sucked through. Fig. 5.1. show the adjustment of the measured to the calculated standard sample gas flow rate.

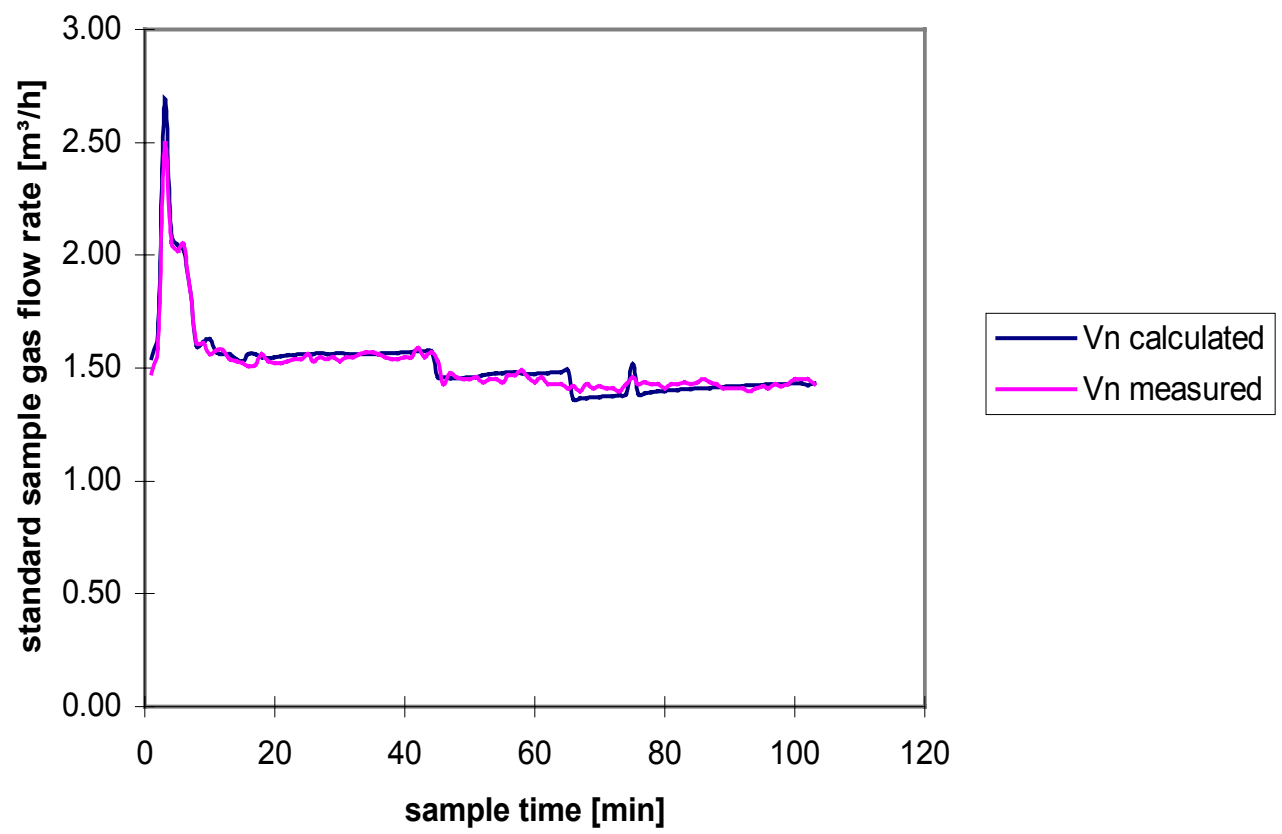

Fig. 5.1: Measured and calculated standard sample gas flow rate after a wood incinerator [108]

\section{Discussion}

The quality of the results concerning the analytical part can be characterized as very good. The recovery rate of the internal and sampling standard is assumed as expectable according the above mentioned guidelines for emission sampling.

The quality of the results concerning the sampling part are also estimated sufficiently. Proof of real competence in the field of emission sampling is the successful accreditation from the accreditation body for chemistry in Germany DACh (Deutsche Akkreditierungsstelle Chemie $\mathrm{GmbH}$ ) on January 2003.

The amount of the blank value is lower than $10 \%$ of the limit value for PCDD/F for the flue gas $0.1 \mathrm{ng} \mathrm{I-TEQ} / \mathrm{Nm}^{3}$ [109]. The calculated PCDD/F values for all emission samples are lower than $10 \%$ of the blank samples. 
The amount of the back-up cartridges show negligible percentage compared to the total sample. That result is a good evidence that the sampled gas during the campaigns is efficiently absorbed of the glass wool and / or XAD-2 cartridge and the final PCDD/F and PCB values are valid.

Another important parameter for the quality of the sampling data (even not included in the validation of the sampling measurements) is the sampled PCDD/F and PCB amount of the resin and glass wool cartridge. Generally such as first trap units such as the condensate flask and the glass wool cartridge are able to absorb most of the aromatic compounds formed during the emission sampling. Nevertheless, the amount of the PCDD/F and PCB in the resin cartridge should be also sufficient. For example, the poor gaseous PCDD/F absorbance in the resin cartridge of campaign No. 3 should be taken in account for further investigations. During that campaign the temperature of the chimney is $500^{\circ} \mathrm{C}$ and high $\mathrm{CO}_{2}$ and $\mathrm{CO}$ gas content is detected. That conditions stimulated the soot formation.

The PCB in the resin cartridges of the above mentioned No. 7 and 8 campaigns is higher compared to the PCDD/F. Explanation of that fact can be based of the physical-chemical properties of PCB molecules.

The estimated isokinetic ratio is most of the times more than 1 . It means that the measured gas flow rate is lower than the theoretical one according equation 9. Furthermore the measured gas flow rate is strongly dependent on the velocity in the chimney and the dynamic pressure according (7) and (8).

As it was explained above a ventilator is used like a source of gas flow. By its operation during the first sampling campaigns a negligible velocity and dynamic pressure in the duck is estimated $\left(v=0.4 \mathrm{~m} / \mathrm{s}, p_{\text {dyn }}=0.01 \mathrm{mbar}\right)$. That cause often a termination of the working of MRU program prior the automatic sampling start. In such cases manual steering of the sampling system where the sample gas flow rate is adjusted by manual regulation with ambient air is also sufficient. In order to avoid that troubleshooting, the ventilator is changed by a stronger one with options for different levels of air flow. It became possible to sample at different sample flow rates, according the equation (8) and to perform automatic sampling.

Here, it should be mentioned that often the fluctuations of the operation parameters related to the sampling (temperature, dynamic pressure, velocity) are varying during the combustion processes. In such cases the automatic steering rather than manual 
is more practical. It responds immediately to any alterations parameters in the duct. Therefore a continuous isokinetic sample gas flow rate is guaranteed and a representative sampling is possible.

The calculated low regulation difference between calculated and measured sampled gas flow rate present MRU 4000 sampling system such as suitable apparatus for emission sampling.

\subsubsection{Influence of Combustion Parameters on the Formation of PCDD/F and PCB in} a Pilot Incinerator

The proposed objectives in this study to find a mechanism of dioxin prevention and the appropriate adjustments for optimum combustion conditions and minimum chlorinated hydrocarbon emission, required sufficient knowledge about the influence of combustion parameters on the dioxin formation.

A revaluation of Austrian national emission inventories performed in 1997 showed that domestic heating with wood is the third largest source of PCDD/F followed by emissions from metallurgical industry [110] and according to the European Emission Inventory [111], wood combustion is one of the most important air emission sources of dioxins. That is why the below mentioned investigations are performed in a domestic oven used for wood incineration. Different combustion conditions are applied in order the optimal parameters of dioxin formation to be determined.

\section{Combustion temperature}

Four sampling campaigns of poplar wood incineration were performed at different temperatures. The samples are analyzed at HRGC/HRMS and the I-TEQ PCDD/F values $\left(\mathrm{pg} / \mathrm{Nm}^{3}\right)$ of all samples are calculated (Fig. 5.2.). Negligible amount of dioxins is measured for the samples at $150^{\circ} \mathrm{C}$ and higher values are detected at $250^{\circ} \mathrm{C}$ and $300^{\circ} \mathrm{C}$. The amount of $\mathrm{PCDD} / \mathrm{F}$ is about three fold more compared to the result at $500^{\circ} \mathrm{C}$. 


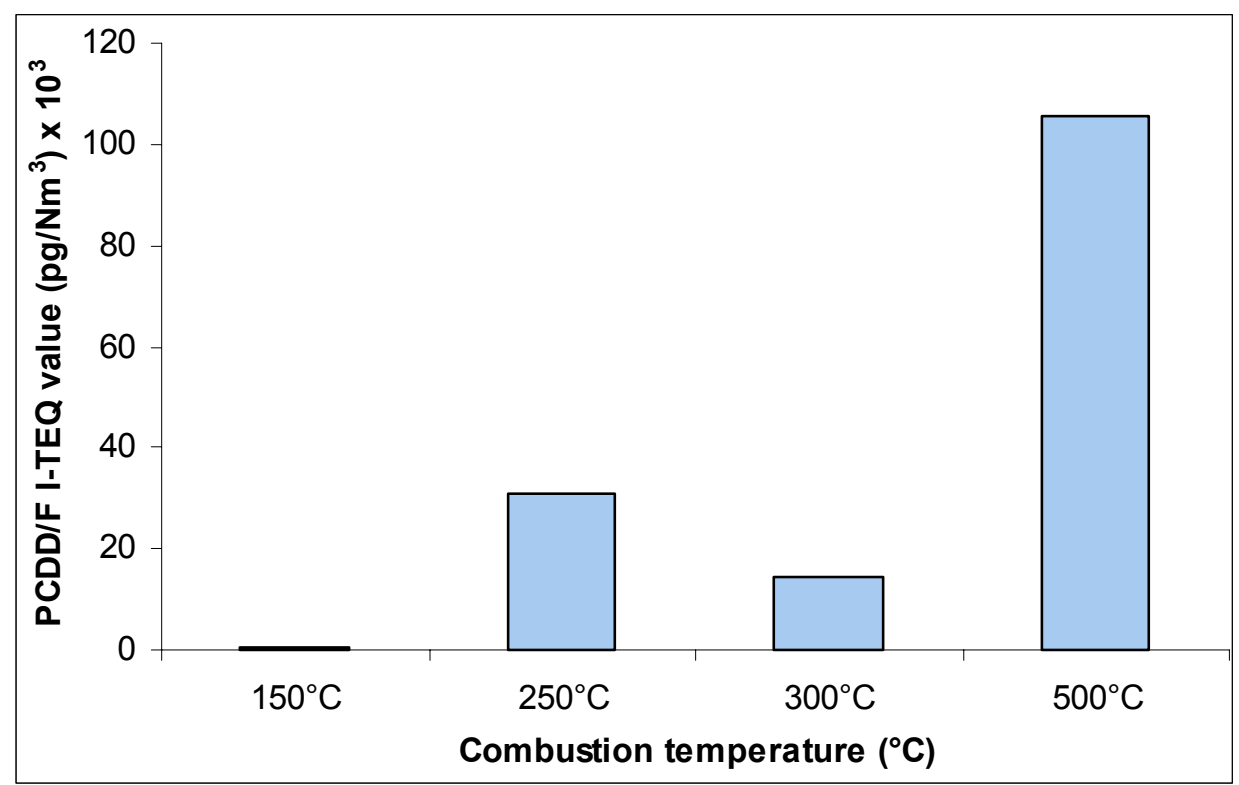

Fig. 5.2: $P C D D / F$ I-TEQ value $\left(\mathrm{pg} / \mathrm{m}^{3}\right)$ in poplar wood combustion at different temperatures

Another three sampling campaigns of poplar wood and 10\% PVC were performed at different temperatures. The samples are also analyzed at HRGC/HRMS and the ITEQ PCDD/F values (pg/Nm3) of each samples are calculated (Fig. 5.3.).

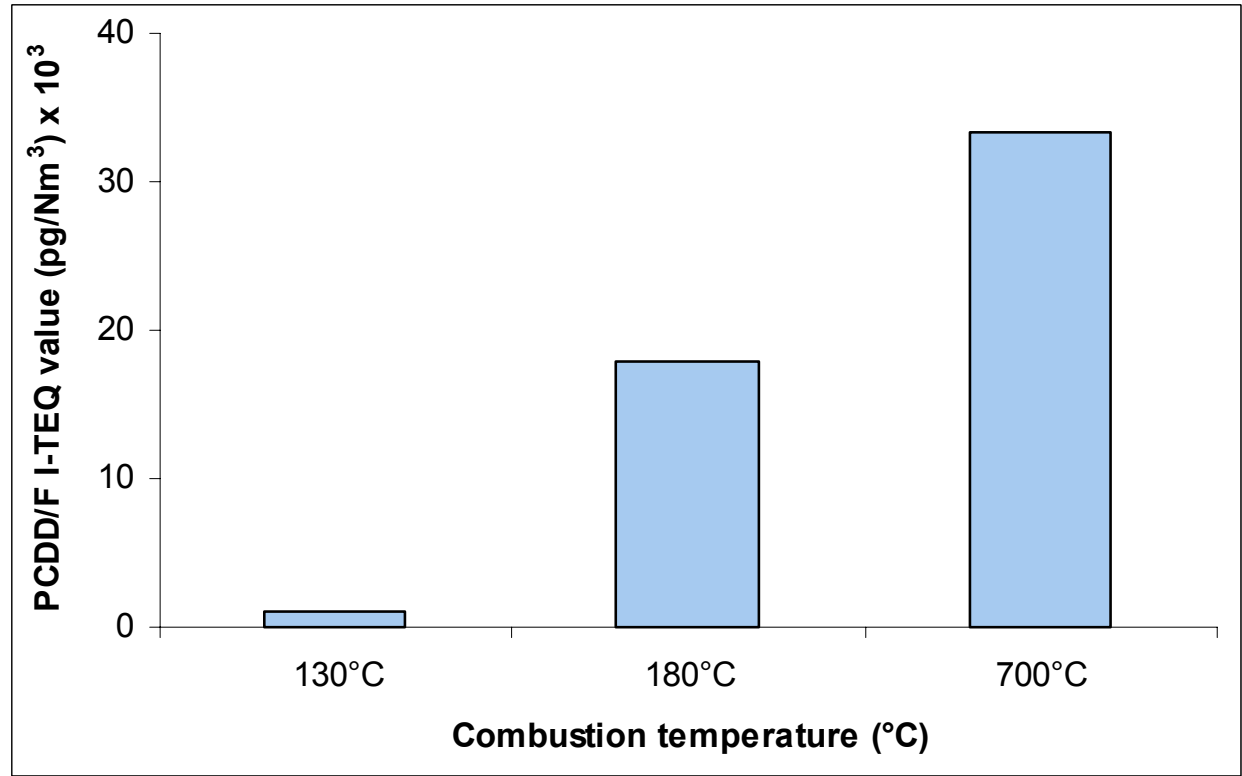

Fig. 5.3: $P C D D / F$ I-TEQ value $\left(\mathrm{pg} / \mathrm{m}^{3}\right)$ in poplar wood and $10 \%$ PVC combustion at different temperatures

Low amount of dioxins is measured for the samples at $130^{\circ} \mathrm{C}$ and much higher at $180^{\circ} \mathrm{C}$. Poplar wood and PVC combustion at $700^{\circ} \mathrm{C}$ show around two times higher $\mathrm{PCDD} / \mathrm{F}$ amount compared to the result at $180^{\circ} \mathrm{C}$. 
The three wood and 10\% PVC sampling campaigns are also analyzed for PCB compounds. The resulted values are shown in Fig. 5.4. and the final PCB concentration for each sample is converted in I-TEQ $\left(\mathrm{pg} / \mathrm{Nm}^{3}\right)$ value. It is noticed that the ratio between the toxicity of the samples corresponding their PCB amount is different compared to the PCDD/F values (Fig. 5.4.). Here, the PCB I-TEQ value for the sample at $130^{\circ} \mathrm{C}$ is at negligible amount. At $180^{\circ} \mathrm{C}$ the $\mathrm{PCB}$ concentration is increased but that value is still around 3 times lower than the same value at $700^{\circ} \mathrm{C}$. The PCDD/F distribution show less than 2 times prevail of the sample combusted at $700^{\circ} \mathrm{C}$. That two comparison show weak correlation between PCDD/F and PCB of the investigated wood and PVC combustion samples.

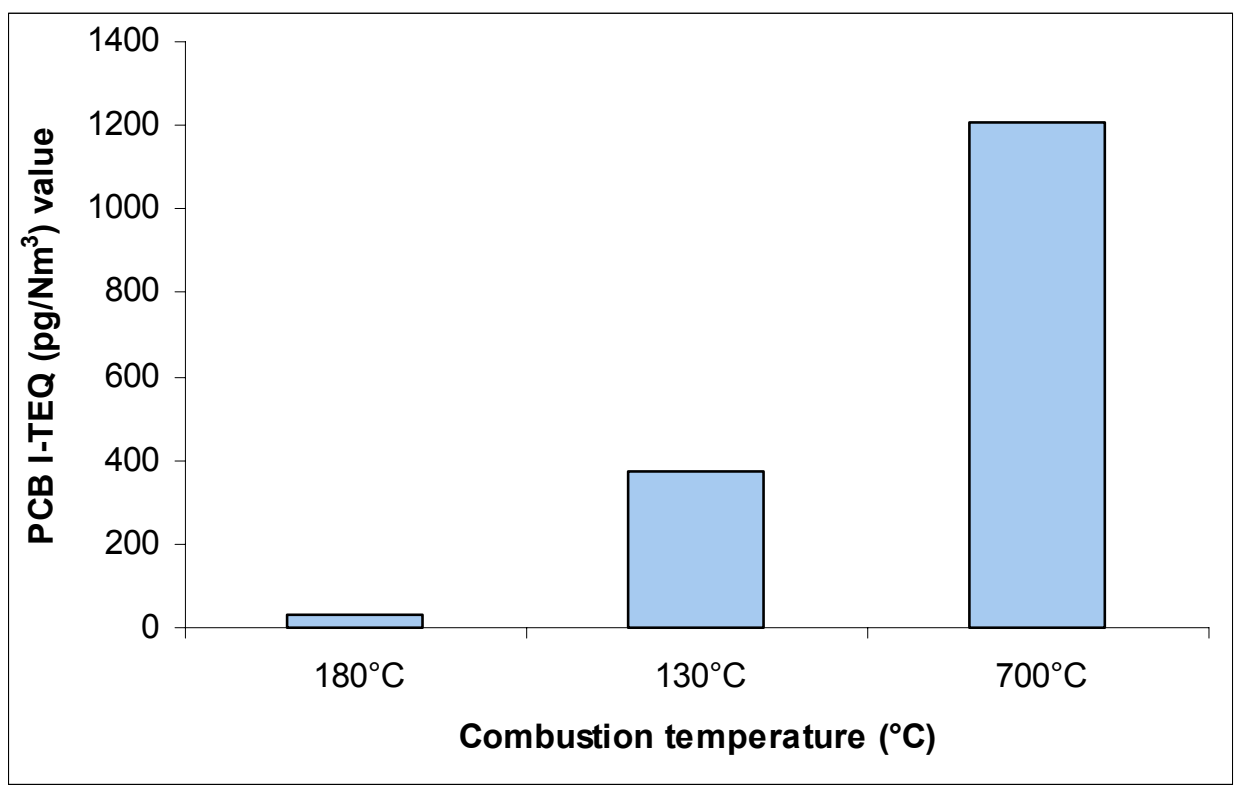

Fig. 5.4: PCB I-TEQ value $\left(\mathrm{pg} / \mathrm{m}^{3}\right)$ in poplar wood and $10 \%$ PVC combustion at different temperatures

\section{Chlorine in feed}

The chlorine content of fuel is obviously an important parameter affecting the PCDD/F formation. Four different sampling campaigns were performed in order to prove the effect of the chlorine in the feed (Fig. 5.5).

These sampling campaigns of wood combustion and 10\% PVC were performed at similar temperatures such as $130^{\circ} \mathrm{C}$ and $150^{\circ} \mathrm{C} ; 180^{\circ} \mathrm{C}-200^{\circ} \mathrm{C}$. The produced dioxins in wood / $10 \%$ PVC combustion are slightly higher at $130^{\circ} \mathrm{C}$ compared to the PCDD/F I-TEQ values at $150^{\circ} \mathrm{C}$ during the wood combustion campaign. Wood / $10 \%$ PVC combustion gives much higher PCDD/F values even at $180^{\circ} \mathrm{C}$ compare to the amount at $200^{\circ} \mathrm{C}$ in wood combustion. The toxicity of the sampling campaign 
performed with chlorine in the feed is as 12 times as high than the one without chlorine in the feed.

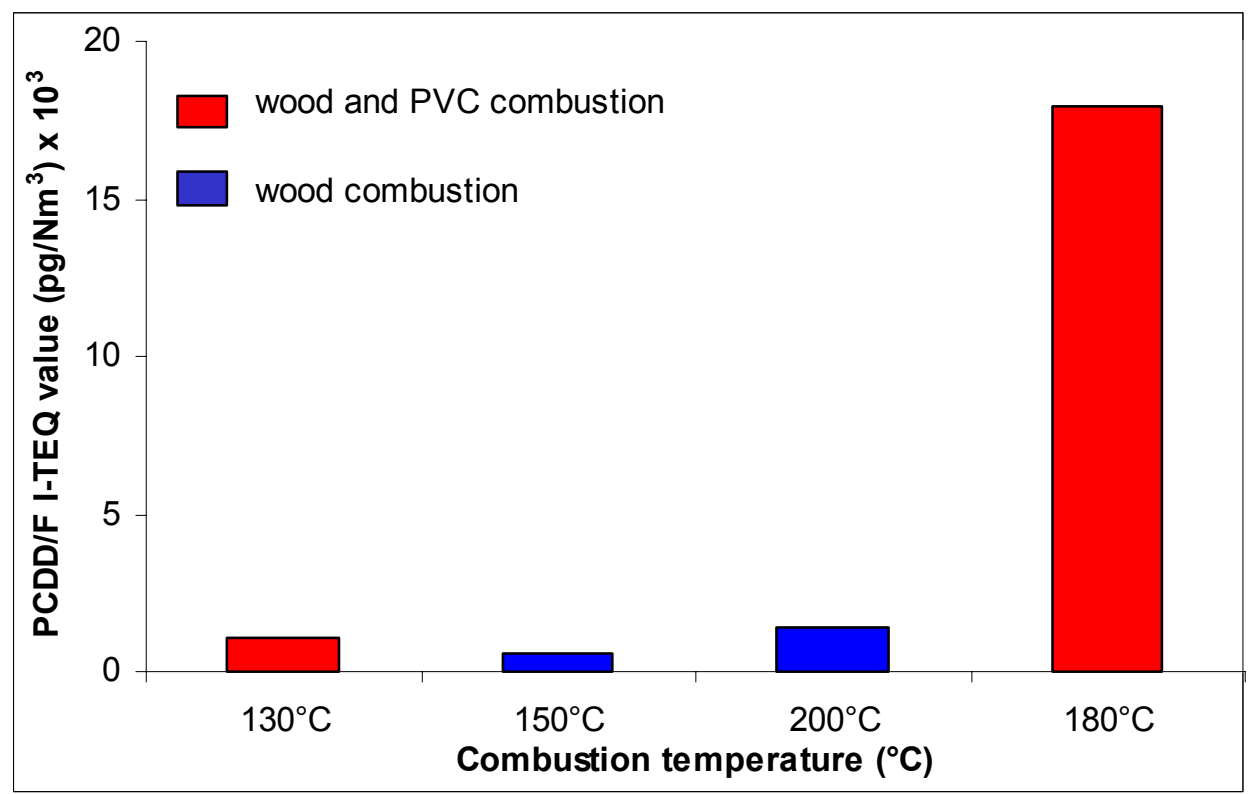

Fig. 5.5: PCDD/F I-TEQ value $\left(\mathrm{pg} / \mathrm{m}^{3}\right)$ in wood and wood/10\% PVC combustion campaigns at similar temperatures

$\mathrm{O}_{2}, \mathrm{CO}_{2}$ and $\mathrm{CO}$ content

The flue gas concentration and the PCDD/F I-TEQ values of four sampling campaigns in wood/ $10 \%$ PVC combustion were studied in order to find out the correlation between them (Fig. 5.6).

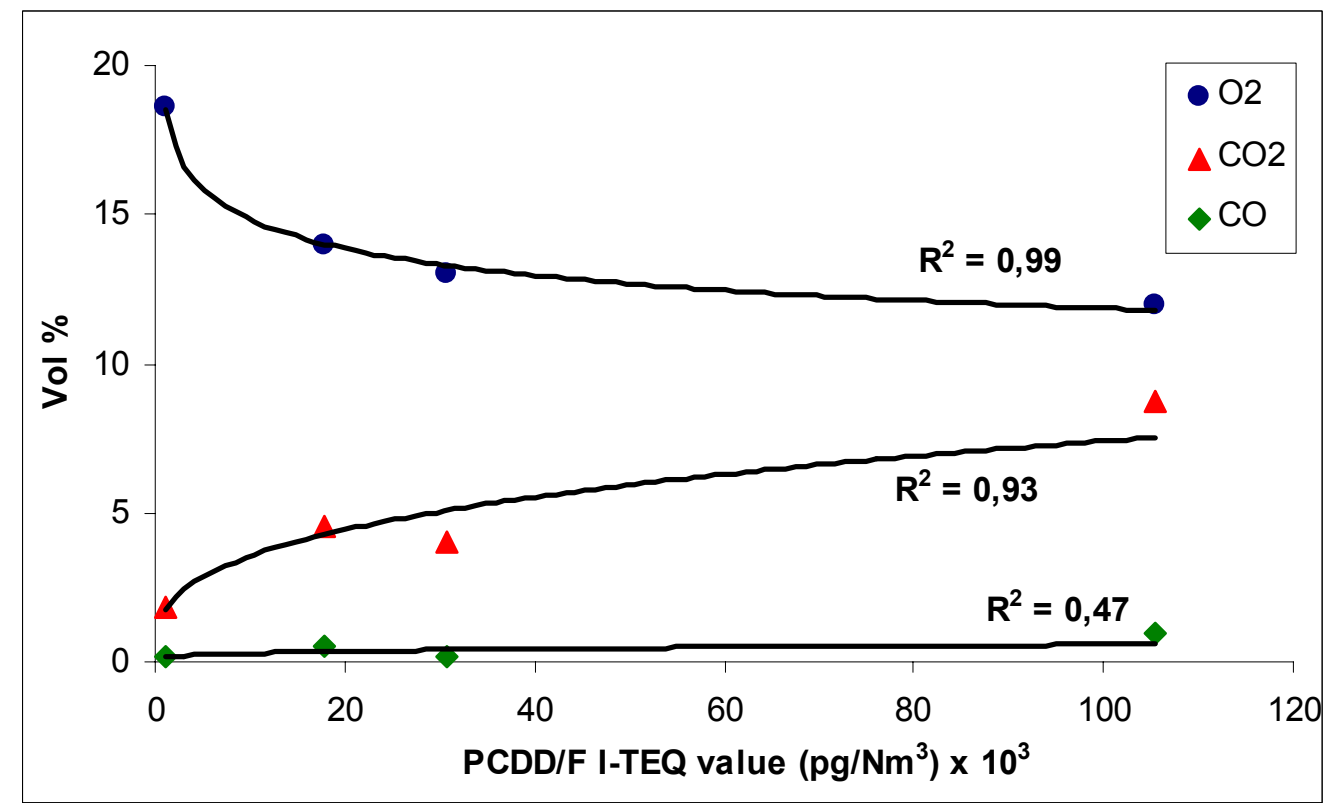

Fig. 5.6: Correlation between PCDD/F I-TEQ value $\left(\mathrm{pg} / \mathrm{m}^{3}\right)$ and $\mathrm{O}_{2}, \mathrm{CO}_{2}$ and $\mathrm{CO}$ gas concentration (Vol \%) in wood $10 \%$ PVC combustion campaigns 
$\mathrm{O}_{2}, \mathrm{CO}_{2}$ and $\mathrm{CO}$ were analyzed just before sampling on TESTO gas analyzer. Because of problems with the instrument during some of the sampling campaigns, not all combustion tests have been analyzed for the mentioned gases.

It is obvious that with increasing PCDD/F concentration, the volume percentage of the $\mathrm{CO}_{2}$ is augmenting slowly from around $1 \mathrm{Vol} \%$ to around $9 \mathrm{Vol} \%$. The opposite effect is observed for the analyzed $\mathrm{O}_{2}$ concentration which drops from $19 \mathrm{Vol} \%$ to 12 Vol\%. CO is mainly zero or slightly increased with the increase of the toxicity of the investigated samples. Very good correlation $R^{2}=0.93-0.99$ is found between $\mathrm{O}_{2}$ and $\mathrm{CO}_{2}$ gases and PCDD/F I-TEQ value. A weak dependence has been calculated for the $\mathrm{CO}$ concentration and PCDD/F emissions

\section{Discussion}

The experimental results of the performed sampling campaigns show that temperature of $200-500^{\circ} \mathrm{C}$ promotes $\mathrm{PCDD} / \mathrm{F}$ formation while temperature greater than $700^{\circ} \mathrm{C}$ destroy the same substances. At temperatures between $130^{\circ} \mathrm{C}$ and $200^{\circ} \mathrm{C}$ the PCDD/F amount is negligible. These conclusions are in a good agreement with the de novo theory and the experimentally confirmed high emissions of PCDD/F in the temperature range of $250-450^{\circ} \mathrm{C}$. The de novo theory suggests that the combustion of organic matter at high temperature of $750-1000^{\circ} \mathrm{C}$ and a short period of cooling from the incinerator to $300^{\circ} \mathrm{C}$ is a main source of PCDD/F [31]. Such conditions of fast cooling flue gases chimney are met in the investigated sampling campaigns. Probably at that time leaving the chamber gases were involved in surface reactions including different compounds of incomplete combustion and in combination with the condensate processes the high dioxins emissions were caused. Temperature of $500^{\circ} \mathrm{C}$ is found as a optimal temperature for PCDD/F formation in such type of incineration. Stimulated combustion conditions in an Entrained Flow Reactor by Wikström have shown also a maximum rate of PCDD/F between 300$400^{\circ} \mathrm{C}[46]$.

Tuppurainen have observed that the amount of PCDD/F does not depend on the temperature in the range of $750-1200^{\circ} \mathrm{C}$ because their destruction is already completed [9]. This means that dioxins are not thermodynamically stable at high combustion temperature. At such temperature the dioxins emission is minimized because some dehalogenation reactions is favour. The proposed results show also 
lower PCDD/F I-TEQ values at $700^{\circ} \mathrm{C}$ compared to the same values at $500^{\circ} \mathrm{C}$ for example.

The PCB results for the sampling campaigns of wood and PVC incineration show much lower I-TEQ values compared to the dioxins concentration. Explanation of that is the lower PCB toxic equivalent factors (TEF) in comparison to the TEF for dioxins. The toxicity ratio in dependence of PCB and PCDD/F concentration is also different for the different samples. This gives the idea of different formation mechanisms of PCB and PCDD/F. The same statement by the help of statistical analysis is also proposed by Blumenstock [51]. Different emission samples of waste wood chips sampled in a waste incineration plant display no correlation between these two classes of toxic compounds.

When wood and $10 \%$ PVC are combusted at $180^{\circ} \mathrm{C}$, enormous difference in PCDD/F emissions is detected compared to at $200^{\circ} \mathrm{C}$. Because of the lower temperatures at $130^{\circ} \mathrm{C}$ and $150^{\circ} \mathrm{C}$ the effect of the chlorine in the fuel can not be accounted for or it is slightly noticed. Generally the known precursor theory and de novo synthesis involved always chlorine in order to explain the PCDD/F formation. Hence state that the dioxin formation will be an inevitable process unless chlorine can be completely eliminated [9]. The influence of the chlorine in the fuel mixture such as PVC and inorganic chlorine such as $\mathrm{NaCl}$ and the different percentage of such chlorine additives is widely investigated by Wikström [52] [46] [112]. All conclusions suggest that chlorine evolved mostly as $\mathrm{HCl}$ promote dioxin formation. Atomic chlorine is quite reactive and therefore it may react with the surface of carbonaceous material such as lignin of the wood to form species which can continue to react and form PCDD/F.

On the basis of the sampling campaigns that were carried out it has been found that $\mathrm{CO}_{2}$ concentration in the flue gas is positively, and $\mathrm{O}_{2}$ concentration is negatively correlated with the PCDD/F emissions. This dependence affect the I-TEQ value or the toxicity of the examined samples. The same relationship has been also found by Lenoir [47] investigating the influence of the operating parameters on PCDD/F emissions in a fluidized bed incinerator. The experimental results of Fängmark show that high level of $\mathrm{O}_{2}$ resulted in less effective formation of $\mathrm{PAH}, \mathrm{PCDD} / \mathrm{F}, \mathrm{PCB}$ and PCBz [50].

Nevertheless the recent findings show that $\mathrm{CO}$ and $\mathrm{CO}_{2}$ are no surrogates of PCDD/F formation [9]. De novo synthesis suggests that in processes of gasification 
of the carbon in the fuel the major products are $\mathrm{CO}$ and $\mathrm{CO}_{2}$. Further condensation processes in the post combustion zone form some byproducts such as a variety of organic compounds including PCDD, PCDF, PCB, PCBz and etc.

\subsection{PCDD, PCDF and PCB Homologues Profiles}

Knowledge of the congeners patterns and homologues profiles of PCDD/F and PCB is important because the toxicity is related to the concentration distribution of the 17 congeners that are fully chlorinated with in the $2,3,7,8$ positions. To understanding the mechanism of how chlorine partitions among the homologues is able to reduce or increase formation of PCDD/F and PCB and/or reduce or increase the concentration of the 17 congeners that comprise the toxic equivalency (TEQ) value. The effort of the work here is to predict both PCDD/F total (sum of tetra-to octa CDD/F concentration) and TEQ values and PCB total (sum of mono- to deca CB) and TEQ values. Sampling results of wood and wood and PVC combustion and different operation conditions (temperature, gas content, ets.) are used to establish a tool for understanding of the mechanism of PCDD/F and PCB formation and to find methods and controls to prevent their formation.

A pattern analysis has been performed for PCDD and PCDF for the 7 sampling campaigns. The percentage of the homologue pattern for PCB for 3 sampling campaigns is also calculated. The results are presented separately for PCDD and PCDF in Fig. 5.7 and Fig. 5. 8. and for PCB in Fig. 5.9.

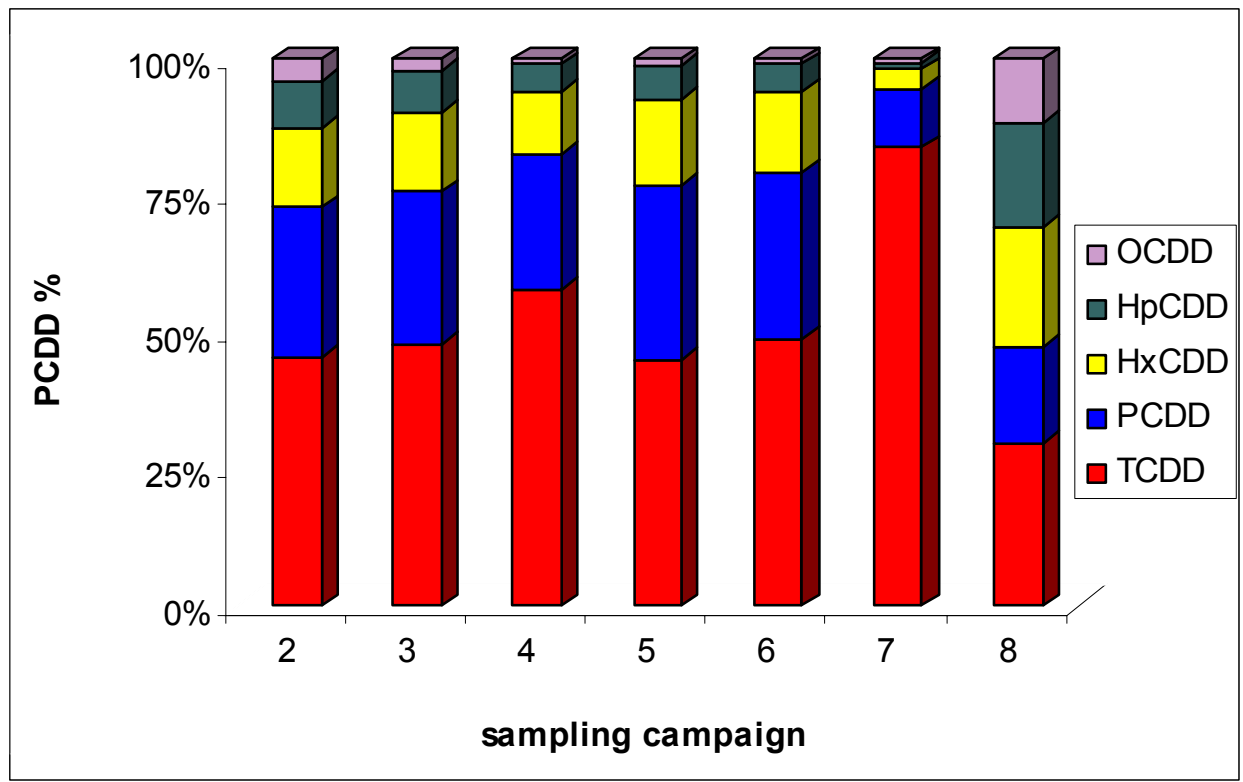

Fig. 5.7: Percentage of PCDD homologues mass distribution of the sampling campaign No.2-8. 


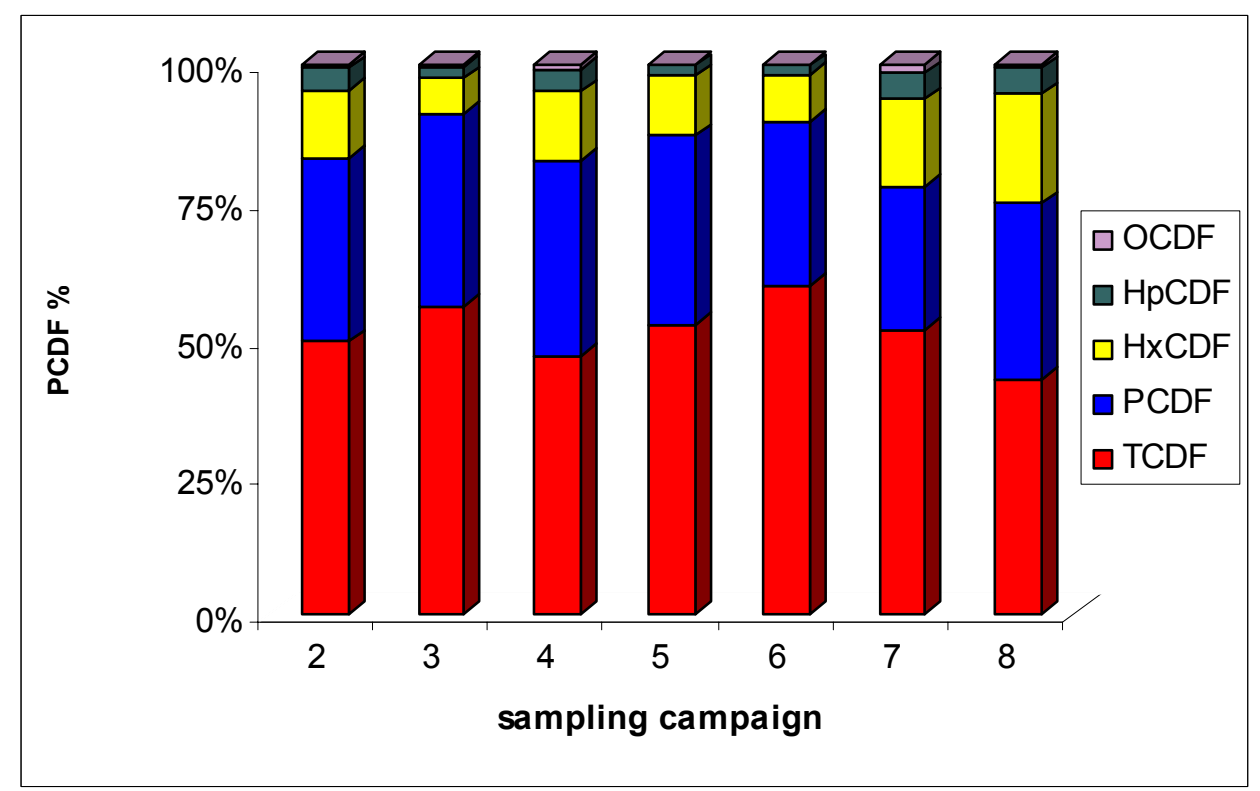

Fig. 5.8: Percentage of PCDF homologues mass distribution of the sampling campaign No.2-8.

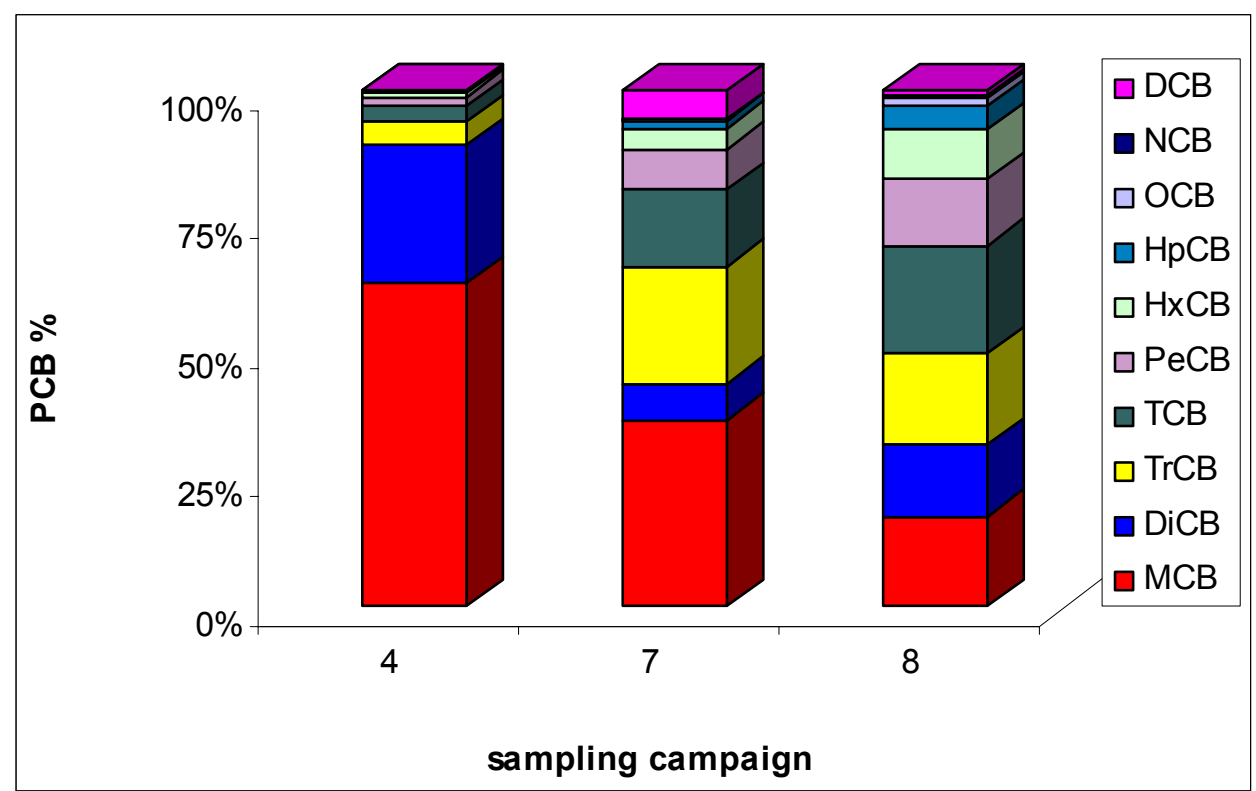

Fig. 5.9: Percentage of PCB homologues mass distribution of the sampling campaign No.4,7 and 8.

Fig. 5.7 shows that for all samples TCDD is the dominant homologue followed by PCDD. HxCDD and HpCDD are present with comparable low percentages but OCDD is almost everywhere in negligible amount. It is observed that sampling campaign 8 , shows very different results for its PCDD pattern. Here, all chlorinated PCDD homologues is present with similar percentage. That sampling campaign is performed at $700^{\circ} \mathrm{C}$ during wood and PVC combustion. In 5.2 it was mentioned that probably during this sampling, destruction reactions of PCDD/F already have occurred. Very high TCDD percentage of around $85 \%$ is estimated for sampling 
campaign No. 7. This sample belongs to wood and PVC combustion at $130^{\circ} \mathrm{C}$. It is known that at that temperature the PCDD/F formation is still not active and here the measured I-TEQ value is low. The other wood and PVC sampling campaign No. 4 is characterized also by a different and slightly higher percentage for TCDD pattern compared to the same TCDD homologue measured during wood combustion.

The percentages of the PCDF homologues shown in Fig. 5.8. indicate very similar results. The dominance of the PCDF homologues is of the following order: TCDF $>$ PCDF $>\mathrm{HxCDF}>\mathrm{HpCDF}>\mathrm{OCDF}$.

The percentage of MCB-DCB homologues during the three wood and PVC sampling campaigns is drawn in Fig. 5.9. The pattern analysis shows very different results for the three samples. Sample No. 4 is an example for optimal conditions of PCDD/F and PCB formation (Fig. 5.3. and Fig. 5.4.) while during sampling campaign No. 7 the PCDD/F and PCB are not formed. Sample No.4 exhibits high percentage for MCB and DiCB. The other PCB patterns such as TrCB - NCB for that sample are present at lower amount compared to lower chlorinated benzenes. The DCB homologue is zero percent. For sample No. 7 the weight patterns are MCB and TrCB followed by TCB. All other chlorinated benzenes are present at lower percentages. DiCB is characterized here at a negligible amount of around $5 \%$.

At $700^{\circ} \mathrm{C}$ during sampling campaign No. 8, the PCDD/F and PCB are already destroyed. The pattern analysis for that sample shows similar percentages during the mono - tetra CB. From penta - deca CB the percentage of these homologues is sufficiently decreased from $13 \%$ to $0.33 \%$.

\section{Discussion}

The experimental results manifest that for all emission samples the lower chlorinated dioxins and furans such as TCDD/F and PeCDD/F prevail over the higher chlorinated ones, in agreement with the typical homologues pattern from combustion processes $[2,113,114]$. The same statement is also true for PCB homologues patterns. Cycloaddition of two chlorophenyl radicals gives polychlorinated biphenyls and PCB compounds even at a lower temperature [9]. PCB can be oxidized and are thus possible precursors for PCDF. In general, the reactivity of the higher chlorinated compounds with oxygen is high and this can explain why they are almost absent from all products of incomplete combustion such as PCDD/F, PCB, PCBz etc. During sampling campaign No. 4 the optimal condition of PCDD/F and PCB formation are 
met. Thus the measured I-TEQ values are also high. For this sample the most dominant is MCB pattern and the abundance of the followed homologues gradually decrease.

The pattern PCDD/F and PCB analysis remains difficult to explain the results regarding the homologues amounts for sample No. 8. Probably because of the higher temperatures some decomposition reactions are preponderant and other mechanisms take place. Thus, the typical homologues pattern for combustion processes are also destroyed. An example where the incineration conditions are characterized by low combustion temperature, high $\mathrm{O}_{2}$ and low $\mathrm{CO}_{2}$ and $\mathrm{CO}$ gas content or generally conditions which are not optimal for PCDD/F and PCB formation, is sample No. 7. In addition the aromatic compounds can participate in various decomposition reactions where the amount of the oxygen is stoichiometric or less. Then, the final products are carbon dioxide and water and the PCDD/F and PCB ITEQ values are very low. For sample No.7 also the pattern analysis shows particularly different results compared to the homologues pattern of sample No.4. The result of Fig. 5.6. show very high TCDD amount. That can be explained only by the higher total sum amount of the rest TCDD isomers. A peculiarity for sample No. 7 is also the PCB homologues behaviour. Normally the most dominant compounds for such emission samples are the lower chlorinated benzenes [114] and their dominance decrease with increasing the chlorine in the benzene ring. For sample No.7 this distribution is not observed. Here, the most abundant homologue are MCB and TrCB, the next dominant homologues are TCB and DiCB is present with a negligible percentage. Lenoir proposed that via condensation reaction in the postcombustion zone in the gas phase, molecular growth reactions of alkyl and chlorinated vinyl radicals might turn out to be important reaction channels to formation of chlorinated aromatics [36]. In the same work it is also mentioned that the octachlorinated PCDD/F isomers are supposed to be formed first, while the other dioxins are subsequently produced through dechlorination of the higher chlorinated isomers. So it is possible that the same mechanism is also valid for the PCB formation. This can explain why MCB and especially DiCB are present at lower percentage for sample No.7. 
$P C D D, P C D F$ and PCB Concentrations. Congeners profile

The actual concentrations of the investigated aromatic compounds presented in $\left(\mathrm{pg} / \mathrm{Nm}^{3}\right)$ for the 7 sampling campaigns are additionally calculated. The view of such type analysis makes possible to look over the ratio between the dioxin/furan and to find the differences between sample to sample according their congeners pattern. The congeners whose concentrations which correlate strongly with the corresponding high or low TEQ of the samples can be easily detected.

The sum of the PCDD and PCDF homologues for the 7 emission samples are shown in Fig. $5.10(A)$ and $(B)$.

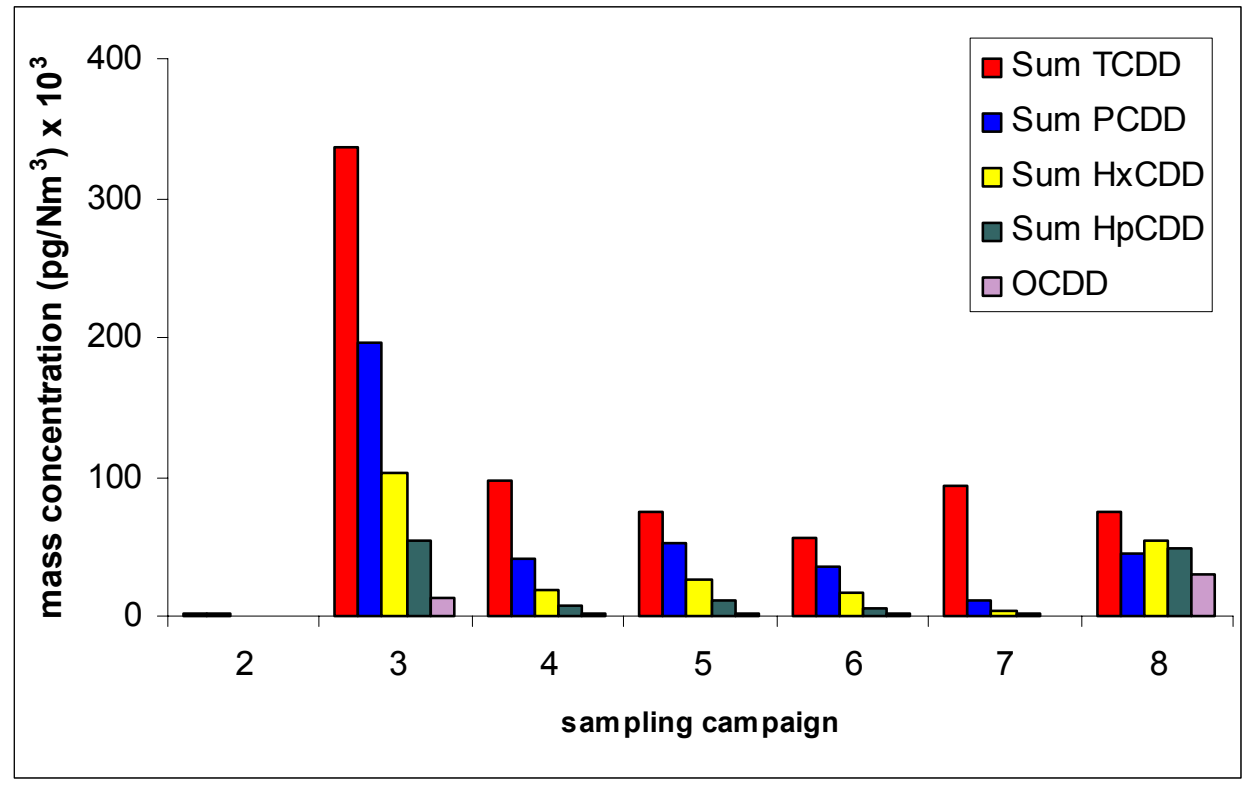

A

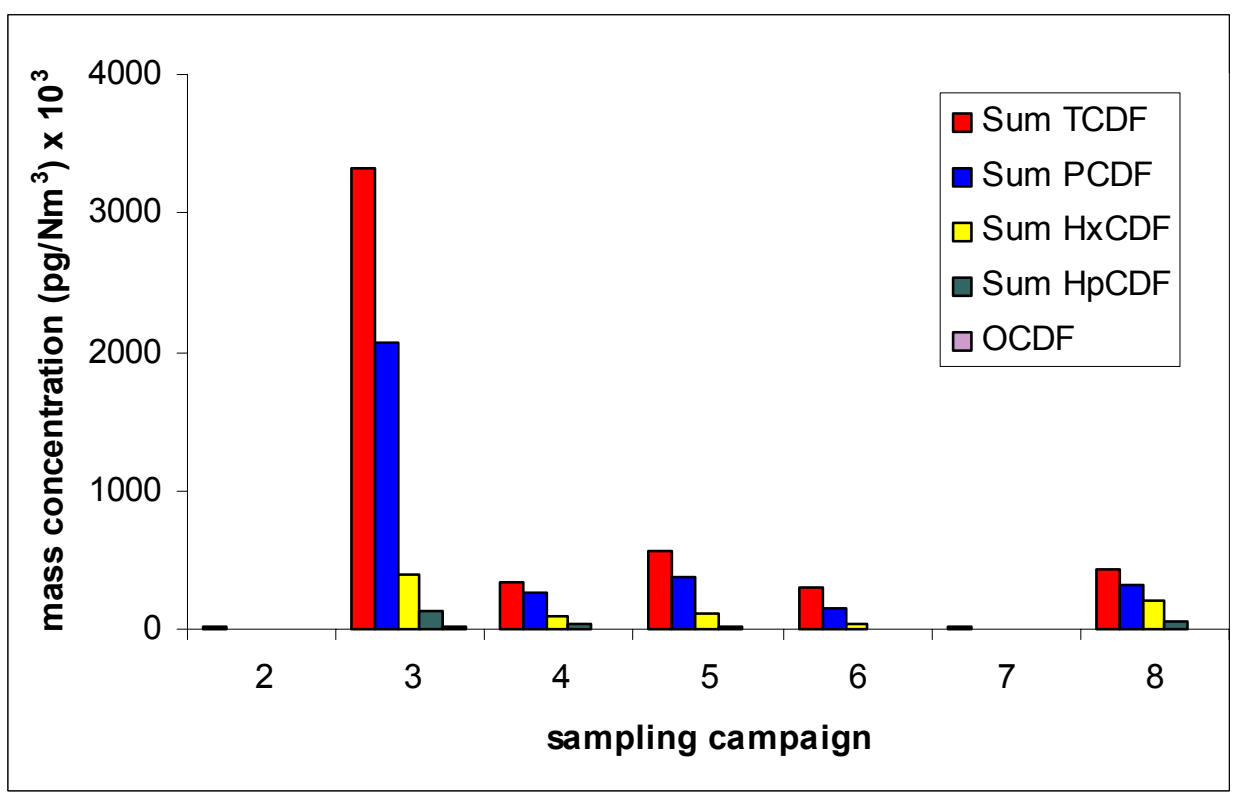

B

Fig. 5.10: Sum of tetra-octa PCDD (A) and sum of tetra-octa PCDF (B) for sampling campaign No. 2-8 
It is clear that the PCDF content is higher than the PCDD amount for all samples. The estimated exhibit ratio is 9 times more abundant furans than dioxins. Sample No. 3 is representing the most abundant PCDF in an emission sample. In the other samples the PCDD amount is about 5 times less compared to PCDF.

It is obvious that samples No. 3-6 in Fig. 5.10. (A) and (B) decrease gradually their tetra to octa chlorinated PCDD and PCDF amount. Samples No. 2 and 7 are present with low PCDD/F amount but the distribution of the chlorinated homologues is similar to that of the other sample. The much higher sum of TCDD for sample No. 7 is an exception among the other PCDD/F homologues. Samples No 2 and 7 belong to samples with lower TEQ. According to Fig. 5.10. (A) and (B) samples 8 has similar to samples 4,5 and 6 abundance. However the TCDD-OCDD distribution of the chlorinated dioxins for this sample is different. In Fig. 5.11. (A) the amount of PeCDD to OCDD for sample No. 8 is similar.

The sums of mono to deca polychlorinated biphenyls (PCB) concentrations $\left(\mathrm{pg} / \mathrm{Nm}^{3}\right)$ for samples No. 4,7 and 8 are shown in Fig. 5.11.

The comparison of the PCB amount in Fig. 5.11 with that of Fig. 5.10 where the sums of PCDD/F homologues are shown, lead to the conclusion that the concentration of PCB compounds in sample No. 4 is much higher than that of dioxins and furans. These are mainly mono and dichlorinated biphenyls present.

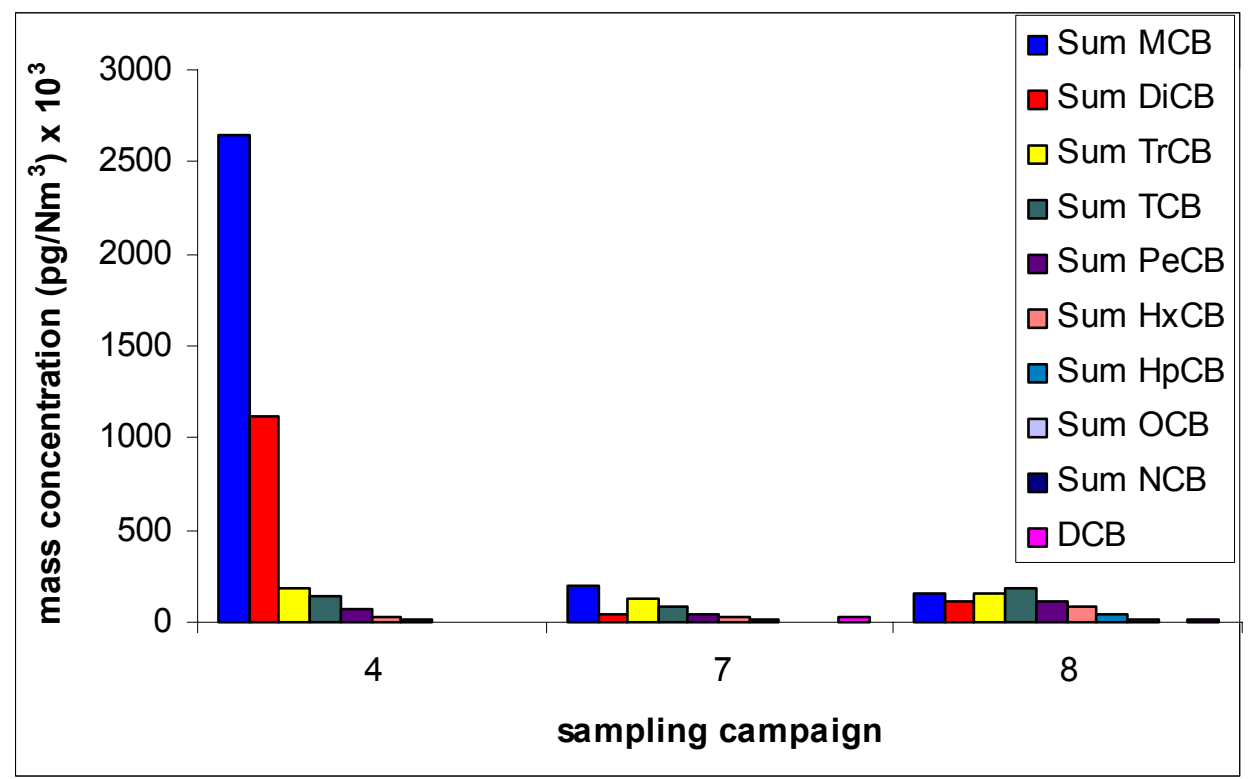

Fig. 5.11: Sum of mono-deca PCB for sampling campaign No. 4,7 and 8.

Sample No. 7 is identified with low PCDD/F and PCB values. It is noticed that sample No. 8 has lower PCB amount compared to PCDF and similar to PCDD value. 
According to the high PCB I-TEQ value (Fig. 5.4.) of sample No 8, also here in Fig. 5.11. high abundances PCB homologues supposed to be detected. Probably the explanation could be the high abundance of some PCB congeners presented with high TEF. Thus, a knowledge of the concentrations of the 12 toxic PCB isomers is indispensable. The distribution of these isomers for the three emission samples is shown in Fig. 5.12.

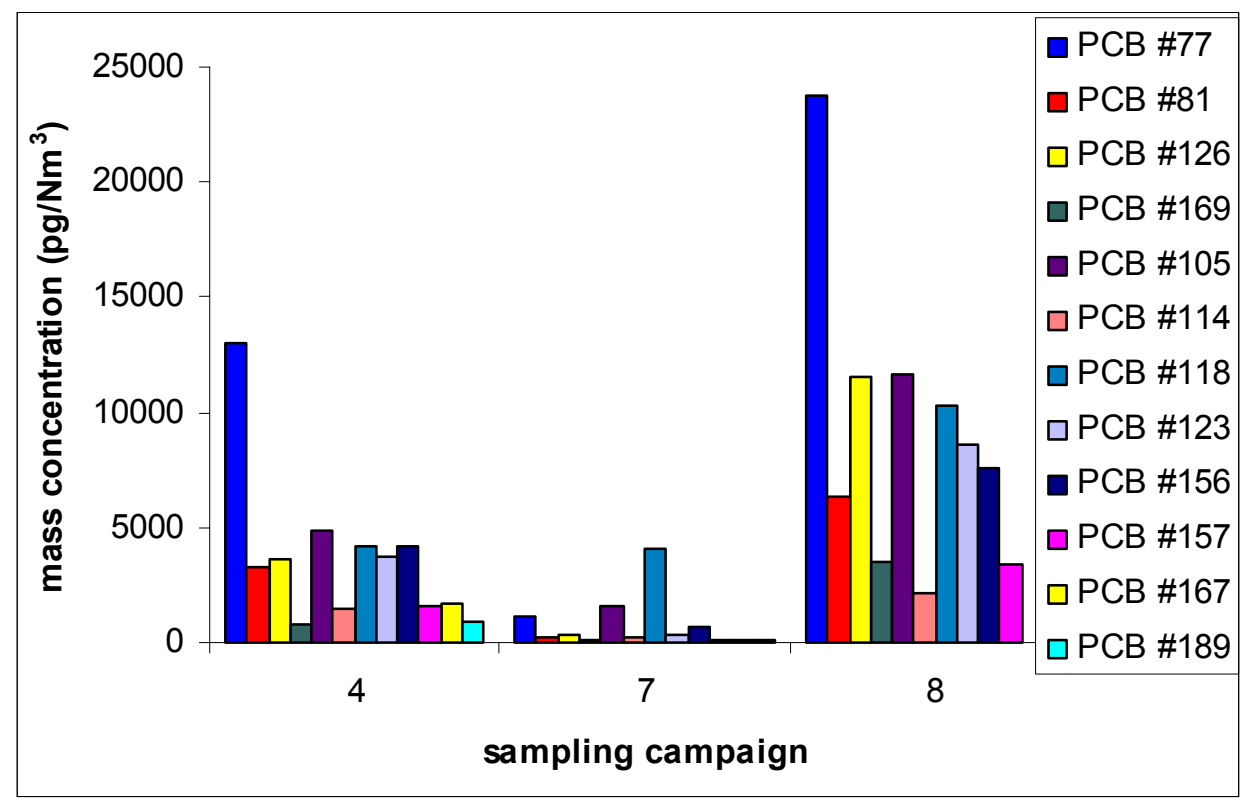

Fig. 5.12: Mass concentration of the 12 toxic PCB congeners for samples No. 4,7 and 8

Since PCB \#126 is the most toxic congener (TEF=0.1) the PCB I-TEQ is strongly dependant of the concentration of that isomer. The next isomer with also high TEF = 0.01 is PCB \#169. Fig. 5.12 shows that both congeners are highly present in sample No.8. Thus, the measured I-TEQ amount is also high and considering the sum of the PCB homologues makes clear that the concentration of the rest non-toxic PCB isomers is low. Sample No. 8 is present with highest PCB emissions for the 12 toxic congeners. Low values for the mentioned congeners are detected for sample No. 7 , and slightly higher values are measured for sample No. 4 .

The mass concentrations $\left(\mathrm{pg} / \mathrm{Nm}^{3}\right)$ of the 17 toxic PCDD and PCDF isomers for samples No. 2-8 are shown in Fig. 5.13. The recent values shows the strong correlation between the PCDD/F I-TEQ amount and some of the most toxic congeners like 2,3,7,8-TCDD, 1,2,3,7,8-PCDD and 2,3,4,7,8-PCDF. The more abundant the congeners such as 2,3,7,8-TCDD, 1,2,3,7,8-PCDD and 2,3,4,7,8-PCDF are the more toxic the corresponding samples are. Such examples are samples No. 3 and 8 which are present with a high emission of the above mentioned congeners. Both samples are presented also with a high amounts of 1,2,3,4,6,7,8-HpCDD and 
OCDD. Samples No. 2 and 7 show also a negligible or almost zero PCDD/F amount for the 17 toxic congeners. These results are in a good agreement with their I-TEQ values. The other samples No. 4,5 and 6 are also present with comparable 2,3,7,8TCDD, 1,2,3,7,8-PCDD and 2,3,4,7,8-PCDF amount like their PCDD/F I-TEQ values.
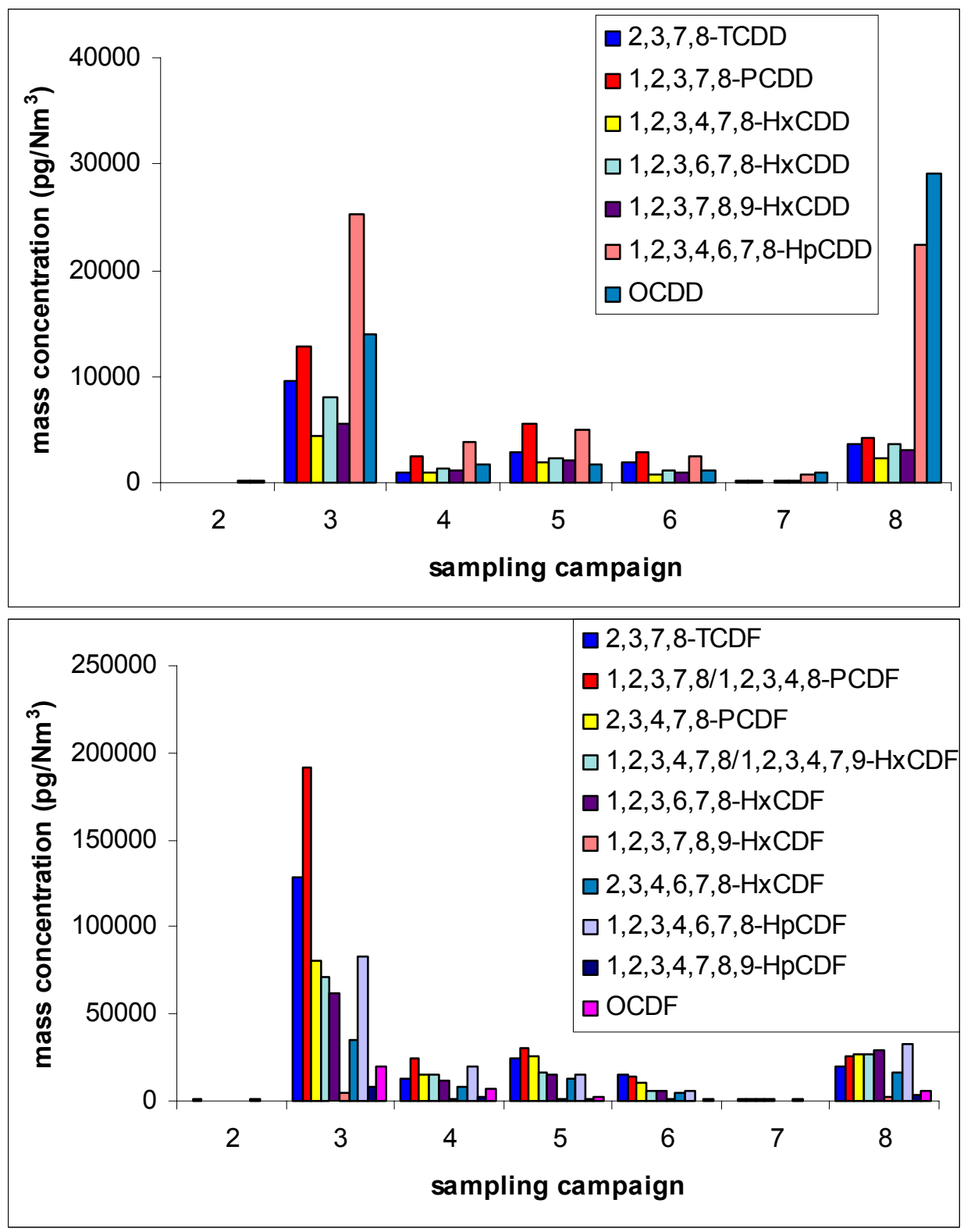

Fig. 5.13: Mass concentration of the 17 toxic PCDD/F congeners for sample No. 2-8.

\section{Discussion}

The PCDF concentrations of the 7 emission samples are between 5-9 times higher than the concentrations of PCDD. Recent finding in pilot plant incinerators indicate similar PCDD/PCDF ratios for different combusted emission samples [2, 65, 115, 116]. Huang has compared de novo synthesis and the precursor theory and has 
proposed that the typical homologues profile for de novo synthesis in actual incinerators is present if the furan/dioxin ratio is higher than 1. In contrast in formation from precursors small amounts of furans are produced and the furan/dioxin ratio is smaller than 1 [29] .

In addition, as shown in Fig. 5.11., the lower chlorinated PCDD/F homologue pattern prevailed over the higher chlorinated, in accordance with the typical profile from combustion process. The same findings are also valid for sample No. 4 and No. 7 concerning their PCB homologues profile. Relatively low PCB abundance and high ITEQ are estimated for sample No. 8. This is due to the higher concentrations of most toxic congeners \#77, \#126 \#169 and \#105. The rest isomers and generally the monodeca homologues are shown in Fig. 5.10 at low amounts.

The most toxic congeners all over the PCDD/F such as 2,3,7,8-TCDD, 1,2,3,7,8PCDD and 2,3,4,7,8-PCDF show a good correlation with PCDD/F I-TEQ value for all samples. 


\subsection{Laboratory scale experiments}

In this study, a laboratory-scale furnace is used to perform a series of experiments aiming at prevent the formation of PCDD/F by the use of inhibitors. The objective of this work is to identify the most effective low cost and low toxicity inhibitors for PCDD/F, making them applicable for use in full-scale combustion units. A mixture of lignite coal, solid waste and PVC is combusted in a laboratory-scale furnace at $400^{\circ} \mathrm{C}$. The most effective inhibitor is also studied at $1000^{\circ} \mathrm{C}$.

\subsubsection{Optimization of the experiment}

Laboratory experiments are known to be very sensitive scale to different factors. Thus, the executed procedure should be carefully identified and carried out in the same manner each time in order to achieve reproducible results. The parameters of main importance are: homogenization of the fuel, fuel content, temperature, air flow and duration of the experiment. Blank samples are generated frequently. The analytical procedure includes clean-up steps and further quantification analysis of PCDD/F, PCB and PCBz is performed on a HRGC/HRMS. Many different experiments are performed in order to elaborate the optimum procedure where the emitted toxic emissions are high enough to study the inhibition processes.

\section{Homogenization of the combustion fuel}

Fuel mixture of $10 \mathrm{~g}$ lignite coal $(80 \%)$ and solid waste $(20 \%)$ is combusted at $300^{\circ} \mathrm{C}$ with $2 \mathrm{~L} / \mathrm{min}$ air flow for $15 \mathrm{~min}$. Prior to the experiment, each fuel of sample 0206016 is stirred with a mechanical mortar to generate a particle size of less than $1 \mathrm{~mm}$. Another sample 0206015 with non stirred solid waste is also combusted employing the same procedure. Both samples are analyzed for PCDD/F. The difference between the results are quite large. Sample 0206015 shows much higher PCDD/F values than sample 0206016 (Tab 5.8).

Tab. 5.8: PCDD/F I-TEQ value (pg/g) of homogenized and not homogenized combusted fuel samples

\begin{tabular}{|c|c|}
\hline Sample number & PCDD/F I-TEQ \\
\hline 0206015 & 4.75 \\
\hline 0206016 & 0.33 \\
\hline
\end{tabular}




\section{Combustion temperature}

The content of compounds added to the fuel was $10 \%$. The results of the most toxic 17 PCDD and PCDF congeners for these samples are shown in Fig. 5.14.
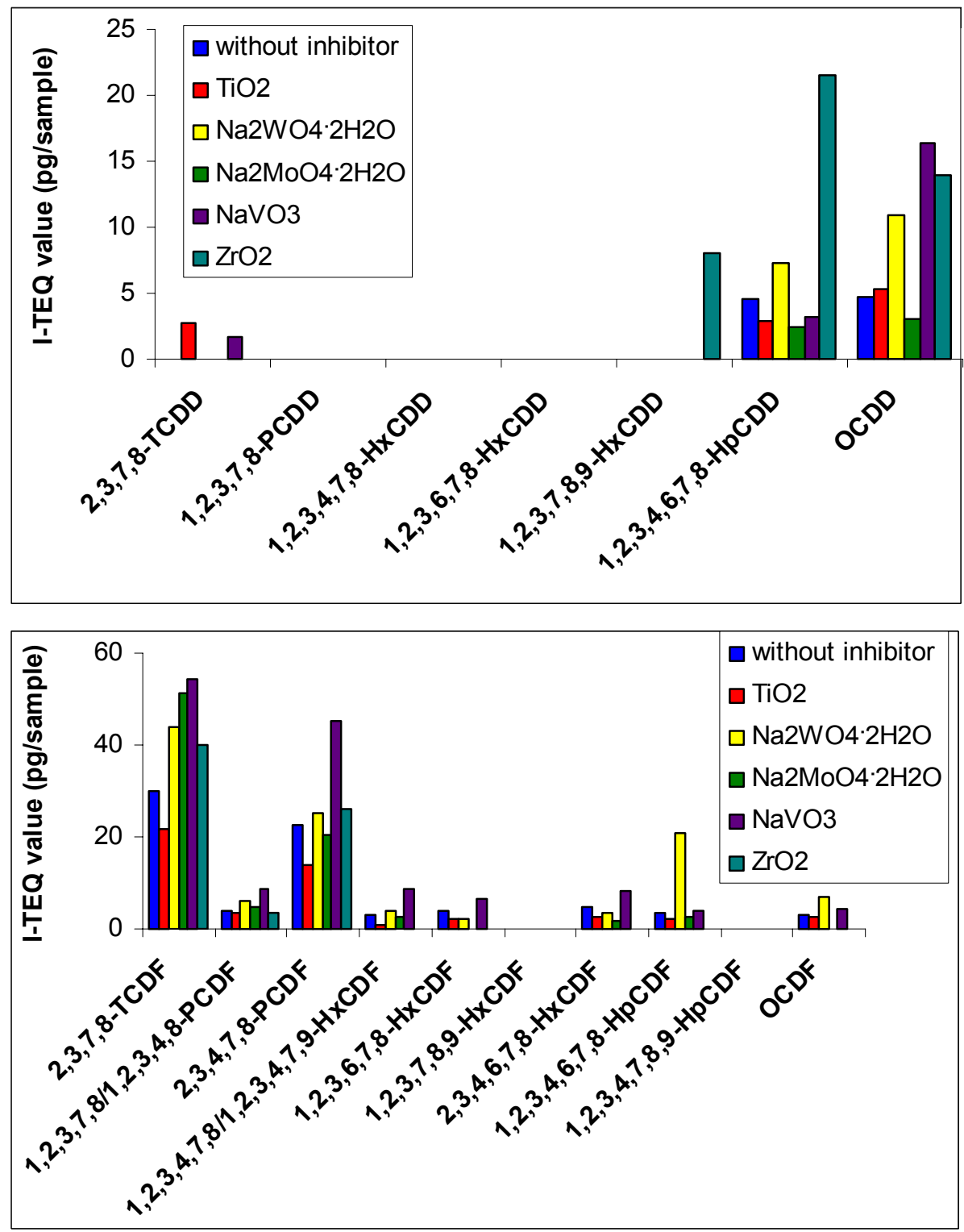

Fig. 5.14: I-TEQ values (pg/sample) of the 17 toxic PCDD and PCDF congeners emitted during fuel combustion at $500^{\circ} \mathrm{C}$ in a laboratory scale furnace.

Before the optimization of the operation procedure for combustion, temperature of $500^{\circ} \mathrm{C}$, duration of the experiment $15 \mathrm{~min}$ and $2 \mathrm{~L} / \mathrm{min}$ air flow were used to investigate the effect of $\mathrm{TiO}_{2}, \mathrm{Na}_{2} \mathrm{MoO}_{4} \cdot 2 \mathrm{H}_{2} \mathrm{O}, \mathrm{Na}_{2} \mathrm{WO}_{4} \cdot 2 \mathrm{H}_{2} \mathrm{O}, \mathrm{NaVO}_{3}$ and $\mathrm{ZrO}_{2}$ as inhibitors. 
Fig. 5.14. shows that the most toxic TCDD, PeCDD and HxCDD and some HxCDF and HpCDF congeners are not detected in the sample treated without inhibitor. The lack of these values means that the performed combustion procedure is not favorable for the PCDD/F formation. Thus, the effect of the used inhibitors cannot be further discussed. However, $\mathrm{TiO}_{2}$ and $\mathrm{NaVO}_{3}$ show some low values for the most toxic $\mathrm{PCDD} / \mathrm{F}$ isomer 2,3,7,8-TCDD. This result should be taken into account for further experiments where these two compounds are used as inhibitors. It was also noticed that results for the sample without inhibitor are not always the highest values compared to the corresponding results of the five samples treated with inhibitors.

Samples of $10 \mathrm{~g}$ stirred lignite coal $(80 \%)$ and solid waste $(20 \%)$ were combusted for $15 \mathrm{~min}$ at $400^{\circ} \mathrm{C}$ with $2 \mathrm{~L} / \mathrm{min}$ air flow (sample number 0206022). The resulting PCDD/F and PCB I-TEQ values are compared to the results at $300^{\circ} \mathrm{C}$ and $500^{\circ} \mathrm{C}$ in Tab. 5.9.

Tab. 5.9: PCDD/F and PCB I-TEQ values (pg/g) for samples combusted at $300^{\circ} \mathrm{C}, 400^{\circ} \mathrm{C}$ and $500^{\circ} \mathrm{C}$.

\begin{tabular}{|c|c|c|c|}
\hline Sample number & Combusted $\mathrm{T}^{\circ} \mathrm{C}$ & PCDD/F I-TEQ & PCB I-TEQ \\
\hline 0206016 & $300^{\circ} \mathrm{C}$ & 0.33 & \\
\hline 0206022 & $400^{\circ} \mathrm{C}$ & 2.03 & 0.27 \\
\hline 0207001 & $500^{\circ} \mathrm{C}$ & 1.58 & 0.03 \\
\hline
\end{tabular}

According to the presented data, the highest PCDD/F and PCB values are detected at $400^{\circ} \mathrm{C}$. The laboratory scale results are in disagreement with the pilot scale incineration where the sample with the highest PCDD/F and PCB emissions is achieved at $500^{\circ} \mathrm{C}$.

\section{Fuel material}

Although a temperature of $400^{\circ} \mathrm{C}$ is the optimum for dioxin formation in the laboratory scale furnace the emissions are still not very high. Thus, the addition of PVC to the lignite coal / solid waste mixture is mandatory. On the basis of the pilot scale wood incineration, it is already known that PVC can highly increase the toxic emissions during its cofiring. Therefore the chlorine containing fraction of the fuel mixture is $20 \%$ with a $13.3: 6.7$ ratio of the solid waste to PVC. PVC was present with a particle size $<1 \mathrm{~mm}$. 


\section{Duration of the experiment}

After each experiments the fly ash of the samples was weighted with a balance. It is noticed that at the end of the $15 \mathrm{~min}$ combustion at $400^{\circ} \mathrm{C}$ and $500^{\circ} \mathrm{C}$ the residues fuel were only $15-20 \%$ of the total sample. Thus, extension of the time or an increase of the air flow is required. It was found that $2 \mathrm{~L} / \mathrm{min}$ air flow is suitable value and 30 min experimental time.

\section{Blank samples}

Blank samples are generated before each series of experiments. These results gives information about the memory effect of the furnace. The PCDD/F and PCB I-TEQ values for the performed blank samples are shown in Tab. 5.10.

Tab. 5.10: PCDD/F and PCB I-TEQ values (pg/sample) of the blank samples performed in a laboratory scale furnace

\begin{tabular}{|c|c|c|c|}
\hline $\begin{array}{c}\text { Sample } \\
\text { number }\end{array}$ & Operation conditions & $\begin{array}{c}\text { PCDD/F I-TEQ } \\
\text { value (pg/sample) }\end{array}$ & $\begin{array}{c}\text { PCB I-TEQ } \\
\text { value (pg/sample) }\end{array}$ \\
\hline 0207023 & $500^{\circ} \mathrm{C}, 2 \mathrm{~L} / \mathrm{min}$ air flow, $15 \mathrm{~min}$ & 2.1 & 0.26 \\
\hline 0208003 & $400^{\circ} \mathrm{C}, 2 \mathrm{~L} / \mathrm{min}$ air flow, $30 \mathrm{~min}$ & 1.8 & 0.08 \\
\hline 0301001 & $400^{\circ} \mathrm{C}, 2 \mathrm{~L} / \mathrm{min}$ synthetic air flow, $30 \mathrm{~min}$ & 0.09 & 0.09 \\
\hline 0307001 & $400^{\circ} \mathrm{C}, 2 \mathrm{~L} / \mathrm{min}$ synthetic air flow, 30 min & - & 0.32 \\
\hline 0310056 & $1000^{\circ} \mathrm{C}, 2 \mathrm{~L} /$ min air flow, $15 \mathrm{~min}$ & 2.3 & 0.49 \\
\hline
\end{tabular}

\section{Discussion}

On the basis of the above mentioned experiments the optimal operation parameters where the PCDD/F and PCB values are high enough to investigate the effect of inhibition is temperature: $400^{\circ} \mathrm{C}$; duration of the experiment: $30 \mathrm{~min}$, air flow: $2 \mathrm{~L} / \mathrm{min}$. At these conditions sample 0208002 was generated. The weight of the fly ash after the experiment was measured to be $5.3 \mathrm{~g}$ or about $47 \%$ of the total sample. The evaluated PCDD/F I-TEQ value was $8.74 \mathrm{pg} / \mathrm{g}$ and PCB I-TEQ value is $0.58 \mathrm{pg} / \mathrm{g}$. Such high I-TEQ amounts of the most toxic PCDD/F and PCB congeners show that sample 0208002 can be used as a reference sample for PCDD/F and PCB formation. The results of the blank samples are very low. However, the values for synthetic air as air source are almost negligible or zero. 


\subsubsection{Effect of various inhibitors}

Experiments with a mixture of $80 \%$ lignite coal and 20\% (13.3: 6.7 ratio) solid waste and PVC were performed five times. The sample number of that experiments is 0208002, 0209018, 0209019, 0212010 and 0212015. The 20 different compounds investigated as inhibitors are added as $10 \%$ of the fuel. The sample number of the used 10\% inhibitors is: $0208004\left(\mathrm{TiO}_{2}\right), 0209007\left(\mathrm{MoNa}_{2} \mathrm{O}_{4} \cdot{ }^{\cdot} \cdot 2 \mathrm{H}_{2} \mathrm{O}\right), 0209024$ $\left(\mathrm{NaVO}_{3}\right), 0209005 \quad\left(\mathrm{ZrO}_{2}\right), 0209008 \quad\left(\mathrm{Al}_{2} \mathrm{O}_{3}\right), 0209009 \quad\left(\mathrm{H}_{2} \mathrm{NSO}_{4} \mathrm{H}\right), \quad 0209025$ $\left(\mathrm{H}_{2} \mathrm{NSO}_{3} \mathrm{H}\right), 0209030$ (S), $0210171\left(\mathrm{H}_{2} \mathrm{NSO}_{2} \mathrm{NH}_{2}\right), 0211001$ (pomace), 0211009 $\left(\mathrm{P}_{2} \mathrm{~S}_{5}\right), 0211008\left(\mathrm{Na}_{2} \mathrm{O}_{4} \mathrm{~W} \cdot 2 \mathrm{H}_{2} \mathrm{O}\right), 0211006\left(\mathrm{~N}\left(\mathrm{CH}_{2} \mathrm{CH}_{2} \mathrm{OH}\right)_{3}\right), 0211011\left(\mathrm{Na}_{2} \mathrm{~S} \cdot \mathrm{H}_{2} \mathrm{O}\right)$, $0212007 \quad\left(\mathrm{Cr}_{2} \mathrm{O}_{3}\right), \quad 0301002 \quad\left(\left(\mathrm{NH}_{4}\right)_{2} \mathrm{~S}_{2} \mathrm{O}_{3}\right), \quad 0301005 \quad\left(\left(\mathrm{NH}_{4}\right)_{2} \mathrm{HPO}_{4}\right), \quad 0301006$ $\left(\left(\mathrm{NH}_{2}\right)_{2} \mathrm{CO}+\mathrm{S}(1: 1)\right), 0212016\left(\left(\mathrm{NH}_{4}\right)_{2} \mathrm{SO}_{4}\right)$ and $0211002\left(\left[\left(\mathrm{CH}_{3}\right)_{2} \mathrm{~N}\right]_{3} \mathrm{P}(\mathrm{O})\right)$.

\section{PCDD/F concentration}

The total amounts of PCDD and PCDF generated during the experiments with a mixture of lignite coal, solid waste and PVC are enough to investigate the effect of inhibition along orders of magnitude. The average I-TEQ value of the sum of PCDD/F is about $15 \mathrm{pg} / \mathrm{g}$ (Fig.5.15).

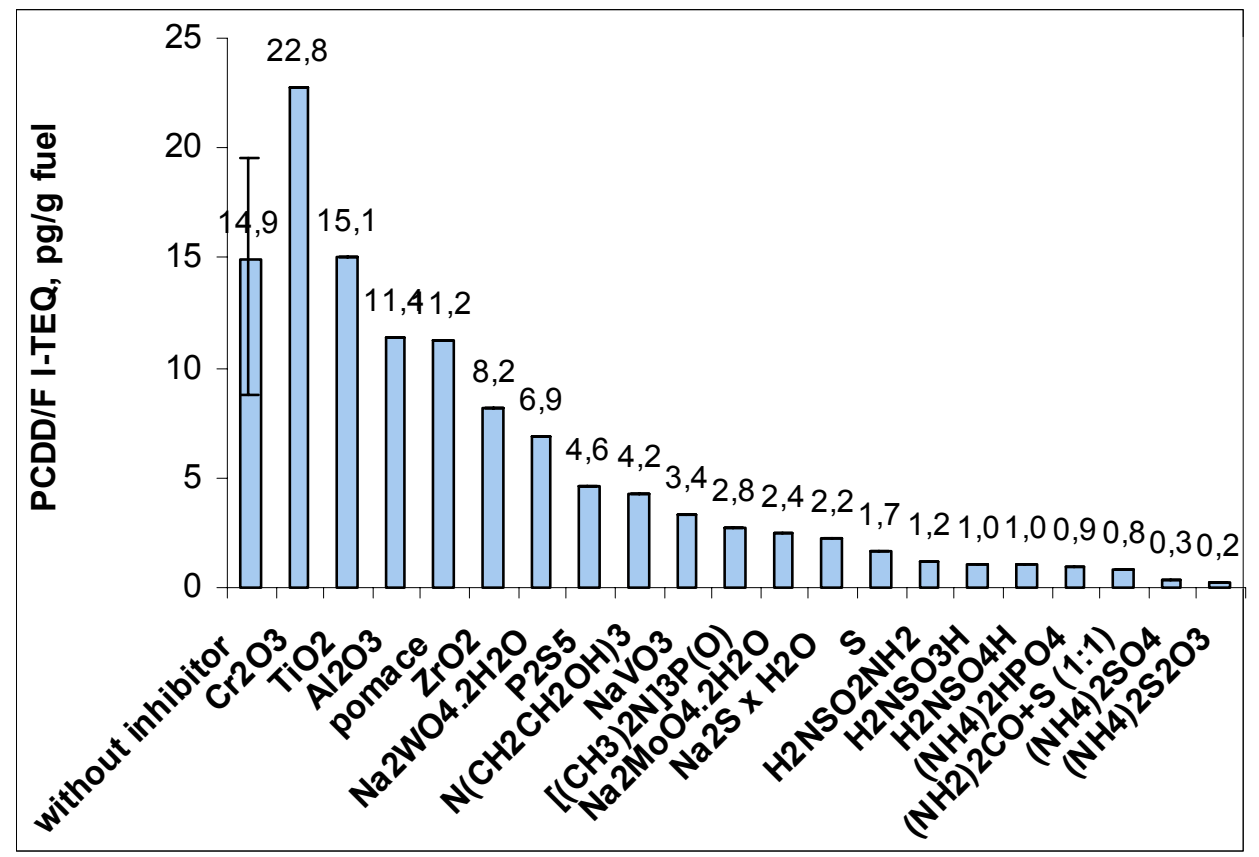

Fig. 5.15: PCDD/F I-TEQ (pg/g) values of the flue gas after combustion of lignite coal, solid waste and $P V C$ for the samples without inhibitor and 20 different compounds used at $10 \%$ inhibitor of the fuel.

(NH4)2SO4 and (NH4)2S2O3 can reduce the PCDD/F emission up to 98-99\%. The performed five replicates show a relatively low standard deviation. The experimental 
results with $10 \%$ inhibitor show very different I-TEQ values. According to Fig. 5.16 some of the compounds led to similar and sometimes higher amount of PCDD/F compared to the samples without an inhibitor. Some other additives show a very strong inhibitory effect in the flue gases.

\section{PCB concentration}

The average I-TEQ value of the sum of PCB for the samples treated without inhibitor is about $1 \mathrm{pg} / \mathrm{g}$ (Fig.5.16). The five replicates show a relatively low standard deviation similar to $\mathrm{PCDD} / \mathrm{F}$.

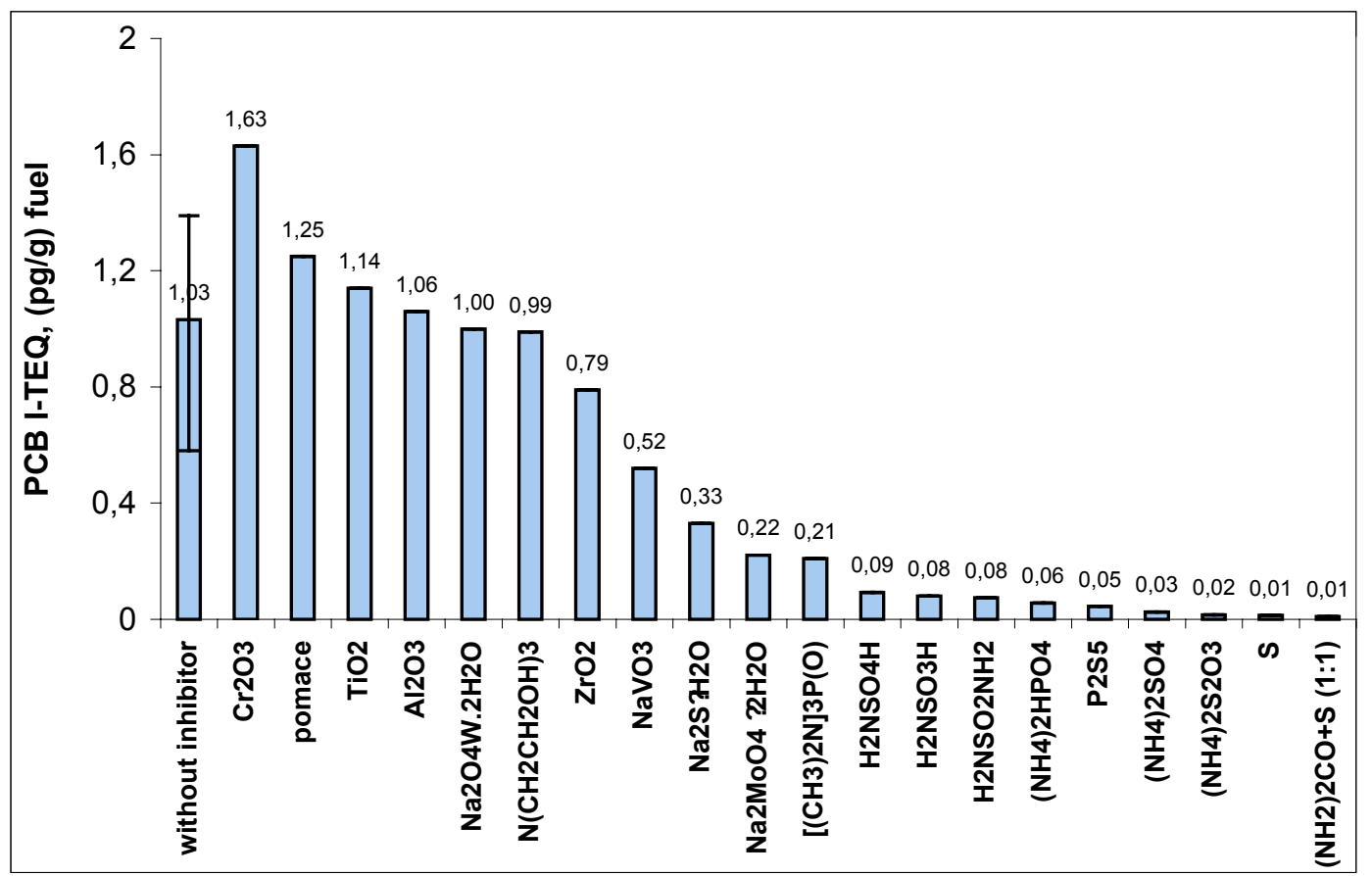

Fig. 5.16: PCB I-TEQ (pg/g) values of the flue gas after combustion of lignite coal, solid waste and $P V C$ for the samples without inhibitor and 20 different compounds used at $10 \%$ inhibitor of the fuel.

The experimental results with $10 \%$ inhibitor display also for PCB very different, from very high to very low, PCB I-TEQ values. The four compounds placed rightly in Fig. 5.16 can inhibit the PCB emission to up to $97-99 \%$. Two of these compounds $\left(\mathrm{NH}_{4}\right)_{2} \mathrm{SO}_{4}$ and $\left(\mathrm{NH}_{4}\right)_{2} \mathrm{~S}_{2} \mathrm{O}_{3}$ are show also strong effects of the PCDD/F emissions.

\section{Principle Component Analysis}

A statistical method called principle component analysis (PCA) is used in order to give a better view of the similarity between the samples using the concentrations of 
the PCDD and PCDF isomers. The statistical score plot for the laboratory-scale experiments with 20 inhibitors is shown in Fig. 5.17.

The matrix for PCDD consists of 37 variables (PCDD isomers) and 25 cases (samples), the matrix of PCDF is comprises 63 variables (PCDF isomers) and 25 cases (samples) and the matrix of PCB consists of 168 variables (PCB isomers) and 25 cases (samples). No transformation of the data was performed during statistical analysis.

Two main groups of samples were observed in the first and second score plots. One group is placed to the right and the other to the left of the ordinate axis. The samples without inhibitor are placed on the right side of the multidimensional space. Neighbouring these toxic samples are some other points, which can be attributed to the metal oxide inhibitors $\mathrm{Cr}_{2} \mathrm{O}_{3}, \mathrm{TiO}_{2}, \mathrm{Al}_{2} \mathrm{O}_{3}$ and pomace. In addition they also belong to the samples with higher concentrations. Near to the ordinate axis and between both groups, other inhibitors as $\mathrm{P}_{2} \mathrm{~S}_{5}, \mathrm{~N}\left(\mathrm{CH}_{2} \mathrm{CH}_{2} \mathrm{OH}\right)_{3}, \mathrm{Na}_{2} \mathrm{WO}_{4} \cdot 2 \mathrm{H}_{2} \mathrm{O}$ and $\mathrm{ZrO}_{2}$ are located. They belong to the $\mathrm{N}$-, S- and metal oxide group. These four compounds are probably additives that manifest low inhibitory effects or samples with high variation of PCDD/F amount.

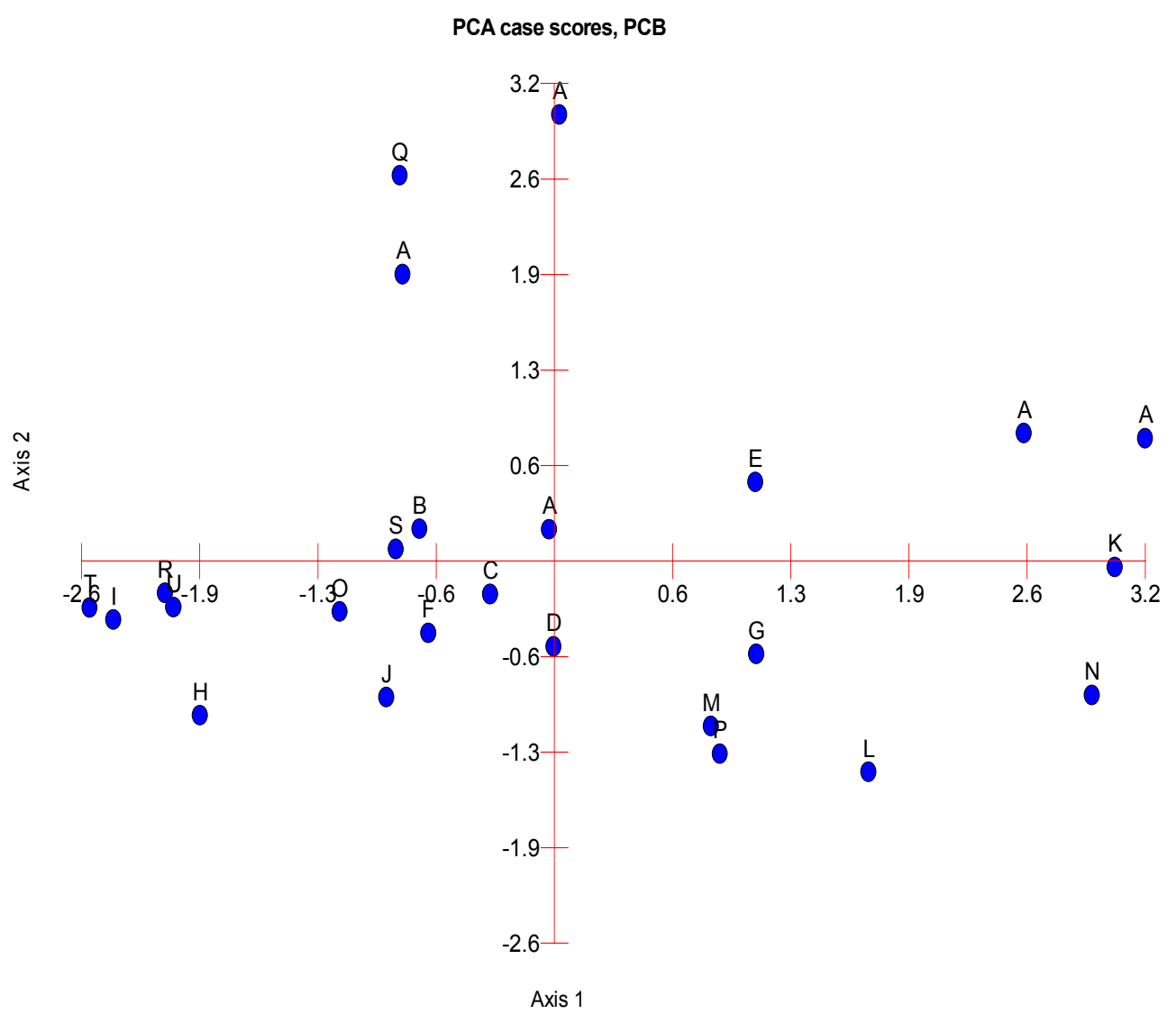



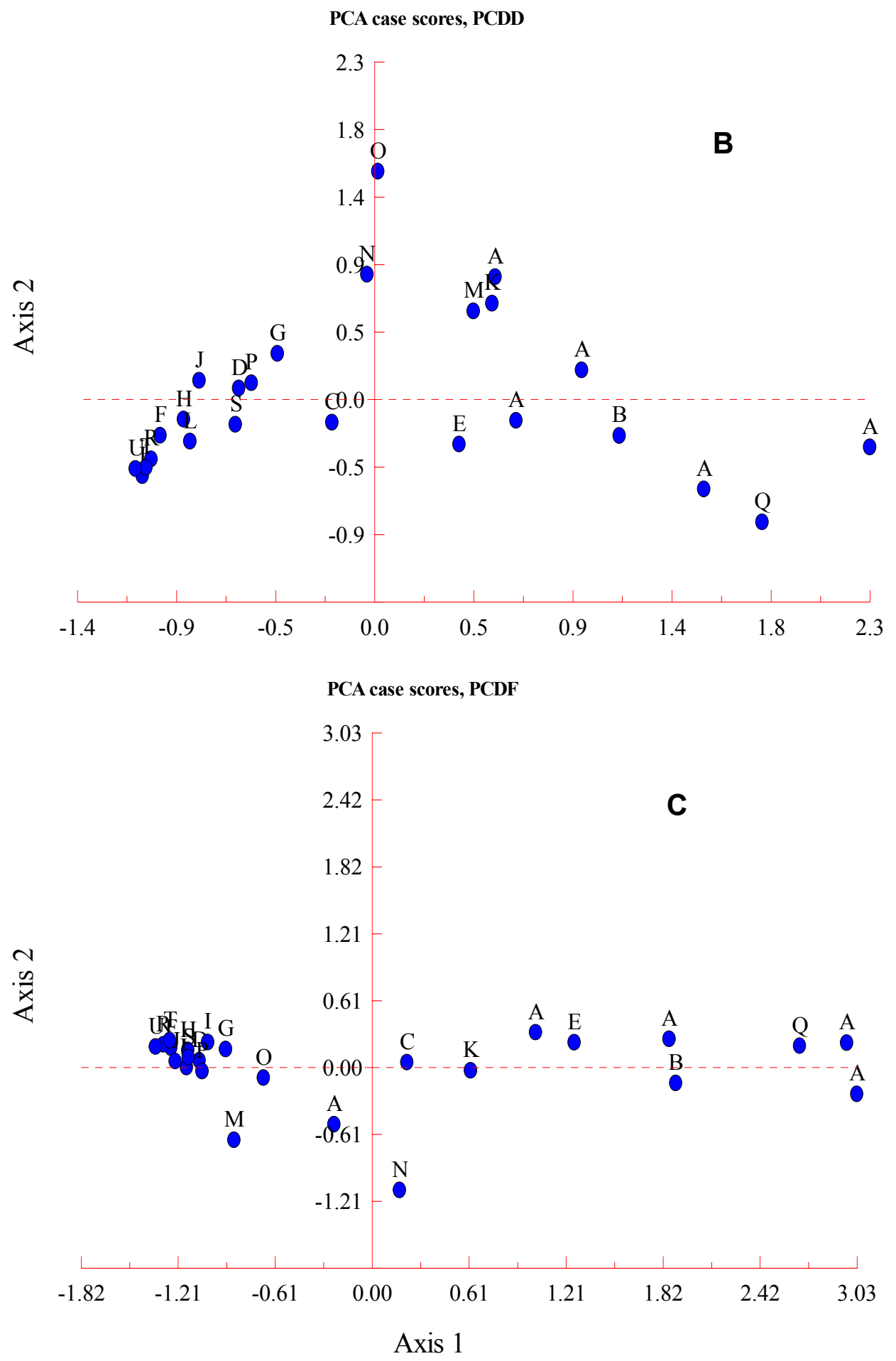

Fig. 5.17: Score plot of $P C B(A), P C D D(B)$ and $P C D F(C)$ of 5 replicates treated without any inhibitor (A) and 20 samples with $10 \%$ inhibitor $\left(\mathrm{B}-\mathrm{TiO}_{2}, \mathrm{C}-\mathrm{ZrO}_{2}, \mathrm{D}-\mathrm{Na}_{2} \mathrm{MoO}_{4} \cdot 2 \mathrm{H}_{2} \mathrm{O}\right.$, E$\mathrm{Al}_{2} \mathrm{O}_{3}, \mathrm{~F}-\mathrm{H}_{2} \mathrm{NSO}_{4} \mathrm{H}, \mathrm{G}-\mathrm{NaVO}_{3}, \mathrm{H}-\mathrm{H}_{2} \mathrm{NSO}_{3} \mathrm{H}$, I- S, J- $\mathrm{H}_{2} \mathrm{NSO}_{2} \mathrm{NH}_{2}$, K- pomace, L$\left[\left(\mathrm{CH}_{3}\right)_{2} \mathrm{~N}\right]_{3} \mathrm{P}(\mathrm{O}), \mathrm{M}-\mathrm{N}\left(\mathrm{CH}_{2} \mathrm{CH}_{2} \mathrm{OH}\right)_{3}, \mathrm{~N}-\mathrm{Na}_{2} \mathrm{WO}_{4} \cdot 2 \mathrm{H}_{2} \mathrm{O}, \mathrm{O}-\mathrm{P}_{2} \mathrm{~S}_{5}, \mathrm{P}-\mathrm{Na}_{2} \mathrm{~S} \cdot \mathrm{H}_{2} \mathrm{O}, \mathrm{Q}-\mathrm{Cr}_{2} \mathrm{O}_{3}, \mathrm{R}-$ $\left(\mathrm{NH}_{4}\right)_{2} \mathrm{SO}_{4}, \mathrm{~S}-\left(\mathrm{NH}_{4}\right)_{2} \mathrm{HPO}_{4}, \mathrm{~T}-\left(\mathrm{NH}_{2}\right)_{2} \mathrm{CO}+\mathrm{S}, \mathrm{U}-\left(\mathrm{NH}_{4}\right)_{2} \mathrm{~S}_{2} \mathrm{O}$

A highly agglomerated group especially for PCDF score plot is on the left hand side. It includes samples with $10 \%$ inhibitor of the fuel, which are all $\mathrm{N}$-and S-containing compounds, and other such as $\mathrm{NaVO}_{3}, \quad \mathrm{Na}_{2} \mathrm{MoO}_{4} .2 \mathrm{H}_{2} \mathrm{O}, \quad\left(\mathrm{NH}_{4}\right)_{2} \mathrm{HPO}_{4}$, 
$\left[\left(\mathrm{CH}_{3}\right)_{2} \mathrm{~N}\right]_{3} \mathrm{P}(\mathrm{O}), \mathrm{S}$ and $\mathrm{Na}_{2} \mathrm{~S} \cdot \mathrm{H}_{2} \mathrm{O}$. The points are very close to each other which can be explained by the similarity in their pattern and their PCDD/F amount formed.

Here the $\mathrm{N}$-and $\mathrm{S}$ - containing compounds are placed much more to the left in the score plot. The more left point in the statistical plot appears, the lower concentration of PCDD/F is found. This effect can also be observed in Fig. 5.15 where the same compounds show a strong inhibitory effect for I-TEQ PCDD/F value in the flue gas. The most agglomerated group especially for PCDF score plot is the left one, representing samples containing the lowest PCDD/F amount with inhibitors used from all $\mathrm{N}$-and $\mathrm{S}$-compounds and other such as $\left(\mathrm{NH}_{4}\right)_{2} \mathrm{HPO}_{4},\left[\left(\mathrm{CH}_{3}\right)_{2} \mathrm{~N}\right]_{3} \mathrm{P}(\mathrm{O}), \mathrm{S}$, $\mathrm{Na}_{2} \mathrm{~S} \cdot \mathrm{H}_{2} \mathrm{O}, \mathrm{NaVO}_{3}, \mathrm{Na}_{2} \mathrm{MoO}_{4} \cdot 2 \mathrm{H}_{2} \mathrm{O}$, representing $\mathrm{N}, \mathrm{S}$, and metal oxide substances. The points are very close to each other which can be explained by the similarity in their pattern and their PCDD/F abundance. The samples treated without any inhibitor, and samples with metal oxides, are spread on the right site of the score plot.

The PCB score plot does not show any agglomerated groups between the samples. The sample points are spread over the multidimensional space which explain their high variability of the 168 PCB isomer. Can be noticed that the samples without inhibitor are placed to the right and along the ordinate axis. Close to these samples are the points of pomace, $\mathrm{Na}_{2} \mathrm{WO}_{4} \cdot 2 \mathrm{H}_{2} \mathrm{O}, \quad\left[\left(\mathrm{CH}_{3}\right)_{2} \mathrm{~N}\right]_{3} \mathrm{P}(\mathrm{O}), \mathrm{Al}_{2} \mathrm{O}_{3}, \quad \mathrm{NaVO}_{3}$, $\mathrm{N}\left(\mathrm{CH}_{2} \mathrm{CH}_{2} \mathrm{OH}\right)_{3}, \mathrm{Na}_{2} \mathrm{~S} \cdot \mathrm{H}_{2} \mathrm{O}, \mathrm{Na}_{2} \mathrm{MoO}_{4} \cdot 2 \mathrm{H}_{2} \mathrm{O}$. Most of these compounds belong to the group of the metal oxides. Some of the $\mathrm{N}$-, S- and $\mathrm{N}$-and S-containing compounds such as $\left(\mathrm{NH}_{4}\right)_{2} \mathrm{HPO}_{4}, \mathrm{H}_{2} \mathrm{NSO}_{4} \mathrm{H}, \mathrm{H}_{2} \mathrm{NSO}_{2} \mathrm{NH}_{2}, \mathrm{P}_{2} \mathrm{~S}_{5}$ and $\mathrm{H}_{2} \mathrm{NSO}_{3} \mathrm{H}$ are placed on the left side with respect of the ordinate axis. The samples $\left(\mathrm{NH}_{4}\right)_{2} \mathrm{SO}_{4}$ and $\left(\mathrm{NH}_{4}\right)_{2} \mathrm{SO}_{4} ; \mathrm{S}$ and $\left(\mathrm{NH}_{2}\right)_{2} \mathrm{CO}+\mathrm{S}$ are grouped in two couples on the quite left side of the PCB score plot. These compounds show also similar low I-TEQ values as shown in Fig. 5.17.

\section{The 17 Toxic PCDD/F Isomers}

It is generally accepted that only 17 out of the 210 dioxin and furan congeners are toxic [117]. A measure for the toxicity of these isomers is the TEF. The calculated value is called the toxic equivalent (TEQ). The TEF of $2,3,7,8,-$ TCDD TEF is 1 , indicating that it is the most toxic congener. Table 5. 11. shows nine of the most effective PCDD/F inhibitors and present a comparison with the samples without inhibitor according their mass concentration value $(\mathrm{pg} / \mathrm{g})$ for the 17 toxic PCDD/F isomer. 
Since 2,3,7,8- TCDD is the most toxic dioxin it must be considered. The inhibitors which have values below the detection limit for this isomer are: $\mathrm{H}_{2} \mathrm{NSO}_{3} \mathrm{H}, \mathrm{S}$, $\mathrm{H}_{2} \mathrm{NSO}_{2} \mathrm{NH}_{2},\left(\mathrm{NH}_{4}\right)_{2} \mathrm{~S}_{2} \mathrm{O}_{3},\left(\mathrm{NH}_{2}\right)_{2} \mathrm{CO}+\mathrm{S}(1: 1)$ and $\left(\mathrm{NH}_{4}\right)_{2} \mathrm{SO}_{4}$. These are also samples with low PCDD/F values in general. Almost all examples with inhibitor additives show non-detectable values for 1,2,3,7,8 - PCDD, 1,2,3,4,7,8 - HxCDD, and 1,2,3,7,8,9HxCDF. The HpCDD and OCDD values are slightly higher for the nine most effective inhibitors. These congeners are as a low TEF which contribute less to the final I-TEQ value.

The TEF for 2,3,4,7,8-PeCDF, the most toxic isomer among all PCDF congeners, is 0.5 . The smallest detectable value of this isomer was found using $\left(\mathrm{NH}_{2}\right)_{2} \mathrm{CO}+\mathrm{S}(1: 1)$, $\left(\mathrm{NH}_{4}\right)_{2} \mathrm{SO}_{4}$ and $\left(\mathrm{NH}_{4}\right)_{2} \mathrm{~S}_{2} \mathrm{O}_{3}$ as inhibitors. The latter two inhibitors show undetectable or negligible amounts for all other PCDF homologues. $\left(\mathrm{NH}_{2}\right)_{2} \mathrm{CO}+\mathrm{S}(1: 1)$ together with $\mathrm{H}_{2} \mathrm{NSO}_{3} \mathrm{H}$ and $\mathrm{S}$ also exhibit very low and sometimes undetectable values for PCDF congeners. All samples have values below the detection limit for 1,2,3,7,8,9$\mathrm{HxCDF}$.

The average amounts of the 17 toxic isomers in the samples without inhibitor is much higher than in those with inhibitor. Some of the most abundant isomers are 2,3,7,8TCDD and 2,3,4,7,8-PeCDF, which make them sufficiently toxic for further inhibition experiments. Looking carefully at the values of the 9 inhibitors and their PCDD/F value, it is obvious that $\left(\mathrm{NH}_{4}\right)_{2} \mathrm{SO}_{4}$ and $\left(\mathrm{NH}_{4}\right)_{2} \mathrm{~S}_{2} \mathrm{O}_{3}$ are the inhibitors with the most diminished PCDD/F amount. 
Tab. 5.11: Values of the 17 toxic $P C D D / F$ isomers pg/g fuel for the most effective inhibitors and the average value of the sample without inhibitor $\left(A-H_{2} N S O_{4} H, B-\right.$ $\mathrm{H}_{2} \mathrm{NSO}_{3} \mathrm{H}, \mathrm{C}-\mathrm{S}, \mathrm{D}-\mathrm{H}_{2} \mathrm{NSO}_{2} \mathrm{NH}_{2}, \mathrm{E}-\mathrm{Na}_{2} \mathrm{MoO}_{4} \cdot 2 \mathrm{H}_{2} \mathrm{O}, \mathrm{F}-\mathrm{Na}_{2} \mathrm{~S} \times \mathrm{H}_{2} \mathrm{O}, \mathrm{G}-\left(\mathrm{NH}_{4}\right)_{2} \mathrm{~S}_{2} \mathrm{O}_{3}, \mathrm{H}-\left(\mathrm{NH}_{2}\right)_{2} \mathrm{CO}+\mathrm{S}(1: 1), \mathrm{I}-\left(\mathrm{NH}_{4}\right)_{2} \mathrm{SO}_{4}$

The 17 toxic PCDD/F isomers Without inhibitor

\begin{tabular}{|c|c|c|c|c|c|c|c|c|c|c|}
\hline 2,3,7,8 -TCDD & 0.23 & 0.15 & n.d. & n.d. & n.d. & 0.35 & 0.08 & n.d. & n.d. & n.d. \\
\hline 1,2,3,7,8 - PCDD & 2.12 & n. d. & n.d. & n.d. & n.d. & n.d. & 0.61 & n.d. & n.d. & n.d. \\
\hline $1,2,3,4,7,8-\mathrm{HxCDD}$ & 5.40 & 0.91 & n.d. & n.d. & n.d. & n.d. & n.d. & n.d. & n.d. & n.d. \\
\hline 1,2,3,6,7,8 -HxCDD & 1.94 & 0.83 & 1.42 & 0.20 & 2.03 & 1.71 & 1.52 & n.d. & n.d. & $\mathrm{d}$. \\
\hline $1,2,3,7,8,9-\mathrm{HxCDD}$ & 1.79 & 0.54 & 0.55 & n.d. & 0.76 & 1.04 & 1.34 & n.d. & n.d. & d. \\
\hline 1,2,3,4,6,7,8 - HpCDD & 9.83 & 2.36 & 4.37 & 0.52 & 5.31 & 5.07 & 5.65 & 1.66 & 2.12 & 4.01 \\
\hline OCDD & 24.54 & 6.22 & 11.20 & 0.54 & 12.50 & 10.40 & 12.80 & 6.85 & 8.14 & 16.6 \\
\hline $2,3,7,8$ - TCDF & 38.44 & 1.13 & 1.53 & 4.48 & 0.78 & 3.87 & 3.65 & 0.57 & 1.41 & 1.09 \\
\hline $1,2,3,7,8 / 1,2,3,4,8$ - PCDF & 11.37 & 0.22 & 0.28 & 1.04 & 0.24 & 0.83 & 1.08 & n.d. & 1.02 & 4 \\
\hline $2,3,4,7,8$ - PCDF & 9.42 & 0.99 & 1.06 & 2.00 & 1.35 & 2.38 & 1.45 & 0.24 & 0.28 & 0.22 \\
\hline $1,2,3,4,7,8 / 1,2,3,4,7,9$ - HxCDF & 3.21 & 0.29 & 0.25 & 0.59 & 0.46 & 0.49 & 0.45 & n.d. & 0.03 & n.d. \\
\hline $1,2,3,6,7,8-\mathrm{HxCDF}$ & 3.05 & 0.06 & 0.26 & 0.35 & n.d. & 0.33 & 0.30 & n.d. & 0.09 & 0.17 \\
\hline 1,2,3,7,8,9 - HxCDF & 0.45 & n.d. & 0.07 & n.d. & n.d. & n.d. & n.d. & n.d. & n.d. & n.d. \\
\hline $2,3,4,6,7,8$ - HxCDF & 1.82 & 0.37 & 0.29 & 0.50 & 0.47 & 0.59 & 0.40 & n.d. & 0.08 & 0.20 \\
\hline $1,2,3,4,6,7,8$ - HpCDF & 1.57 & 0.28 & 0.30 & 0.15 & 0.33 & 0.37 & 0.56 & 0.21 & 0.06 & 0.34 \\
\hline $1,2,3,4,7,8,9-\mathrm{HpCDF}$ & 0.23 & n.d & n.d. & n.d. & n.d. & 0.09 & 0.50 & n.d. & n.d. & \\
\hline OCDF & 0.74 & 0.82 & n.d. & n.d. & 0.34 & 0.37 & n.d. & n.d. & 0.42 & . \\
\hline
\end{tabular}




\section{The 12 Toxic PCB isomers}

It is generally accepted that only 12 out of the 210 PCB congeners are toxic. The toxicity rating of these isomers is reflected by their toxic equivalent factor, or TEF. The calculated value is called the toxic equivalent (TEQ). The TEF of $3,3^{\prime}, 4,4^{\prime}, 5-$ PeCB (\#126) is 0.1 indicating that it is the most toxic congener. It is followed by the other very toxic congener 3,3',4,4',5,5'-HxCB (\#169) which TEF is 0.01 . Table 5.12 shows four of the most effective PCDD/F inhibitors and compares to the samples without inhibitor according their mass concentration value $(\mathrm{pg} / \mathrm{g})$ for the 12 toxic $\mathrm{PCDD} / \mathrm{F}$ isomer.

Tab. 5.12: Values of the 12 toxic PCB isomers $\mathrm{pg} / \mathrm{g}$ fuel for the most effective inhibitors and the average value of the sample without inhibitor $\left(A-S, B-\left(N H_{2}\right)_{2} \mathrm{CO}+\mathrm{S}(1: 1), C-\left(N_{4}\right)_{2} S_{4}, D-\left(N H_{4}\right)_{2} S_{2} O_{3}\right)$

\begin{tabular}{|c|c|c|c|c|c|}
\hline $\begin{array}{c}\text { The 12 toxic } \\
\text { PCB isomers }\end{array}$ & $\begin{array}{c}\text { Without } \\
\text { inhibitor }\end{array}$ & A & B & C & D \\
\hline PCB \#77 & 166.64 & 8.04 & 23.10 & 5.24 & 9.84 \\
\hline PCB \#81 & 28.82 & 1.48 & n.d & n.d & n.d \\
\hline PCB \#126 & 9.08 & n.d & n.d. & n.d. & n.d. \\
\hline PCB \#169 & 1.40 & n.d. & n.d. & n.d. & n.d. \\
\hline PCB \#105 & 106.90 & 16.30 & 19.60 & 43.60 & 30.50 \\
\hline PCB \#114 & 13.68 & n.d. & n.d. & n.d & n.d. \\
\hline PCB \#118 & 318.12 & 37.90 & 46.20 & 107.00 & 86.40 \\
\hline PCB \#123 & 40.52 & 4.18 & 2.72 & 9.17 & 7.59 \\
\hline PCB \#156 & 64.42 & 1.52 & 1.74 & 7.77 & 5.08 \\
\hline PCB \#157 & 7.80 & n.d. & n.d. & n.d & n.d. \\
\hline PCB \#167 & 8.62 & 1.13 & n.d. & 1.97 & 0.13 \\
\hline PCB \#189 & 8.25 & 0.89 & n.d. & n.d & n.d. \\
\hline
\end{tabular}

The observed inhibitors are the samples with very low PCB I-TEQ values (Tab. 5.12.). These inhibitors show values below the detection limit for the most toxic $\# 126$ and \#169 isomers. All inhibitor compounds show non- detectable values for \#114 and \#157. Seven of total 12 toxic PCB congeners are non-detectable for $\left(\mathrm{NH}_{2}\right)_{2} \mathrm{CO}+\mathrm{S}$ (1:1), $\left(\mathrm{NH}_{4}\right)_{2} \mathrm{SO}_{4}$ and $\left(\mathrm{NH}_{4}\right)_{2} \mathrm{~S}_{2} \mathrm{O}_{3}$ proposed as inhibitors in Tab. 5.12. Taking into account their similar low I-TEQ values (Fig.5.17) and the current values, it's obvious that these three compounds can successfully suppress the PCB emissions. 


\section{Discussion}

Twenty different compounds subsumed into four different types of groups according to their chemical nature are studied as inhibitors of PCDD/F and PCB in flue gases of lignite coal, solid waste and PVC combustion. This method is simpler than others where the inhibitor is sprayed into the post combustion zone, resulting in significant disturbances of large incineration plants. The effect of inhibitors is studied here empirically, and mechanistic studies are under way. The results show that the substances belonging to the metal oxide group have no inhibitory effect. Some of the additives such as $\mathrm{Cr}_{2} \mathrm{O}_{3}, \mathrm{Al}_{2} \mathrm{O}_{3}$ and $\mathrm{TiO}_{2}$ could even slightly increase the PCDD/F emissions. This fact can be explained by the mechanism of the de novo reaction for PCDD/F formation. The catalyst is a transition metal, such copper, iron or one of the oxides of these metals. It seems that the metal oxides can also promote the de novo reaction. They produce very high amounts of the most toxic isomers and a high amount of lower chlorinated PCDD/F. Some other substances belonging to the metal oxide groups such as $\mathrm{NaVO}_{3}, \mathrm{Na}_{2} \mathrm{MoO}_{4} \cdot 2 \mathrm{H}_{2} \mathrm{O}$ and $\mathrm{Na}_{2} \mathrm{WO}_{4} \cdot 2 \mathrm{H}_{2} \mathrm{O}$ show low but still inhibitory effects, especially for PCDD. These substances are active for catalytic oxidation. Their chemical structure consists of a strong oxide base such as $\mathrm{VO}_{3}{ }^{-}$, $\mathrm{MoO}_{4}^{-2}, \mathrm{WO}_{4}^{-2}$. Probably due to this base, a better performance of incineration during the experiments occurs. Regardless, these additives cannot reduce PCDD/F and PCB sufficiently.

Relatively low inhibitory effects are also observed for the $\mathrm{N}$-containing substances. The samples of this group of additives are located somewhere between the two extremes of the score plot. The inhibition behaviour of triethanolamine was investigated with FTIR analysis [118]. Ethanolamine as an inhibitory molecule containing the amino and hydroxyl functional groups and can undergo intermolecular dehydroamination reactions. Bromobenzene or the benzene precursors are displaced from the catalytically active sites, which are blocked by ethanolamine. Higher reduction effects of PCDD/F and PCB can be derived for the S- containing substances present at $10 \%$ of the fuel. Sulfur shows a very strong inhibition effect of $\mathrm{PCDD} / \mathrm{F}$ and especially of PCB. It is already known that sulfur is converted into $\mathrm{SO}_{2}$ and it reduces $\mathrm{Cl}_{2}$ to $\mathrm{HCl}$, and therefore dioxin and $\mathrm{PCB}$ formation can be reduced [38]. Probably, also because of this mechanism, the rest of the S-containing compounds inhibit PCDD/F flue gases. 
Although the single $\mathrm{N}$ - and $\mathrm{S}$ - containing compounds are not very effective as inhibitors, all other $\mathrm{N}$ - and $\mathrm{S}$ - containing substances seem to be able to reduce strongly PCDD/F flue gas emission if used as a $10 \%$ additive of lignite coal, solid waste and PVC as fuel. Mixture of $\left(\mathrm{NH}_{2}\right)_{2} \mathrm{CO}+\mathrm{S}(1: 1)$ can strongly suppress the PCB emissions and this additive can also successfully inhibit PCDD/F toxic gases. However, the most effective inhibitors for PCDD/F and PCB are $\left(\mathrm{NH}_{4}\right)_{2} \mathrm{SO}_{4}$ and $\left(\mathrm{NH}_{4}\right)_{2} \mathrm{~S}_{2} \mathrm{O}_{3}$. Both compounds are cheap and non-toxic materials.

\subsubsection{Experiments with Varying Inhibitor Amount}

The combustion experiments are performed according to the same procedure each time in order to achieve comparable results. The sample number of these experiments is $0208002,0209018,0209019,0212010,0212015$ and 0307002 . The sample numbers of: $10 \%\left(\mathrm{NH}_{4}\right)_{2} \mathrm{SO}_{4}(0212016,0302031,03030017)$ and $10 \%$ $\left(\mathrm{NH}_{4}\right)_{2} \mathrm{~S}_{2} \mathrm{O}_{3}$ (0301002, 0303019, 0303022); 5\% $\left(\mathrm{NH}_{4}\right)_{2} \mathrm{SO}_{4}(03030023,0305002$, $0305003)$ and $5 \%\left(\mathrm{NH}_{4}\right)_{2} \mathrm{~S}_{2} \mathrm{O}_{3} \quad(0303034,0305148,0305151) ; 3 \% \quad\left(\mathrm{NH}_{4}\right)_{2} \mathrm{SO}_{4}$ (0304014, 0307045, 0308095), 3\% $\left(\mathrm{NH}_{4}\right)_{2} \mathrm{~S}_{2} \mathrm{O}_{3}(0304020,0307046,0308096)$ and $3 \%\left(\mathrm{NH}_{2}\right)_{2} \mathrm{CO}+\mathrm{S}(1: 1)(0307047) ; 1 \%\left(\mathrm{NH}_{4}\right)_{2} \mathrm{SO}_{4}(0304022,0307007,0308102), 1 \%$ $\left(\mathrm{NH}_{4}\right)_{2} \mathrm{~S}_{2} \mathrm{O}_{3}(0304021,0307016,0308103)$ and $1 \%\left(\mathrm{NH}_{2}\right)_{2} \mathrm{CO}+\mathrm{S}(1: 1)(0307039)$.

\section{PCDD/F concentration}

$\left(\mathrm{NH}_{4}\right)_{2} \mathrm{SO}_{4}$ and $\left(\mathrm{NH}_{4}\right)_{2} \mathrm{~S}_{2} \mathrm{O}_{3}$ show stronger inhibition effects than the other substances. The resulted differences between the samples treated without any inhibitors and these substances are promising. Therefore, they were examined another two times and experiments in which these substances constituted at a lower fraction of the fuel were performed. $\left(\mathrm{NH}_{4}\right)_{2} \mathrm{SO}_{4}$ and $\left(\mathrm{NH}_{4}\right)_{2} \mathrm{~S}_{2} \mathrm{O}_{3}$ result in an approximately 50 fold reduction of PCDD/F I-TEQ values (Fig. 5.15). Another effective inhibitor for PCDD/F is $\left(\mathrm{NH}_{2}\right)_{2} \mathrm{CO}+\mathrm{S}(1: 1)$ even not so strong as $\left(\mathrm{NH}_{4}\right)_{2} \mathrm{SO}_{4}$ and $\left(\mathrm{NH}_{4}\right)_{2} \mathrm{~S}_{2} \mathrm{O}_{3}$. Thus, these substances are examined further in the same laboratory furnace under the same conditions in order to generate comparable results (Fig.5.18).

To optimise the amount of inhibitor needed, these substances are also studied at $5 \%$, $3 \%, 1 \%$ of the fuel. The experiments were performed in triplicate. The experiments with $\left(\mathrm{NH}_{2}\right)_{2} \mathrm{CO}+\mathrm{S}(1: 1)$ are studied only once at $10 \%, 3 \%$ and $1 \%$. In addition, the experiment without any inhibitor was repeated in order to obtain actual value during 
the time of the investigation. The standard deviation of that pattern is calculated on the basis of six measurements. The calculated average value for PCDD/F I-TEQ is $16.4 \mathrm{pg} / \mathrm{g}$ with a maximum value of $21.2 \mathrm{pg} / \mathrm{g}$ and minimum value of $13.4 \mathrm{pg} / \mathrm{g}$.

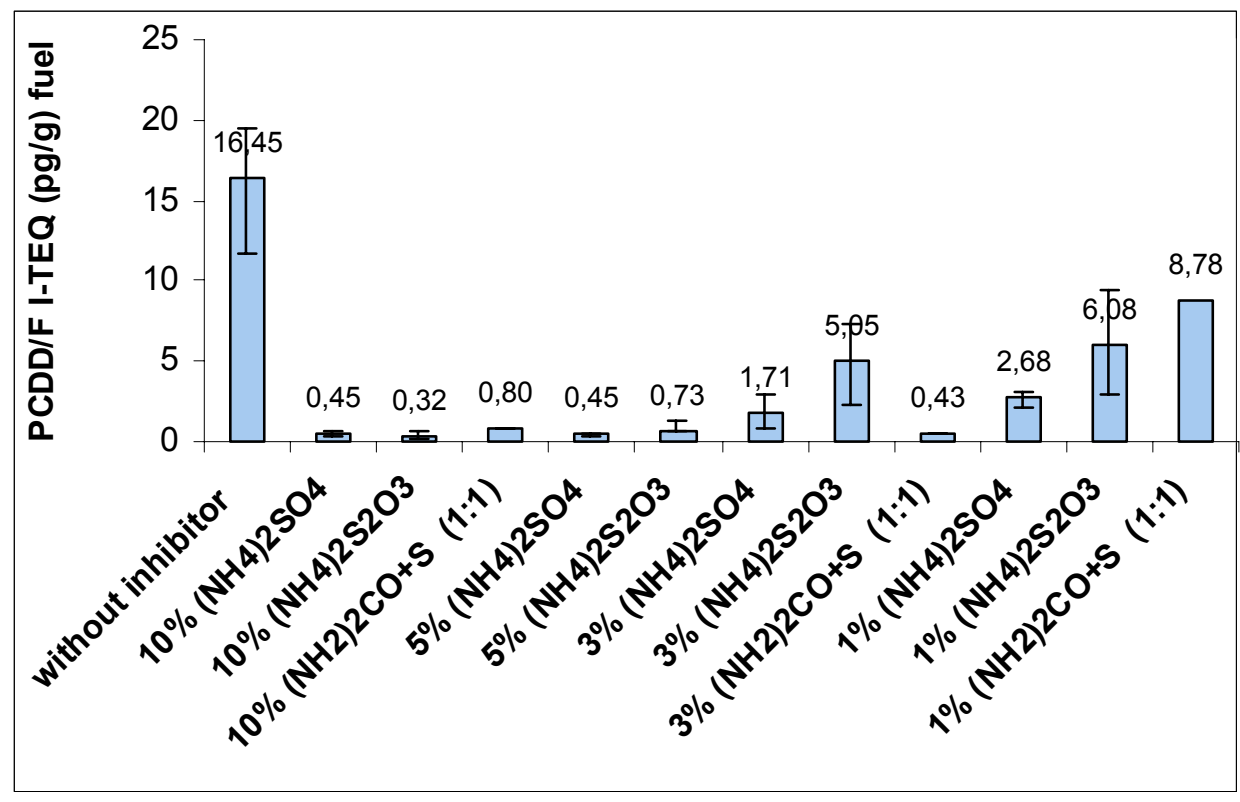

Fig. 5.18: PCDD/F I-TEQ pg/g fuel values in the flue gas for the samples without inhibitor and with $\left(\mathrm{NH}_{4}\right)_{2} \mathrm{SO}_{4}$ and $\left(\mathrm{NH}_{4}\right)_{2} \mathrm{~S}_{2} \mathrm{O}_{3}$ at $10 \%, 5 \%, 3 \%$ and $1 \%$ and $\left(\mathrm{NH}_{2}\right)_{2} \mathrm{CO}+\mathrm{S}$ at $10 \%, 3 \%$ and $1 \%$ as inhibitor of the fuel.

The variation among the results is found to be acceptable for such type of laboratory experiments. $\left(\mathrm{NH}_{4}\right)_{2} \mathrm{SO}_{4}$ and $\left(\mathrm{NH}_{4}\right)_{2} \mathrm{~S}_{2} \mathrm{O}_{3}$ are still effective inhibitors at $10 \%$ and $5 \%$ of the fuel for PCDD/F (Fig.5.19). If the percentage of these substances is decreased further, the suppressing effect of PCDD/F formation is also decreased. According to Fig. 5.16, $\left(\mathrm{NH}_{2}\right)_{2} \mathrm{CO}+\mathrm{S}(1: 1)$ can suppress strongly the PCDD/F emissions even at $3 \%$ of the fuel but the obtained value at $1 \%$ shows a high increase of the measured dioxins amount. $\left(\mathrm{NH}_{4}\right)_{2} \mathrm{SO}_{4}$ might also reduce the PCDD/F flue gas emission at $3 \%$ but not as effectively as at higher percentages.

\section{PCB concentration}

$\left(\mathrm{NH}_{4}\right)_{2} \mathrm{SO}_{4},\left(\mathrm{NH}_{4}\right)_{2} \mathrm{~S}_{2} \mathrm{O}_{3}$ and $(\mathrm{NH} 2) 2 \mathrm{CO}+\mathrm{S}(1: 1)$ show stronger inhibition effect for PCB emissions. Thus, these compounds were also examined in triplicate with a lower percentage of the fuel such as $5 \%, 3 \%$ and $1 \%$ of the fuel. The experiments with $\left(\mathrm{NH}_{2}\right)_{2} \mathrm{CO}+\mathrm{S}(1: 1)$ were also here repeated once at $10 \%, 3 \%$ and $1 \%$ of the fuel mixture. The results present in I-TEQ (pg/g) fuel are drawn in Fig. 5.19.

The experiment without any inhibitor was repeated also for PCB concentrations in order to have actual value during the time of the investigation. The standard deviation of that pattern is calculated on the basis of six measurements. The calculated 
average value for PCB I-TEQ is $1.01 \mathrm{pg} / \mathrm{g}$ with a maximum value of $1.39 \mathrm{pg} / \mathrm{g}$ and minimum value of $0.58 \mathrm{pg} / \mathrm{g}$. $\left(\mathrm{NH}_{4}\right)_{2} \mathrm{SO}_{4}$ and $\left(\mathrm{NH}_{4}\right)_{2} \mathrm{~S}_{2} \mathrm{O}_{3}$ are still effective inhibitors at $10 \%$ and $5 \%$ of the fuel for PCDD/F (Fig.5.19).

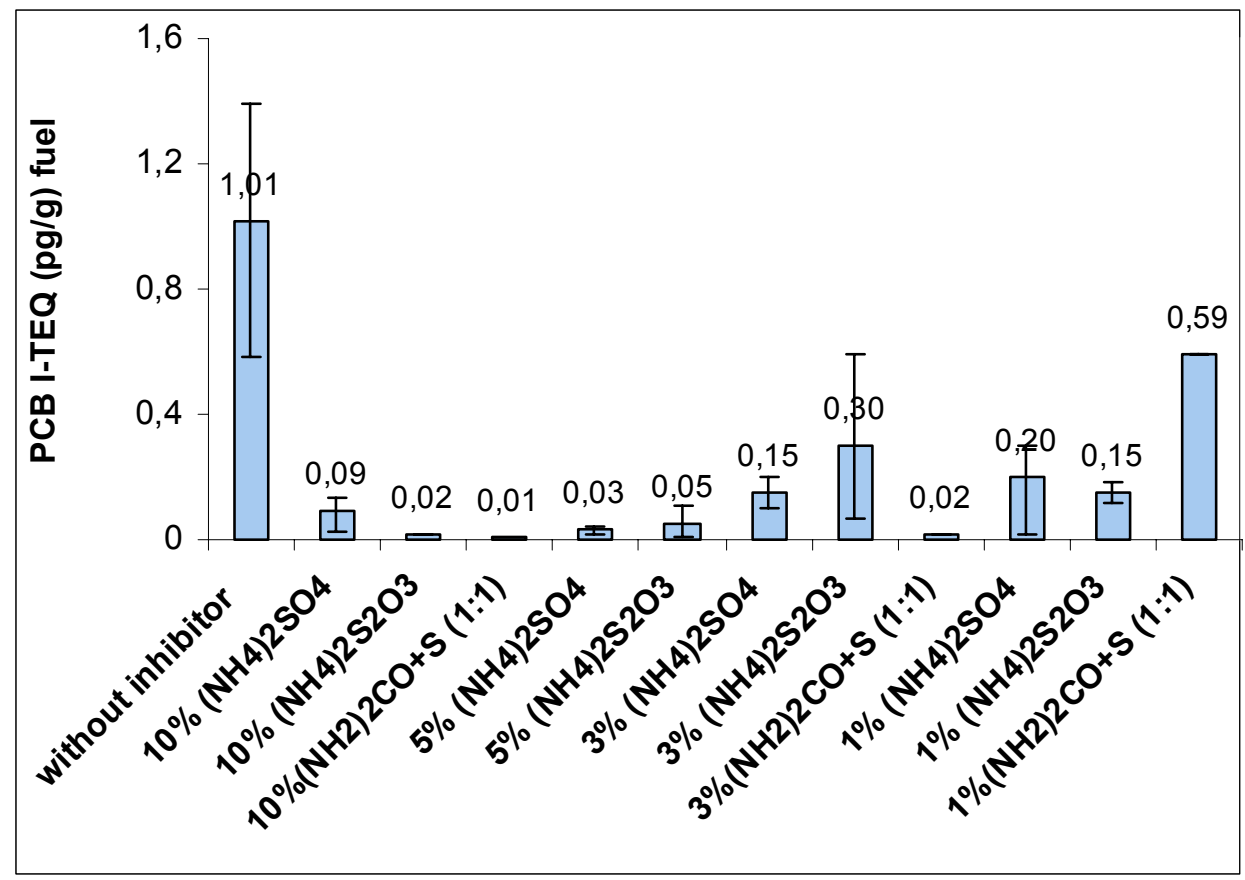

Fig. 5.19: PCB I-TEQ pg/g fuel values in the flue gas for the samples without inhibitor and with $\left(\mathrm{NH}_{4}\right)_{2} \mathrm{SO}_{4}$ and $\left(\mathrm{NH}_{4}\right)_{2} \mathrm{~S}_{2} \mathrm{O}_{3}$ at $10 \%, 5 \%, 3 \%$ and $1 \%$ and $\left(\mathrm{NH}_{2}\right)_{2} \mathrm{CO}+\mathrm{S}$ at $10 \%, 3 \%$ and $1 \%$ as inhibitor of the fuel.

However it, the percentage of these substances is decreased further, the suppressing effect of PCB formation also decreased. $\left(\mathrm{NH}_{2}\right)_{2} \mathrm{CO}+\mathrm{S}(1: 1)$ show very strong reduction effect at $3 \%$ of the fuel and very low inhibitory effect at $1 \%$ of the fuel for PCB formation in the same laboratory furnace under the same conditions such type laboratory experiments (see also Fig. 5.18).

PCBz concentration

The triplicate experiments with $5 \%, 3 \%$ and $1 \%\left(\mathrm{NH}_{4}\right)_{2} \mathrm{SO}_{4}$ and $\left(\mathrm{NH}_{4}\right)_{2} \mathrm{~S}_{2} \mathrm{O}_{3}$ and the sample treated without any inhibitor performed during that time of the same series of investigations are analysed for $\mathrm{PCBz}$ concentrations. $\left(\mathrm{NH}_{2}\right)_{2} \mathrm{CO}+\mathrm{S}(1: 1)$ is also used once as inhibitor for PCBz with $3 \%$ and $1 \%$ of the fuel. The sum of the PCBz mass concentrations for the analysed samples is shown Fig. 5.20.

According to the single experiment where the mixture of lignite coal and solid waste/PVC was combusted without addition of any inhibitor the sum of the PCBz is $135 \mathrm{pg} / \mathrm{g}$ fuel. The additives of $5 \%$ and $3 \%\left(\mathrm{NH}_{4}\right)_{2} \mathrm{SO}_{4}$ show strong inhibition effect of 
PCBz. $5 \%$ ( $\left(\mathrm{NH}_{4}\right)_{2} \mathrm{~S}_{2} \mathrm{O}_{3}$ is relatively good example for $\mathrm{PCBz}$ reduction but at $3 \%$ of the same compound the PCBz concentration is drastically increased.

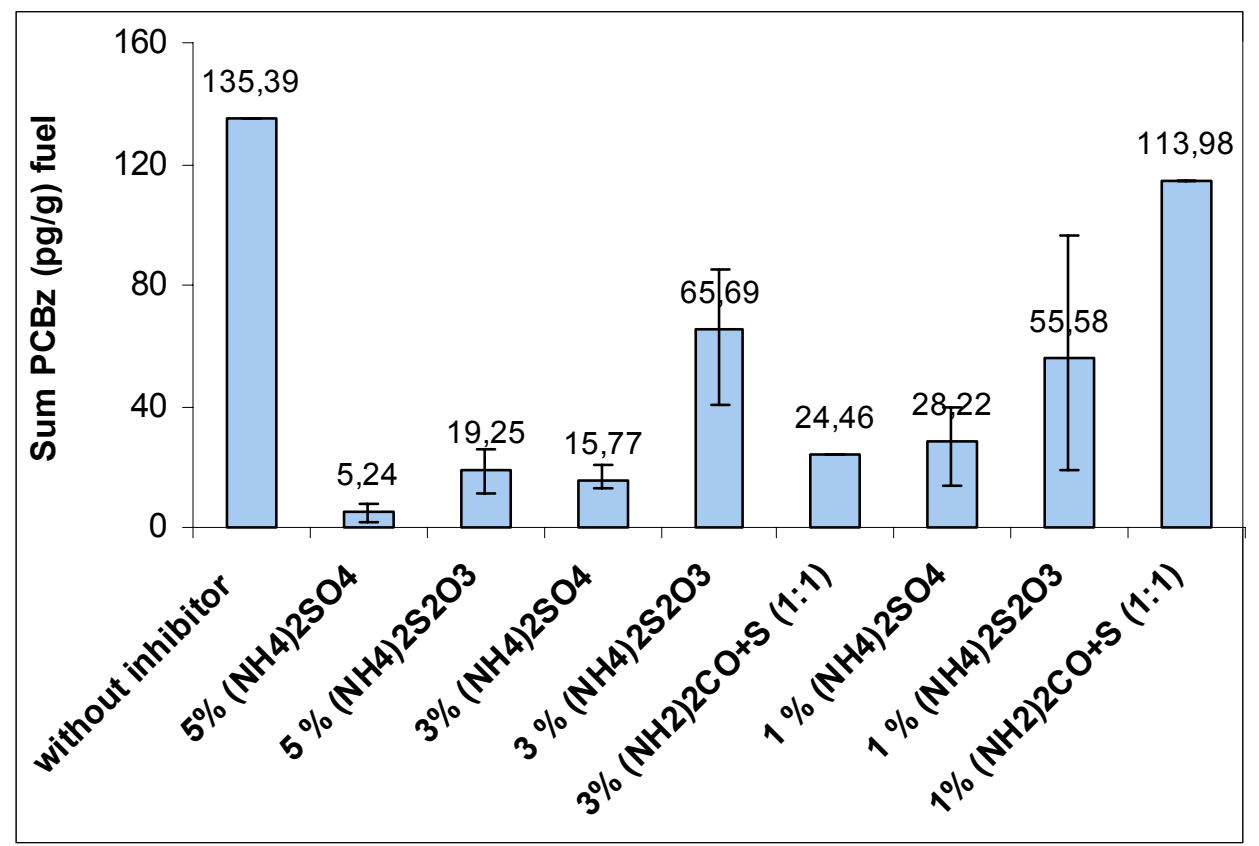

Fig. 5.20: Sum PCBz pg/g fuel values in the flue gas for the samples without inhibitor and with $\left(\mathrm{NH}_{4}\right)_{2} \mathrm{SO}_{4}$ and $\left(\mathrm{NH}_{4}\right)_{2} \mathrm{~S}_{2} \mathrm{O}_{3}$ at $5 \%, 3 \%$ and $1 \%$ and $\left(\mathrm{NH}_{2}\right)_{2} \mathrm{CO}+\mathrm{S}$ at $3 \%$ and $1 \%$ of the fuel.

The samples at $3 \%$ and $1 \%\left(\mathrm{NH}_{4}\right)_{2} \mathrm{~S}_{2} \mathrm{O}_{3}$ Fig. 5.18 show a high standard deviation. $\left(\mathrm{NH}_{2}\right)_{2} \mathrm{CO}+\mathrm{S}(1: 1)$ used as inhibitor at $3 \%$ show relatively similar PCB amount as the sample with $3 \%\left(\mathrm{NH}_{4}\right)_{2} \mathrm{SO}_{4}$. Despite that at $1 \%\left(\mathrm{NH}_{2}\right)_{2} \mathrm{CO}+\mathrm{S}(1: 1)$ the PCB concentrations are nearly the same as the sample treated without any inhibitor.

\section{Discussion}

The most effective inhibitors all over the used 20 different compounds are $\left(\mathrm{NH}_{4}\right)_{2} \mathrm{SO}_{4}$, $\left(\mathrm{NH}_{4}\right)_{2} \mathrm{~S}_{2} \mathrm{O}_{3}$ and $\left(\mathrm{NH}_{2}\right)_{2} \mathrm{CO}+\mathrm{S}(1: 1)$. $\left(\mathrm{NH}_{4}\right)_{2} \mathrm{SO}_{4}$ present at $3 \%$ of the fuel can reduce the PCDD/F, PCB and PCBz emissions by $90 \%$ and at $1 \%$ the reduction of the same toxic compounds is slightly decreased to $80-85 \%$. $\left(\mathrm{NH}_{4}\right)_{2} \mathrm{~S}_{2} \mathrm{O}_{3}$ present at $3 \%$ of the fuel can reduce the PCDD/F, PCB emissions to around $70 \%$ and poorly decrease the PCBz emissions up to $60 \%$. $\left(\mathrm{NH}_{2}\right)_{2} \mathrm{CO}+\mathrm{S}(1: 1)$ present at $3 \%$ show very strong reduction of PCDD/F, PCB and PCBz emissions of about $80-97 \%$. It is noticed that at $3 \%\left(\mathrm{NH}_{2}\right)_{2} \mathrm{CO}+\mathrm{S}(1: 1)$ the reduction of $\mathrm{PCDD} / \mathrm{F}$ is stronger than the result at $10 \%$ of the same substances. However $\left(\mathrm{NH}_{2}\right)_{2} \mathrm{CO}+\mathrm{S}(1: 1)$ at $1 \%$ of the fuel does not show any reduction effect (50-15\%) for the analysed toxic congeners. 
Finally the results presented in this chapter show that $\left(\mathrm{NH}_{4}\right)_{2} \mathrm{SO}_{4}$ is the most effective inhibitor for PCDD/F, PCB and PCBz emissions. This compound is low cost and a non-toxic material, making it applicable for use in full-scale combustion units.

\subsubsection{PCDD/F and PCB Homologue Distribution for the 20 Different Inhibitors}

Present as $10 \%$ of the Fuel

The results of pattern analysis are compared to the samples without inhibitors and to the samples investigated with metal oxide additives. The percentage of the homologue pattern for PCDD and PCDF and PCB is calculated for the twenty different inhibitors used at $10 \%$ of the fuel including the average value of five samples without any inhibitors. The PCDD, PCDF and PCB results are presented in Fig. 5. 21.
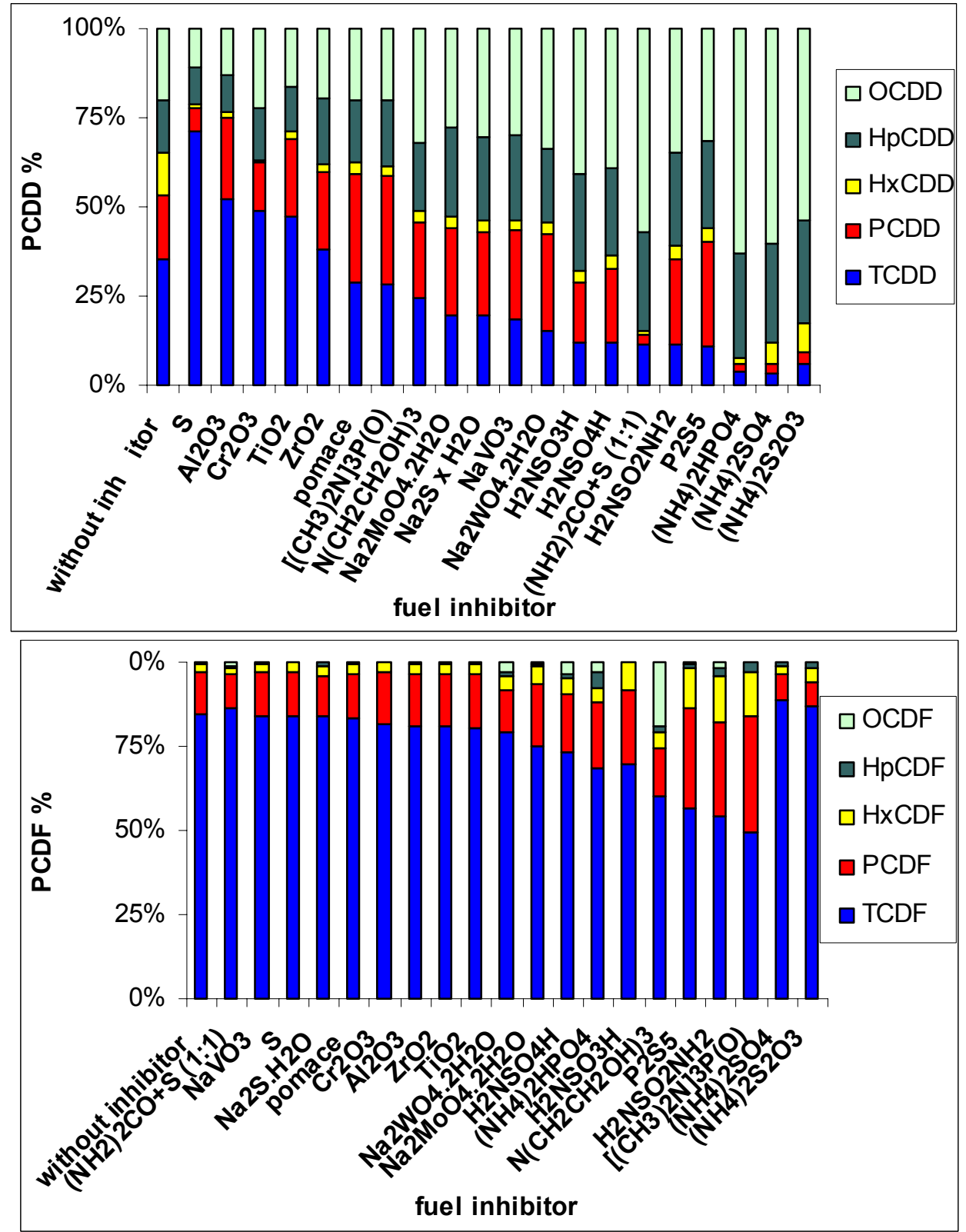

B 


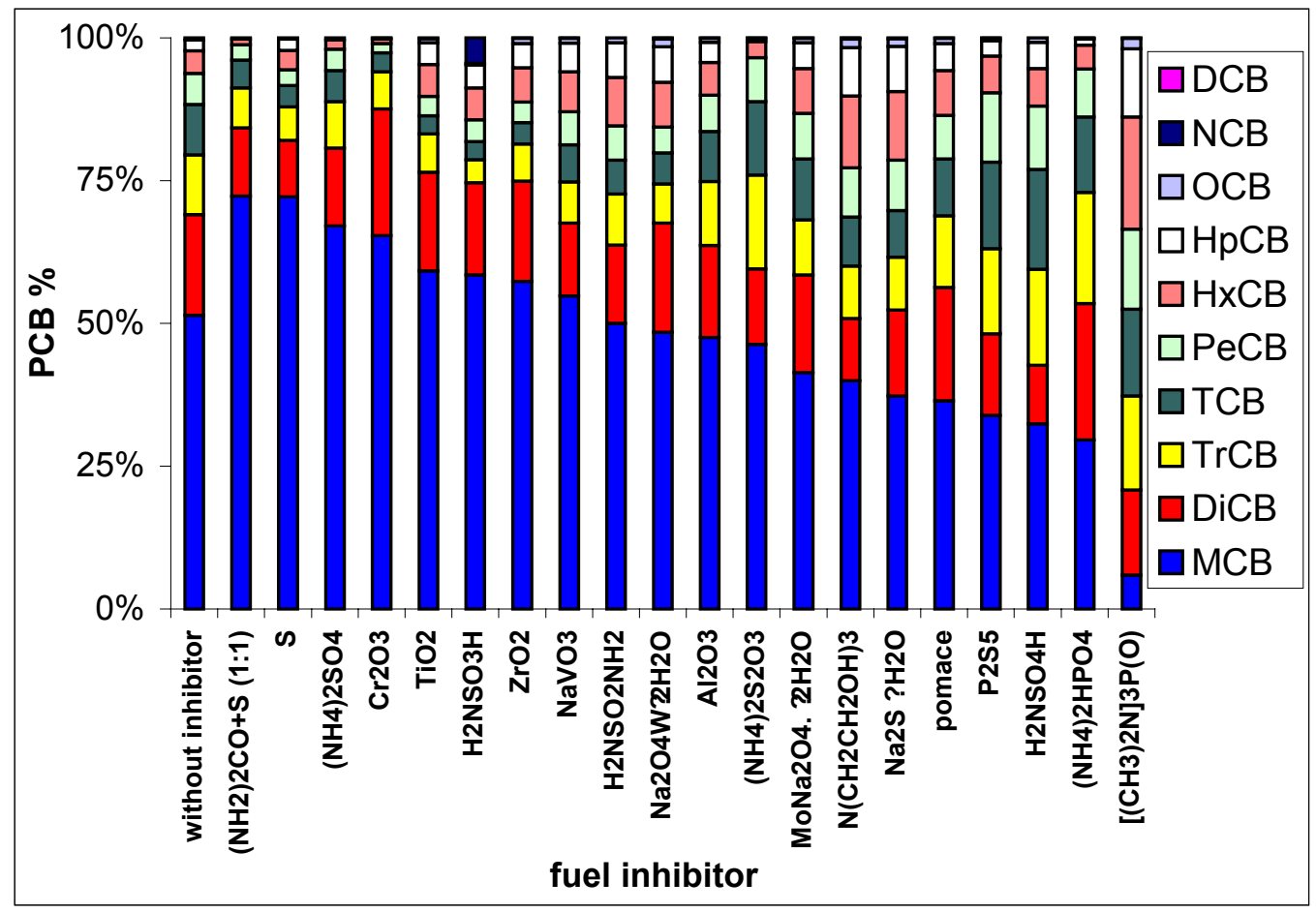

C

Fig. 5.21: Percentage of PCDD (A), PCDF (B) and PCB (C) homologues mass distribution of the samples with and without inhibitor during combustion of lignite coal, solid waste and $P V C$ in lab scale experiments.

Fig. 5.21. shows very different results for the PCDD pattern. For almost half of the samples TCDD is the dominant homologues and for the other half OCDD is the most dominant compound. PeCDD and HpCDD vary strongly from sample to sample and $\mathrm{HxCDD}$ is always present at negligible amounts. For the samples without inhibitor, PeCDD, HxCDD and HpCDD are at similar percentages. The samples combusted without inhibitors and samples belonging to the metal oxide group and sulphur exhibit higher percentage for TCDD. The next dominant pattern is PeCDD followed by OCDD and HpCDD.For the weak inhibitors positioned in the middle of that ordinate, the percentage of all homologues except HxCDD is on average around $25 \%$.

Compounds which drastically reduced TCDD and PCDD are $\left(\mathrm{NH}_{4}\right)_{2} \mathrm{HPO}_{4},\left(\mathrm{NH}_{4}\right)_{2} \mathrm{SO}_{4}$ and $\left(\mathrm{NH}_{4}\right)_{2} \mathrm{~S}_{2} \mathrm{O}_{3}$. The latter two compounds were already assigned to be the most effective inhibitors of PCDD. Despite the lower percentage of the lower chlorinated congeners here, HpCDD and OCDD compose around $80 \%$ of the remaining homologues. Fig. 5.21. shows similar results for the TCDF pattern. For all samples, TCDF is the most dominant homologue groups, taking around $75 \%$ of the remaining homologues. There is also a low reduction to $50 \%$ for the samples inhibited with 
$\mathrm{H}_{2} \mathrm{NSO}_{2} \mathrm{NH}_{2},\left[\left(\mathrm{CH}_{3}\right)_{2} \mathrm{~N}\right]_{3} \mathrm{P}(\mathrm{O}), \mathrm{P}_{2} \mathrm{~S}_{5} .\left(\mathrm{NH}_{4}\right)_{2} \mathrm{SO}_{4},\left(\mathrm{NH}_{4}\right)_{2} \mathrm{~S}_{2} \mathrm{O}_{3}$ and $\left(\mathrm{NH}_{2}\right)_{2} \mathrm{CO}+\mathrm{S}(1: 1)$ cannot reduce

TCDF, but increase it up to $85 \%$. The other PCDF congeners are present at very low or zero percent. One exception is $\mathrm{N}\left(\mathrm{CH}_{2} \mathrm{CH}_{2} \mathrm{OH}\right)_{3}$, which has around $20 \%$ OCDF.

Fig. 5.21. shows similar results for the MCB pattern. For all samples, MCB is the most dominant homologue, taking between $40-75 \%$ of the remaining homologues. An exceptional species is $\left[\left(\mathrm{CH}_{3}\right)_{2} \mathrm{~N}\right]_{3} \mathrm{P}(\mathrm{O})$ where MCB percentage is less than $20 \%$. $\left(\mathrm{NH}_{4}\right)_{2} \mathrm{SO}_{4}\left(\mathrm{NH}_{4}\right)_{2} \mathrm{~S}_{2} \mathrm{O}_{3}$ and $\left(\mathrm{NH}_{2}\right)_{2} \mathrm{CO}+\mathrm{S}(1: 1)$ show also high values of around $70 \%$ MCB. The next prevailed pattern for all samples is DiCB. From Fig. 5.21. it seems that $\left(\mathrm{NH}_{4}\right)_{2} \mathrm{SO}_{4}(\mathrm{NH} 4)_{2} \mathrm{~S}_{2} \mathrm{O}_{3}$ and $\left(\mathrm{NH}_{2}\right)_{2} \mathrm{CO}+\mathrm{S}(1: 1)$ can strongly suppress the PeCB and $\mathrm{HxCB}$ and the HpCB-DCB content for that samples is almost zero.

\section{Discussion}

The homologues patterns analysis shows that the most effective inhibitors have a strong effect on the formation mechanisms of PCDD and PCDF. They remove the TCDD amount in combustion with a high percentage of TCDF and MCB. The lower chlorinated dioxin isomers, PeCDF, PeCB and $\mathrm{HxCB}$ isomers show negligible or undetectable amount for those substances and due to their high TEF, they do not contribute to the I-TEQ values.

The samples treated without any inhibitor and samples treated with metal oxides shows higher percentage of the mentioned above isomers. So that their I-TEQ values is also high. The samples where single $\mathrm{N}$ - and $\mathrm{S}$-compounds are used as inhibitors the final PCDD/F and PCB I-TEQ values are low. These samples are present with relatively high TCDD amount which include the amount of the most toxic congener 2,3,7,8-TCDD. The PeCDF , PeCB and HxCB amount is nearly similar to the values of the reference samples without inhibitor.

In general, a constant ratio of various classes of chloroaromatic compounds like PCDD, PCDF and PCB have been found expressed by indicator parameter relationship. This relationship may be explained by quasi- stationary equilibria of the various classes of chloroaromatic compounds occurring by catalytic reactions on the surface of fly ash species. By the inhibitors the catalytic active sides of the fly ash become blocked resulting in breaking down the quasi- stationary equilibria. This is also true for the distribution of homologues with the series PCDD, PCDF and PCB. 
5.2.5. PCDD/F, PCB and PCBz Homologue Distribution for the $\left(\mathrm{NH}_{4}\right)_{2} \mathrm{SO}_{4}$ and $\left(\mathrm{NH}_{4}\right)_{2} \mathrm{~S}_{2} \mathrm{O}_{3}$ Present as $10 \%, 5 \%, 3 \%$ and $1 \%$ of the Fuel.

PCDD and PCDF pattern analysis is also performed for $\left(\mathrm{NH}_{4}\right)_{2} \mathrm{SO}_{4}$ and $\left(\mathrm{NH}_{4}\right)_{2} \mathrm{~S}_{2} \mathrm{O}_{3}$ at 10, 5,3 and $1 \%$ of the fuel. The homologue percentages in Fig. 5.22. are presented as average values of the triplicate experiments with inhibitor and 6 combustion measurements for the samples without inhibitor.

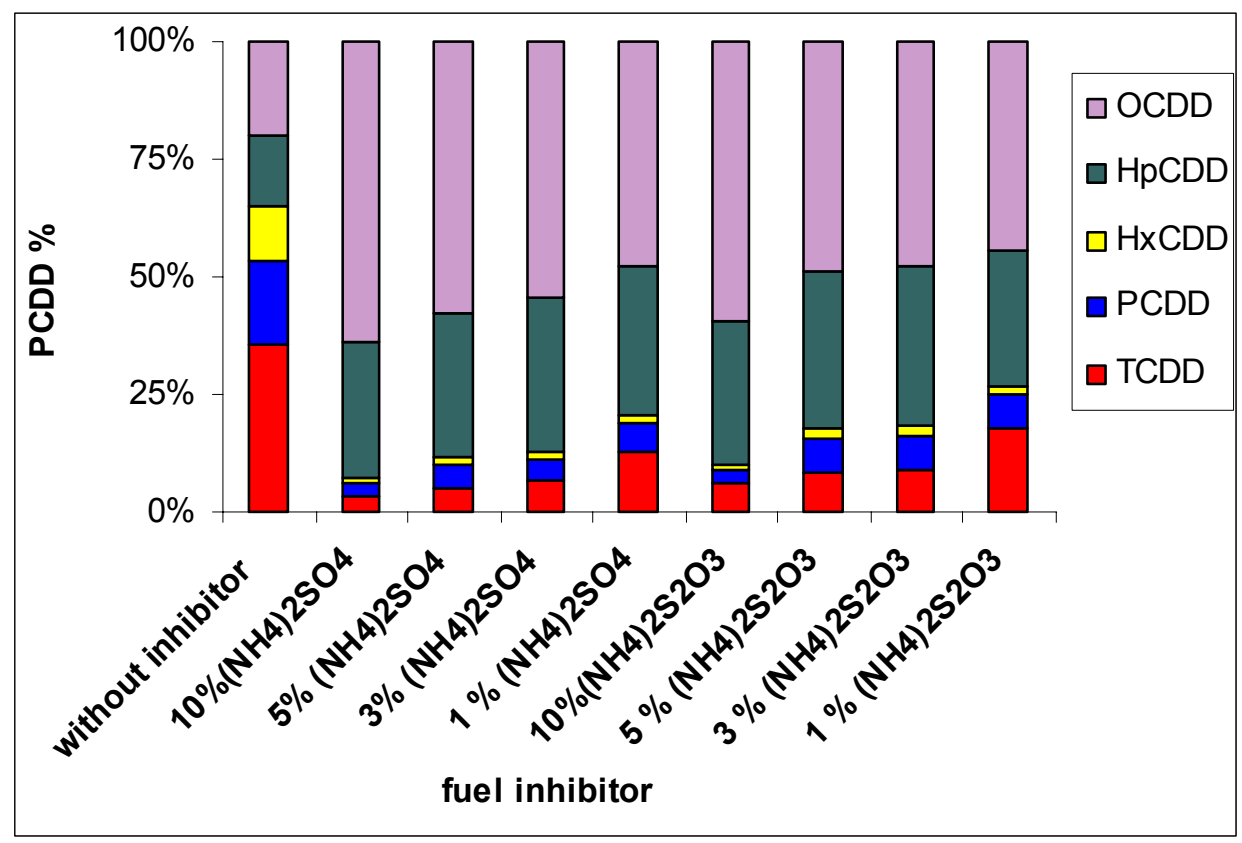

A

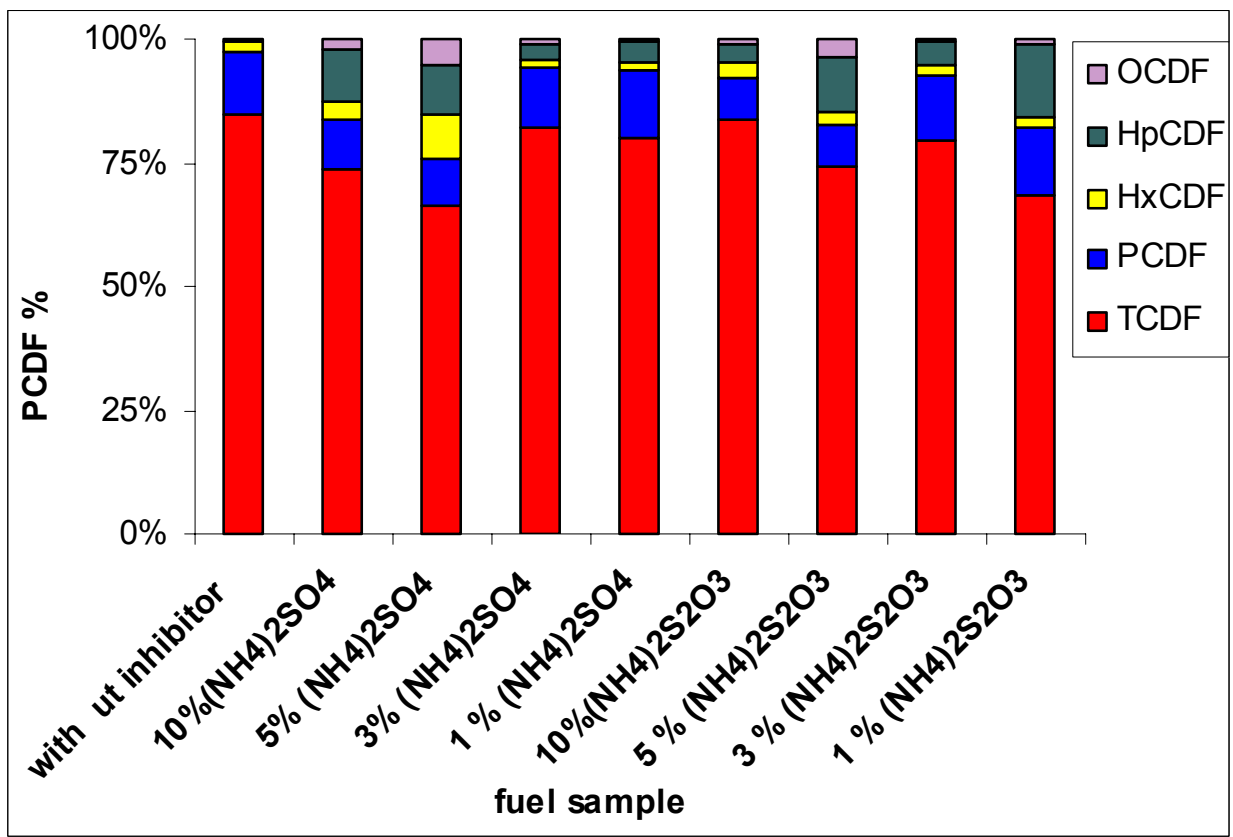

Fig. 5.22: Percentage of $P C D D(A)$ and $P C D F(B)$ homologues mass distribution of the samples without inhibitor and with $10 \%, 5 \%, 3 \%$ and $1 \%\left(\mathrm{NH}_{4}\right)_{2} \mathrm{SO}_{4}$ and $\left(\mathrm{NH}_{4}\right)_{2} \mathrm{~S}_{2} \mathrm{O}_{3}$ during combustion of lignite coal, solid waste and PVC in lab scale experiments 
According to Fig.5.22., it becomes obvious that in the samples with $\left(\mathrm{NH}_{4}\right)_{2} \mathrm{SO}_{4}$ and $\left(\mathrm{NH}_{4}\right)_{2} \mathrm{~S}_{2} \mathrm{O}_{3}$, the lower chlorinated PCDD as TCDD, PeCDD and HxCDD took the smaller part among all other homologues. Despite that, the opposite was found for samples without inhibitors. In that case, the higher chlorinated PCDDs as OCDD, HpCDD and HxCDD took the smaller part of all other homologues. If a trend is observed along different percentages of inhibitors, the result can be proven. The lower percentage of the inhibitors results in the higher percentage of lower chlorinated PCDD. The same relationship is also valid for the I-TEQ PCDD/F values. The percentages of the PCDF homologues are also shown in Fig. 5.22. Here the TCDF is the dominant homologue group for all samples, at around $75 \%$. The next dominant homologue group for almost all samples is PeCDF. While higher percentage of inhibitors can suppress the lower PCDD, the opposite relationship seems to be valid for PCDF. As we have concluded from Fig. 5.18, promising inhibitors such as $\left(\mathrm{NH}_{4}\right)_{2} \mathrm{SO}_{4}$ and $\left(\mathrm{NH}_{4}\right)_{2} \mathrm{~S}_{2} \mathrm{O}_{3}$ used at $10 \%$ can increase the lowerchlorinated furans like TCDF. Thus, reducing the percentage of the inhibitor should decrease the relative TCDF amount. This relation holds true for each sample at $10 \%$ and $5 \%$ of additives and $1 \%$ of $\left(\mathrm{NH}_{4}\right)_{2} \mathrm{~S}_{2} \mathrm{O}_{3}$. The TCDF content is reduced slightly with decreasing the percentage of the inhibitor. The other combustion experiments at $3 \%$ of inhibitor and $1 \%$ of $\left(\mathrm{NH}_{4}\right)_{2} \mathrm{SO}_{4}$ do not obey the abovementioned rules. Instead of TCDF for the samples with $5 \%\left(\mathrm{NH}_{4}\right)_{2} \mathrm{SO}_{4}$ and $\left(\mathrm{NH}_{4}\right)_{2} \mathrm{~S}_{2} \mathrm{O}_{3}, \mathrm{HpCDF}$ and OCDF increase their percentage compared to the reference samples without an inhibitor. All other samples are found at negligible amounts for HxCDF and OCDF.

PCB and PCBz pattern analysis is performed for $\left(\mathrm{NH}_{4}\right)_{2} \mathrm{SO}_{4}$ and $\left(\mathrm{NH}_{4}\right)_{2} \mathrm{~S}_{2} \mathrm{O}_{3}$ at 5,3 and $1 \%$ of the fuel. The homologue percentages in Fig. 5.23 are presented as average values of the triplicate experiments with inhibitor and 6 combustion measurements for the samples without inhibitor. The amount of PCB homologues MCB-DCB and the PCBz homologues TCBz-HxCBz is shown in percentage in Fig.5.23.

Here the MCB is the dominant homologue group for all samples, at around $50 \%$ followed by DiCB at about $20 \%$ and TrCB at about $10 \%$. The higher chlorinated PCB homologues TCB-DCB are present with gradual decreasing percentage. According to Fig. 5.23 it seems that $5 \%$ and $3 \%$ of $\left(\mathrm{NH}_{4}\right)_{2} \mathrm{SO}_{4}$ results slightly decrease of MCB amount prevailed over the TrCB. The lower percentage of $\left(\mathrm{NH}_{4}\right)_{2} \mathrm{SO}_{4}$ results in the higher percentage of higher chlorinated $\mathrm{HxCB}$ and $\mathrm{HpCB}$. The varying amounts of 
5,3 and $1 \%$ of $\left(\mathrm{NH}_{4}\right)_{2} \mathrm{~S}_{2} \mathrm{O}_{3}$ show no changes in $\mathrm{PCB}$ homologues pattern compared to reference samples without an inhibitor.

The percentages of the PCBz homologues are also shown in Fig. 5.23.

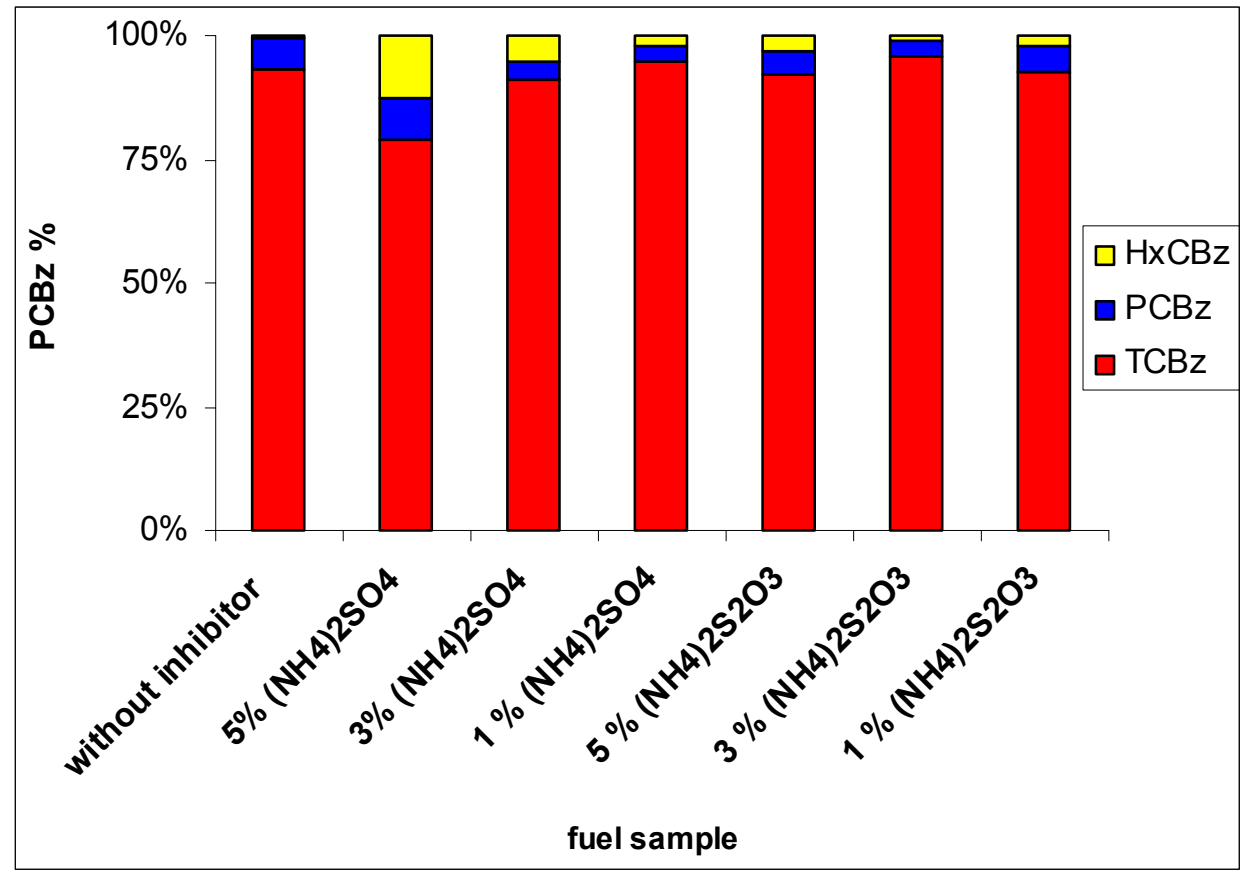

A

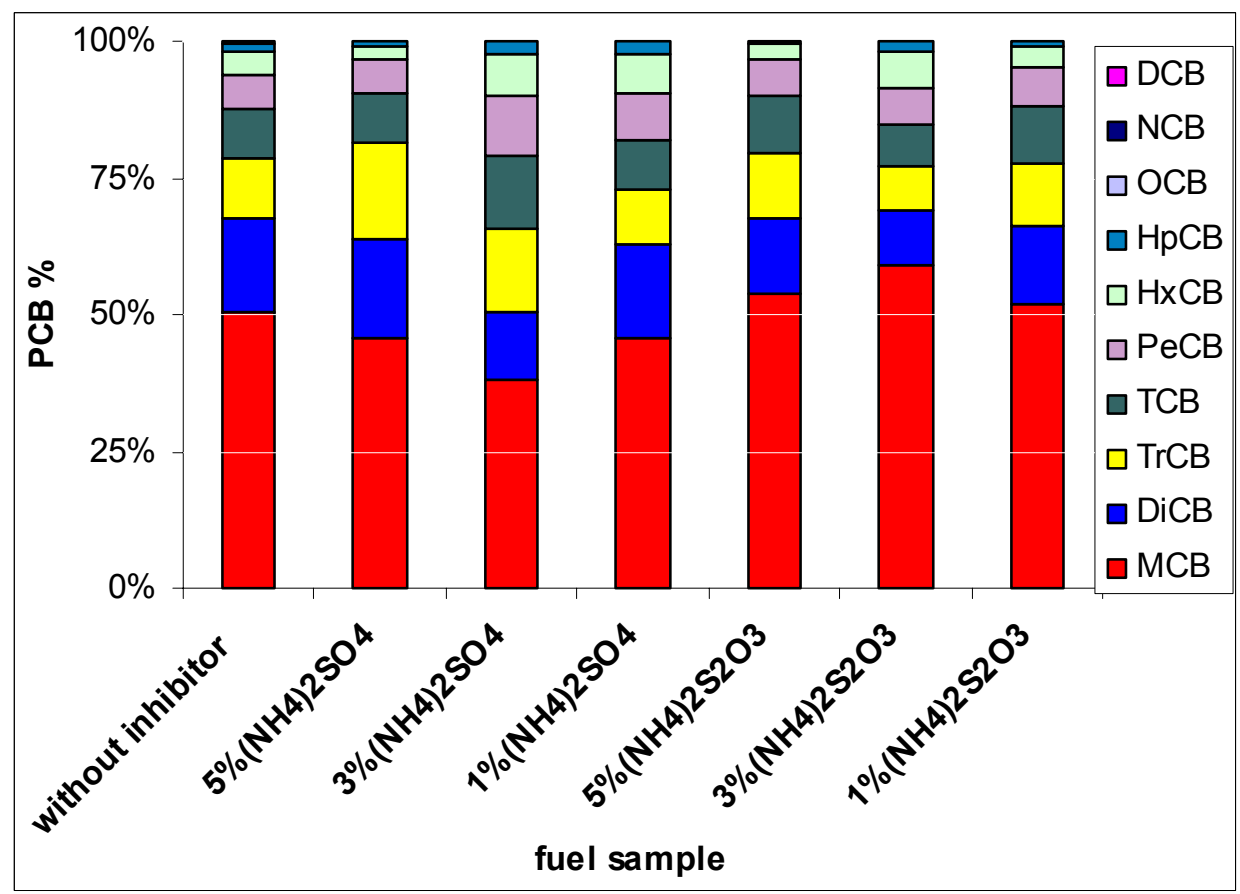

B

Fig. 5.23: Percentage of $P C B(A)$ and $P C B z(B)$ homologues mass distribution of the samples without inhibitor and with $5 \%, 3 \%$ and $1 \%\left(\mathrm{NH}_{4}\right)_{2} \mathrm{SO}_{4}$ and $\left(\mathrm{NH}_{4}\right)_{2} \mathrm{~S}_{2} \mathrm{O}_{3}$ during combustion of lignite coal, solid waste and PVC in lab scale experiments

Here the TCBz is the dominant homologue group for all samples at around $95 \%$. The samples treated without any inhibitors are illustrated in Fig. 5.23 at about 5\% PCBz and amost zero percentage of $\mathrm{HxCBz}$. Taking into account the same figure it 
becomes obvious that the higher percentage of $\left(\mathrm{NH}_{4}\right)_{2} \mathrm{SO}_{4}$ results in a lower percentage of lower chlorinated PCBz. The TCBz amount is gradually increased from $80 \%$ to $95 \%$ with decreasing the $\left(\mathrm{NH}_{4}\right)_{2} \mathrm{SO}_{4}$ concentration. The same effect but not so pronounced is shown for the samples treated with $\left(\mathrm{NH}_{4}\right)_{2} \mathrm{~S}_{2} \mathrm{O}_{3}$.

\section{Discussion}

Higher percentages of the most effective inhibitors $\left(\mathrm{NH}_{4}\right)_{2} \mathrm{SO}_{4}$ and $\left(\mathrm{NH}_{4}\right)_{2} \mathrm{~S}_{2} \mathrm{O}_{3}$ produced lower percentage of lower chlorinated PCDD and PCBz. For the PCDF and PCB content the opposite is found. The lower chlorinated dioxin isomers, PeCDF, PeCB and $\mathrm{HxCB}$ isomers show negligible amounts when those substances are present with $10 \%$ and $5 \%$ of the fuel. That concentrations of $\left(\mathrm{NH}_{4}\right)_{2} \mathrm{SO}_{4}$ and $\left(\mathrm{NH}_{4}\right)_{2} \mathrm{~S}_{2} \mathrm{O}_{3}$ are the best examples where the PCDD/F, PCB and PCBz emissions can be strongly suppressed.

Lower percentage of $3 \%$ and $1 \%\left(\mathrm{NH}_{4}\right)_{2} \mathrm{SO}_{4}$ and $\left(\mathrm{NH}_{4}\right)_{2} \mathrm{~S}_{2} \mathrm{O}_{3}$ produced still lower percentage of lower chlorinated PCDD and PCBz. However, less than 5\% inhibitor of the fuel resulted in a weaker inhibition of TCDD and TCBz. The PeCDF, PeCB and $\mathrm{H} \times \mathrm{CB}$ are illustrated with a higher content comparable to the reference samples without inhibitor. Thus, the inhibition effect of these two substance is slightly decreased. Due to the strong reduction of TCDD amount for the sample at $3 \%$ $\left(\mathrm{NH}_{4}\right)_{2} \mathrm{SO}_{4}$ the PCDD/F I-TEQ value is kept low (Fig. 5.19).

The samples treated without any inhibitor show higher percentage of TCDD, PeCDF, PeCB and PCBz.

\subsubsection{Inhibitory Effect of $\left(\mathrm{NH}_{4}\right)_{2} \mathrm{SO}_{4}$ at $1000^{\circ} \mathrm{C}$}

Laboratory scale experiments are a very sensitive system for sample investigations. Many factors influence the final data results (5.2.1). High temperature of $1000^{\circ} \mathrm{C}$ may establish quite different thermal behaviour of the fuel sample and the additionally used inhibitors.

Based on the preliminary results described above another series experiments are carried out with $\left(\mathrm{NH}_{4}\right)_{2} \mathrm{SO}_{4}$ using different duration of the experiment time (15 min and $60 \mathrm{~min}$ ) and different combustion conditions at a temperature of $1000^{\circ} \mathrm{C}$ in order to find the (1) optimal inhibition, (2) to examine the mechanism of inhibition, (3) to 
obtain comprehensive data set for studies of PCDD, PCDF, PCB and PCBz correlations, (4) the stability and efficiency of the inhibitor.

\subsubsection{Combustion where the sample is introduced at preheated $1000^{\circ} \mathrm{C}$ furnace}

The combustion experiments are performed according to the same procedure each time in order to achieve comparable results. The furnace is electrically preheated to the desired temperature of $1000^{\circ} \mathrm{C}$ and the sample is pushed in the centre of the heating zone and combustion took place $15 \mathrm{~min}$ at a flow of $2 \mathrm{~L} / \mathrm{min}$ synthetic air. Experiments without inhibitor are performed two times. The sample number of that experiments is 0311014 and 0311036 . The sample numbers of $10 \%$ and $5 \%$ $\left(\mathrm{NH}_{4}\right)_{2} \mathrm{SO}_{4}$ used as inhibitor are 0312006 and 0312013.

\section{PCDD/F concentration}

The PCDD/F I-TEQ amount generated during the experiments with a mixture of lignite coal, solid waste and PVC is enough to investigate the effect of inhibition along orders of magnitude. The measured two samples show around $600 \mathrm{pg} / \mathrm{g}$ and around 1200 pg/g PCDD/F I-TEQ values (Fig.5.24). The PCDD/F flue gas concentrations during these experiments is much higher values compared to the same samples at $400^{\circ} \mathrm{C}$. That two-fold difference between the samples is explained by the higher variation during the conducted experiments at $1000^{\circ} \mathrm{C}$.

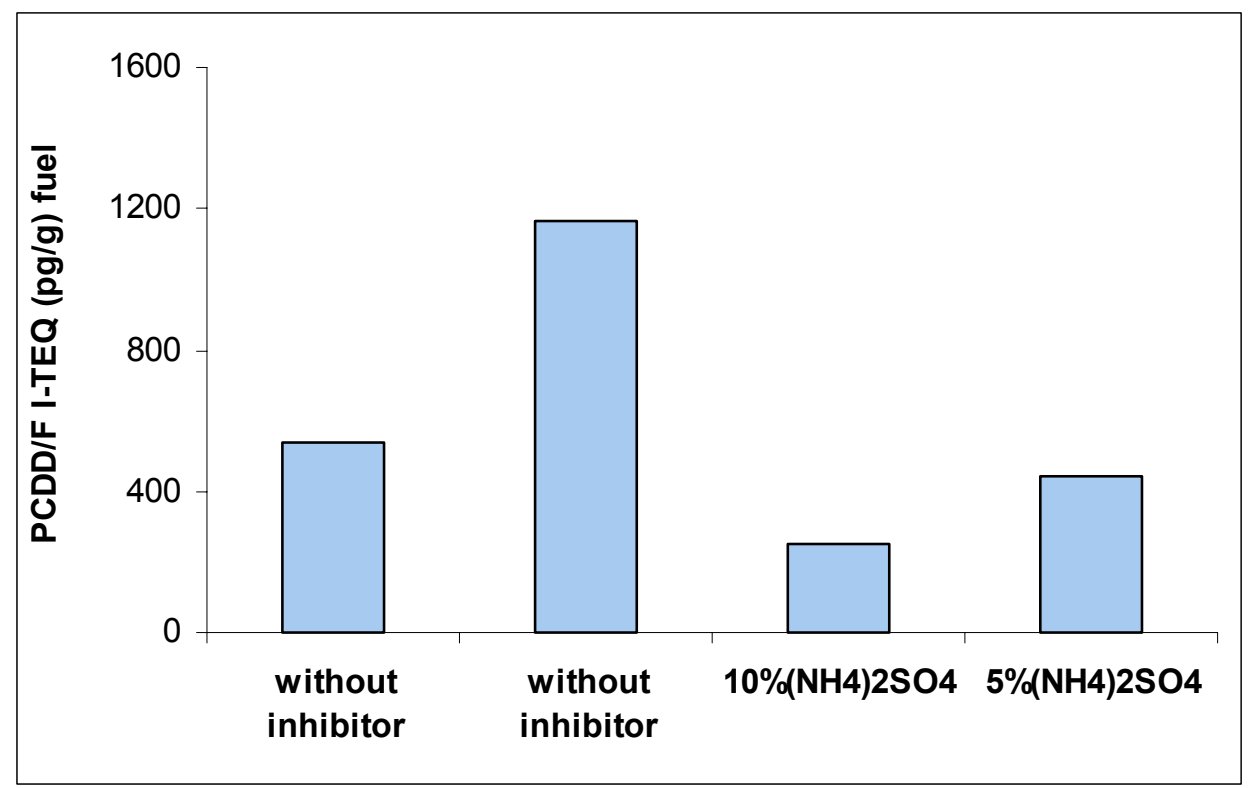

Fig. 5.24: PCDD/F I-TEQ pg/g fuel values in the flue gas at $1000^{\circ} \mathrm{C}$ for the samples without inhibitor and with $\left(\mathrm{NH}_{4}\right)_{2} \mathrm{SO}_{4}$ at $10 \%$ and $5 \%$ introduced at preheated $1000^{\circ} \mathrm{C}$ furnace. 
However, the amount of the most toxic PCDD/F congener 2,3,7,8-TCDD is considered for the samples without inhibitor and with $10 \%$ and $5 \%\left(\mathrm{NH}_{4}\right)_{2} \mathrm{SO}_{4}(\mathrm{Tab}$. 5.13). The samples treated with $\left(\mathrm{NH}_{4}\right)_{2} \mathrm{SO}_{4}$ show non detectable values for this toxic isomer.

Tab. 5.13: 2,3,7,8-TCDD I-TEQ (pg/g) fuel values in the flue gas at $1000^{\circ} \mathrm{C}$ for the samples without inhibitor and with $\left(\mathrm{NH}_{4}\right)_{2} \mathrm{SO}_{4}$ at $10 \%$ and $5 \%$ introduced at preheated $1000^{\circ} \mathrm{C}$ furnace.

\begin{tabular}{|c|c|}
\hline Sample & $2,3,7,8-\mathrm{TCDD}$ I-TEQ $(\mathrm{pg} / \mathrm{g})$ fuel \\
\hline without inhibitor & 3.3 \\
\hline without inhibitor & 8.7 \\
\hline $10 \%\left(\mathrm{NH}_{4}\right)_{2} \mathrm{SO}_{4}$ & n.d. \\
\hline $5 \%\left(\mathrm{NH}_{4}\right)_{2} \mathrm{SO}_{4}$ & n.d. \\
\hline
\end{tabular}

PCB concentration

The measured PCB amount for the two samples treated without inhibitor is around 2 $\mathrm{pg} / \mathrm{g}$ and around $4 \mathrm{pg} / \mathrm{g}$ PCDD/F I-TEQ values (Fig.5.25).

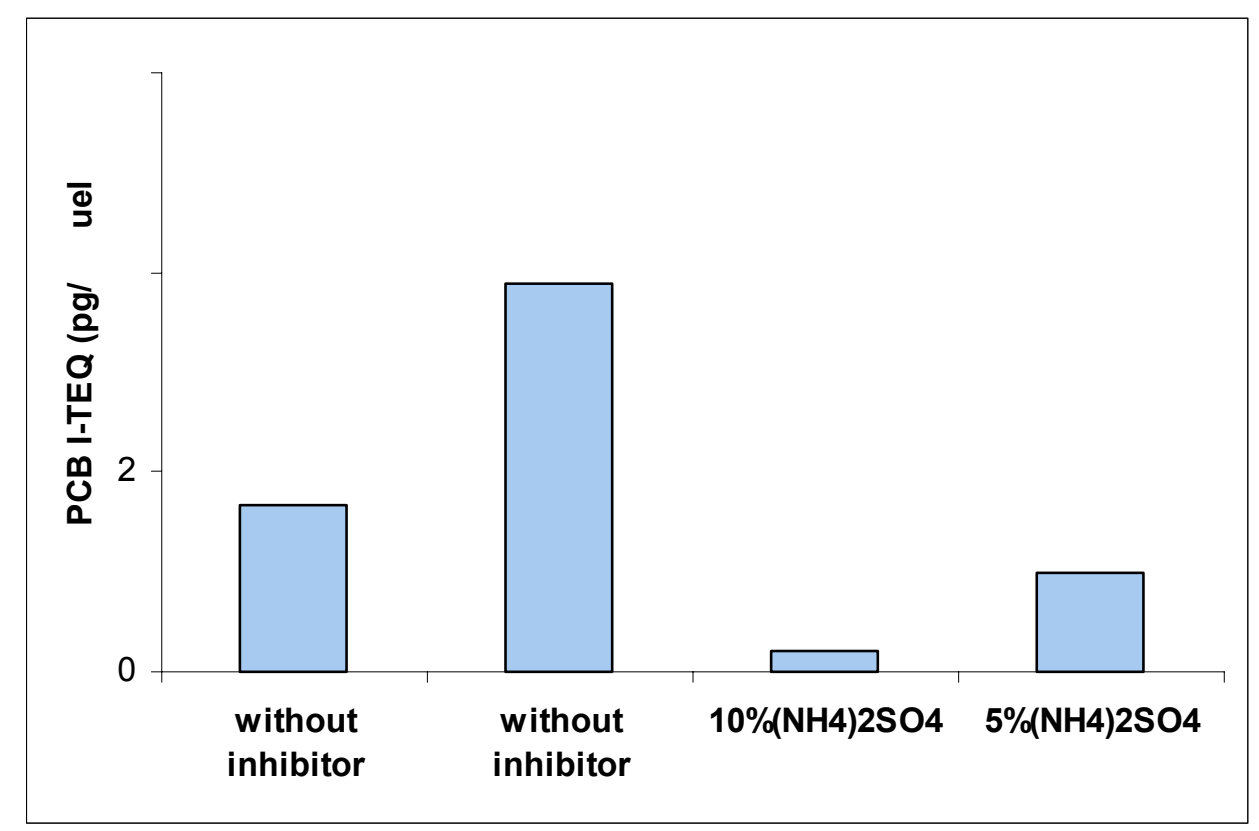

Fig. 5.25: PCB I-TEQ pg/g fuel values in the flue gas at $1000^{\circ} \mathrm{C}$ for the samples without inhibitor and with $\left(\mathrm{NH}_{4}\right)_{2} \mathrm{SO}_{4}$ at $10 \%$ and $5 \%$ introduced at preheated $1000^{\circ} \mathrm{C}$ furnace.

\section{Discussion}

At $1000^{\circ} \mathrm{C}$, higher $\mathrm{PCDD} / \mathrm{F}$ amount for the samples without inhibitor is detected. During these experiments the inhibition effect of $\left(\mathrm{NH}_{4}\right)_{2} \mathrm{SO}_{4}$ shows lower values for PCDD/F and PCB and a non detectable concentration for 2,3,7,8-TCDD isomer. It should be taken into account that the conclusions for inhibitory effect are quite tentative due to low number of cases. 
Probably the much higher PCDD/F and PCB I-TEQ values at $1000^{\circ} \mathrm{C}$ can be explained by the very different combustion conditions during that type of experiments. Here, combustion evolves in a quite different way compared to that at $400^{\circ} \mathrm{C}$. The introduced sampling boat in the hot zone of the furnace at $1000^{\circ} \mathrm{C}$ cause a lot of sooty gases in oven for short time. Soot appeared in the first couples of minutes of the experiment. The chlorine sources such as solid waste and PVC of the sample fuel are completely burnt during the shorter experimental time. Due to the lower temperature of $400^{\circ} \mathrm{C}$ and more stable combustion the formation of the high soot did not occur. It's recommendable that the experiments at $1000^{\circ} \mathrm{C}$ for the best inhibitor by employing an adjusted protocol, which avoids the fast initial poor combustion be repeated. It is proposed to push the sample in already to $200^{\circ} \mathrm{C}$ preheated hot zone and continuously increase the temperature to $1000^{\circ} \mathrm{C}$. That can avoid the soot formation during the experiment and provide good performance and representability.

\subsubsection{Combustion where the sample is introduced at preheated $200^{\circ} \mathrm{C}$} programmed furnace

The combustion experiments are performed according to the same procedure each time in order to achieve comparable results. The furnace is preheated to $200^{\circ} \mathrm{C}$ and the sample is pushed in the centre of the heating zone. Immediately the furnace is set to $800^{\circ} \mathrm{C}$ for $30 \mathrm{~min}$ and in a final step to $1000^{\circ} \mathrm{C}$ for another $30 \mathrm{~min}$. The combustion took time $60 \mathrm{~min}$ at a flow of $2 \mathrm{~L} / \mathrm{min}$ synthetic air. Experiments with a mixture of $80 \%$ lignite coal and $20 \%$ (13.3: 6.7 ratio) solid waste and PVC are performed two times. The sample numbers of these experiments are 0402016 and 0403001. Experiments at $5 \%\left(\mathrm{NH}_{4}\right)_{2} \mathrm{SO}_{4}$ used as inhibitor are performed also two times. The sample numbers of these experiments are 0402028 and 0402036.

\section{PCDD/F concentration}

The PCDD/F I-TEQ amount generated during the experiments with a mixture of lignite coal, solid waste and PVC is enough to investigate the effect of inhibition along orders of magnitude. The two samples show around $60 \mathrm{pg} / \mathrm{g}$ and around $25 \mathrm{pg} / \mathrm{g}$ PCDD/F I-TEQ (Fig. 5.26). These amount is slightly higher compared to the same samples performed at $400^{\circ} \mathrm{C}$ but much lower than the experiments at $1000^{\circ} \mathrm{C}$ where the sampling boat was pushed into the hot zone for a experimental time of $15 \mathrm{~min}$. 
The difference determined between the samples is also around two-fold for this type of samples. The sample generated first among this series of experiments exhibits the highest concentration of dioxins at $60 \mathrm{pg} / \mathrm{g}$. It is a sample without an inhibitor. Second and third samples treated with $5 \%\left(\mathrm{NH}_{4}\right)_{2} \mathrm{SO}_{4}$. According to Fig. 5.23 it seems that the PCDD/F I-TEQ amount decrease among this two repeated samples. If the average values of PCDD/F for the two type of samples are taken in account then the inhibitory effect of $\left(\mathrm{NH}_{4}\right)_{2} \mathrm{SO}_{4}$ is estimated up to $90 \%$.

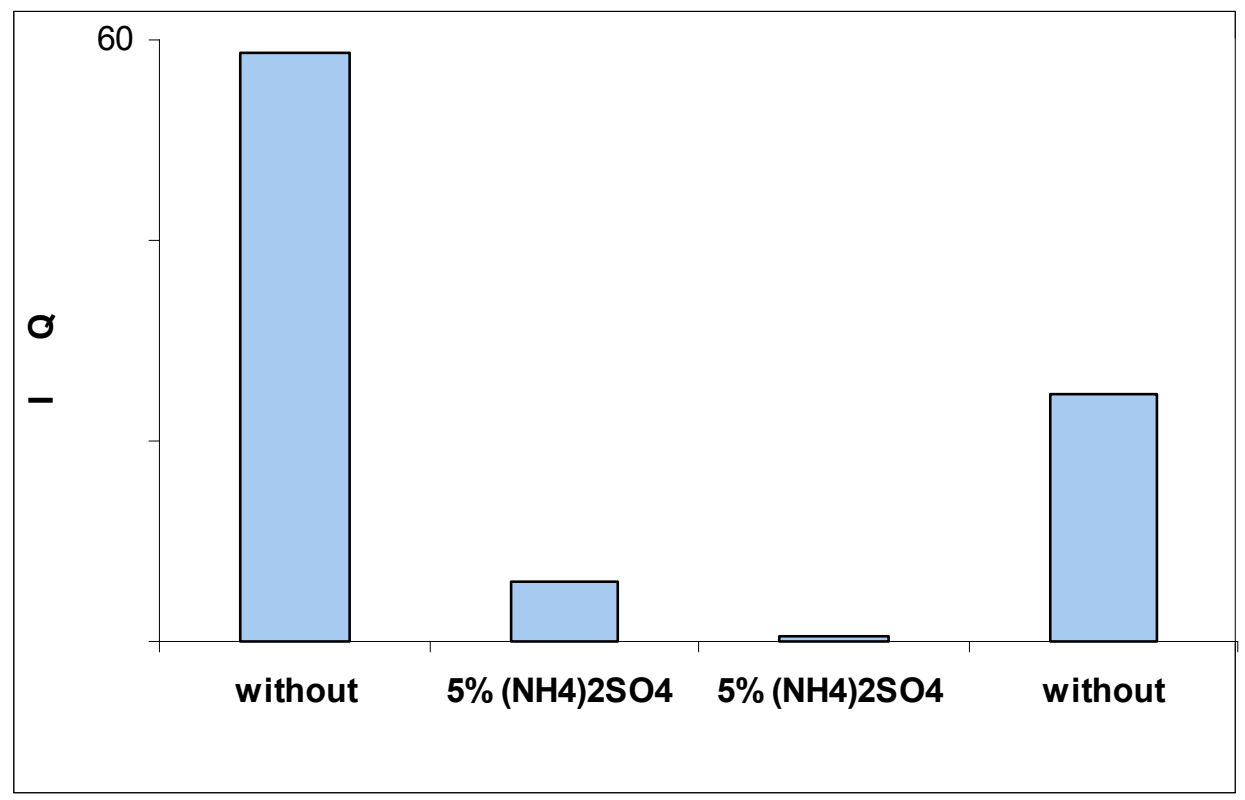

Fig. 5.26: PCDD/F I-TEQ pg/g fuel values in the flue gas at $1000^{\circ} \mathrm{C}$ for the samples without inhibitor and with $\left(\mathrm{NH}_{4}\right)_{2} \mathrm{SO}_{4}$ at $5 \%$ introduced at preheated $200^{\circ} \mathrm{C}$ programmed furnace.

\section{PCB concentration}

Only one sample treated without inhibitor was analysed for the PCB concentration. The amount of $1.6 \mathrm{pg} / \mathrm{g}$ PCB I-TEQ value in Fig. 5.27 is similar to the one of the generated PCB concentrations during the experiments at $1000^{\circ} \mathrm{C}$ with experimental time of $15 \mathrm{~min}$ (Fig. 5.25). The two samples where $5 \%$ of $\left(\mathrm{NH}_{4}\right)_{2} \mathrm{SO}_{4}$ is used as a inhibitor show significant suppressed effect for the PCB emissions. It is estimated up to $75-97 \%$. The variation between both results is lower than the PCDD/F variables for the same samples. 


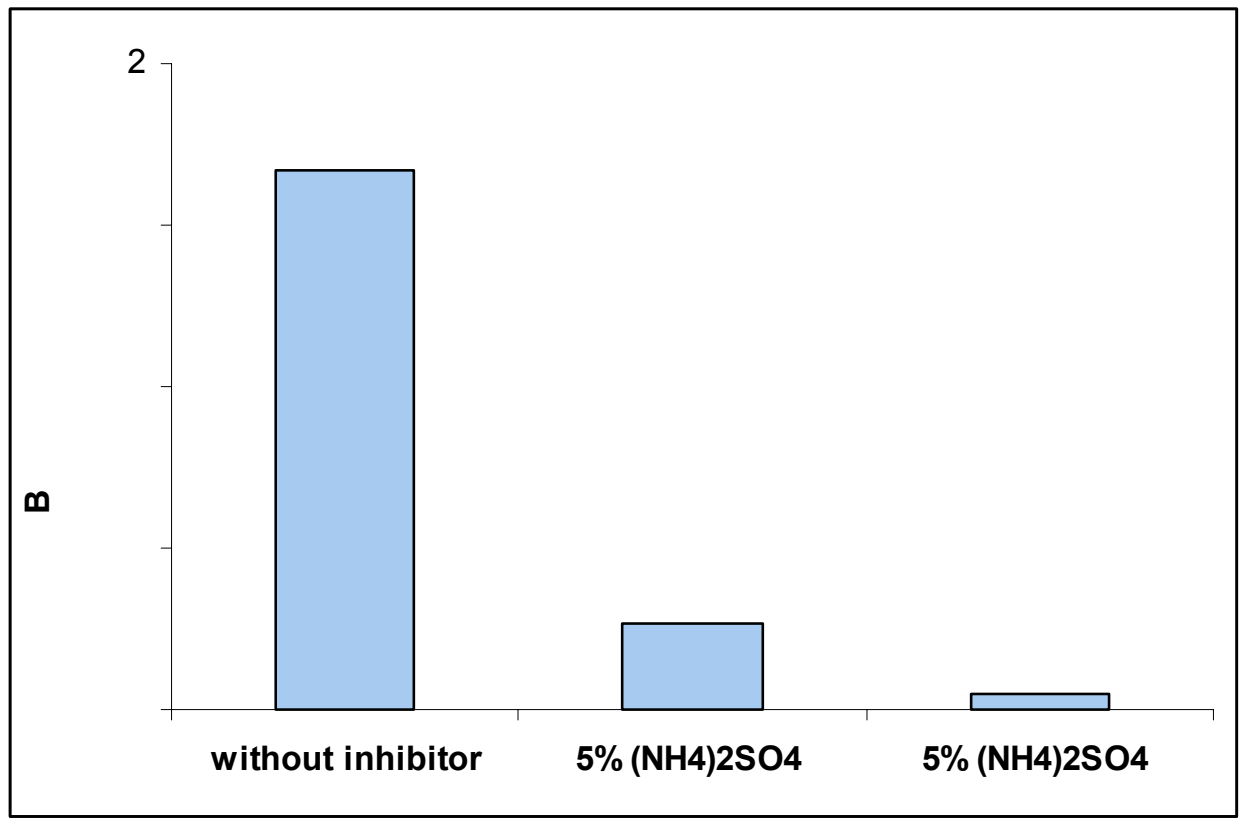

Fig. 5.27: PCB I-TEQ pg/g fuel values in the flue gas at $1000^{\circ} \mathrm{C}$ for the sample without inhibitor and with $\left(\mathrm{NH}_{4}\right)_{2} \mathrm{SO}_{4}$ at $5 \%$ introduced at preheated $200^{\circ} \mathrm{C}$ programmed furnace.

\section{PCBz concentration}

Both samples treated with $5 \%\left(\mathrm{NH}_{4}\right)_{2} \mathrm{SO}_{4}$ and the sample without inhibitor was also analysed for PCBz concentration. The results are shown in Fig. 5. 28.

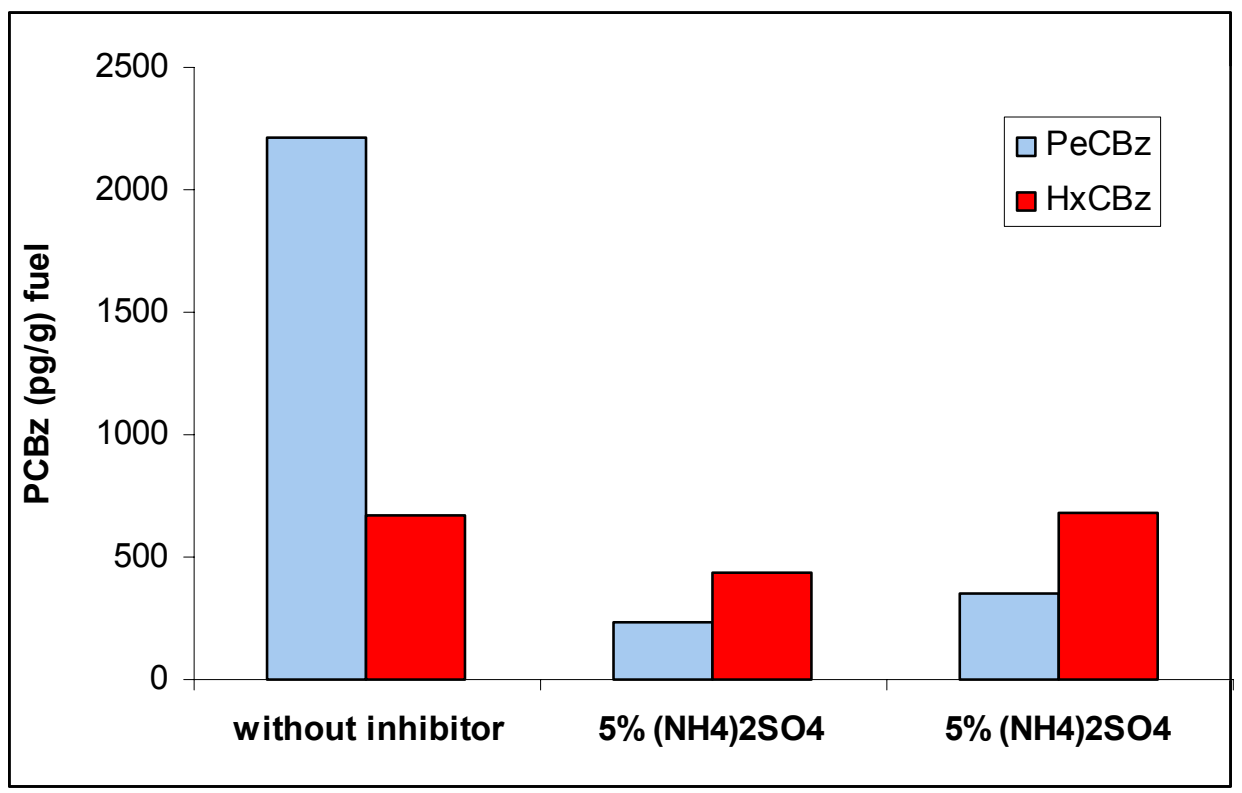

Fig. 5.28: $P C B z \mathrm{pg} / \mathrm{g}$ fuel values in the flue gas at $1000^{\circ} \mathrm{C}$ for the sample without inhibitor and with $\left(\mathrm{NH}_{4}\right)_{2} \mathrm{SO}_{4}$ at $5 \%$ introduced at preheated $200^{\circ} \mathrm{C}$ programmed furnace.

Due some impurities in the samples the lower chlorinated TCBz were not calculated.

Fig. 5.28 present the amount of the penta- and hexa-chlorinated benzenes. Regarding PeCBz the inhibitory effect of $5 \%\left(\mathrm{NH}_{4}\right)_{2} \mathrm{SO}_{4}$ is estimated up to $85-90 \%$. 
However, the $\mathrm{HxCBz}$ amount is not reduced when the inhibitor is used. The values for that homologue are nearly similar for all samples.

\section{Discussion}

Combustion of lignite coal, solid waste and PVC where the sample is introduced at preheated $200^{\circ} \mathrm{C}$ programmed furnace generate high PCDD/F, PCB and PCBz concentrations. These values are much higher compared to the emissions measured at $400^{\circ} \mathrm{C}$ for the same type of samples. However, the dioxins amount during that combustion procedure are about 10 times lower than the values estimated at $1000^{\circ} \mathrm{C}$ where the sample was pushed into the hot zone. Using the procedure where the sample is gradually preheated into the hot zone, better combustion was occurred.

Strong suppression of PCDD/F, PCB and PCBz is estimated when $5 \%\left(\mathrm{NH}_{4}\right)_{2} \mathrm{SO}_{4}$ is added to the fuel. The variables determined between the results are less than twofold for this type of samples. No inhibition of $\mathrm{HxCBz}$ is evaluated during the experiments with $5 \%\left(\mathrm{NH}_{4}\right)_{2} \mathrm{SO}_{4}$. Despite the amount of the $\mathrm{PeCBz}$ is sufficiently reduced.

The final conclusions state that if $\left(\mathrm{NH}_{4}\right)_{2} \mathrm{SO}_{4}$ is used at concentration of $5 \%$ of the fuel, the optimal inhibition of PCDD/F, PCB and PCBz formation is determined. The stability and the efficiency of the inhibitor at high temperature such as $1000^{\circ} \mathrm{C}$ are still valid. The reduction by its use is estimated up to $90 \%$. Thus, $\left(\mathrm{NH}_{4}\right)_{2} \mathrm{SO}_{4}$ can block successfully the chloroaromatic mechanisms of dioxin formation in the postcombustion zone of an incinerator. This compound is low cost and non-toxic materials, making it applicable for use in full-scale combustion units. 


\subsection{Correlation between PCDD, PCDF, PCB and PCBz in coal / solid waste and PVC combustion at the influence of various inhibitors.}

The relationship between PCDD/F and indicator parameters can be used in several ways, e.g. for optimizing incinerator operating condition, for emission monitoring. Furthermore using of indicator parameters can save a lot of time and make the $\mathrm{PCDD} / \mathrm{F}$ control emission low cost.

\subsubsection{Correlation between PCDD, PCDF, PCB and PCBz. Influence of Varying Inhibitors Amount}

Principle component analysis (PCA) is used in order to give a better view of the similarity between the 21 samples including samples treated with and without inhibitor and different percentage of inhibitors (Tab 5.14.). The matrix used for statistical investigation of PCB, PCBz and PCDD/F includes 36 variables, see Tab. 5.15 .

Tab. 5.14: Number of the cases used for PCA and CA statistical analyses.

\begin{tabular}{|c|c|c|c|}
\hline $\mathrm{S} 1$ & $5 \%\left(\mathrm{NH}_{4}\right)_{2} \mathrm{SO}_{4}$ & $\mathrm{~S} 11$ & without inhibitor \\
\hline $\mathrm{S} 2$ & $5 \%\left(\mathrm{NH}_{4}\right)_{2} \mathrm{~S}_{2} \mathrm{O}_{3}$ & $\mathrm{~S} 12$ & $1 \%\left(\mathrm{NH}_{4}\right)_{2} \mathrm{SO}_{4}$ \\
\hline $\mathrm{S} 3$ & $3 \%\left(\mathrm{NH}_{4}\right)_{2} \mathrm{SO}_{4}$ & $\mathrm{~S} 13$ & $1 \%\left(\mathrm{NH}_{4}\right)_{2} \mathrm{~S}_{2} \mathrm{O}_{3}$ \\
\hline $\mathrm{S} 4$ & $3 \%\left(\mathrm{NH}_{4}\right)_{2} \mathrm{~S}_{2} \mathrm{O}_{3}$ & $\mathrm{~S} 14$ & $1 \%$ urea+S $(1: 1)$ \\
\hline $\mathrm{S} 5$ & $1 \%\left(\mathrm{NH}_{4}\right)_{2} \mathrm{~S}_{2} \mathrm{O}_{3}$ & $\mathrm{~S} 15$ & $3 \%\left(\mathrm{NH}_{4}\right)_{2} \mathrm{SO}_{4}$ \\
\hline $\mathrm{S} 6$ & $1 \%\left(\mathrm{NH}_{4}\right)_{2} \mathrm{SO}_{4}$ & $\mathrm{~S} 16$ & $3 \%\left(\mathrm{NH}_{4}\right)_{2} \mathrm{~S}_{2} \mathrm{O}_{3}$ \\
\hline $\mathrm{S} 7$ & $5 \%\left(\mathrm{NH}_{4}\right)_{2} \mathrm{SO}_{4}$ & $\mathrm{~S} 17$ & $3 \% \mathrm{urea}+\mathrm{S}(1: 1)$ \\
\hline $\mathrm{S} 8$ & $5 \%\left(\mathrm{NH}_{4}\right)_{2} \mathrm{SO}_{4}$ & $\mathrm{~S} 18$ & $3 \%\left(\mathrm{NH}_{4}\right)_{2} \mathrm{SO}_{4}$ \\
\hline $\mathrm{S} 9$ & $5 \%\left(\mathrm{NH}_{4}\right)_{2} \mathrm{~S}_{2} \mathrm{O}_{3}$ & $\mathrm{~S} 19$ & $3 \%\left(\mathrm{NH}_{4}\right)_{2} \mathrm{~S}_{2} \mathrm{O}_{3}$ \\
\hline $\mathrm{S} 10$ & $5 \%\left(\mathrm{NH}_{4}\right)_{2} \mathrm{~S}_{2} \mathrm{O}_{3}$ & $\mathrm{~S} 20$ & $1 \%\left(\mathrm{NH}_{4}\right)_{2} \mathrm{SO}_{4}$ \\
\hline & $\mathrm{S} 21$ & $1 \%\left(\mathrm{NH}_{4}\right)_{2} \mathrm{~S}_{2} \mathrm{O}_{3}$ \\
\hline
\end{tabular}


Tab.5.15: Number of the variables used for PCA and CA statistical analyses. * - I-TEQ value

\begin{tabular}{|c|c|c|c|c|c|}
\hline V1 & TCDD & V13 & $\mathrm{PCDD} / \mathrm{F}$ * & V25 & $\mathrm{HxCDF}$ * \\
\hline V2 & PeCDD & V14 & TCB * & V26 & HpCDF * \\
\hline V3 & $\mathrm{HxCDD}$ & V15 & PeCB * & V27 & $\mathrm{TCDD} / \mathrm{F}^{*}$ \\
\hline V4 & HpCDD & V16 & $\mathrm{H} \times \mathrm{CB}$ * & V28 & $\mathrm{PeCDD} / \mathrm{F}^{*}$ \\
\hline V5 & OCDD & V17 & $\mathrm{HpCB}$ * & V29 & $\mathrm{HxCDD} / \mathrm{F}^{*}$ \\
\hline V6 & Sum PCDD & V18 & PCB * & V30 & $\mathrm{HpCDD} / \mathrm{F}^{*}$ \\
\hline V7 & TCDF & V19 & TCDD * & V31 & $1,2,3,5-\mathrm{TClBz}$ \\
\hline V8 & PeCDF & V20 & PeCDD * & V32 & $1,2,4,5-\mathrm{TCIBz}$ \\
\hline V9 & HxCDF & V21 & $\mathrm{HxCDD}$ * & V33 & 1,2,3,4-TCIBz \\
\hline V10 & HpCDF & V22 & HpCDD * & V34 & $\mathrm{PeClBz}$ \\
\hline V11 & OCDF & V23 & TCDF * & V35 & $\mathrm{HxClBz}$ \\
\hline V12 & Sum PCDF & V24 & PeCDF * & V36 & Sum PCIBz \\
\hline
\end{tabular}

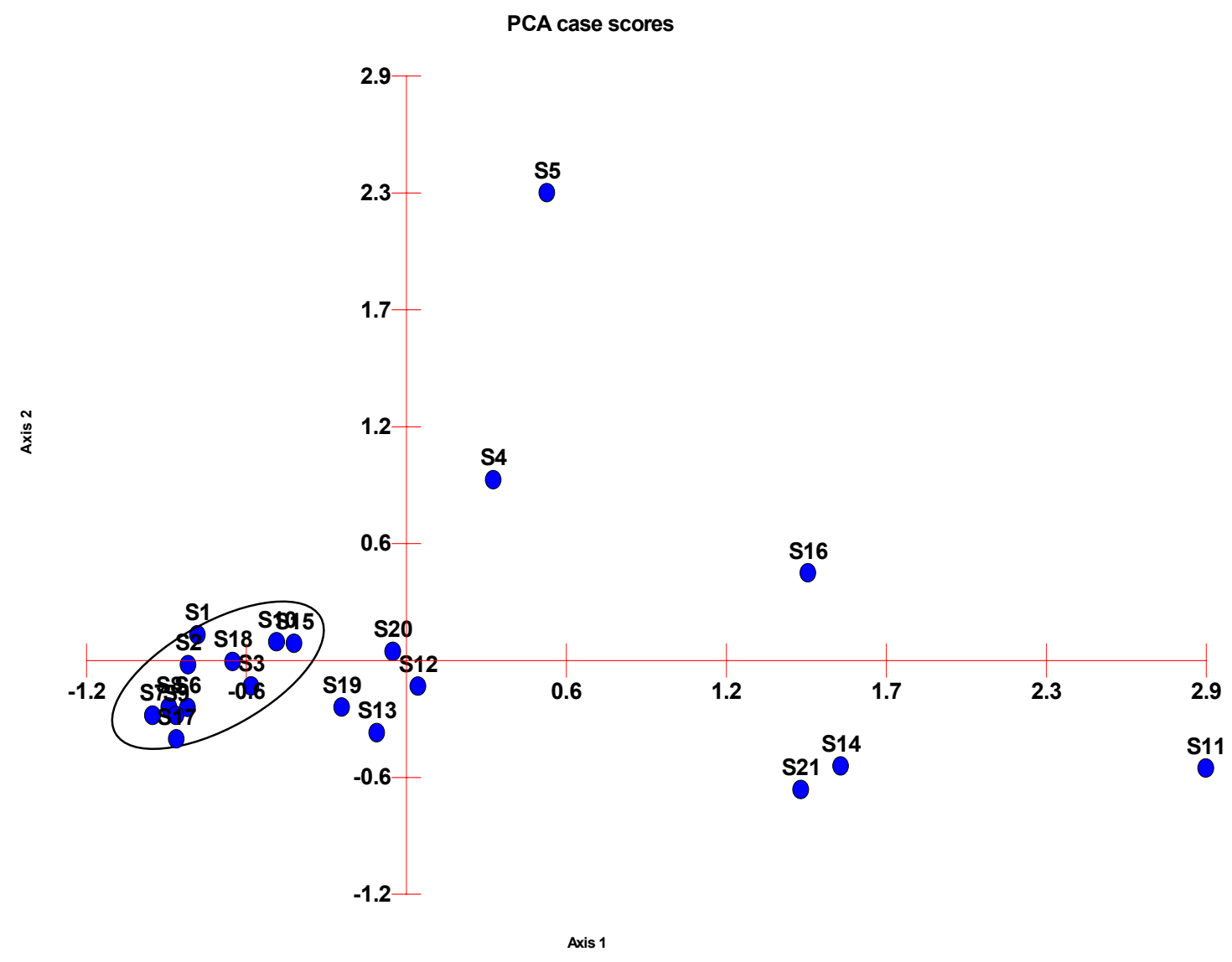

Fig.5.27: PCA score plot of 21 cases (samples) and 36 variables (PCDD/F, PCB and PCBZ homologues) 
One agglomerated group of samples, placed to the left of the ordinate axis is observed in the proposed PCA score plots (Fig. 5.27). These are the samples with lower concentrations of the investigated toxic compounds or samples treated with higher percentage such as $5 \%$ and $3 \%$ of the inhibitor. The samples to the right of the ordinate and in the middle of the multidimensional space are the ones without inhibitor and with higher amount of PCDD/F, PCB and PCBz i.e. to the sample number S4, S5, S11, S12, S13, S14, S16, S19, S20 and S21. The more right the points in the statistical plot are appear the higher the concentration of PCDD/F has been found. Since S11 belongs to a sample treated without an inhibitor, and it is placed extremely to the right in the score plot. Vicinity of these toxic sample are some other points which can be attributed to the 1\%( $\left(\mathrm{NH}_{2}\right)_{2} \mathrm{CO}+\mathrm{S}(1: 1), 3 \%\left(\mathrm{NH}_{4}\right)_{2} \mathrm{~S}_{2} \mathrm{O}_{3}$ and $1 \%\left(\mathrm{NH}_{4}\right)_{2} \mathrm{~S}_{2} \mathrm{O}_{3}$. It is already known that these two inhibitors show weaker inhibitory effect than $\left(\mathrm{NH}_{4}\right)_{2} \mathrm{SO}_{4}$. Their PCDD/F, PCB and PCBz reduction ability is highly decreased at $3 \%$ of the fuel.

CA is performed separately for these two groups of samples visualised by the PCA score plot (Fig. 5.28).

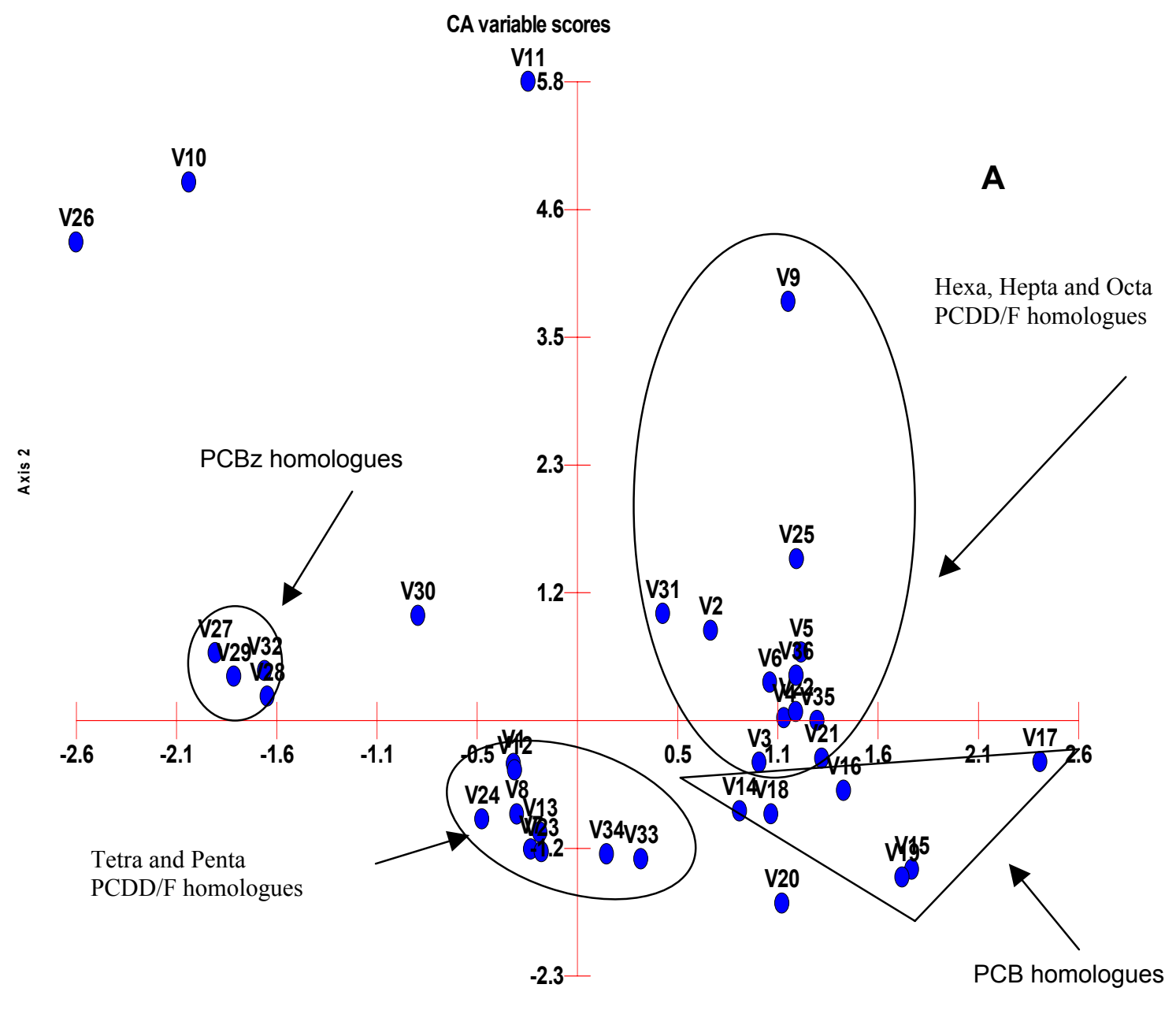




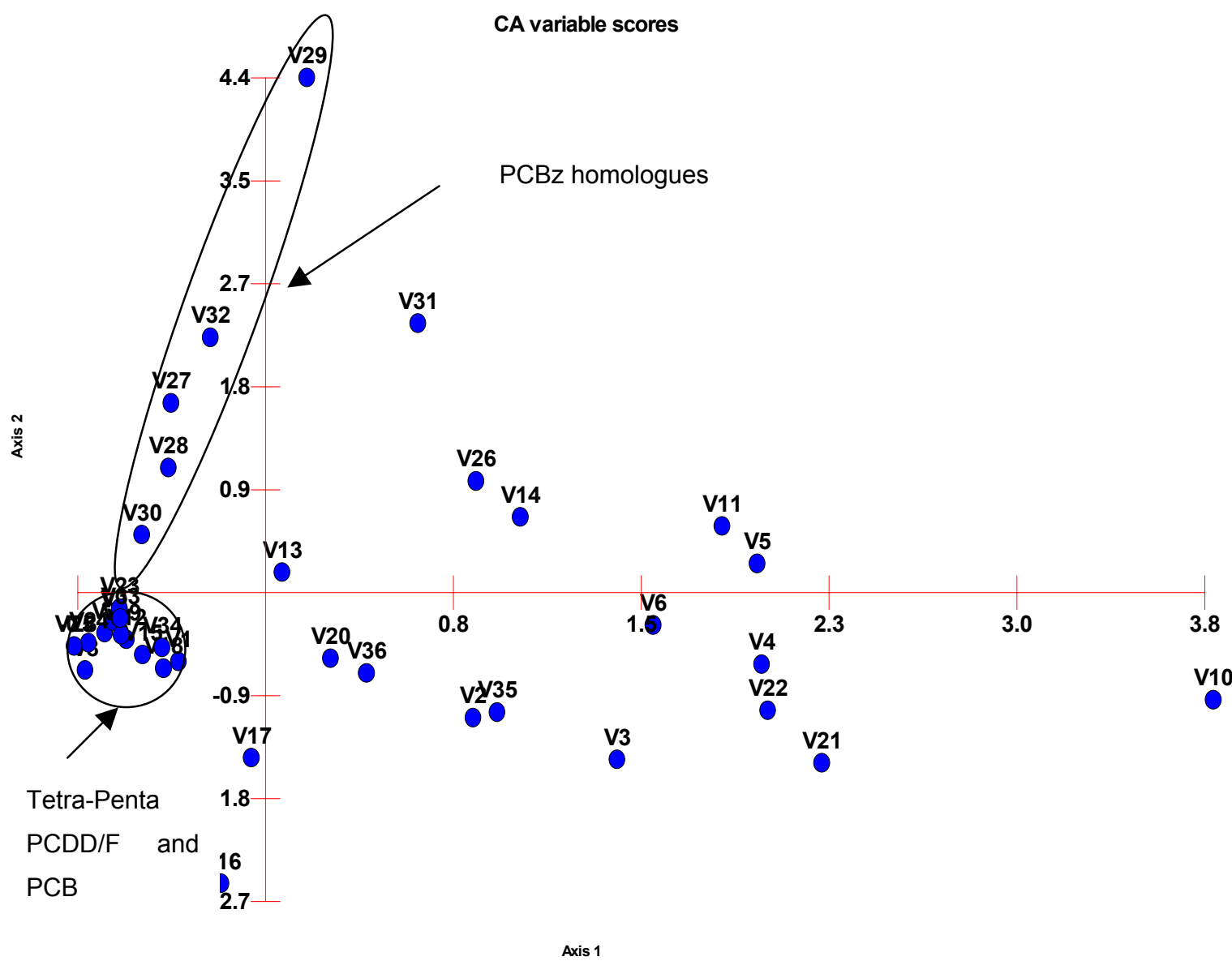

Fig. 5.28: CA score variables plots for the samples with lower TEQ (A) and higher TEQ (B)

The first matrix used for CA includes 10 cases and 36 variables and the second is present with 11 cases and 36 variables. Taking into account that in case of the effective inhibitors the higher chlorinated PCDD/F prevailed over the lower chlorinated one, Fig. 5.28 (B) proves this statement. Thus, the tetra-penta PCDD/F are placed more to the left of the ordinate axis and hexa, hepta and octa PCDD/F group to the right of the multidimensional space. In the score plot (B) the observed agglomerated groups are mostly pairs which consist of different classes of compounds and/or different levels chlorinated congeners. There is also one main group of samples placed to the left of the ordinate axis. It includes almost all tetra and penta PCDD/F congeners, PeCB I-TEQ and PCB I-TEQ variables. This agglomerate is very close to the PCBz group.

So that many different combinations of good correlated tetra and penta PCDD/F, PCB and PCBz congeners and homologues can be elaborated.

Some of the most interesting corresponding correlations are drawn in two dimensional figures in Fig. 5.29. 

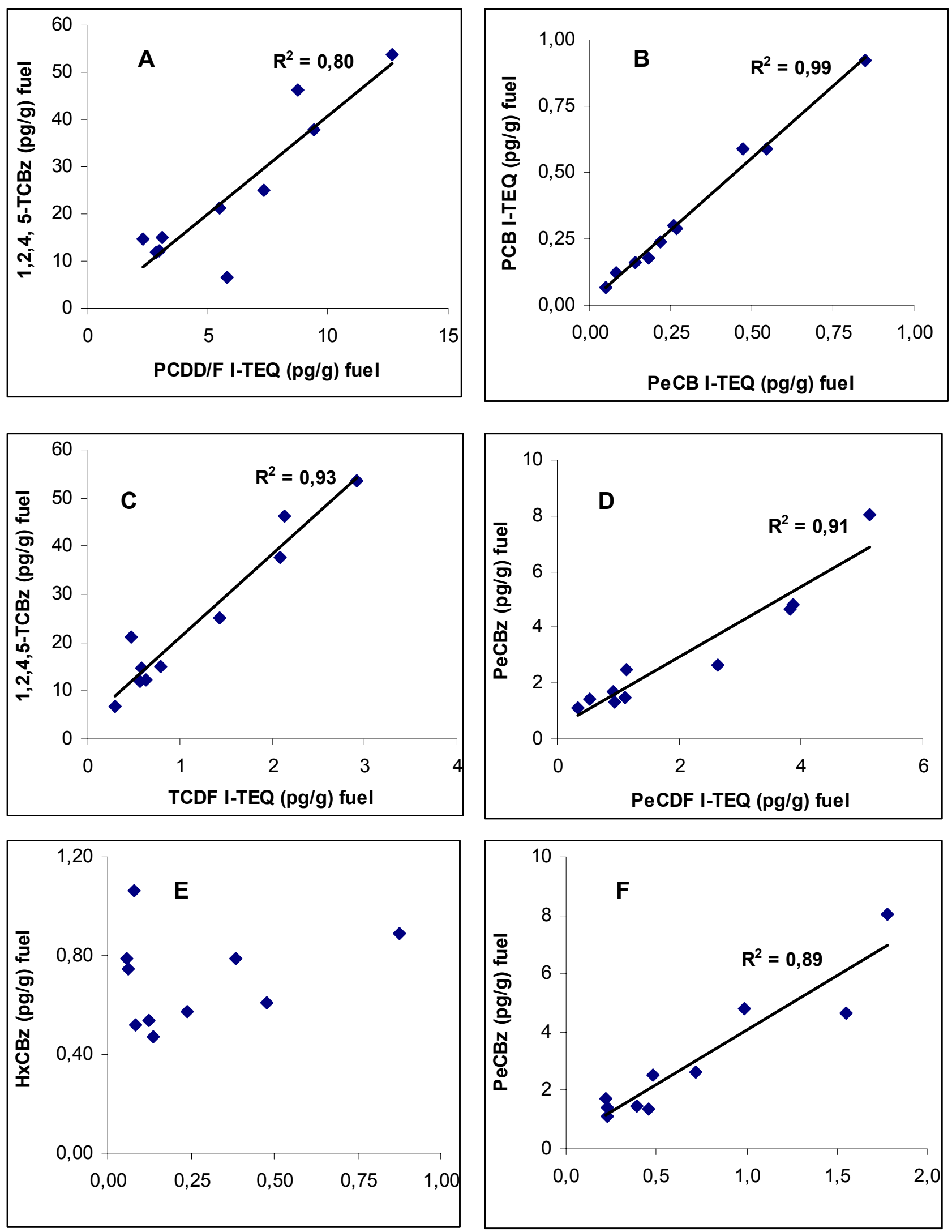

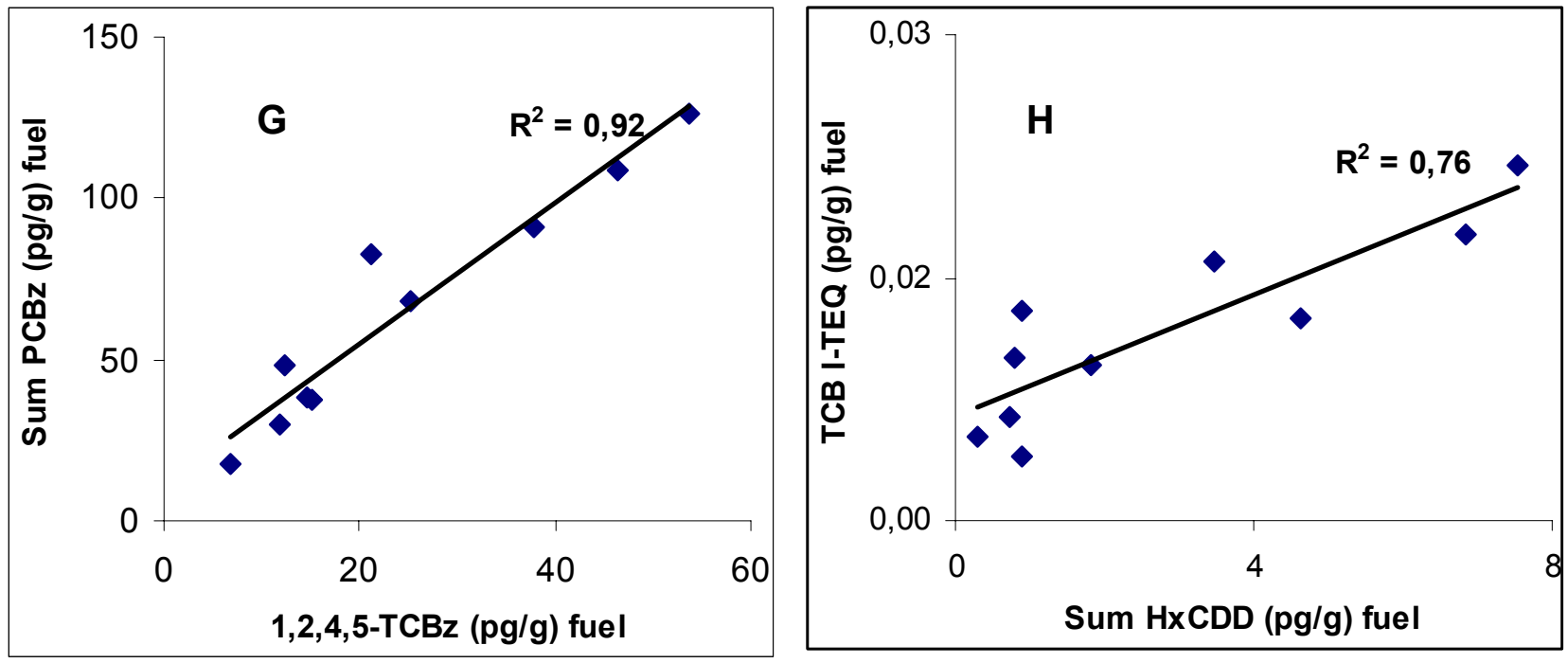

Fig. 5.29: Couple points of score variables plot (B) of CA in Fig. 22.(V15 and V18 (A); V13 and V32 (B), V23 and V32 (C); V24 and V34 (D); V25 and V35 (E); V 19 and V34 (F); V32 and V36 (G); V3 and V14 (H)).

A well expressed linear dependance is found for PeCB I-TEQ value and PCB I-TEQ value for the samples treated without inhibitor or with low percentage of inhibitor. The total PCDD/F I-TEQ amount is well correlated with 1,2,4,5-TCBz congener. The last one shows also high correlation coefficients of determination $\left(R^{2}\right)$ with TCDF I-TEQ value. On the basis of plot $(G)$ an implication that 1,2,4,5-TCBz strongly correlated with the sum of all PCBz congeners can be made. According to Fig. 5.23 the concentration profile I-TEQ value of the most toxic 2,3,7,8-TCDD congener is quantitatively similar to those of $\mathrm{PeCBz}$. A fairly good relationship is obtained for PeCBz and PCDF I-TEQ. However, the higher chlorinated HxCDF and $\mathrm{HxCBz}$ congeners do not show correlation. The PCB homologues and the other PCDD/F and PCBz for the samples with higher toxicity have relatively low correlation coefficient. These homologues are placed far apart in score plot (B) of Fig. 5.29., the results demonstrate that TCB I-TEQ can be correlated with the sum of HxCDD in flue gas even with a low correlation coefficients.

Fig. 5.23 show the correlation between tetra and penta PCBz and PCDF corresponding homologues and some of the close by located variables points of score plot (A ) Fig. 5. 28. Most of the observed pairs of variables in the same score plot belong to the same class of compounds. No correlation is observed between tetra and penta PCBz homologues and the corresponding PCDF- homologues (Fig. 5.30) for the samples with lower toxicities. Even the close to space located variables in the multidimensional space such as the higher chlorinated PCDD/F and PCB homologues show no any relationship. Only TCB I-TEQ and sum of HxCDD show 
significantly high correlation coefficient. Also $1,2,4,5-\mathrm{TCBz}$ is strongly correlated with the sum of PCBz homologues.
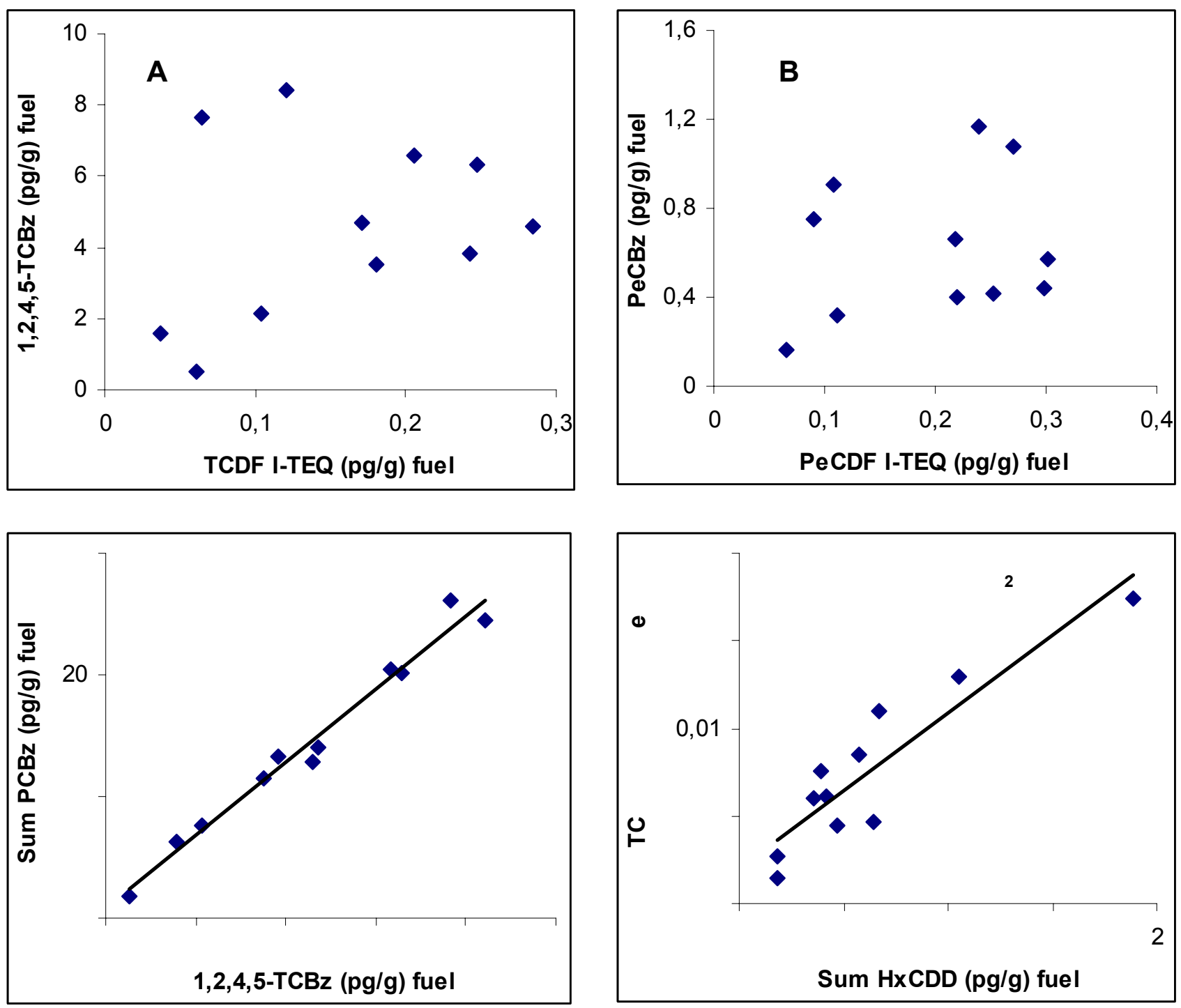

Fig.5.30: Couple points of score variables plot (A) of CA in Fig. 22. (V27 and V32 (A); V28 and V34 (B); V32 and V36 (C); V3 and V14 (D)).

\section{Discussion}

Among the samples two groups of different toxicity are estimated by PCA. Each of that group is further analysed with CA. A good correlation is found between tetra and pentachlorinated benzenes and tetra and penta chlorinated dibenzo-p-furans for the samples treated without inhibitor or with low percentage of inhibitor. According to the precursor theory of PCDD/F formation a fusion of two chlorophenyl radicals result in PCB compounds. In a later steps that molecules can be oxidized and are thus potential precursors of PCDF [9]. This relationship could be also due to the similar 
temperature dependence of PCBz and PCDF in formation processes [119]. Furthermore, Blumenstock showed that more than $80 \%$ of the total I-TEQ value is assigned to the PCDF [57]. For the basic thermodynamics of PCDD/F it has been observed that the precursor mechanism produced more PCDFs and particular penta congeners, than PCDDs, of which the most favoured are hexa and hepta congeners [9]. These arguments may explain the high and reliable correlation between chlorinated benzene and the emissions of PCDF I-TEQ.

The best indicator parameter between the investigated PCBz congeners is 1,2,4,5TCBz. That isomer is also significantly correlated with PCDD/F I-TEQ value. Blumenstock observed statistically the same promising correlation between the lower chlorinated PCBz congeners and PCDD/F I-TEQ value [57]. However Öberg proposed hexachlorobenzene [61] and Kaune penta-chlorobenzene and pentachlorobiphenyl [62] as an indicator parameters of PCDD/F formation.

The best relationship between the chlorinated benzenes and PCB I-TEQ value, is found for PeCB. The relationship between 2,3,7,8-TCDD I-TEQ amount and PeCBz are in a good agreement with the work of Kaune [59]. The current publication proposed the same correlation on the base of different sampling points of three hazardous waste incinerators. PCBz is precursor of PCDD/F [44] and is involved in the complex reaction pathway of chloroaromatic compounds.

For the samples treated with high percentage of inhibitors the above mentioned relationships are not observed. This missing correlation is probably due to the strong inhibition of the compounds used and the non-detectable values for some of the most important congeners such as 2,3,7,8-TCDD and some other lower chlorinated $\mathrm{PCDD} / \mathrm{F}$ isomers. It is also possible that different pathways of chloroaromatic formation are dominating for that type of samples.

Generally no correlation is found for both group of samples between PCB homologues and PCDD/F or PCBz homologues. The only promising correlated couples is the sum of HxCDD and the TCB I-TEQ values for the samples with higher and lower toxicity. Probably that correlation is possible due to the significant HxCDD amount also for the samples treated with high percentage of inhibitor. The lower chlorinated PCDD and PCDF homologues for the samples of lower toxicity are present with a negligible amount. $1,2,4,5-\mathrm{TCBz}$ is the best correlated isomer with the sum of PCBz among the other PCBz congeners. 


\subsubsection{Correlation between PCDD, PCDF and PCB. Influence of Various Inhibitors.}

Principle component analysis (PCA) is used to give a better view of the similarity between the 49 samples including samples treated without and with inhibitor and different percentage of inhibitors (Tab. 5.16.). Some of the samples were performed more only once. The matrix used for statistical investigation of PCB and PCDD/F includes 26 variables (see Tab.5.17). Not all 49 samples were analysed for PCBz so that this values are not included as variables in the matrix.

Tab. 5.16: Number of the cases used for PCA and CA statistical analyses.

\begin{tabular}{|c|c|c|c|c|c|}
\hline without inhibitor & $\mathrm{S} 1,2,3,4,5,49$ & $\mathrm{TiO}_{2}$ & $\mathrm{~S} 6$ & $\mathrm{Cr}_{2} \mathrm{O}_{3}$ & $\mathrm{~S} 21$ \\
\hline $10 \%\left(\mathrm{NH}_{4}\right)_{2} \mathrm{SO}_{4}$ & $\mathrm{~S} 22,26,27$ & $\mathrm{ZrO}_{2}$ & $\mathrm{~S} 7$ & $\left(\mathrm{NH}_{4}\right)_{2} \mathrm{HPO}_{4}$ & $\mathrm{~S} 24$ \\
\hline $10 \%\left(\mathrm{NH}_{4}\right)_{2} \mathrm{~S}_{2} \mathrm{O}_{3}$ & $\mathrm{~S} 23,28$ & $\mathrm{Na}_{2} \mathrm{MoO}_{4} \cdot 2 \mathrm{H}_{2} \mathrm{O}$ & $\mathrm{S} 8$ & {$\left[\left(\mathrm{CH}_{3}\right)_{2} \mathrm{~N}\right]_{3} \mathrm{P}(\mathrm{O})$} & $\mathrm{S} 16$ \\
\hline $5 \%\left(\mathrm{NH}_{4}\right)_{2} \mathrm{SO}_{4}$ & $\mathrm{~S} 29,35,36$ & $\mathrm{Al}_{2} \mathrm{O}_{3}$ & $\mathrm{~S} 9$ & $\mathrm{~N}\left(\mathrm{CH}_{2} \mathrm{CH}_{2} \mathrm{OH}\right)_{3}$ & $\mathrm{~S} 17$ \\
\hline $5 \%\left(\mathrm{NH}_{4}\right)_{2} \mathrm{~S}_{2} \mathrm{O}_{3}$ & $\mathrm{~S} 30,37,38$ & $\mathrm{H}_{2} \mathrm{NSO}_{4} \mathrm{H}$ & $\mathrm{S} 10$ & $\mathrm{Na}_{2} \mathrm{WO}_{4} \cdot 2 \mathrm{H}_{2} \mathrm{O}$ & $\mathrm{S} 18$ \\
\hline $3 \%\left(\mathrm{NH}_{4}\right)_{2} \mathrm{SO}_{4}$ & $\mathrm{~S} 31,41,45$ & $\mathrm{NaVO}_{3}$ & $\mathrm{~S} 11$ & $\mathrm{P}_{2} \mathrm{~S}_{5}$ & $\mathrm{~S} 19$ \\
\hline $3 \%\left(\mathrm{NH}_{4}\right)_{2} \mathrm{~S}_{2} \mathrm{O}_{3}$ & $\mathrm{~S} 32,42,46$ & $\mathrm{H}_{2} \mathrm{NSO}_{3} \mathrm{H}$ & $\mathrm{S} 12$ & $\mathrm{Na}_{2} \mathrm{~S} \cdot \mathrm{H}_{2} \mathrm{O}$ & $\mathrm{S} 20$ \\
\hline $1 \%\left(\mathrm{NH}_{4}\right)_{2} \mathrm{SO}_{4}$ & $\mathrm{~S} 34,39,47$ & $\mathrm{~S}$ & $\mathrm{~S} 13$ & $\left(\mathrm{NH}_{2}\right)_{2} \mathrm{CO}+\mathrm{S}$ & $\mathrm{S} 25$ \\
\hline $1 \%\left(\mathrm{NH}_{4}\right)_{2} \mathrm{~S}_{2} \mathrm{O}_{3}$ & $\mathrm{~S} 33,40,48$ & $\mathrm{H}_{2} \mathrm{NSO}_{2} \mathrm{NH}_{2}$ & $\mathrm{~S} 14$ & $3 \%\left(\mathrm{NH}_{2}\right)_{2} \mathrm{CO}+\mathrm{S}$ & $\mathrm{S} 43$ \\
\hline & & pomace & $\mathrm{S} 15$ & $1 \%\left(\mathrm{NH}_{2}\right)_{2} \mathrm{CO}+\mathrm{S}$ & $\mathrm{S} 44$ \\
\hline
\end{tabular}

Tab. 5.17: Number of the variables used for PCA and CA statistical analyses. * - I-TEQ value

\begin{tabular}{|l|l|l|l|l|l|}
\hline V1 & TCDD & V10 & HpCDF & V19 & TCDD * $^{*}$ \\
\hline V2 & PeCDD & V11 & OCDF & V20 & PeCDD * \\
\hline V3 & HxCDD & V12 & Sum PCDF & V21 & HxCDD * $^{*}$ \\
\hline V4 & HpCDD & V13 & PCDD/F * & V22 & HpCDD * $^{*}$ \\
\hline V5 & OCDD & V14 & TCB * $^{*}$ & V23 & TCDF * $^{*}$ \\
\hline V6 & Sum PCDD & V15 & PeCB * & V24 & PeCDF * $^{*}$ \\
\hline V7 & TCDF & V16 & HxCB * & V25 & HxCDF $^{*}$ \\
\hline V8 & PeCDF & V17 & HpCB * & V26 & HpCDF $^{*}$ \\
\hline V9 & HxCDF & V18 & PCB * & & \\
\hline
\end{tabular}

One agglomerated group of samples, placed to the left side of the ordinate axis is observed in the proposed PCA score plots (Fig. 5.31). These are the samples with lower concentrations of the investigated toxic compounds or samples treated with $\mathrm{N}$ and S- compounds or with higher percentage $\left(\mathrm{NH}_{4}\right)_{2} \mathrm{SO}_{4}$ and $\left(\mathrm{NH}_{4}\right)_{2} \mathrm{~S}_{2} \mathrm{O}_{3}$. The samples to the right hand side and in the middle of the multidimensional space are samples without an inhibitor and with higher amount of PCDD/F and PCB i.e. sample 
number S1, S2, S3, S4, S5, S6, S7, S9, S11, S15, S17,S18, S19, S21, S32, S42, S44, S48 and S49.

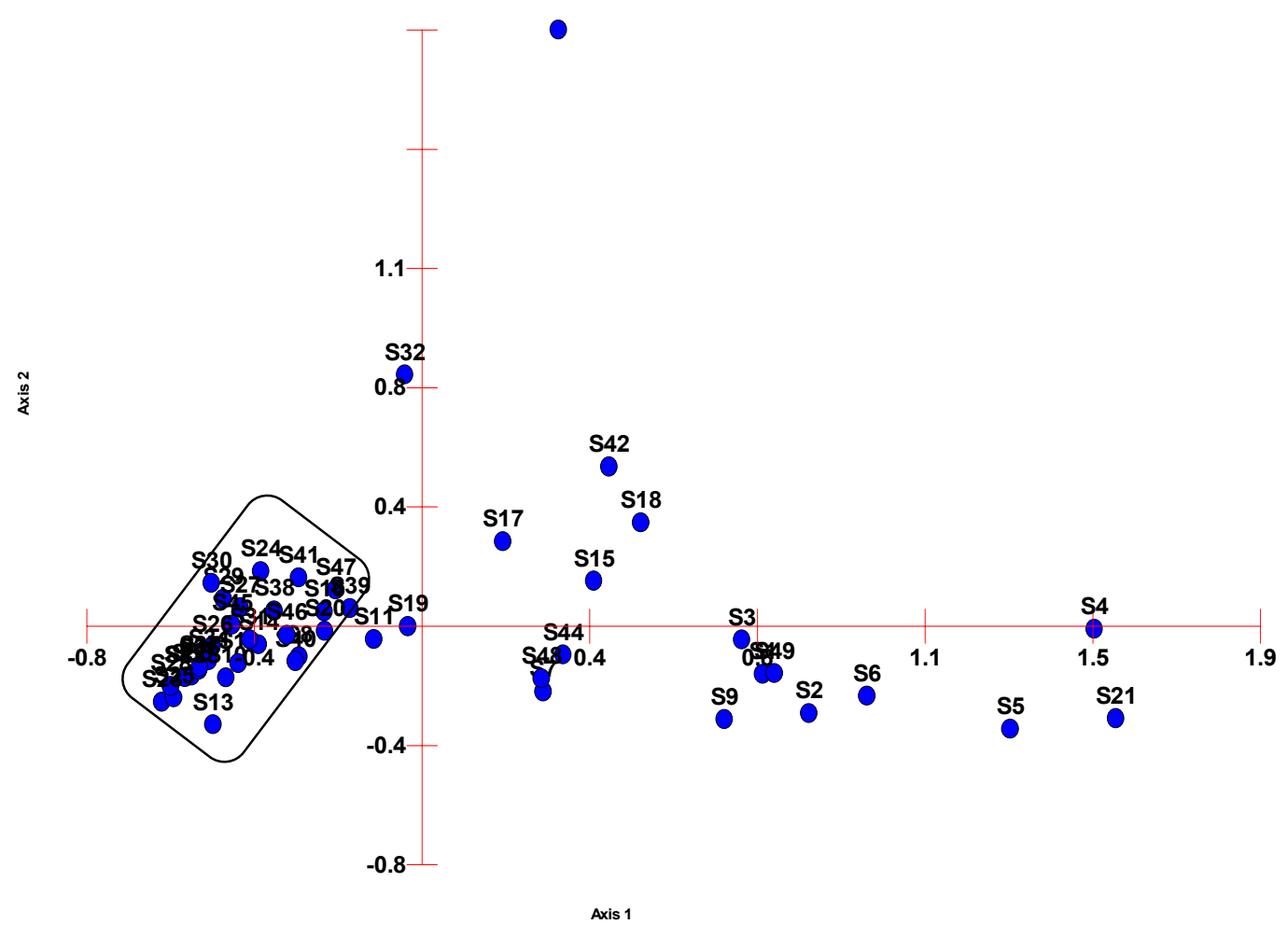

Fig.5.31: PCA score plot of 49 cases (samples) and 26 variables (PCDD/F and PCB homologues)

The more right the point in the statistical plot are appeared the higher concentration of PCDD/F and PCB has been found. Since S3, S4, S5, S6 and S49 belong to sample treated without an inhibitor and it is placed much more to the right in the score plot. Vicinity of these toxic samples are some other points which can be attributed to the $\mathrm{Cr}_{2} \mathrm{O}_{3}, \mathrm{TiO}_{2}, \mathrm{Al}_{2} \mathrm{O}_{3}$. It is already discusses that these metal oxides show no inhibitory effect even their PCDD/F and PCB emissions are higher compared to the samples treated without an inhibitor. Far apart of all sample points of the PCA score plot is placed sample S33. This sample represents to the experiment where $1 \%\left(\mathrm{NH}_{4}\right)_{2} \mathrm{~S}_{2} \mathrm{O}_{3}$ is used as inhibitor for PCDD/F and PCB minimization. Due to its high variation, that sample could be assigned as outlier and is not included in further statistical analysis.

CA is performed separately for that two groups of samples visualised by the PCA score plot. The score variable plots are shown in Fig. 5.31. 

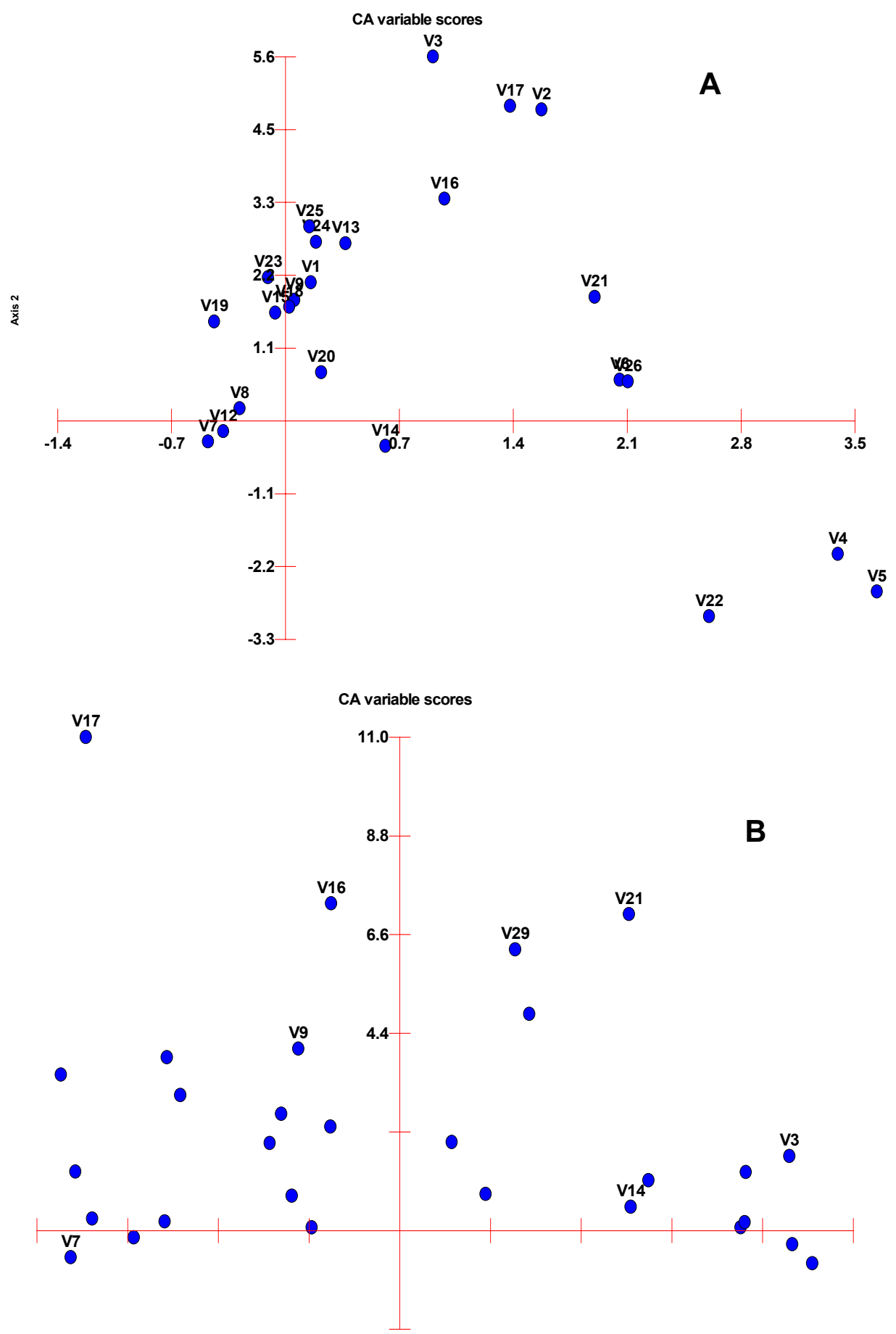

Fig. 5.32: CA score variables plots for the samples with higher TEQ (A) and lower TEQ (B)

The first matrix used for $\mathrm{CA}$ includes 19 cases and 24 variables. Due to the higher variation of $\mathrm{V} 10$ and $\mathrm{V} 11$, the values of the sum of HpCDF and OCDF are dismissed of the matrix. The second matrix is present with 29 cases and 25 variables. Also here V10 is considered as outlier and is removed from the matrix variations. 
In score variables plot (A) of Fig. 5.31. the observed agglomerated groups are mostly pairs which consist of different classes of compounds and/or different levels chlorinated congeners. There is also one main group of samples placed on the ordinate axis. It includes some PCB and PCDD/F congeners. In score variables plot (B) of Fig. 5.31. it seems that all PCDD/F and PCB homologues variables are spread chaotic in the multidimensional space. Most of the neighboured variable points belong to the same PCDD or PCDF homologues groups.

No correlation is found between PCDD/F and PCB homologues for the samples with higher and lower I-TEQ.

Some of the most interesting corresponding correlations concerning the samples with higher toxicity are drawn in two dimension plots in Fig. 5.32.

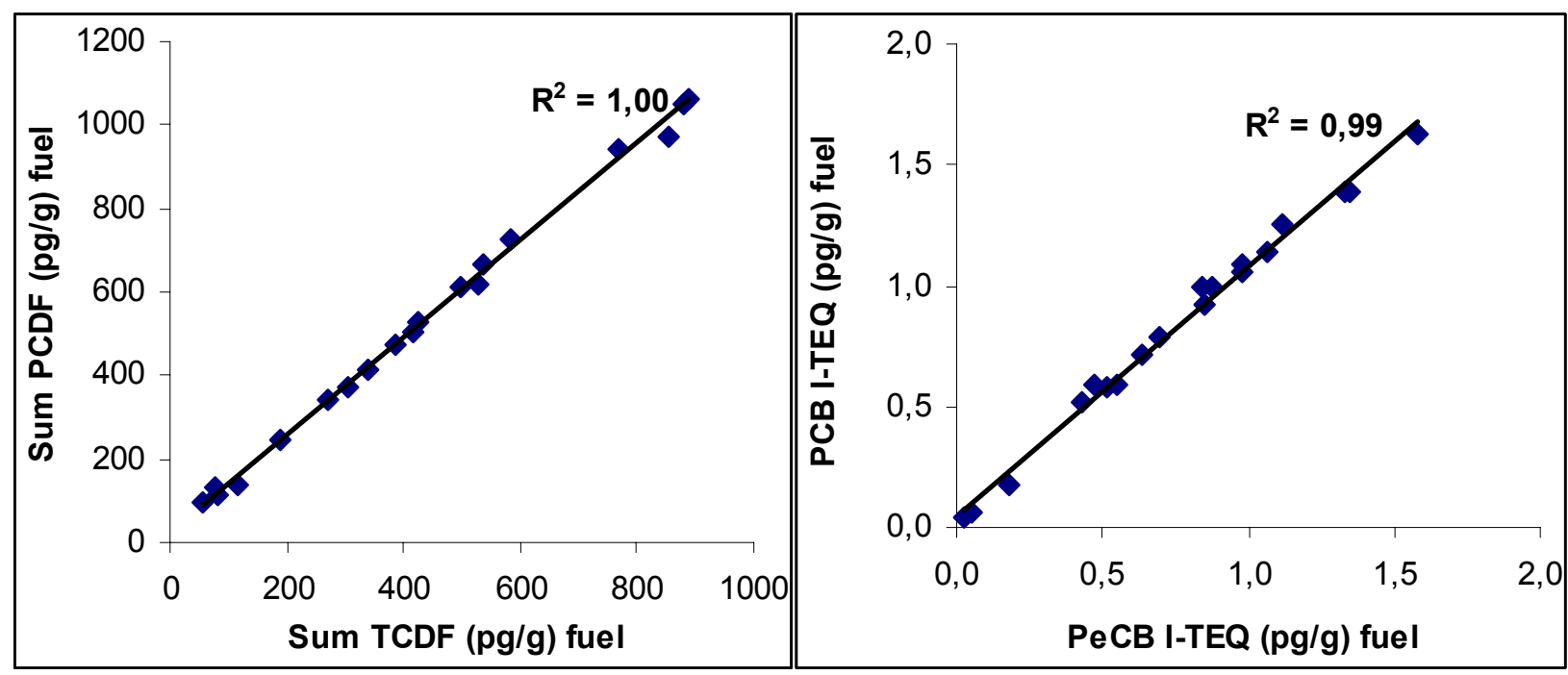

Fig.5.33: Couple points of score variables plot (A) of CA in Fig. 26. (V7 and V12 (A); V15 and V18 (B))

\section{Discussion}

Among the samples two groups of different I-TEQ are estimated by PCA. Each group is further analysed with CA. Very good correlation is found for the sum of TCDF congeners and the sum of all PCDF congeners. The calculated coefficient of determination $\left(R^{2}\right)=1.00$ show that that two variables are perfectly correlated. According to Fig. 5.21. the percentage of the TCDF homologues among the other PCDF homologues for the samples with higher I-TEQ is estimated to be up to $85 \%$. Thus, the above-mentioned correlation mainly is a result of the TCDF presence. Significant relationship for the samples with higher I-TEQ is also found between PeCB I-TEQ and PCB I-TEQ values. Since PCB 126 is the most toxic isomer among 
the PeCB homologue and all other PCB congeners, it is very possible that that isomer relate strongly to the correlation and correlate with itself.

The samples with lower I-TEQ show no any sufficient correlation between the variables investigated. The missing correlation can be also explained with the strong inhibition of the used compounds and the non-detectable values for some of the most important congeners.

No correlation is found between PCDD/F and PCB homologues for the samples with higher and lower toxicity. Generally the knowledge about PCB and PCDD/F correlation is less than the investigated relation between PCBz and PCDD/F homologues. From practical view the measurement of PCB homologue is more difficult than that of PCBz. Based on statistical analysis such as PCA, Blumenstock proposed that the formation of PCB differs from the other chlorinated aromatics like PCDD/F [51]. The theory of precursor character of PCB for PCDF, via an oxidation followed by an internal ring closure [120] was not found for the proposed results. Investigations at a hazardous waste incinerator, for example, pointed out that some PCBs such as PCB 138, hexa- and heptachlorobiphenyls are good indicators for ITEQ values [62]. Furthermore taking into account the same paper, Kaune discussed that in the stack gas of the HWI no correlation between PCB and PCDD/F homologues or congeners appeared. 


\section{Discussion}

High emissions of PCDD/F and PCB are formed during the investigated pilot plant emission sampling campaigns. It is well known that PCDD/F are formed during wood combustion via precursors like phenol and lignin [121]. Wood combustion is important source of PAH and also considered to be responsible for significant amount of PCDD/F [122]. Choudhry and Hutzinger [120] identified that in the combustion of lignin could ultimately yield benzene. The last one take part in de novo dioxins synthesis. Even non-treated wood contain small amount of chlorine which can promote dioxins formation [121].

Much higher PCDD/F and PCB emission are detected during poplar wood and PVC incineration (campaign No. 4, 7, and 8). Alkyl substituted benzenes are the major organic products of the thermal decomposition of poly(vinyl chloride) PVC. On chlorination of benzene, polychlorinated benzenes are formed. By later steps the free radicals species react with oxygen to form peroxide radicals and finally the PCDFs are generated. The PCDDs are produced by incinerations of precursors like polychlorinated phenols [120].

The highest PCDD/F emissions are detected during wood incineration at $500^{\circ} \mathrm{C}$ where the measured $\mathrm{O}_{2}$ content is low and the analyzed $\mathrm{CO}_{2}$ and $\mathrm{CO}$ concentrations are high. These conditions stimulate soot formation and by de novo synthesis high concentrations of dioxins are formed. That process become possible if the sooty particles of the flue gas are reacting with $\mathrm{O}_{2}$, chlorine and metal ion create dioxins in the flame.

The results of the poplar wood combustion and PVC at $700^{\circ} \mathrm{C}$ show that dioxins are not thermodynamically stable at higher temperature. 2,3,7,8-TCDD isomer and the ITEQ value of that sample are present at a lower values than the combusted sample at $500^{\circ} \mathrm{C}$. Choudhry proposed that the chlorine source $\left(\mathrm{Cl}_{2}\right)$ may react with oxygen to produce chlorine gas but the extend of the reaction decrease as the temperature rise [120]. Relatively low are the PCDD/F and PCB emissions of samples No. 2 and 7, combusted at $150^{\circ} \mathrm{C}$ and $130^{\circ} \mathrm{C}$.

According to the sampling campaigns performed and their corresponding operation conditions and their final PCDD/F and PCB I-TEQ values it can be concluded that different parameters influence dioxin formation. That is the combustion temperature, oxygen availability, chlorine in the feed and residence time. 
Experimental evidence suggests that temperature of $250-500^{\circ} \mathrm{C}$ promote $\mathrm{PCDD} / \mathrm{F}$ and PCB formation, while temperature greater than $700^{\circ} \mathrm{C}$ decrease the concentrations of the same compounds. Insufficient oxygen content of around 12 Vol\% increase the dioxins emissions and poor combustion conditions are promoted. Presence of chlorine in the fuel such as PVC indicates higher PCDD/F and PCB emissions.

In this study, a laboratory-scale furnace is used to perform a series of experiments designed to prevent the formation of PCDD/F formation by use of inhibitors. A mixture of lignite coal, solid waste and PVC are combusted at $400^{\circ} \mathrm{C}$. Twenty different additives are investigated at a level of $10 \%$ of the total fuel during the experiments. They divide into four different types of groups according their chemical nature are studied as inhibitors of PCDD/F in flue gases of lignite coal, solid waste and PVC combustion.

This method is much simpler than others in which the inhibitor is sprayed into the post combustion zone, resulting in significant disturbances of large incineration plants. The results show that the substances belonging to the metal oxide group have no inhibitory effect. Some of the additives such as $\mathrm{Cr}_{2} \mathrm{O}_{3}, \mathrm{Al}_{2} \mathrm{O}_{3}$ and $\mathrm{TiO}_{2}$ could even increase the PCDD/F emissions. This fact can be explained by the mechanism of the de novo reaction for PCDD/F formation. The catalyst is a transition metal, such as copper, iron or one of the oxides of these metals, as it seems that the metal oxides can also promote the de novo reaction. They produce very high amounts of the most toxic isomers and high amount of lower chlorinated PCDD/F. Some other substances belonging to the metal oxides groups such as $\mathrm{NaVO}_{3}, \mathrm{Na}_{2} \mathrm{MoO}_{4} \cdot 2 \mathrm{H}_{2} \mathrm{O}$ and $\mathrm{Na}_{2} \mathrm{WO}_{4} \cdot 2 \mathrm{H}_{2} \mathrm{O}$ show low but still inhibitory effects, especially for PCDD. These substances are active for catalytic oxidation. Their chemical structure consists of a strong oxide base such as $\mathrm{VO}_{3}{ }^{-}, \mathrm{MoO}_{4}{ }^{-2}, \mathrm{WO}_{4}{ }^{-2}$. Probably due to that base, a better performance of incineration during the experiments occurs. Regardless, these additives cannot reduce PCDD/F sufficiently.

Relatively low inhibitory effects are also observed for the $\mathrm{N}$-containing substances. The samples of that group of additives are located somewhere between the two extremes of the score plot. Ethanolamine as an inhibitory molecule contains the amino and hydroxyl functional groups and can undergo intermolecular dehydroamination reactions. Bromobenzene or the benzene precursors are displaced from the catalytically active sites, which are blocked by ethanolamine. 
Higher reduction effects of PCDD/F can be derived for the S- containing substances present at $10 \%$ of the fuel. Sulfur shows a very strong inhibition effect of PCDD. It is already known that sulfur is converted into $\mathrm{SO}_{2}$ and it reduces $\mathrm{Cl}_{2}$ to $\mathrm{HCl}$, and therefore dioxin formation can be reduced [38]. Probably, also because of this mechanism, the rest of the S-containing compounds inhibit PCDD/F flue gases.

Although the single $\mathrm{N}$ - and $\mathrm{S}$ - containing compounds are not very effective as inhibitors, all other $\mathrm{N}$ - and $\mathrm{S}$ - containing substances seem to be able to reduce strongly PCDD/F flue gas emission if used as a $10 \%$ additive of lignite coal, solid waste and PVC as fuel. The most effective inhibitors are $\left(\mathrm{NH}_{4}\right)_{2} \mathrm{SO}_{4}$ and $\left(\mathrm{NH}_{4}\right)_{2} \mathrm{~S}_{2} \mathrm{O}_{3}$; they are inexpensive and non-toxic materials. Both compounds can suppress the formation of toxic compounds like PCDD/F by more than $98-99 \%$, and the most toxic $\mathrm{PCDD} / \mathrm{F}$ isomers are not detectable in most of the samples. Thus, these compounds were also studied at lower percentage of the fuel. $\left(\mathrm{NH}_{4}\right)_{2} \mathrm{SO}_{4}$ resulted in a greater than $90 \%$ reduction of PCDD/F even composing only $3 \%$ of the fuel combusted. However, less than $5 \%\left(\mathrm{NH}_{4}\right)_{2} \mathrm{~S}_{2} \mathrm{O}_{3}$ of the fuel resulted in weaker inhibition. The PCDD/F homologues distribution ratio for all samples and samples with varying percentage of $\left(\mathrm{NH}_{4}\right)_{2} \mathrm{SO}_{4}$ and $\left(\mathrm{NH}_{4}\right)_{2} \mathrm{~S}_{2} \mathrm{O}_{3}$ is also investigated. Higher percentages of the inhibitors produced lower percentage of lower chlorinated PCDD and PCBz. For the PCDF and PCB content the opposite is found.

At $1000^{\circ} \mathrm{C}$, higher PCDD/F amount for the samples without inhibitor is determined. During that experiments the inhibition effect of $\left(\mathrm{NH}_{4}\right)_{2} \mathrm{SO}_{4}$ show lower values for PCDD/F and PCB but not detectable concentration for 2,3,7,8-TCDD isomer. Despite conclusions for inhibitory effect are quite uncertainty because of the high variable $\mathrm{PCDD} / \mathrm{F}$ and PCB emissions emitted during the experiments where no any inhibitor is used. Thus, it's recommendable to repeat the experiments by employing an adjusted protocol. During that new set experiments, the furnace is prior electrically preheated to the $200^{\circ} \mathrm{C}$ and the sample is introduced in the centre of the heating zone. In later steps the furnace is set to $800^{\circ} \mathrm{C}$ for $30 \mathrm{~min}$ and then to $1000^{\circ} \mathrm{C}$ for another $30 \mathrm{~min}$. During that procedure the estimated PCDD/F is higher compared to the same samples performed at $400^{\circ} \mathrm{C}$ but much lower than the previously performed experiments at $1000^{\circ} \mathrm{C}$. Concerning the inhibitory effect of $\left(\mathrm{NH}_{4}\right)_{2} \mathrm{SO}_{4}$, according Fig. 5. 23, seems that the PCDD/F I-TEQ amount decrease among the two repeatable samples. Explanation is found due to the amass lay of $\left(\mathrm{NH}_{4}\right)_{2} \mathrm{SO}_{4}$ in the post combustion zone which can inhibit additionally the further produced PCDD/F 
emissions during the next experiments. Taking into account that hypotheses, the realistic value for the inhibitory effect of $\left(\mathrm{NH}_{4}\right)_{2} \mathrm{SO}_{4}$ at $1000^{\circ} \mathrm{C}$ is estimated about $90 \%$ reduction of PCDD/F emission. That result is considered for the experiments where the inhibitor is used firstly among the set of experiments.

The correlation between the PCDD/F, PCB and PCBz for the samples elaborate in a laboratory furnace is also investigated. By the help of PCA, the samples are easily divided according their toxicity. A good correlation is found between tetra and penta chlorinated benzenes and tetra and penta chlorinated dibenzo-p-furans for the samples with higher toxicity. The best indicator parameter between the investigated PCBz congeners is 1,2,4,5-TCBz. That isomer is also significantly correlated with PCDD/F I-TEQ value. For the samples treated with high percentage of inhibitors the above mentioned relationships are not observed. This correlation lacks is probably due to the strong inhibition of the used compounds and the non-detectable values for some of the most important congeners such as 2,3,7,8-TCDD and some other lower chlorinated $\mathrm{PCDD} / \mathrm{F}$ isomers. It is also possible that different pathways of chloroaromatic formation are dominated for that kind of samples. However good correlation between I-TEQ value and PCBz concentration is found in the flue gases of wet scrubber and stack gas of HSW incinerator [62], [50], [123]. That proof the fact that the minimization of toxic emissions by cleaning systems like wet scrubber can not influence to the pathway of dioxin formation. While when addition of selected compounds like inhibitors is used, the dioxins and their precursors are totally blocked or probably some other mechanistic ways prevailed.

No correlation is found for both group of samples between PCB homologues and $\mathrm{PCDD} / \mathrm{F}$ or PCBz homologues. It may mean that the formation mechanisms of PCB and PCDD/F and / or PCBz is different. Such conclusion is also proposed from other authors. 


\section{Outlook}

According the final results $\left(\mathrm{NH}_{4}\right)_{2} \mathrm{SO}_{4}$ is the most effective inhibitor for dioxins emissions among the used additives to the fuel mixture in a laboratory scale furnace. It is an inexpensive and non-toxic material. So that this compound is recommendable to be used in a full scale plant of coal / waste combustion.

The mechanism of $\left(\mathrm{NH}_{4}\right)_{2} \mathrm{SO}_{4}$ inhibition is necessary to be considered. During the performed laboratory experiments the fly ash of each sample was saved in bottles sealed in Ar atmosphere. A further spectroscopic investigation can on one hand light shed upon the mechanisms of the bond formation in molecules in the combustion processes and on the other hand it may detect some new complexes which manifest dioxin suppression effects. 


\section{Appendix}

\subsection{Dioxin Laboratory}

\subsubsection{Materials}

\section{Equipment}

Rotary evaporator precision Balance

$\mathrm{N}_{2}$-Thermoblock

Ultrasonic bath

Drying oven

Laboratory machine for rinsing

Glassware

Round flask

Erlenmeyer flask

Soxhlet apparatus

Dropping funnel

Graduated cylinder

Chromatographic column

Pasteur pipet

Solvents, adsorbents, consumptions

Aceton

Acetonitrile

Benzene

Dichloromethane

Chloroform

Nonan

n- Hexane

Tetradecan

Toluene

Aluminium oxide B Super I

Bio-Bed SX-8

C-18

Sodium chloride

Silica gel

Florisil

Glass wool

XAD -2

Vials

\section{Company}

Büchi

Sartorius

Labor Technik Barkley

Bandelin, Sonorex

Heraeus-Wärmetechnik

Miele, Typ Mielabor

\section{Volume}

100, 250, 500, $1000 \mathrm{~mL}$

$50,100,250,500,1000$

$\mathrm{mL}$

$500,1000 \mathrm{~mL}$

$100,300 \mathrm{~mL}$

$25,50,100,250,500 \mathrm{~mL}$
Type

EL 131

LC $4800 \mathrm{P}$

RK $510 \mathrm{H}$

WU 610

G 7733

\section{Trimble}

NS 29/32

NS 29/32

NS 29/32

NS $29 / 32$

\section{Package Quantity}

$4 \mathrm{~L}$

2. $5 \mathrm{~L}$

2. $5 \mathrm{~L}$

$4 \mathrm{~L}$

2. $5 \mathrm{~L}$

2. $5 \mathrm{~L}$

2. $5 \mathrm{~L}$

$500 \mathrm{~mL}$

$2.5 \mathrm{~L}$

$500 \mathrm{~g}$

$100 \mathrm{~g}$

$5 \mathrm{Kg}$

$1 \mathrm{Kg}$

$500 \mathrm{~g}$

$1 \mathrm{Kg}$

$100 \mathrm{~g}$
Supplier

Promochem

Riedel-de-Haen

Promochem

Promochem

Merck

Promochem

Promochem

Aldrich Chemical

Riedel-de-Haen

ICN Biomedicals

Bio Rad

Bulb

Merck

Promochem

Promochem

Neolab

Supelco

neolab 


\subsubsection{Equipment and Program adjustment}

Tab. 8.1:Equipment and program adjustment for PCDD/F analysis

\begin{tabular}{|c|c|c|c|}
\hline \multicolumn{2}{|l|}{ PCDD/F } & & \\
\hline \multicolumn{2}{|l|}{ Equipment } & & \\
\hline HRGC & Agilent 6890 & & \\
\hline HRMS & Finnigan MAT 95S & & \\
\hline \multirow[t]{4}{*}{ Capillary column } & Restek Rtx-2330 & & \\
\hline & length: $60 \mathrm{~m}$ & Ionisation mode & El \\
\hline & Inner Diameter: $0.25 \mathrm{~mm}$ & Ionisation energy & $70 \mathrm{eV}$ \\
\hline & Film thickness: $0.1 \mu \mathrm{m}$ & Ion source temperature & $260^{\circ} \mathrm{C}$ \\
\hline Carrier gas & $\begin{array}{l}\text { Helium, } 1.2 \mathrm{ml} / \mathrm{min} \text { constant } \\
\text { flow }\end{array}$ & Interface temperature & $260^{\circ} \mathrm{C}$ \\
\hline \multirow[t]{3}{*}{ Injection } & Gerstel KAS 4 & \multirow[t]{3}{*}{ Resolution } & \multirow[t]{3}{*}{10000} \\
\hline & splitless & & \\
\hline & $120^{\circ} \mathrm{C}, 12^{\circ} \mathrm{C} / \mathrm{sec} 280^{\circ} \mathrm{C}$ & & \\
\hline $\begin{array}{l}\text { Temperature- } \\
\text { program }\end{array}$ & \multicolumn{3}{|c|}{$90^{\circ} \mathrm{C} ; 1.5 \mathrm{~min}, 25^{\circ} \mathrm{C} / \min 180^{\circ} \mathrm{C}, 2^{\circ} \mathrm{C} / \min 260^{\circ} \mathrm{C} ; 15 \min$} \\
\hline
\end{tabular}


Tab. 8.2:Equipment and program adjustment for PCB analysis

\begin{tabular}{|c|c|c|c|}
\hline РCB & & & \\
\hline \multicolumn{2}{|l|}{ Equipment } & & \\
\hline HRGC & Agilent 5890 Series II & & \\
\hline HRMS & Finnigan MAT 95 & & \\
\hline \multirow[t]{4}{*}{ Capillary column } & J\&W DB-5ms & & \\
\hline & length: $60 \mathrm{~m}$ & Ionisation mode & El \\
\hline & Inner Diameter: 0.25 mm & Ionisation energy & $70 \mathrm{eV}$ \\
\hline & Film thickness: $0.1 \mu \mathrm{m}$ & \multirow[t]{2}{*}{ Ion source temperature } & \multirow[t]{2}{*}{$260^{\circ} \mathrm{C}$} \\
\hline Carrier gas & $\begin{array}{l}\text { Helium, } 2 \text { bar head } \\
\text { pressure }\end{array}$ & & \\
\hline \multirow{4}{*}{ Injection } & Gerstel KAS 3 & \multirow[t]{3}{*}{ Interface temperature } & \multirow[t]{3}{*}{$300^{\circ} \mathrm{C}$} \\
\hline & splitless & & \\
\hline & \multirow[t]{2}{*}{$60^{\circ} \mathrm{C}, 12^{\circ} \mathrm{C} / \sec 280^{\circ} \mathrm{C}$} & & \\
\hline & & Resolution & 8500 \\
\hline Temperature program & $\begin{array}{l}90^{\circ} \mathrm{C} ; 1.5 \mathrm{~min}, 20^{\circ} \mathrm{C} / \mathrm{min} \\
170^{\circ} \mathrm{C} ; 7.5 \mathrm{~min}, 3^{\circ} \mathrm{C} / \mathrm{min} \\
280^{\circ} \mathrm{C} ; 10 \mathrm{~min}\end{array}$ & & \\
\hline
\end{tabular}


8.1.3. Standard substances

\begin{tabular}{|c|c|c|c|c|c|}
\hline PCDD/F & $\begin{array}{c}\mathrm{c} \\
(\mathrm{pg} / \mathrm{\mu l})\end{array}$ & PCDF & $\begin{array}{c}\mathrm{c} \\
(\mathrm{pg} / \mathrm{\mu l})\end{array}$ & РCB & $\begin{array}{c}\mathrm{c} \\
(\mathrm{pg} / \mathrm{\mu l})\end{array}$ \\
\hline Sampling standard & & Internal standard & & Recovery standard & \\
\hline${ }^{13} \mathrm{C}_{6}-1,2,3,4-\mathrm{TCDD}$ & 500 & ${ }^{13} \mathrm{C}_{12}-2,8-\mathrm{DiCDF}$ & 100 & ${ }^{13} \mathrm{C}_{12}-1,2,3,4-\mathrm{TCDD}$ & 500 \\
\hline \multirow[t]{2}{*}{${ }^{13} \mathrm{C}_{12} 1,2,3,7,8,9-\mathrm{HxCDD}$} & 500 & ${ }^{13} \mathrm{C}_{12}-2,3,7,8-\mathrm{TCDF}$ & 100 & 4-МCB & 800 \\
\hline & & ${ }^{13} \mathrm{C}_{12}-1,2,3,7,8-\mathrm{PeCDF}$ & 400 & $4,4^{\prime}-\mathrm{DiCB}$ & 800 \\
\hline Internal standard & & ${ }^{13} \mathrm{C}_{12}-2,3,4,7,8-\mathrm{PeCDF}$ & 200 & 2,4,4'-TriCB & 800 \\
\hline \multirow[t]{2}{*}{${ }^{13} \mathrm{C}_{12}-1,2,3,4-\mathrm{TCDD}$} & 100 & ${ }^{13} \mathrm{C}_{12}-1,2,3,4,7,8-\mathrm{HxDF}$ & 300 & $2,2^{\prime}, 5,5^{\prime}-\mathrm{TeCB}^{\prime}$ & 700 \\
\hline & & ${ }^{13} \mathrm{C}_{12}-1,2,3,6,7,8-\mathrm{HxDF}$ & 300 & $3,3^{\prime}, 4,4^{\prime}-\mathrm{TeCB}^{\prime}$ & 1000 \\
\hline Recovery standard & & ${ }^{13} \mathrm{C}_{12}-1,2,3,7,8,9-\mathrm{HxDF}$ & 300 & $2,2^{\prime}, 4,5,5^{\prime}-\mathrm{PeCB}$ & 1000 \\
\hline${ }^{13} \mathrm{C}_{12}-2,7-\mathrm{DiCDD}$ & 100 & ${ }^{13} \mathrm{C}_{12}-2,3,4,6,7,8-\mathrm{HxDF}$ & 300 & $2,3,3^{\prime}, 4,4^{\prime}-\mathrm{PeCB}$ & 1000 \\
\hline${ }^{13} \mathrm{C}_{12}-2,3,7-T r i C D D$ & 100 & ${ }^{13} \mathrm{C}_{12}-1,2,3,4,6,7,8-\mathrm{HpDF}$ & 400 & $3,3^{\prime}, 4,4^{\prime}, 5-\mathrm{PeCB}$ & 700 \\
\hline${ }^{13} \mathrm{C}_{12}-2,3,7,8-\mathrm{TCDD}$ & 100 & ${ }^{13} \mathrm{C}_{12}-1,2,3,4,7,8,9-\mathrm{HpDF}$ & 400 & $2,2^{\prime}, 4,4^{\prime}, 5,5^{\prime}-\mathrm{H} \times \mathrm{CB}$ & 1200 \\
\hline${ }^{13} \mathrm{C}_{12}-1,2,3,7,8-\mathrm{PeCDD}$ & 250 & OCDF & 900 & $2,2^{\prime}, 3,4,4^{\prime}, 5^{\prime}-\mathrm{HxCB}$ & 700 \\
\hline${ }^{13} \mathrm{C}_{12}-1,2,3,4,7,8-\mathrm{HxDD}$ & 200 & & & $3,3^{\prime}, 4,4^{\prime}, 5,5-^{\prime} \mathrm{HxCB}$ & 900 \\
\hline${ }^{13} \mathrm{C}_{12}-1,2,3,6,7,8-\mathrm{HxDD}$ & 200 & & & $2,2^{\prime}, 3,4,4^{\prime}, 5,5^{\prime}-\mathrm{HpCB}$ & 1000 \\
\hline${ }^{13} \mathrm{C}_{12}-1,2,3,7,8,9-\mathrm{HxDD}$ & 200 & & & $2,2^{\prime}, 3,3^{\prime}, 4,4^{\prime}, 5,5^{\prime}-\mathrm{OCB}$ & 700 \\
\hline${ }^{13} \mathrm{C}_{12}-1,2,3,4,6,7,8-\mathrm{HpDD}$ & 300 & & & $2,2^{\prime}, 3,3^{\prime}, 4,4^{\prime}, 5,5^{\prime}, 6-\mathrm{NCB}$ & 1000 \\
\hline OCDD & 900 & & & $\begin{array}{c}2,2^{\prime}, 3,3^{\prime}, 4,4^{\prime}, 5,5^{\prime}, 6,6^{\prime}- \\
\text { DCB }\end{array}$ & 800 \\
\hline
\end{tabular}




\subsection{Emission Sampling}

\subsubsection{Equipments}

\section{Equipment}

Nozzles

Nozzles

Sampling tube

Suction tube

Condensate flask

Hose connection

Gas meter

Gas meter

Drying tower

Gas-tight pump

MRU 4000V Regulating valve

MRU 4000R control unit

Notebook for MRU 4000

Prandtl tube

Prandtl tube

Manometer

Thermocouple

TESTO analyzer

Notebook for TESTO 350

Klimacenter with

U-shaped tube

calcium chloride

Pump

\section{Specifications}

material: high-grade steel

diameter: 25; $30 \mathrm{~mm}$

material:titanium

diameter: $6 ; 8 ; 10 ; 12 ; 14 ; 18$

DURAN glass, $1460 \mathrm{~mm}$, internal $\varnothing 9 \mathrm{~mm}$, outside $\varnothing 10 \mathrm{~mm}$

Steel, $1000 \mathrm{~mm}$

$2 \mathrm{~L}$, brown glass, DURAN

Rubber Hose Variopress 20 bar BD

Typ G4/6, 1996

Typ G4, 1995

$70 \mathrm{~mm} \varnothing$

Typ TV15/12, 1450 per min, Motor Leistung $0,58 \mathrm{kw}, 50 \mathrm{~Hz}, 16,3 \mathrm{~m}^{3} / \mathrm{h}$

$230 \mathrm{~V}, 50 \mathrm{~Hz}$

$230 \mathrm{~V}, 50 \mathrm{~Hz}, 25 \mathrm{VA}$

$75 \mathrm{MHz}$, Pentium

length $1000 \mathrm{~mm}$, nozzle head $15 \mathrm{~mm}$, Ströhlein

length $1000 \mathrm{~mm}$, nozzle head $10 \mathrm{~mm}$, Gothe

Typ Digima LPU 250

$\mathrm{NiCr}-\mathrm{Ni}$, length $1020 \mathrm{~mm}$

Typ 350

Pentium III, Hard disk $10 \mathrm{G}$ bytes

hygrometer, barometer and thermometer

glass, internal diameter $14 \mathrm{~mm}$

dried, granulate, 1-2 mm,

flow rate of 2 Litres per minute

\section{Company}

Ströhlein

Gothe

Hand made

Ströhlein

Pirelli Treg

Elster

Ströhlein

Ströhlein

Ströhlein

Ströhlein

Ströhlein

Texas Instrument

Special Instrument

Ströhlein

TESTO

Dell

TFA, Germany

Ströhlein

Merck 
8.2.2. Combusted fuel

\begin{tabular}{|l|l|}
\hline Combusted fuel & Supplier \\
\hline Poplar wood & OBI market \\
\hline Beech/ Oak wood & Brennstoff- Vertrieb-Gesellschaft, München \\
\hline PVC & waste from ground carpet \\
\hline PVC & CIEMAT, Spain \\
\hline Solid waste & Rethmann Plano GmbH \\
\hline
\end{tabular}




\subsection{Laboratory Scale Experiments}

\subsubsection{Equipment}

\begin{tabular}{|c|c|c|}
\hline Equipment & Specifications & Company \\
\hline $\begin{array}{c}\text { Three zone horizontal tube } \\
\text { furnace }\end{array}$ & $\begin{array}{c}\text { type HZS \& TVS } \\
\text { length: } 900 \mathrm{~mm} \\
\text { max temperature: } 1200^{\circ} \mathrm{C} \\
415 \mathrm{~V}, 3 \text { phases, } 50 \mathrm{~Hz}, 4.5 \mathrm{~kW}\end{array}$ & $\begin{array}{c}\text { CARBOLITE GmbH, } \\
\text { Ubstadt-Weiher }\end{array}$ \\
\hline mechanical mortar & $6 \mathrm{~A}$ & Retsch apparatus \\
\hline
\end{tabular}

\subsubsection{Reagents}

$\begin{array}{ll}\text { chromium (III) oxide }\left(\mathrm{Cr}_{2} \mathrm{O}_{3}\right) & \text { Merck } \\ \text { titanium (IV) oxide }\left(\mathrm{TiO}_{2}\right) & \text { Merck } \\ \text { sodium (meta) vanadate }\left(\mathrm{NaVO}_{3}\right) & \text { Fluka } \\ \text { zirconium (IV) oxide }\left(\mathrm{ZrO}_{2}\right) & \text { Merck } \\ \text { aluminium(III)oxide }\left(\mathrm{Al}_{2} \mathrm{O}_{3}\right) & \text { ICN-EcoChrom } \\ \text { sodium molybdate dihydrate }\left(\mathrm{Na}_{2} \mathrm{MoO}_{4} \cdot 2 \mathrm{H}_{2} \mathrm{O}\right) & \text { Fluka } \\ \text { sodium tungstate dihydrate }\left(\mathrm{Na}_{2} \mathrm{WO}_{4} \cdot 2 \mathrm{H}_{2} \mathrm{O}\right) & \text { Fluka } \\ \left.\text { di-ammoniumhydrogenphosphate }\left(\left(\mathrm{NH}_{4}\right)_{2} \mathrm{HPO}\right)_{4}\right) & \text { Merck } \\ \text { triethanolamine }\left(\mathrm{N}\left(\mathrm{CH}_{2} \mathrm{CH}_{2} \mathrm{OH}\right)_{3}\right) & \text { Merck } \\ \text { hexamethylphosphoramide }\left(\left[\left(\mathrm{CH}_{3}\right)_{2} \mathrm{~N}_{3} \mathrm{P}(\mathrm{O})\right)\right. & \text { Sigma-Aldrich Chemie } \\ \text { sulfur }(\mathrm{S}) & \text { Sigma-Aldrich Chemie } \\ \text { phosphorus }(\mathrm{V}) \text { sulfide }\left(\mathrm{P}_{2} \mathrm{~S}_{5}\right) & \text { Merck } \\ \text { sodium sulfide }\left(\mathrm{Na}_{2} \mathrm{~S} \cdot \mathrm{H}_{2} \mathrm{O}\right) & \text { Merck } \\ \text { hydroxylamine-O-sulfonic acid }\left(\mathrm{H}_{2} \mathrm{NSO}_{4} \mathrm{H}\right) & \text { Merck } \\ \text { amidosulfonic acid }\left(\mathrm{H}_{2} \mathrm{NSO}_{3} \mathrm{H}\right) & \text { Sigma-Aldrich Chemie } \\ \text { sulfamide }\left(\mathrm{H}_{2} \mathrm{NSO}{ }_{2} \mathrm{NH}_{2}\right) & \text { Sigma-Aldrich Chemie } \\ \left.\text { ammoniumthiosulfate }\left(\mathrm{NH}_{4}\right)_{2} \mathrm{~S}_{2} \mathrm{O}_{3}\right) & \text { Merck } \\ \text { urea+sulfur }\left((\mathrm{NH})_{2} \mathrm{CO}_{+} \mathrm{S}\right)(1: 1) & \text { urea, techn. } \\ \text { ammoniumsulfate }\left(\left(\mathrm{NH}_{4}\right)_{2} \mathrm{SO}_{4}\right) & \text { Merck } \\ \text { synthetic air } & \text { Linde }\end{array}$




\section{$9 \quad$ References}

1. Stieglitz, L., G. Zwick, J. Beck, W. Roth, and H. Vogg, On the De-Novo Synthesis of PCDD/PCDF On Fly-Ash of Municipal Waste Incinerators. Chemosphere, 1989. 18(1-6): p. 1219-1226.

2. Samaras, P., G. Skodras, G.P. Sakellaropoulos, M. Blumenstock, K.-W. Schramm, and A. Kettrup, Toxic emissions during co-combustion of biomasswaste wood-lignite blends in an industrial boiler. Chemosphere, 2001. 43(4-7): p. 751-755.

3. Technology status report, Waste/biomass co-gasification with coal. Department of trade and industry, 2002.

4. VGB Power Tech, Co-Combustion Emission Control. Technical report project ECSC 7220-PR-108, 2002.

5. München, A., Müll von A bis Z. 2003: p. 1-1.

6. Kicherer, A., T. Gerhardt, H. Spliethoff, and K.R.G. Hein, Final report IVD, APAS-Clean Coal Technology Programme. 1995.

7. Van de Kamp, W.L. and D.J. Morgan, Final report IFRF, APAS-Clean Coal Technology Programme. 1995.

8. Thomé -Kozmiensky, K.J., Thermische Abfallbehandlung. EF- Ver. Für Energie- und Umwelttechnik, 1994. ISBN 3-924511-77-2.

9. Tuppurainen, K., I. Halonen, P. Ruokojarvi, J. Tarhanen, and J. Ruuskanen, Formation of PCDDs and PCDFs in municipal waste incineration and its inhibition mechanisms: A review. Chemosphere, 1998. 36(7): p. 1493-1511.

10. Olie, K., P.L. Vermeulen, and H. O., Chlorodibenzo-p-dioxins and chlorodibenzofurans are trace components of fly ash and fly gas of some municipal incinertors in the Netherlands. Chemosphere, 1977. 6: p. 182-191.

11. Bundesgesetzblatt, Siebzehnte Verordnung zur Durchführung des BundesImmissionsschutzgesetzes: Verordnung über Verbrennungsanlagen für Abfälle und ähnliche brennbare Stoffe.

12. United States Environmental Protection Agency., Combustion Emission Technical Resource Document (CETRED), Report No. EPA 530-R-94-014. 1994b.

13. United States Environmental Protection Agency, Office of Research and Development; Health Assessment Document for 2,3,7,8-Tetrachlorodibenezo- 
p-dioxin (TCDD) and Related Compounds; EPA/600/Bp-92/001c Estimation Exposure to Dioxin-Like Compounds, EPA/600/6-88/005Cb;. 1994a.

14. Öberg, L.G., R. Anderson, and R. C., De novo formation of hepta-and octachlorodibenzo-p-dioxins from pentachlorophenol in municipal sewage sludge. Organohalogenic Compounds, 1992. 9: p. 351-354.

15. Schramm, K.-W., C. Klimm, B. Henkelmann, and A. Kettrup, Formation of octa- and heptachlorodibenzo-p-dioxins during semi-anaerobic digestion of sewage sludge. Organohalogen Compounds, 1996. 27: p. 84-87.

16. Hutzinger, O., M.J. Blumich, M. Vanderberg, and K. Olie, Sourcesand Fate of $P C D D$ s and PCDFs - an Overview. Chemosphere, 1985. 14(6-7): p. 581-600.

17. Luthardt, P., J. Mayer, and J. Fuchs, Total TEQ emissions (PCDD/F and PCB) from industrial sources. Chemosphere, 2002. 46(9-10): p. 1303-1308.

18. Gullett, B.K., P.M. Lemieux, C.C. Lutes, C.K. Winterrowd, and D.L. Winters, Emissions of PCDD/F from uncontrolled, domestic waste burning. Chemosphere, 2001. 43(4-7): p. 721-725.

19. Vogg, H. and L. Stieglitz, Thermal-Behavior of PCDD/PCDF in Fly-Ash From Municipal Incinerators. Chemosphere, 1986. 15(9-12): p. 1373-1378.

20. Manninen, H., K. Peltola, and J. Ruuskanen, Co-combustion of refuse-derived and packaging-derived fuels (RDF and PDF) with conventional fuels. Waste Management \& Research, 1997. 15(2): p. 137-147.

21. Fre, R., M. Wevers, and G. Vanermen, Dioxin and PAH in chimney soot from domestic heating appliances with solid fuels. Dioxin 2003 Boston Conference, 2003. 60-65.

22. Yoneda, K., T. Ikeguchi, Y. Yagi, Y. Tamade, and K. Omori, A research on dioxin generation from the industrial waste incineration. Chemosphere, 2002. 46(9-10): p. 1309-1319.

23. Sakai, S., T. Ukai, H. Takatsuki, K. Nakamura, S. Kinoshita, and T. Takasuga, Substace flow analysis of coplanar PCBs released from waste incineration processes. J. Mater Cycles Waste Manag., 1999. 1: p. 62-74.

24. Sakai, S.I., K. Hayakawa, H. Takatsuki, and I. Kawakami, Dioxin-like PCBs released from waste incineration and their deposition flux. Environmental Science \& Technology, 2001. 35(18): p. 3601-3607. 
25. Jiang, K., L.J. Li, Y.D. Chen, and J. Jin, Determination of PCDD/Fs and dioxinlike PCBs in Chinese commercial PCBs and emissions from a testing PCB incinerator. Chemosphere, 1997. 34(5-7): p. 941-950.

26. Levendis, Y.A., A. Atal, J.B. Carlson, and M.D. Quintana, PAH and soot emissions from burning components of medical waste: examination/surgical gloves and cotton pads. Chemosphere, 2001. 42(5-7): p. 775-783.

27. Kaune, A., K.-W. Schramm, R. Lehnardt, A. Kettrup, I. Ollenschlager, and H. Rossel, Polychlorinated dibenzodioxins and dibenzofurans in the aluminium recycling process. Journal of Analytical and Applied Pyrolysis, 1999. 49(1-2): p. 191-198.

28. Snaub, W.M. and W. Tsang, Dioxin formation in incinerators. Environ. Sci. \& Technol., 1983. 17: p. 721-730.

29. Huang, $\mathrm{H}$. and A. Buekens, On the Mechanisms of Dioxin Formation in Combustion Processes. Chemosphere, 1995. 31(9): p. 4099-4117.

30. Stieglitz, L., Selected topics on the de novo synthesis of PCDD/PCDF on fly ash. Environmental Engineering Science, 1998. 15(1): p. 5-18.

31. Stieglitz, L., H. Bautz, W. Roth, and G. Zwick, Investigation of precursor reactions in the de-novo-synthesis of PCDD/PCDF on fly ash. Chemosphere, 1997. 34(5-7): p. 1083-1090.

32. Stieglitz, L., H. Vogg, G. Zwick, J. Beck, and H. Bautz, On Formation Conditions of Organohalogen Compounds From Particulate Carbon of FlyAsh. Chemosphere, 1991. 23(8-10): p. 1255-1264.

33. Stieglitz, L., M. Eichberger, J. Schleihauf, J. Beck, G. Zwick, and R. Will, The Oxidative-Degradation of Carbon and Its Role in the De-Novo-Synthesis of Organohalogen Compounds in Fly-Ash. Chemosphere, 1993. 27(1-3): p. 343350.

34. Taylor, P.H., A. Wehrmeier, S.S. Sidhu, D. Lenoir, K.W. Schramm, and A. Kettrup, Copper-catalyzed chlorination and condensation of acetylene and dichloroacetylene. Chemosphere, 2000. 40(12): p. 1297-1303.

35. Taylor, P.H. and D. Lenoir, Chloroaromatic formation in incineration processes. Science of the Total Environment, 2001. 269(1-3): p. 1-24.

36. Lenoir, D., A. Wehrmeier, K.-W. Schramm, A. Kaune, R. Zimmermann, P.H. Taylor, and S.S. Sidhu, Thermal formation of polychlorinated dibenzo-p- 
dioxins and -furans: Investigations on relevant pathways. Environmental Engineering Science, 1998. 15(1): p. 37-47.

37. Lenoir, D., A. Wehrmeier, S.S. Sidhu, and P.H. Taylor, Formation and inhibition of chloroaromatic micropollutants formed in incineration processes. Chemosphere, 2001. 43(1): p. 107-114.

38. Gullett B., Bruce K.R., and Beach L.O., Effect of sulfur dioxide on the formation mechanism of polychlorinated dibenzodion and dibenzofuran in municipal waste combustors. Environ. Sci. Technol., 1992. 26: p. 1938.

39. Milligan, M.S. and E. Altwicker, The relationship between de novo synthesis of polychlorinated dibenzo-p-dioxins and dibenzofurans and low temperature carbon gasifucation in fly ash. Environ. Sci. \& Technol., 1993. 27: p. 15951601.

40. Blaha, J. and H. Hagenmaier, Time dependence of the de novo synthesis of PCDD/PCDF and potential precursors on the fly ash. Organohalogen Compounds, 1995. 23: p. 403-406.

41. Huang, $\mathrm{H}$. and A. Buekens, Chemical kinetic modeling of de novo synthesis of PCDD/F in municipal waste incinerators. Chemosphere, 2001. 44(6): p. 15051510.

42. Lippert, T., A. Wokaun, and D. Lenoir, Copper Catalyzed Aryl Dehalogenation Reactions and Their Inhibition. Berichte Der Bunsen-Gesellschaft-Physical Chemistry Chemical Physics, 1991. 94(12): p. 1465-1471.

43. Karasek, F. and D.C. Dickson, Model studies of polychlorinated dibenzo-pdioxin formation during municipal refuse incineration. Science, 1987. 19(754756).

44. Altwicker, E.R., Formation of PCDD/F in municipal solid waste incinerators: Laboratory and modeling studies. Journal of Hazardous Materials, 1996. 47(13): p. 137-161.

45. Hell, K., L. Stieglitz, E.R. Altwicker, R. Addink, and R. Will, Reactions of 2,4,6trichlorophenol on model fly ash: oxidation to $\mathrm{CO}$ and $\mathrm{CO} 2$, condensation to PCDD/F and conversion into related compounds. Chemosphere, 2001. 42(57): p. 697-702.

46. Wikström, E., S. Ryan, A. Touati, and B.K. Gullett, Key parameters for de novo formation of polychlorinated dibenzo-p-dioxins and dibenzofurans. Environmental Science \& Technology, 2003. 37(9): p. 1962-1970. 
47. Lenoir, D., A. Kaune, O. Hutzinger, G. Mutzenich, and K. Horch, Influence of Operating Parameters and Fuel Type On Pcdd-F Emissions From a FluidizedBed Incinerator. Chemosphere, 1991. 23(8-10): p. 1491-1500.

48. Takeshita, R., Y. Akimoto, and S. Nito, Relationship Between the Formation of Polychlorinated Dibenzo-Para-Dioxins and Dibenzofurans and the Control of Combustion, Hydrogen-Chloride Level in Flue-Gas and Gas Temperature in a Municipal Waste Incinerator. Chemosphere, 1992. 24(5): p. 589-598.

49. Gullett, B.K., J.E. Dunn, S.K. Bae, and K. Raghunathan, Effects of combustion parameters on polychlorinated dibenzodioxin and dibenzofuran homologue profiles from municipal waste and coal co-combustion. Waste Management, 1998. 18(6-8): p. 473-483.

50. Fängmark I., Bavel B., Marklund S., Strömberg B., Berge N., and Rappe C., Influence of Combustion Parameters on the Formation of Polychlorinated Dibenzo-p-dioxins, Dibenzofurans, Benzenes, and Biphenyls and Polyaromatic Hydrocarbons in a Pilot Incinerator. Environ. Sci. Technol., 1993. 27: p. 1602-1610.

51. Blumenstock, M., R. Zimmermann, K.-W. Schramm, and A. Kettrup, Influence of combustion conditions on the PCDD/F-, PCB-, PCBZ- and PAHconcentrations in the post-combustion chamber of a waste incineration pilot plant. Chemosphere, 2000. 40(9-11): p. 987-993.

52. Wikström, E. and S. Marklund, The influence of level and chlorine source on the formation of mono- to octa-chlorinated dibenzo-p-dioxins, dibenzofurans and coplanar polychlorinated biphenyls during combustion of an artificial municipal waste. Chemosphere, 2001. 43(2): p. 227-234.

53. Halonen, I., J. Tarhanen, S. Ollikainen, P. Ruokojarvi, K. Tuppurainen, and J. Ruuskanen, The Effect of Inorganic and Organic Chlorine On Formation of Highly Chlorinated Organic-Compounds During Incineration - Laboratory PilotStudy (Vol 12, Pg 2129, 1994). Chemosphere, 1994. 29(6).

54. Halonen, I., J. Tarhanen, P. Ruokojarvi, K. Tuppurainen, and J. Ruuskanen, Effect of Catalysts and Chlorine Source On the Formation of Organic Chlorinated Compounds. Chemosphere, 1995. 30(7): p. 1261-1273.

55. Wang, L.C., W.J. Lee, W.S. Lee, G.P. Chang-Chien, and P.J. Tsai, Effect of chlorine content in feeding wastes of incineration on the emission of 
polychlorinated dibenzo-p-dioxins/dibenzofurans. Science of the Total Environment, 2003. 302(1-3): p. 185-198.

56. Wobst, M., H. Wichmann, and M. Bahadir, Influence of heavy metals on the formation and the distribution behavior of PAH and PCDD/F during simulated fires. Chemosphere, 2003. 51(2): p. 109-115.

57. Blumenstock, M., R. Zimmermann, K.-W. Schramm, A. Kaune, U. Nikolai, D. Lenoir, and A. Kettrup, Estimation of the dioxin emission (PCDD/FI-TEQ) from the concentration of low chlorinated aromatic compounds in the flue and stack gas of a hazardous waste incinerator. Journal of Analytical and Applied Pyrolysis, 1999. 49(1-2): p. 179-190.

58. Zimmermann, R., H.J. Heger, M. Blumenstock, R. Dorfner, K.-W. Schramm, U. Boesl, and A. Kettrup, On-line measurement of chlorobenzene in waste incineration flue gas as a surrogate for the emission of polychlorinated dibenzo-p-dioxins/furans (I-TEQ) using mobile resonance laser ionization timeof-flight mass spectrometry. Rapid Communications in Mass Spectrometry, 1999. 13(5): p. 307-314.

59. Kaune, A., D. Lenoir, K.-W. Schramm, R. Zimmermann, A. Kettrup, K. Jaeger, H.G. Ruckel, and F. Frank, Chlorobenzenes and chlorophenols as indicator parameters for chlorinated dibenzodioxins and dibenzofurans in incineration processes: Influences of various facilities and sampling points. Environmental Engineering Science, 1998. 15(1): p. 85-95.

60. Blumenstock, M., R. Zimmermann, K.-W. Schramm, and A. Kettrup, Identification of surrogate compounds for the emission of PCDD/F (I-TEQ value) and evaluation of their on-line realtime detectability in flue gases of waste incineration plants by REMPI-TOFMS mass spectrometry. Chemosphere, 2001. 42(5-7): p. 507-518.

61. Öberg T. and Bergström J.G.T., Hexachlorobenzene as an indicator of dioxin production from combustion. Chemosphere, 1985. 14(8): p. 1081-1086.

62. Kaune, A., D. Lenoir, U. Nikolai, and A. Kettrup, Estimating concentrations of polychlorinated dibenzo-p-dioxins and dibenzofurans in the stack gas of a hazardous waste incinerator from concentrations of chlorinated benzenes and biphenyls. Chemosphere, 1994. 29(9-11): p. 2083-2096.

63. Oehme, M., S. Man, and A. Mikalsen, Formation and presence of polyhalogenated and polycyclic compounds in the emissions of small and 
large scale municipal waste incinerators. Chemosphere, 1987. 16(1): p. 143153.

64. Tuppurainen, K., A. Asikainen, P. Ruokojarvi, and J. Ruuskanen, Perspectives on the formation of polychlorinated dibenzo-p-dioxins and dibenzofurans during municipal solid waste (MSW) incineration and other combustion processes. Accounts of Chemical Research, 2003. 36(9): p. 652-658.

65. Gullett, B.K. and E. Wikstrom, Mono- to tri-chlorinated dibenzodioxin (CDD) and dibenzofuran (CDF) congeners/homologues as indicators of CDD and CDF emissions from municipal waste and waste/coal combustion. Chemosphere, 2000. 40(9-11): p. 1015-1019.

66. Öberg, T. and B. J.G.T., Indicator parameters for PCDD/F. Chemosphere, 1989. 19: p. 337-344.

67. Manninen H., Perkiö A., Vartianen T., and Ruuskanen J., Effect of fuel and fly ash composion on the formation of PCDD/PCDF in the co-combustion of refuse-derived and packaging-derived fuels. Environ. Sci. \& Pollut. Res., 1996. 3(3): p. 129-134.

68. McKay, G., Dioxin characterisation, formation and minimisation during municipal solid waste (MSW) incineration: review. Chemical Engineering Journal, 2002. 86(3): p. 343-368.

69. Hentschel, B. and H. Riedel, Contribution of stack gases and solid process wastes to the organic pollutant output of thermal waste treatment plants. Chemosphere, 2001. 43(4-7): p. 727-735.

70. Bonte, J.L., K.J. Fritsky, M.A. Plinke, and M. Wilken, Catalytic destruction of $P C D D / F$ in a fabric filter: experience at a municipal waste incinerator in Belgium. Waste Management, 2002. 22(4): p. 421-426.

71. Huang, Y., M. Takaoka, and N. Takeda, Chlorobenzenes removal from municipal solid waste incineration fly ash by surfactant-assisted column flotation. Chemosphere, 2003. 52(4): p. 735-743.

72. Takaoka, M., P. Liao, N. Takeda, T. Fujiwara, and K. Oshita, The behavior of PCDD/Fs, PCBs, chlorobenzenes and chlorophenols in wet scrubbing system of municipal solid waste incinerator. Chemosphere, 2003. 53(2): p. 153-161.

73. Takeda, N., M. Takaoka, T. Fujiwara, H. Takeyama, and S. Eguchi, Measures to prevent emissions of PCDDs/DFs and co-planar PCBs from crematories in Japan. Chemosphere, 2001. 43(4-7): p. 763-771. 
74. Naikwadi, K.P. and F.W. Karasek, Prevention of Pcdd Formation in Msw Incinerators By Inhibition of Catalytic Activity of Fly-Ash Produced. Chemosphere, 1989. 19(1-6): p. 299-304.

75. Strömberg, B., Low temperature formation and minimization of chlorinated hydrocarbons. Chemosphere, 1991. 23(8-10): p. 1515-1525.

76. Addink, R., R. Paulus, and K. Olie, Prevention of polychlorinated dibenzo-pdioxins/dibenzofurans formation on municipal waste incinerator fly ash using nitrogen and sulfur compounds. Environmental Science \& Technology, 1996. 30(7): p. 2350-2354.

77. Weber, R., T. Takasuga, K. Nagai, H. Shiraishi, T. Sakurai, T. Matuda, and M. Hiraoka, Dechlorination and destruction of PCDD, PCDF and PCB on selected fly ash from municipal waste incineration. Chemosphere, 2002. 46(9-10): p. 1255-1262.

78. Sun, R.D., H. Irie, T. Nishikawa, A. Nakajima, T. Watanabe, and K. Hashimoto, Suppressing effect of $\mathrm{CaCO} 3$ on the dioxins emission from poly(vinyl chloride) (PVC) incineration. Polymer Degradation and Stability, 2003. 79(2): p. 253-256.

79. Suzuki, K., T. Yamasaki, and Y. Yamashita, Control of dioxin formation using new sorbent contained calcium compound as main componenet in incinerators. Dioxin 2003 Boston Conference, 2003. 60-65.

80. Cho, C.H. and S.K. Ihm, Development of new vanadium-based oxide catalysts for decomposition of chlorinated aromatic pollutants. Environmental Science \& Technology, 2002. 36(7): p. 1600-1606.

81. Stoll, M., J. Furrer, H. Seifert, G. Schaub, and D. Unruh, Effects of flue gas composition on the catalytic destruction of chlorinated aromatic compounds with a V-oxide catalyst. Waste Management, 2001. 21(5): p. 457-463.

82. Krishnamoorthy, S., J.A. Rivas, and M.D. Amiridis, Catalytic oxidation of 1,2dichlorobenzene over supported transition metal oxides. Journal of Catalysis, 2000. 193(2): p. 264-272.

83. Yim, S.D., D.J. Koh, and I.S. Nam, A pilot plant study for catalytic decomposition of PCDDs/PCDFs over supported chromium oxide catalysts. Catalysis Today, 2002. 75(1-4): p. 269-276.

84. Andreeva, D., T. Tabakova, L. Ilieva, A. Naydenov, D. Mehanijev, and M.V. Abrashev, Nanosize gold catalysts promoted by vanadium oxide supported on 
titania and zirconia for complete benezene oxidation. App. Catal. A., 2001. 209: p. 291-300.

85. Dickson, L.C., D. Lenoir, O. Hutzinger, K.P. Naikwadi, and F.W. Karasek, Inhibition of Chlorinated Dibenzo-Para-Dioxin Formation On Municipal Incinerator Fly-Ash By Using Catalyst Inhibitors. Chemosphere, 1989. 19(8-9): p. 1435-1445.

86. Buekens, A., L. Stieglitz, K. Hell, H. Huang, and P. Segers, Dioxins from thermal and metallurgical processes: recent studies for the iron and steel industry. Chemosphere, 2001. 42(5-7): p. 729-735.

87. Xhrouet, C., C. Nadin, and E. De Pauw, Amines compounds as inhibitors of PCDD/Fs de novo formation on sintering process fly ash. Environmental Science \& Technology, 2002. 36(12): p. 2760-2765.

88. Lenoir, D., H. O., G. Mützenich, and K. Horch, Verhinderung der Entstehung chlorierter Dibenzodioxine und Furane bei der Müllverbrennung: Inhibierung der katalytische Bildung. UWSF.-Z. Umweltchem, 1989. 4: p. 3-6.

89. Tuppurainen, K., M. Aatamila, P. Ruokojarvi, I. Halonen, and J. Ruuskanen, Effect of liquid inhibitors on PCDD/F formation, prediction of particle-phase PCDD/F concentrations using PLS modelling with gas-phase chlorophenol concentrations as independent variables. Chemosphere, 1999. 38(10): $p$. 2205-2217.

90. Yli-Kenturi, N., P.H. Ruokojärvi, A. Asikainen, J. Ruskanen, I. Halonen, and K. Hänninen, Urea as PCDD/F inhibitor in incineration of RDF. Organohalogen Compounds, 1999. 41: p. 311-314.

91. Ruokojarvi, P., M. Aatamila, K. Tuppurainen, and J. Ruuskanen, Effect of urea on fly ash PCDD/F concentrations in different particle sizes. Chemosphere, 2001. 43(4-7): p. 757-762.

92. Ruokojarvi, P.H., I.O.A. Halonen, K.A. Tuppurainen, J. Tarhanen, and R. J., Effect of gaseous inhibitors on PCDD/F formation. Environ. Sci. \& Technol., 1998. 32: p. 3099-3103.

93. Samaras, P., M. Blumenstock, D. Lenoir, K.-W. Schramm, and A. Kettrup, $P C D D / F$ inhibition by prior addition of urea to the solid fuel in laboratory experiments and results statistical evaluation. Chemosphere, 2001. 42(5-7): $p$. 737-743. 
94. Buekens, A. and H. Huang, Coparative evaluation of techniques for controlling the formation and emnission of chlorinated dioxins/furans in municipal waste incineration. J.Hazard. Mater., 1998. 62: p. 1-33.

95. Bechtler, R., L. Stieglitz, G. Zwick, R. Will, W. Roth, and K. Hedwig, Influence of elemental sulfur on the de-novo-synthesis of organochlorine compounds from residual carbon on fly ash. Chemosphere, 1998. 37(9-12): p. 2261-2278.

96. Ogawa, H., N. Orita, M. Horaguchi, T. Suzuki, M. Okada, and S. Yasuda, Dioxin reduction by sulfur component addition. Chemosphere, 1996. 32(1): p. 151-157.

97. Samaras, P., M. Blumenstock, D. Lenoir, K.-W. Schramm, and A. Kettrup, PCDD/F prevention by novel inhibitors: Addition of inorganic $S$ - and $N$ compounds in the fuel before combustion. Environmental Science \& Technology, 2000. 34(24): p. 5092-5096.

98. VDI 4220, Quality assurance - Requirements for emission and immission testing laboratories for the determination of air pollutants. 1999.

99. DIN-EN-ISO/IEC 17025, General requirements for the competence of testing and calibration laboratories. 2000.

100. VDI 2066, Particulate matter measurement; measuring of particulate matter in flowing gases; gravimetric determination of dust load; fundamentals. 1975. sheet 1.

101. Multi-Variate-Statistical Package (MVSP)., Kovach Computing Services. http://kovcomp.com, 2000. Version 3.11.

102. Morrison, D.F., Multivariate statistical method. 1978: p. 266-302.

103. EPA, Method 8290 A., Polychlorinated Dibenzodioxins (PCDDs) and polychlorinated dibenzofurans (PCDFs) by high resolution gas chromatographie/high resolution mass spectrometry (HRGC/HRMS)." 1998: p. 1-67.

104. DIN-EN 1948-1, D.E., Emissions from stationary sources- Determination of mass concentration of PCDD/PCDF. 1997(1).

105. DIN-EN 13284-1, Stationary source emissions-Determination of low range mass concentration of dust. 2002(1).

106. VDI 2066, Measurement of particulate matter; manual dust measurement in flowing gases; gravimetric determination of dust load; tubular filter devices (4 $m 3 / h, 12 m 3 / h) .1993$. sheet 2. 
107. DIN-EN 1948, Emissionen aus stationären Quellen - Bestimmung der Massenkonzentration von PCDD/PCDF, German standards. 1997. parts 1, 2, 3.

108. Lehnardt, R., A. Kaune, K.-W. Schramm, A. Kettrup, and . Sampling exhaust gases of thermal processes with continuous, automatic adjustment to isokinetic conditions. Organohalogen Compounds, 1998. 36: p. 77-80.

109. Bundesimmissionsschutzverordnung,

Qualitätssicherungskonzept- Analytik von PAK, PCB und Dioxinen im Boden. 1990.

110. Agency-Austria, U.F.E., Emission von Dioxinen, PCbs und PAHs aus Kleinfeuerungsanlagen. 2002: p. M-153.

111. Quass, U., Fermann, MW., and Bröger, G., Steps towards a European dioxin inventory. Chemosphere, 2000. 40(9-11): p. 1125-9.

112. Wikström, E., S. Ryan, A. Touati, M. Telfer, D. Tabor, and B.K. Gullett, Importance of chlorine speciation on de Novo formation of polychlorinated dihenzo-p-dioxins and polychlorinated dibenzofurans. Environmental Science \& Technology, 2003. 37(6): p. 1108-1113.

113. Skodras, G., P. Grammelis, P. Samaras, P. Vourliotis, E. Kakaras, and G.P. Sakellaropoulos, Emissions monitoring during coal waste wood co-combustion in an industrial steam boiler. Fuel, 2002. 81(5): p. 547-554.

114. Hunsinger H., Kreisz S., and Vogg H., Experiences gained from the sampling of chlorine aromatics in the raw gas of waste incineration plants. Chemosphere, 1996. 32(1): p. 109-118.

115. Samaras, P., M. Blumenstock, K.-W. Schramm, and A. Kettrup, Emissions of chlorinated aromatics during sludge combustion. Water Science and Technology, 2000. 42(9): p. 251-258.

116. Wirkstöm E. and M. S., Combustion of an artifical municipal solid waste in a laboratory fluidised bed reactor. Waste Management \& Research, 1998. 16(4): p. 342-350.

117. United States Environmental Protection Agency., Office of Research and Development; Health Assessment Document for 2,3,7,8-Tetrachlorodibenezop-dioxin (TCDD) and Related Compounds; EPA/600/Bp-92/001c Estimation Exposure to Dioxin-Like Compounds, EPA/600/6-88/005Cb;. 1994. 
118. Lippert, T., A. Wokaun, and D. Lenoir, Copper Catalyzed Aryl Dehalogenation Reactions and Their Inhibition. Berichte Der Bunsen-Gesellschaft-Physical Chemistry Chemical Physics, 1990. 94(12): p. 1465-1471.

119. Wikström, E., Persson A., and Marklund S., Secondary formation of PCDDs, PCDFs, PCBs, PCBz, PCPhs and PAHs during MSW combustion. Organohalogen Compounds, 1998. 36: p. 65-68.

120. Choudhry GG. and Hutzinger O., Mechanistic aspects of the thermal formation of halogenated organic compounds including polychlorinated dibenzo-pdioxins. New York: Gordon and Breach, 1983.

121. Salthammer T., Klipp H., Peek RD., and Marutzky R., Formation of polychlorinated dibenzo-p-dioxins (PCDD) and polychlorinated dibenzo-pfurans(PCDF) during the combustion of impregnated wood. Chemosphere, 1995. 30(11): p. 2051-60.

122. Schatowitz B., Brandt G., Gatner F., Schlumpf E., Bühler R., Husler P., and Nussbaumer T., Dioxin emissions from wood combustion. Chemosphere, 1994. 29: p. 2005-2013.

123. Öberg, T. and B. J.G.T., Indicator parameters for PCDD/PCF-plant secific models. Organohalogen Compounds, 1992. 8: p. 197-200. 


\section{LEBENSLAUF}

Persönliche

Angaben

Ausbildung

Tätigkeiten
Name: $\quad$ Marchela Pandelova

Geburtsdatum: $\quad$ 07. März 1977

Geburtsort: $\quad 7000$ Russe, Bulgarien

Staatsangehörigkeit: bulgarisch

Familienstand: $\quad$ verheiratet

Ledig Name: $\quad$ Lebikyan

1990 - 1995 Naturwissenschaftliches Gymnasium, „Olimpi Panov“, Bulgarien

Abitur mit Note: Sebr gut

1995- 2000 Studium, Fachrichtung allg. Chemie, Diplom an der Sofia Universität „St. Kliment Ochridski“, Bulgarien

Diplomarbeit im Bereich elektrothermische Atomabsorptionsspektroskopie Abschluss mit Note: Ausgezeichnet

Seit $2001 \quad$ Studium, Ökologische Chemie, Promotionsstudium an der Technischen Universität München

Wissenschaftliche Mitarbeiterin

Bulgarische Akademie der Wissenschaften, Institute für Ökologie,

2000-2001: Wissenschaftliche Mitarbeiterin im Chromatographischen Labor

Umwelt und Wasser Ministerium - Bulgarien, Agentur- Russe

Seit $2001 \quad$ Doktorand, GSF - Forschungszentrum für Umwelt und Gesundheit GmbH 